Aus dem Institut für Molekulare Onkologie

(Prof. Dr. med. M. Dobbelstein)

der Medizinischen Fakultät der Universität Göttingen

\title{
The DNA damage kinases MK2, Chk1 and the chromatin remodeling factor CHD8 determine the cellular outcome after replicative stress and DNA damage
}

\author{
INAUGURAL-DISSERTATION \\ zur Erlangung des Doktorgrades \\ der Medizinischen Fakultät der \\ Georg-August-Universität zu Göttingen
}

vorgelegt von

Anna Maria Binkowski

aus

Marburg

Göttingen 2020 
Dekan: $\quad$ Prof. Dr. med. W. Brück

Referent Prof. Dr. med. M. Dobbelstein

Ko-Referentin: $\quad$ PD Dr. Elisabeth Heßmann

Datum der mündlichen Prüfung: $\quad$ 15. April 2021 
Hiermit erkläre ich, die Dissertation mit dem Titel "The DNA damage kinases MK2, Chk1 and the chromatin remodeling factor CHD8 determine the cellular outcome after replicative stress and DNA damage" eigenständig angefertigt und keine anderen als die von mir angegebenen Quellen und Hilfsmittel verwendet zu haben.

Göttingen, den 25. März 2021 


\section{TABLE OF CONTENTS}

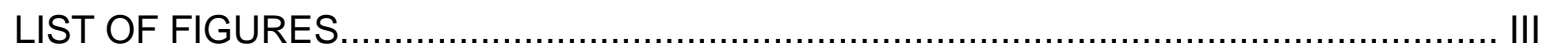

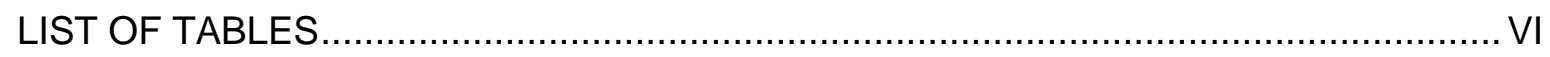

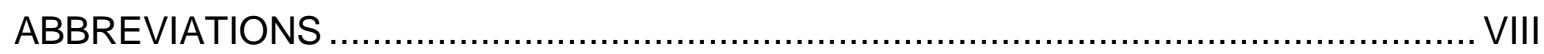

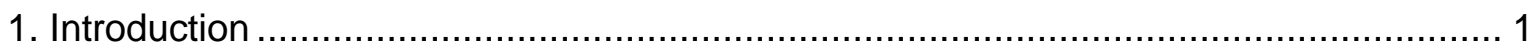

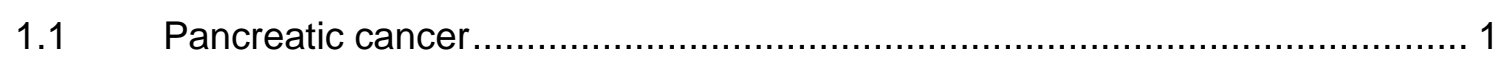

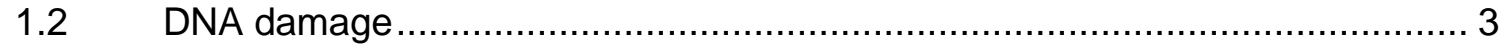

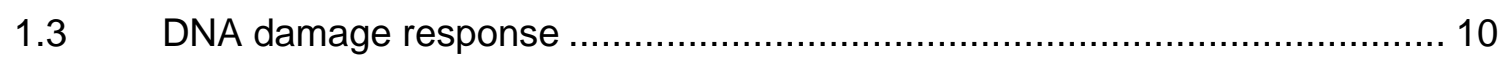

$1.4 \quad$ Consequences of the DNA damage response ...................................... 17

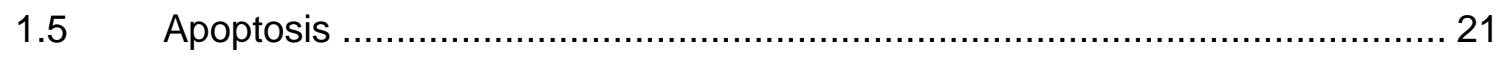

$1.6 \quad$ The MK2/Chk1 system in the DNA damage response .............................. 23

1.7 Chromatin remodeling in response to DNA damage ................................... 25

1.8 The CHD family of chromatin remodeling enzymes ................................ 27



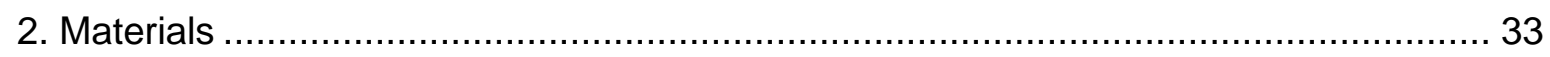

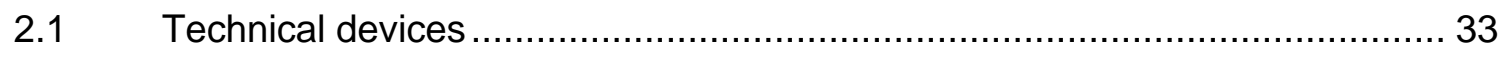

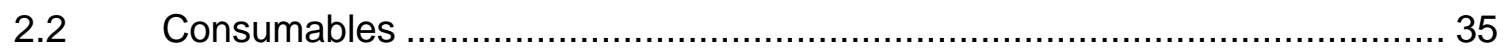

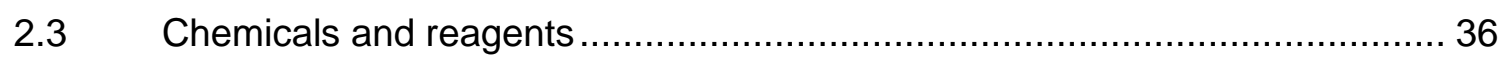

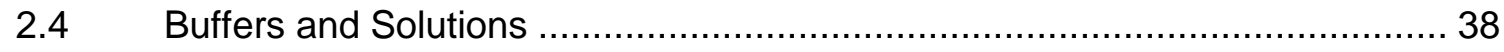

2.5 Chemotherapeutics and pharmacological inhibitors ................................. 41

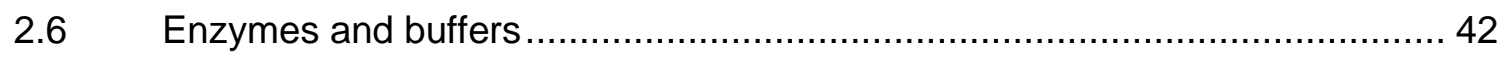

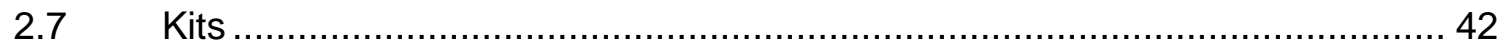

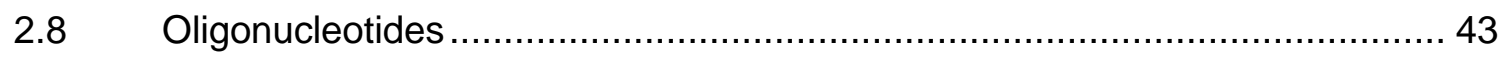

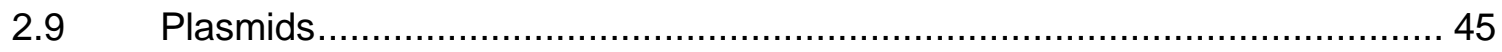

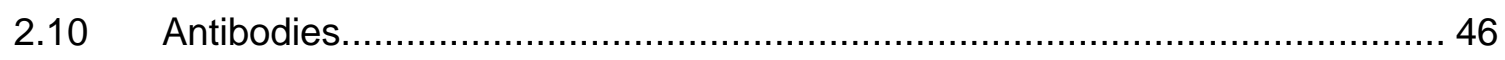

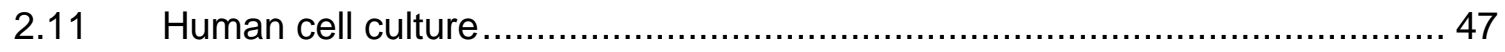

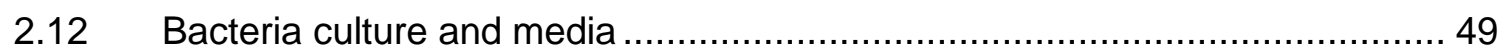

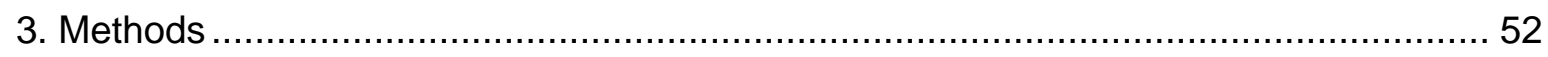

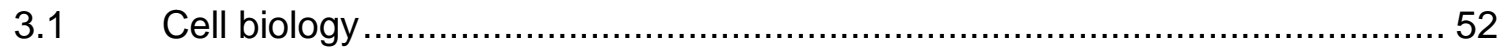

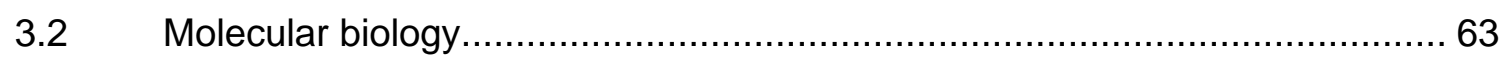




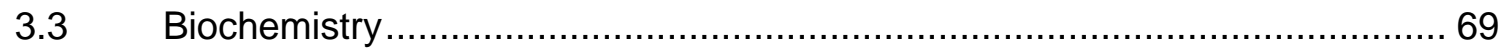

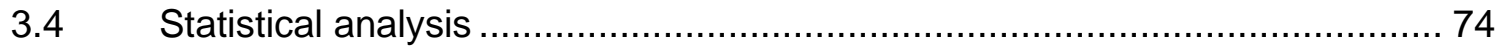

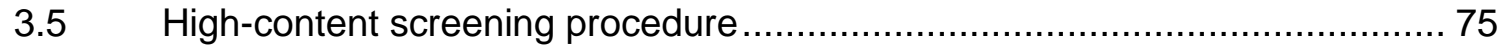

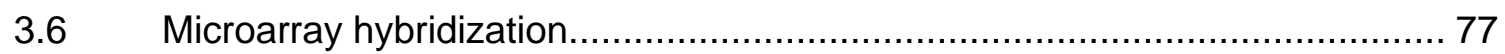

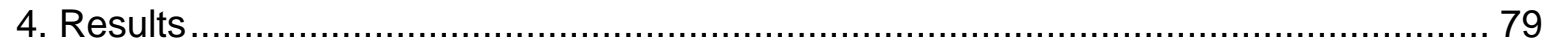

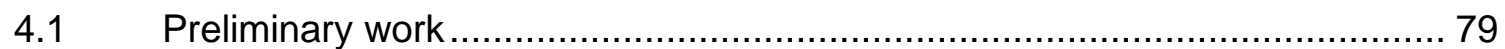

4.2 Optimization of systematic high-content cell screening in gemcitabine-treated pancreatic cancer cells ....................................................................... 86

4.3 High-content screen for mediators of the DDR after gemcitabine treatment... 91

4.4 CHD8 is a mediator of the DNA damage response ..................................... 99

4.5 CHD8 regulates progression through the cell cycle and apoptosis .............. 107

4.6 CHD8 influences phosphorylation and total protein levels of p53................ 110

4.7 A genome-wide microarray analysis after CHD8 knockdown identifies DNA damage response genes as potential mediators of CHD8 knockdown effects

5. Discussion

5.1 MK2 and Chk1: Two kinases govern the response of pancreatic cancer cells to gemcitabine treatment

5.2 Validation of screening quality of a high-content siRNA screen in pancreatic cancer cells to identify new regulators of the DNA damage response.......... 126

5.3 CHD8 modulates the DNA damage response after various types of

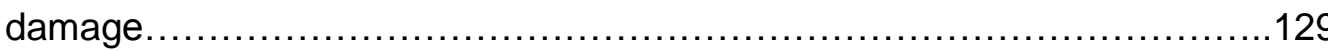

5.4 CHD8-dependent transcription of DNA damage response factors 133

5.5 A model of chromatin reorganization induced by CHD8 depletion for efficient promotion of DNA repair after UV and gemcitabine treatment ................... 136

5.6 Conclusions and future perspectives .................................................... 139

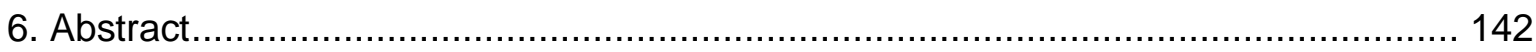

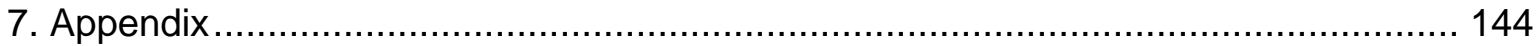

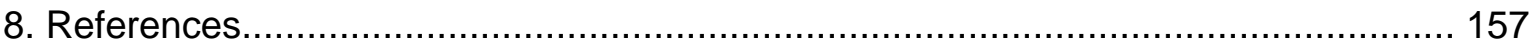




\section{LIST OF FIGURES}

Figure 1.1 UV-induced DNA lesions. 5

Figure 1.2 Structure of the nucleoside analog gemcitabine. ..................................... 6

Figure 1.3 Core signaling pathways in the DNA damage response........................... 11

Figure 1.4 Activation of the ATR/Chk1 pathway in response to ssDNA. ...................... 13

Figure 1.5 Response to double strand breaks.................................................... 14

Figure 1.6 Cell cycle checkpoints upon DNA damage .......................................... 17

Figure 1.7 Repair of stalled replication forks....................................................... 20

Figure 1.8 Regulation of p53 activity in response to genotoxic stress.........................22

Figure 1.9 Structure and functional domains of CHD8 ......................................... 28

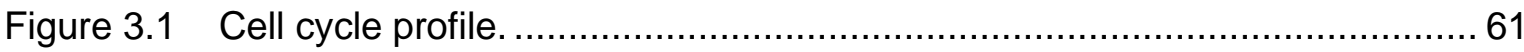

Figure 3.2 Component assembly of a wet blot experiment. ..................................... 70

Figure 4.1 Sensitivity of pancreatic cancer cells towards gemcitabine treatment correlates with the amount of gemcitabine-induced $\mathrm{yH} 2 \mathrm{AX}$.

Figure 4.2 Inhibition or depletion of MK2 affects efficient H2AX phosphorylation in pancreatic cancer cells.

Figure 4.3 MK2 is a determinant of cell survival after gemcitabine-induced DNA damage.

Figure 4.4 MK2 and Chk1 determine H2AX phosphorylation after gemcitabine treatment in pancreatic cancer cells.

Figure 4.5 Inhibition of MK2 and Chk1 in gemcitabine-treated pancreatic cancer cells.85

Figure 4.6 siRNA-mediated knockdown efficiency and cell growth morphology of pancreatic cancer cells.

Figure 4.7 Central indicators of the DNA damage response and apoptosis are activated in a time-dependent manner.

Figure 4.8 $\mathrm{yH} 2 \mathrm{AX}$ level in MIA PaCa-2 and PANC-1 cells are modulated by positive and negative controls within the library. 90

Figure 4.9 RNAi-based screening identifies mediators of H2AX phosphorylation following gemcitabine treatment.

Figure 4.10 Results of RNAi-based screening for $\mathrm{yH} 2 \mathrm{AX}$ levels gated for DNA-replicating cells. 
Figure 4.11 Control-based validation of main hits confirms various known and novel mediators of the DNA damage response. .............................................. 96

Figure 4.12 Knockdown efficiency of siRNAs against the main hits of the screen..........98

Figure 4.13 DNA damage modulators after depletion of candidate proteins. 98

Figure 4.14 Enhanced DNA damage response in CHD8-depleted PANC-1 cells is not a secondary effect due to the induction of apoptosis.

Figure 4.15 CHD8 does not accumulate after DNA damage induction following gemcitabine treatment.

Figure 4.16 CHD8 depletion in PANC-1 cells causes increased DNA damage response following UV irradiation. 101

Figure 4.17 Overexpression of CHD8 does not show opposing effects to CHD8 depletion but causes increased DNA damage response. 102

Figure 4.18 CHD8 depletion leads to increased H2AX phosphorylation after induction of double strand breaks. 103

Figure 4.19 Depletion of CHD8 increases the DNA damage response in U2OS cells. 104

Figure 4.20 CHD8 depletion also causes apoptosis in the presence of p53. 105

Figure 4.21 Overexpressed CHD8 does not relocalize in response to UV-induced DNA damage. 106

Figure 4.22 CHD8 depletion promotes progression through S-phase. 108

Figure 4.23 CHD8 depletion causes apoptosis independent of the presence or functionality of p53. 109

Figure 4.24 CHD8 depletion reduces activated and overall wild type and mutant p53 levels.

Figure 4.25 Reduced p53 levels are partially based on increased protein degradation.112

Figure 5.1 A model for the induction of resistance to Chk1 inhibitors.

Figure 5.2 Depletion of CTCF does not increase the cellular DNA damage response but rescues the effect of CHD8 depletion in UV-treated cells.

Figure 5.3 Influence of CHD8 knockdown on cell proliferation after gemcitabine treatment.

Figure 5.4 A model for CHD8 in the DNA damage response. 138

Figure 7.1 Results of RNAi-based screening for EdU levels as measure for DNA replication.

Figure 7.2 Control-based validation of main hits in EdU-positive cells.

Figure 7.3 Relative changes in EdU levels caused by main hits of the screen.........

Figure 7.4 Control-based validation of selected hits in MIA PaCa-2 cells. 
Figure 7.5 Control-based validation of selected hits in PaTu8902 cells. .................... 154

Figure 7.6 Control-based validation of selected hits in U2OS cells.......................... 155

Figure 7.7 Effect of candidate gene knockdown on $\mathrm{yH} 2 \mathrm{AX}$ is not attributable to a decrease in Rad51 or p53 levels......................................................... 156 


\section{LIST OF TABLES}

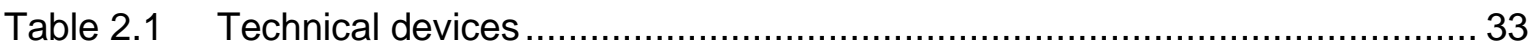

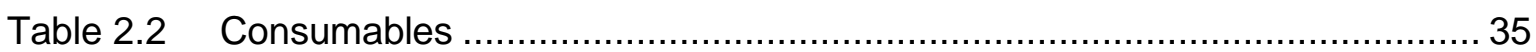

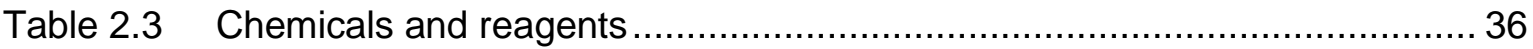

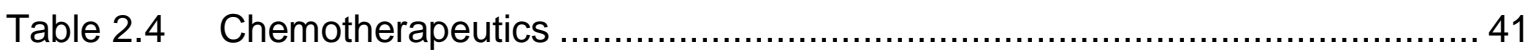

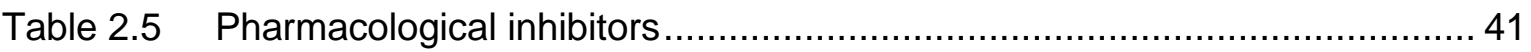

Table 2.6 Enzymes and buffers..................................................................... 42

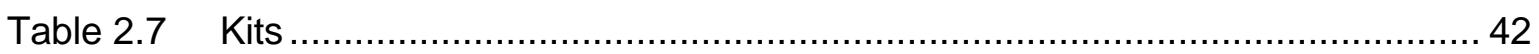

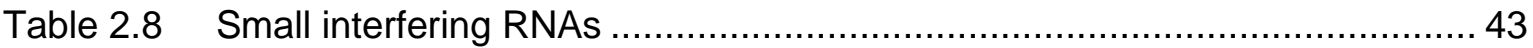

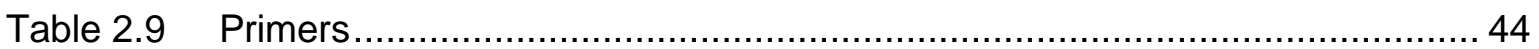

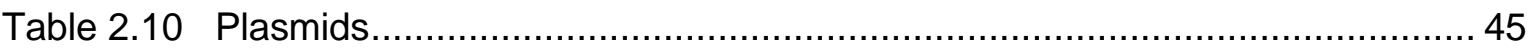

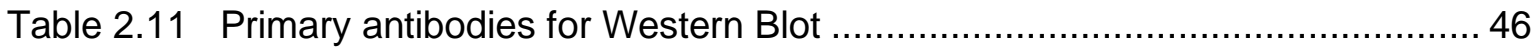

Table 2.12 Primary antibodies for immunofluorescence ………………………….... 46

Table 2.13 Secondary antibodies for Western Blot..................................................... 47

Table 2.14 Secondary antibodies for immunofluorescence ........................................ 47

Table 2.15 Human cell lines ............................................................................. 47

Table 2.16 Media and additives for eukaryotic cell culture........................................... 48



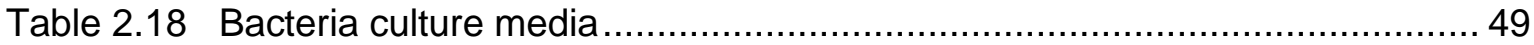

Table 3.1 Culture media for human cell lines......................................................... 52

Table 3.2 Number of cells which were usually seeded for different cell lines ................53

Table 3.3 Volumes of culture medium, siRNA and transfection reagent used for different well sizes for siRNA transfection............................................................ 55

Table 3.4 Volumes of culture medium, siRNA and transfection reagent used for different wells sizes for transfection of expression vectors........................................ 56

Table 3.5 Concentrations and time periods for chemical treatment. ............................. 57

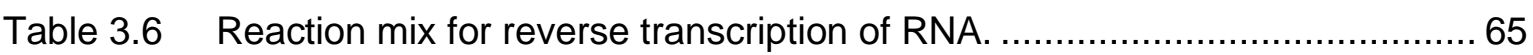

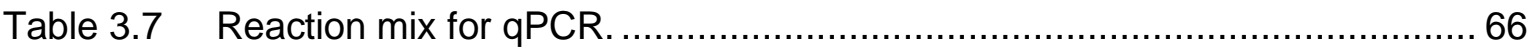

Table 3.8 Cycler program for qPCR. .................................................................. 67

Table 3.9 Composition of gels for SDS-PAGE........................................................ 70 
Table 3.10 Components for click-iT® reaction cocktail.

Table 4.1 Top candidates whose gene expression is most influenced by CHD8 knockdown.

Table 4.2 Candidate CHD8-regulated genes were grouped by cellular processes. .... 115

Table 7.1 Screen candidates based on overall $\mathrm{yH} 2 \mathrm{AX}$ levels................................... 144

Table 7.2 Screen candidates based on yH2AX levels in EdU-positive cells................. 145

Table 7.3 Relevant biological processes associated with screen candidates. 148 


\section{ABBREVIATIONS}

36B4

5-FU

6-4-PP

9-1-1 Complex

A

APS

Ara-C

ATM

ATP

ATR

ATRIP

BER

bp

BRCA2

BRD4

BrdU

BSA

caspase

Cdc25

CDK

CDKN2A

cDNA

$\mathrm{CHD}$

Chk1

Chk2

CPD

CTCF

$\mathrm{C}$-terminus

dCK

dCTP

ddNTP

DDR

DMEM

DMSO

DNA

DNA-PK

dNTP

DPC4/SMAD4

DSB

EDTA

EdU
Acidic ribosomal phosphoprotein P0

5-Fluorouracil

6-4 Photoproducts

Rad9-Hus1-Rad1

Adenine

Ammonium persulfate

Cytarabine

Ataxia telangiectasia mutated

Adenosine triphosphate

ATM- and Rad3-related

ATR interacting protein

Base excision repair

Base pair

Breast cancer 2

Bromodomain-containing protein 4

Bromodeoxyuridine

Bovine serum albumine

Cysteinyl-aspartate specific protease

Cell division cycle 25

Cyclin-dependent kinase

Cyclin-dependent kinase inhibitor 2A

Complementary DNA

Chromodomain-helicase-DNA-binding protein

Checkpoint kinase 1

Checkpoint kinase 2

Cyclobutane pyrimidine dimer

CCCTC-binding factor

Carboxy terminus

Deoxycytidine kinase

Deoxycytidine triphosphate

Dideoxynucleotide triphosphate

DNA damage response

Dulbecco's modified eagle medium

Dimethylsulfoxide

Deoxyribonucleic acid

DNA-dependent protein kinase

Deoxynucleotide triphosphate

Deleted in pancreatic cancer 4 /

Mothers against decapentaplegic homolog 4

Double strand break

Ethylene diamine tetraacetic acid

5-Ethinyl-2'-desoxyuridine 


\begin{tabular}{|c|c|}
\hline ERK & Extracellular signal-regulated kinase \\
\hline $\mathrm{EtOH}$ & Ethanol \\
\hline FCS & Fetal calf serum \\
\hline $\mathrm{g}$ & Gravitational force \\
\hline GAPDH & Glycerinaldehyd-3-phosphat-dehydrogenase \\
\hline GFP & Green fluorescent protein \\
\hline $\mathrm{H} 2 \mathrm{AX}$ & Histone variant $2 \mathrm{AX}$ \\
\hline HELLS & Helicase, lymphoid-specific \\
\hline $\mathrm{HR}$ & Homologous recombination \\
\hline HRP & Horseradish peroxidase \\
\hline Hsp27 & Heat shock protein of $27 \mathrm{kDa}$ \\
\hline $\mathrm{HU}$ & Hydroxyurea \\
\hline IF & Immunofluorescence \\
\hline Inh & Inhibitor \\
\hline $\mathrm{kb}$ & Kilo base \\
\hline $\mathrm{kDa}$ & Kilodalton \\
\hline KRAS & Kirsten rat sarcoma viral oncogene homolog \\
\hline M & Molar \\
\hline MAPK & Mitogen activated protein kinase \\
\hline MB & Mega base \\
\hline MCM10 & $\begin{array}{l}\text { Minichromosome maintenance complex } \\
\text { component } 10\end{array}$ \\
\hline MDC1 & Mediator of DNA damage checkpoint 1 \\
\hline MDM2 & Mouse double minute 2 homolog \\
\hline $\mathrm{MetOH}$ & Methanol \\
\hline MK / MAPKAPK & MAPK activated protein kinase \\
\hline MMR & Mismatch repair \\
\hline MRN & MRE11, RAD50 and NBS1 \\
\hline mRNA & Messenger RNA \\
\hline NCS & Neocarzinostatin \\
\hline NER & Nucleotide excision repair \\
\hline NES & Nuclear export signal \\
\hline NHEJ & Non-homologous end joining \\
\hline NuRD & Nucleosome remodeling deacetylase \\
\hline PARP & Poly-ADP-ribosylating polymerases \\
\hline PBS & Phosphate-buffered saline \\
\hline PCNA & Proliferating cell nuclear antigen \\
\hline PCR & Polymerase chain reaction \\
\hline $\mathrm{PI}$ & Propidium iodide \\
\hline PIKK & Phosphatidylinositol 3-kinase related kinase \\
\hline PLK1 & Polo-like kinase 1 \\
\hline PP2A & Protein phosphatase $2 \mathrm{~A}$ \\
\hline PP4 & Protein phosphatase 4 \\
\hline $\mathrm{pX}$ & indicates phosphrylated protein \\
\hline qPCR & Quantitative real-time PCR \\
\hline RevT & Reverse transcriptase \\
\hline RNA & Ribonucleic acid \\
\hline
\end{tabular}




$\begin{array}{ll}\text { RNAi } & \text { RNA interference } \\ \text { ROI } & \text { Region of interest } \\ \text { ROS } & \text { Reactive oxygen species } \\ \text { RPA } & \text { Replication protein A } \\ \text { rpm } & \text { Rounds per minute } \\ \text { RT } & \text { Room temperature } \\ \text { SDS } & \text { Sodium dodecyl sulfate } \\ \text { SDS-PAGE } & \text { SDS-polyacrylamide gel electrophoresis } \\ \text { siRNA } & \text { Small interfering ribonucleic acid } \\ \text { SSDNA } & \text { Single-stranded DNA } \\ \text { STAG2 } & \text { Stromal antigen 2 } \\ \text { SWI/SNF } & \text { SWltch/Sucrose non-fermentable } \\ \text { TBST } & \text { Tris-buffered saline + Tween 20 } \\ \text { TEMED } & \text { Tetramethylethylenediamine } \\ \text { TIP60/KAT5 } & \text { Lysine histone acetyl transferase 5 } \\ \text { TLS } & \text { Translesion synthesis } \\ \text { TOPBP1 } & \text { DNA topoisomerase 2-binding protein 1 } \\ \text { Tris } & \text { Trisamine } \\ \text { TS } & \text { Template switch } \\ \text { U } & \text { Unit } \\ \text { UV } & \text { Ultraviolet } \\ \text { UV-B } & \text { Ultraviolet light, wavelength 302 nm } \\ \text { UV-C } & \text { Ultraviolet light, wavelength 254 nm } \\ \text { WEE1 } & \text { WEE1 kinase } \\ \text { WIP1 } & \text { Wild type p53-induced phosphatase } \\ \text { WT } & \text { Wild type } \\ \text { YH2AX } & \text { H2AX phosphorylated on S319 } \\ & \end{array}$




\section{Introduction}

\subsection{Pancreatic cancer}

\subsubsection{Clinics and prognosis of pancreatic cancer}

Pancreatic adenocarcinoma is a comparably rare cancer, but the fourth leading cause of cancer deaths as a result of its bad prognosis (Conroy et al. 2016). With a five-year survival rate of less than $6 \%$, the mortality of this disease almost equals its incidence. Discomfort occurs only in an advanced stage, and even then, symptoms are not specific. Although several risk factors are known, there is no established screening program for early detection, and $80 \%$ of the patients display distant metastases or locally advanced tumors upon diagnosis and are not eligible for surgery, the only potentially curative treatment (Kamisawa et al. 2016).

In contrast to other solid tumors, for pancreatic cancer there is a low chance to render it a chronic disease if yet curation is not achievable. Most of the patients die within the first year after diagnosis, and chemotherapy, although alleviating symptoms in a palliative care setting, hardly improves survival. It is estimated that deaths from pancreatic cancer will further increase, as known risk factors remain highly prevalent (male sex, family history, cigarette smoke, alcohol abuse and chronic pancreatitis) or become even more frequent (obesity, diabetes) combined with the lack of improved therapeutic options (Conroy et al. 2016).

\subsubsection{Characteristics and biomarkers for pancreatic cancer}

Adenocarcinoma, derived from ductal epithelial cells, account for $95 \%$ of pancreatic cancer. Although not unique to this tumor, it is genetically highly heterogenic with extensive tumor cell plasticity making it hardly accessible for targeted therapies as the main driver mutations cannot yet be successfully targeted (Falasca et al. 2016). Like in other tumors, some genetic alterations occur at specific stages of tumorigenesis and characterize the genetic landscape of pancreatic cancer. Oncogenic KRAS mutations are found in 90-95\% of tumors and occur in a very early stage, promoting tumor cell growth and metabolism. Intermediate alterations are found with deletions or epigenetic silencing of the cell cycle regulator CDKN2A/p16 
(cyclin-dependent kinase inhibitor 2A), which are also found in $95 \%$ of pancreatic tumors. Late events concern mutations or deletions of the tumor suppressor p53 (50-75\%) and the transcription factor DPC4/SMAD4 (deleted in pancreatic cancer 4/mothers against decapentaplegic homolog 4) which is a chromatin remodeling enzyme and involved in the transforming growth factor beta signaling pathway. Around $10 \%$ of pancreatic cancers have a familial basis, most of which are germline mutations in the tumor suppressor BRCA2 (breast cancer 2) (Ying et al. 2016). Global genomic analyses of pancreatic cancers gained insight in altered core signaling pathways and mutation patterns. An average of 63 genes were found to be mutated in each pancreatic cancer sample. Although none of the mutations except the above described was overrepresented, this large number of mutations could be reduced to twelve core signaling pathways, among them apoptosis (altered in $100 \%$ of the tumors), cell cycle regulation (altered in $100 \%$ of the tumors) and DNA damage signaling (altered in $80 \%$ of the tumors) (Falasca et al. 2016). In knowledge of gemcitabine acting mainly through the induction of DNA damage, these results underline the importance of investigating the DNA damage response (DDR) as potential target to increase gemcitabine sensitivity.

\subsubsection{Therapeutic options}

Surgery of locally defined pancreatic cancer remains the only curative treatment, but is an option for only $20 \%$ of patients. The five-year survival rate is increased to $25 \%$ for resected patients, but $80-90 \%$ eventually relapse. Efficient neoadjuvant chemotherapy may increase both the number of patients eligible for surgical therapy and its therapeutic success. For all patients with advanced disease, chemotherapy is the only option. Ever since monotherapeutic gemcitabine has proved beneficial in 1997, it has governed pancreatic cancer therapy, and all other single and combination therapies as well as targeted therapies have since been compared to its success. However, only a minority of patients respond to that treatment at all, and it prolongs median survival only to 5.65 months after diagnosis compared to 4.41 months after treatment with 5-fluor-uracil (5-FU) (Burris et al. 1997). The combination of gemcitabine with the epidermal growth factor inhibitor erlotinib marginally increased response and overall survival. Furthermore, recent studies established the combination with nanoalbumin-bound mitotic spindle inhibitor paclitaxel (nab-paclitaxel, Abraxane), which improved response to $23 \%$ and overall survival to 8.5 months. The best option for patients with advanced and metastatic pancreatic cancer is the FOLFIRINOX regimen (5-FU and folinic acid, irinotecan, oxaliplatin), which prolonged survival to almost eleven months, but brings along extensive side effects and is therefore only eligible for 30 $40 \%$ of patients: those under 65 years of age and with a very good performance state 
(Conroy et al. 2016). In case of acquired resistance to primary therapeutic regimens and onset of a progressive disease after chemotherapy, a second line treatment can be discussed although there is no robust clinical data for a clear benefit of it.

Progress in the treatment of pancreatic cancers ranks far behind improved treatment options for other cancers, resulting in the need for even more research efforts.

\subsection{DNA damage}

The maintenance of genomic integrity is the major prerequisite for health and functionality of the human body from conception to death and for the creation of following generations. Besides the proper distribution of chromosomes during mitosis, the maintenance of the genetic code within the DNA is crucial for tissue renewal. Even without exposure to mutagens, it is estimated that a single cell has to cope with 50,000 to 100,000 DNA lesions per day (Hoeijmakers 2009; Swenberg et al. 2011; Takahashi et al. 1990). Most of them occur spontaneously or as consequence of metabolic processes like the generation of reactive oxygen species (ROS) resulting from the respiratory chain of a cell. They most frequently affect single bases, resulting in single base adducts and abasic sites (De Bont and van Larebeke 2004; Jackson and Loeb 2001; Swenberg et al. 2011). If not repaired before, those bases are eventually mispaired during DNA replication by low fidelity polymerases, leading to heritable mutations (Marnett and Plastaras 2001). The cell has evolved DNA repair mechanisms that sense and emit altered bases or mismatched base pairs by base excision repair (BER), nucleotide excision repair (NER) and mismatch repair (MMR). These mechanisms form a steady state with DNA lesions in a constant challenge for genomic integrity and mutations accumulate with age provoking the onset and progression of cancer. While single base adducts do not activate the full DDR, major insults can occur when the damaged site is cleaved into a double-strand DNA break, for example by topoisomerases, or results in single-strand DNA breaks if the base adduct blocks DNA replication (Marnett and Plastaras 2001).

The accumulation of mutations resulting in genomic instability is cause as well as consequence of the malignant transformation of a cell. Mutations in coding regions or promoter regions of the genome inactivate tumor suppressors, and tumors are characterized by a defective system to cope with DNA lesions which in turn results in the accumulation of mutations (De Bont and van Larebeke 2004; Hoeijmakers 2009; Jackson and Loeb 2001; Stratton et al. 2009). 
It is generally underlined that a constant baseline of DNA damage occurs endogenously and that the contribution of exogenous factors is comparably small. Nevertheless, it can trigger and prepone the onset of mutations (De Bont and van Larebeke 2004; Jackson and Loeb 2001). Finally, the massive induction of exogenous DNA damage has its clinical use in chemotherapy.

\subsubsection{DNA damage induced by UV radiation}

Sunlight is essential for the evolution of life. On the other hand, ultraviolet (UV) radiation causes DNA damage and is the most frequent source of exogenous DNA damage in all organisms. According to its wavelength, it is divided into UV-C (240-290 nm), UV-B (290$320 \mathrm{~nm}$ ) and UV-A (320-400 nm). While UV-C is absorbed by the atmosphere and does not hit living organisms to a relevant extent, UV-A and -B cause damage to cells in nature. UV radiation and visible light are absorbed by the DNA, especially by the pyrimidine bases thymine and cytosine, but only UV-B and UV-C provide energy high enough to excite carbon double bonds and induce the formation of cyclobutane-pyrimidine dimers (CPD) and 6-4 photoproducts (6-4-PP) between two bases, of which the primary structure is detailed in Figure 1.1 (Herrlich et al. 2008; Li et al. 2006). In prokaryotes and most eukaryotes, these products are restored by specialized photolyases using visible light energy, but those enzymes seem to be missing in mammals. Although 6-4-PPs cause only $25 \%$ of UVinduced DNA damage and are repaired much faster than CPDs, they threat genomic integrity more than CPDs, which cause $75 \%$ of the UV-specific adducts. First, 6-4-PPs cause nicks in the sugar-phosphate backbone of DNA which makes strand breaks more likely, while CPDs do not alter the DNA structure but only the angle to neighboring bases. Second, 6-4-PPs cause mispairing and loss of bases after replication by low fidelity polymerases, whereas CPDs do not (Rastogi et al. 2010).

UV radiation affects compacted chromatin, too, but its ability to induce a DDR is increased in actively transcribed regions of DNA where access is better for damage-sensing proteins. UV-induced damage is finally of note when a cell replicates its DNA. Then, pyrimidine dimers cause stalling of DNA and RNA polymerases and lead to the formation of single stranded DNA (ssDNA) at stalled replication forks, as detailed in chapter 1.3.2 and 1.3.3 (Herrlich et al. 2008).

We used UV irradiation to induce DNA damage in our experiments for two reasons: First, we exploited the possibility to switch DNA damage induction on and off at an exactly defined time point. Second, and compared to gemcitabine-induced DNA damage, the cellular context does not mediate the formation of UV-induced DNA adducts as their amount does 
<smiles>[R]c1cn([12F])c(=O)[nH]c1=O</smiles>

$\downarrow$ UV light



CPD

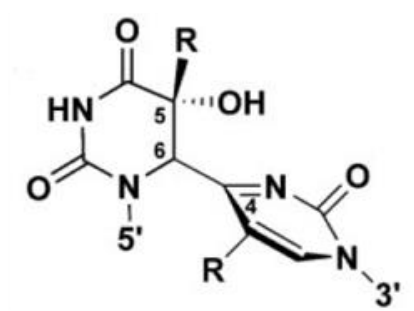

6-4 photoproduct

\section{Figure 1.1 UV-induced DNA lesions.}

Pyrimidine bases absorb the energy from UV light, leading to the formation of cyclobutane pyrimidine dimers (CPD) or 6-4 photoproducts with neighboring bases. Both change the primary structure of DNA and induce DNA damage signaling (figure adapted from Li et al. 2006 with permission from the Journal of Biological Chemistry).

not change in cellular compared to naked DNA (Cadet et al. 2005). Thus, influences of drug metabolism is excluded as a confounder for readouts if we shall neglect that UV is a potent inductor of ROS and protein malformation. Still and so far known, pyrimidine dimers and gemcitabine lead to similar DDR patterns.

The advantage of UV-C is that its high energy is best absorbed by the DNA, thus leading to a high ratio of DNA lesions compared to the above mentioned secondary cytoplasmatic effects.

\subsubsection{Chemotherapy with nucleoside analogs and antimetabolites}

Chemotherapy constitutes one column of anticancer treatment. In resectable solid tumors, it is used to prepare surgery to define a tumor's size and borders (neoadjuvant treatment) or to support the surgical outcome by diminishing the load of remaining malignant cells (adjuvant treatment). In malignant hematological diseases as well as in metastatic solid tumors, chemotherapy, besides immunotherapy, represents the predominant treatment option. Usually, chemotherapy does not consist of one single agent, but of a combination of agents that target the DNA of a cell by different mechanisms. This effect can be supported 
by the inhibition of key signaling pathways by small molecules and by binding surface markers of a malignant cell with antibodies.

Due to their interference with DNA replication, nucleoside analogs and antimetabolites specifically target cells going through S-phase. While nucleoside analogs are incorporated into a nascent DNA strand during replication, antimetabolites interfere with enzymes which are essential for the cellular supply of deoxynucleotide triphosphate (dNTPs) (Ewald et al. 2008). This is of therapeutic advantage for two reasons: First, malignant tumors are generally characterized by a high proliferation rate and a much higher turnover of DNA than are healthy tissues, therefore suffering replicative stress. Second, high susceptibility to genotoxic stress is a hallmark of malignant cells, which is enhanced during S-phase when DNA-related processes need to be densely regulated (Hanahan and Weinberg 2000).

Despite the high structural similarity, different nucleoside analogs display a broad spectrum of effects within a cell. As example, structural analogs of deoxycytidine, the chemotherapeutics Ara-C (2'-deoxycytidine) and gemcitabine (2'2'-difluoro-deoxycytidine), only differ in the substitution on the 2'-carbon of ribose, but have largely differing applications (Galmarini et al. 2002) (see Figure 1.2). Ara-C is predominantly used as single and combination treatment in acute myeloic leukemia. It is incorporated into the DNA and provides a poor substrate to the DNA polymerase to attach further nucleotides on the 3'carbon resulting in slow DNA replication and eventually in a replication block (see section 1.3.2) (Ewald et al. 2008).

A typical antimetabolite is hydroxyurea $(\mathrm{HU})$, which is used as cytostatic agent in malignant hematological diseases, too. It depletes the cellular dNTP pool and thereby inhibits DNA synthesis, which leads to a growth arrest of highly malignant cells only, followed by the

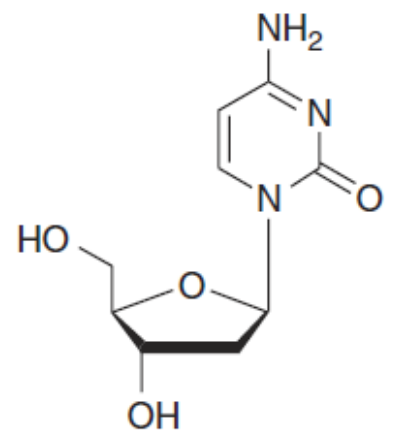

2'-Deoxycytidine



ara-C

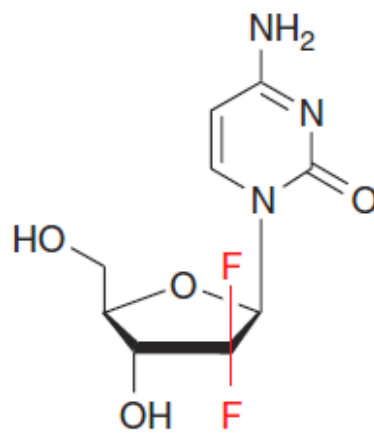

Gemcitabine

Figure 1.2 Structure of the nucleoside analog gemcitabine.

Gemcitabine is a derivative of deoxycytidine. As functional substitutes, it contains two fluorine atoms at the 2'-position of the ribose backbone neighboring the 3'-carbon where in naturally occurring nucleotides DNA strand elongation takes place (figure from Ewald et al. 2008 with permission from Oncogene). 
induction of apoptosis. Hydroxyurea (HU) and Ara-C are both not effective in solid tumors which contain a comparably high portion of non-replicating cells, which is possibly compensated by the slower metabolism of gemcitabine (Galmarini et al. 2002).

Gemcitabine, instead, combines features of an antimetabolite and a nucleoside analog and targets much more processes in a cell than does Ara-C (Ewald et al. 2008). Additionally, it is retained inside the cell for a much longer period of time and metabolized only slowly, which opens the opportunity to target those cells that are not in the replication process at the time of administration (Huang et al. 1991).

Although nucleoside analogs are one of the oldest antineoplastic substances in clinical use, only little is known about their mode of action and the cellular response which they elicit. Modulators of the DDR and different DNA repair pathways have been proposed as target for chemosensitization (Ewald et al. 2008). To date, there is no targeted therapy approved to enhance DNA damage and pro-apoptotic signaling induced by nucleoside analogs. Researchers and clinicians argue that there is a need for better understanding of the above processes in order to improve therapeutic efficacy of nucleoside analogs especially in solid tumors.

\subsubsection{Gemcitabine}

Gemcitabine has been studied in a variety of malignant diseases since its cytostatic effect had been discovered in the 1990s. As single and first line treatment, it governs the therapeutic regimens for pancreatic cancer, but it is used in combination therapy in a spectrum of solid tumors including non-small cellular lung cancer, bladder cancer and breast cancer (Ewald et al. 2008).

Gemcitabine is taken up into the cell by specific nucleotide transporters (hNTs), predominantly by the concentration-dependent equilibrative transporter hENT1, and needs to be phosphorylated by deoxycytidine kinase (dCK) to be activated (Mini et al. 2006). The phosphorylation event is the effect-limiting step in the clinics because dCK is saturated at a dose of $15-20 \mu \mathrm{M}$ plasma gemcitabine concentration, and intracellular gemcitabine concentrations are not achieved by higher dosage but only by prolonged infusion rate (Veltkamp et al. 2008). The triphosphate is incorporated into the DNA instead of deoxycytidine in a concentration-dependent manner. The DNA polymerase then attaches one single nucleotide to gemcitabine and immediately pauses replication, an event called "masked chain determination" (Mini et al. 2006). Different reasons for that have been suggested: First, the incorporation of gemcitabine alters the torsion angle for the following base. This retires its 3 '-C and reduces its reactivity as substrate of DNA polymerases, 
leading to a non-permanent stalling of replication forks. This is supported by the finding that, in primer extension assays, DNA fragments of greater molecular weight are found than would be expected with gemcitabine in the penultimate position. Second, the fluorine atoms of gemcitabine are highly electronegative, altering the electrostatic surface of a polynucleotide, and thereby reducing the reactivity of the 3'-C-hydroxyl group that is necessary for strand elongation and possibly for the binding capacities of proteins involved in DNA-dependent replication processes (Konerding et al. 2002).

Gemcitabine appears resistant to conventional DNA repair mechanisms for single base defects, possibly due to its induction of only relatively small sterical changes to DNA. BER as well as NER pathways, which are usually involved in repair of unnatural bases, do not influence gemcitabine sensitivity (Crul et al. 2003). Additionally, the proofreading function of DNA and RNA polymerases is not able to detect and excise gemcitabine (Gandhi et al. 1996). Gemcitabine is incorporated into RNA, too, and inhibits RNA synthesis, although to a much lesser extent than it inhibits DNA synthesis (Huang et al. 1991; Mini et al. 2006). It further inhibits ribonucleotide reductase, an enzyme which is crucial for the generation of deoxynucleotide triphosphates (dNTPs) and thereby leads to imbalance in the cellular dNTP pool. This causes an imbalance of cellular dNTPs as DNA components, which already affects DNA replication, and which facilitates the frequency of its own incorporation, a mechanism termed self-potentiation (Ewald et al. 2008). However, while the direct DNAdamaging effect of gemcitabine occurs immediately, the consequence of dNTP depletion occurs only after hours and the initial DDR, and apoptosis induced by gemcitabine cannot be rescued by the addition of a balanced dNTP mix (Huang et al. 1991).

In conclusion, targeting DNA repair pathways has not been a suitable strategy for gemcitabine chemosensitization so far. The manipulation of DNA damage checkpoints has proven effective to sensitize cells towards this treatment (Ewald et al. 2008), but the identification of other new targets in order to enhance gemcitabine-induced DDR is required in order to improve the therapeutic efficacy of gemcitabine.

\subsubsection{Targeting resistance to gemcitabine treatment}

With a high fraction of pancreatic tumors already showing intrinsic resistance to gemcitabine, every tumor acquires resistance in the course of treatment. Resistance mechanisms are essentially unknown and probably highly heterogeneous among tumor cells. The best-characterized resistance mechanisms are involved in gemcitabine uptake and metabolism. The expression of the involved enzymes is highly predictive for the gemcitabine response but has not been established as predictive marker or therapeutic 
targets in clinical practice. Hypoxic conditions in the tumor microenvironment confer a selective pressure for resistance-driving somatic mutations, and hypoxia itself induces cellular reprogramming and activates resistance-associated signaling cascades. A large compendium of genetic alterations associated with gemcitabine resistance has been risen over the years, but none of them has been exploited for the profit of cancer patients, possibly due to the high intra- and interpersonal variety of resistance mechanisms (Akada et al. 2005; Harsha et al. 2009).

Inhibition of the checkpoint kinase 1 (Chk1) to increase gemcitabine induced replicative stress has been tested in many clinical trials but has been abandoned due to inacceptable side effects (Ma et al. 2011).

\subsection{5 lonizing radiation and neocarzinostatin}

In contrast to DNA damage induced by nucleoside analogs and UV, ionizing irradiation primarily induces replication-independent DNA breaks after its energy is absorbed by bases of the DNA and the sugar phosphate backbone. While the above chemotherapeutics target mostly replicating cells, ionizing radiation is less selective and causes chromosome breaks also in heterochromatin and in healthy as well as in malignant cells. DNA double-strand breaks (DSBs) are repaired by homologous recombination (HR) or non-homologous end joining (NHEJ) but still constitute the most apoptotic DNA lesion (Ciccia and Elledge 2010; Stucki and Jackson 2006). The establishment of ionizing radiation in cancer therapy is based on the fact that malignant cells are often defective in the above-mentioned repair pathways and therefore anyway suffer genomic instability, which makes them highly susceptible for cell death upon DSB induction. Yet, ionizing radiation needs to be targeted precisely to the tumor to reduce extensive side effects in surrounding healthy tissue. It is therefore mostly applied for locally defined tumors or local complications of a tumor.

In the 1990s, radiomimetic agents that induce DSBs have been extensively studied in clinical trials. One example is neocarzinostatin (NCS), a small molecule complex consisting of an enediyne chromophore which is highly unstable. It is therefore tightly tethered to a small apoprotein that stabilizes the molecule and delivers it to the DNA where it is released. The chromophore is activated in the reductive milieu inside the cell, where it forms a biradical that abstracts hydrogen atoms from DNA and leads to DNA cleavage (Nicolaou et al. 1993). NCS induces sequence-specific ssDNA breaks (primarily $80 \%$ ) and DSBs (primarily $20 \%$ ) (Povirk 1996). It was tested for clinical use in primary liver cancer, small cell lung cancer and acute myeloic leukemia (Creech et al. 1984; Ishii et al. 2003; McKelvey et al. 1981) and in an antibody-coupled fashion for colorectal and pancreatic cancer 
(Takahashi et al. 1990). While none of the radiomimetics have been approved for cancer treatment, some of them are still in lab use for the immediate induction of replicationindependent DNA breaks, and some are highly specific for the induction of DSBs (Nicolaou et al. 1993; Smith and Nicolaou 1996). We used NCS in our experiments to induce DSBs.

\subsection{DNA damage response}

Cells have evolved mechanisms to cope with DNA damage in order to prevent the accumulation of mutations, leading to genomic instability and the development of cancer. DDR is activated in early states of cancer as a barrier to tumor development (Bartek et al. 2007), and genetic as well as epigenetic downregulation of DDR factors occur early during cancer progression (Halazonetis et al. 2008). Having in mind the vast amount of DNA lesions a cell has to cope with, DDR is not an occasional event, but a steady state of highly regulated enzyme cascades active enough to repair DNA efficiently but defined enough to not hamper cellular processes if not necessary. If DNA is damaged, transcription and replication need to be stopped near the damaged DNA in order to make it accessible for repair factors. If damaged DNA exceeds the cellular repair capacities, the damaged cell needs to be eliminated from the proliferative pool via the induction of apoptosis or senescence (Ciccia and Elledge 2010). Current models of the DDR differentiate between damage sensors, transducers and effectors, although this is artificial as many factors are known to play a role at more than one step of the DDR. While sensors bind to damaged DNA and recruit or activate signal transducers, the latter serve as amplifiers of the damage signal: They activate effectors that carry out alterations in cellular processes as mentioned above and recruit DNA repair factors (Zhou and Elledge 2000).

A fast-acting DDR is driven by posttranslational modifications of proteins such as phosphorylation and ubiquitination, and kinases involved in the DDR are well characterized to date. Their inhibition is already subject to clinical research aiming to sensitize cells towards DNA-damaging agents (Blackford and Jackson 2017).

Subsequent to immediate reactions to damaged DNA, lasting processes in the DDR come up and are far less understood than DNA damage-induced kinase signaling. These cellular responses consist of chromatin remodeling and transcriptional reactions which integrate the DDR over time and might decide on the fate of a cell after genomic insults (Blackford and Jackson 2017). An overview of the immediate response to DNA damage as well as its consequences is given in figure 1.3. 
There are many ways to sense and repair damaged DNA. For example, the excision of mispaired or unphysiological single DNA bases or oligonucleotides is carried out by BER and NER, respectively. In this thesis, we will introduce into detail only the pathways which are relevant for the work, namely the response to stalled replication forks and single-strand DNA (sSDNA) breaks on the one hand and to DSBs on the other hand.



Figure 1.3 Core signaling pathways in the DNA damage response.

Central sensor kinases are activated by DSBs and ssDNA after replicative stress, respectively. All phosphorylate $\mathrm{H} 2 \mathrm{AX}$ and $\mathrm{p53}$, and contributions of each pathway strongly depend on the type of lesion and extent of damage. There are many other common but also pathway-specific downstream targets. Crosstalks and mutually activating events occur on several intersection points. Consequences are the activation of cell cycle checkpoints, chromatin remodeling and DNA repair, damage-responsive gene transcription and apoptosis.

\subsubsection{A fast reaction: kinase signaling in the DNA damage response}

Although involved in a complex network, there are three kinases of the PIKK (phosphoinositol-3-kinase-related kinase) family which have been identified to form an intersection for signal transduction in the DDR. ATM (ataxia-teleangiectasia mutated), ATR (ataxia-teleangiectasia and Rad3-related) and DNA-PK (DNA-dependent protein kinase) 
share the minimal phosphorylation motif and the majority of more than 700 substrates (Kim et al. 1999; Matsuoka et al. 2007). Still, as the affinity to the substrates might differ and some of the downstream targets are specifically activated by ATM or ATR, distinct response pathways arise. DNA-PK has the smallest amount of substrates and those are mainly shared with ATM, a fact that ascribes a smaller or redundant function to DNA-PK in the DDR. DNA-PK binds to DNA at DSBs where it stabilizes DNA and allows DNA end-binding during the repair pathway of NHEJ (Jette and Lees-Miller 2015; Meek et al. 2008). Although downstream signaling of ATR and ATM overlaps and, for example, the transcription factor and tumor suppressor p53 as well as the histone variant $\mathrm{H} 2 \mathrm{AX}$ are substrates of both, ATM and ATR are activated in response to different stimuli. While ATM is mainly involved in the response to DSBs, ATR is needed for DNA damage signaling following replicative stress and ssDNA breaks at stalled replication forks (see fig. 1.3 and following chapters) (Blackford and Jackson 2017; Ciccia and Elledge 2010).

\subsubsection{Response to replicative stress and single-strand DNA breaks: the ATR/Chk1 pathway}

Fast replicating tumor cells suffer a high level of endogenous replicative stress and are susceptible to additional stresses induced by chemotherapy (Blackford and Jackson 2017). During replication, DNA helicases unwind the DNA ahead of DNA polymerases, which then synthesize the complementary strand. DNA polymerases stall when they encounter a replicative block, for example any event that interferes with strand elongation, for example a conformational change of the DNA induced by UV or gemcitabine. The unwinding of DNA is consecutively uncoupled and long fibers of SSDNA emerge, which are immediately coated and therefore stabilized by RPA (replication protein A) to avoid secondary DNA structures, as schematically illustrated in figure 1.4. RPA then recruits ATR through its essential cofactor ATRIP (ATR-interacting protein) (Zou and Elledge 2003). The additional colocalization of another factor, the 9-1-1 complex (RAD9-Hus1-RAD1 complex) occurs largely independent from ATR binding. It is, however, critical for ATR activation that TOPBP1 (DNA topoisomerase 2-binding protein 1) binds to the 9-1-1 complex and, brought in close proximity to ATR, potentiates and sustains ATR activity (Cimprich and Cortez 2008). The assembly of the scaffolding complex mentioned above and the activation of ATR promotes replication fork stability and DNA repair, as well as the activation of many downstream targets (Ciccia and Elledge 2010). Among the major targets of ATR are the histone variant $\mathrm{H} 2 \mathrm{AX}$ and the checkpoint kinase Chk1. The expression of Chk1 is increased in S-phase of the cell cycle and it is phosphorylated on Ser317 and Ser345 by ATR (Zhao and Piwnica-Worms 2001). Whereas ATR is largely immobilized to DNA, the active form of 
Chk1 is released from chromatin and can diffuse throughout the cell to phosphorylate further substrates (Cimprich and Cortez 2008). Chk1 attenuates DNA replication, promotes DNA repair or lesion bypass of stalled replication forks and slows down progression through the cell cycle (Dai and Grant 2010). Further, it induces the proapoptotic tumor suppressor p53, linking ATR/Chk1-mediated DDR to apoptosis. Mice lacking either ATR or Chk1 are not viable due to a high occurrence of replicative stress and apoptosis. Cultured cells depleted of ATR or Chk1 exhibit strong DNA damage signaling and a phenotype resembling mitotic catastrophe. The dependance of highly replicating tumor cells on ATR/Chk1 signaling might be a reason for both proteins hardly being found mutated in tumors (Lecona and FernandezCapetillo 2014). The dependance of a cell on the replicative stress response could explain the previously mentioned extensive adverse effects seen in clinical trials with the objective to establish ATR or Chk1 inhibitors as cancer therapeutics (Ma et al. 2011).

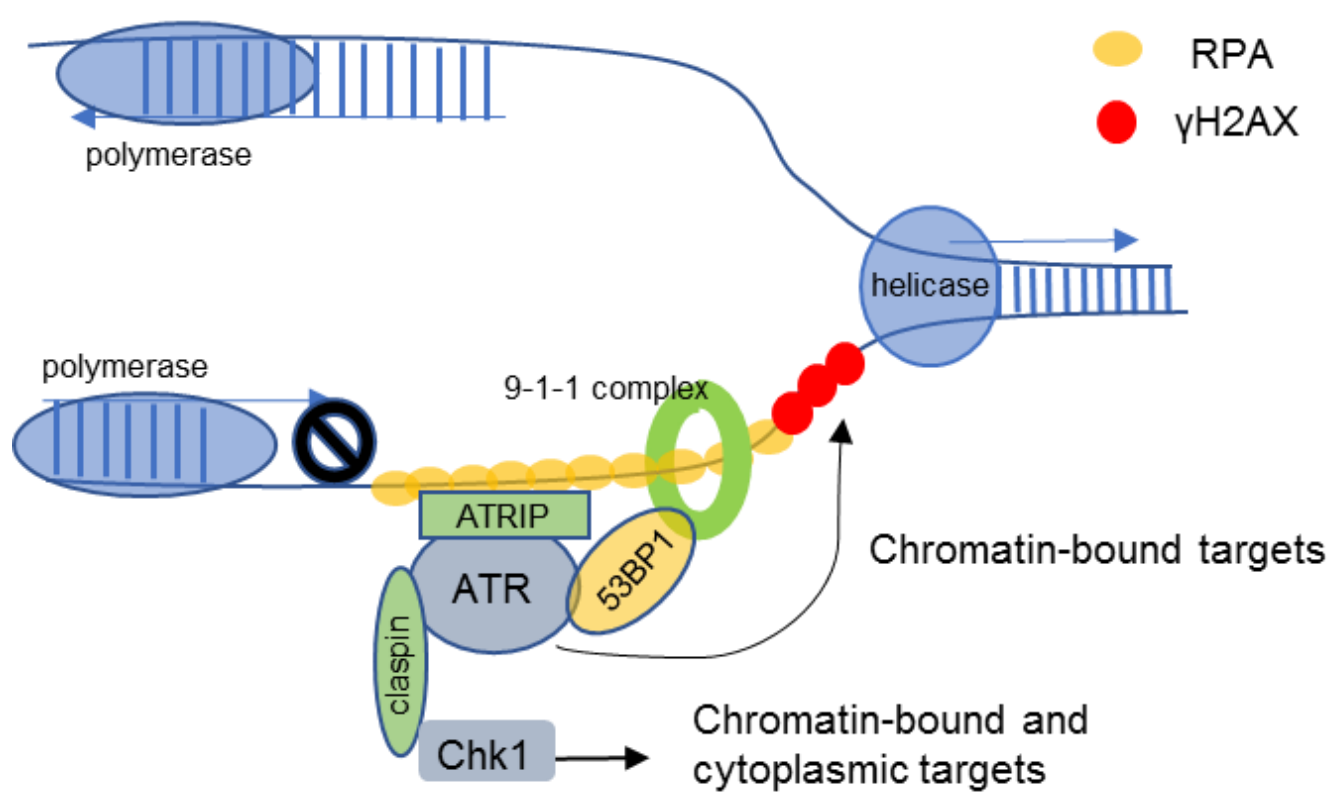

Figure 1.4 Activation of the ATR/Chk1 pathway in response to ssDNA.

When replication forks stall, arising SSDNA is coated by RPA to stabilize it and to scaffold ATRIP and the 91-1 complex. ATRIP binds and immobilizes ATR to chromatin, which leads to its activation. Chk1 is phosphorylated by ATR when both are brought together by Chk1's essential cofactor claspin. Activated Chk1 partially diffuses from chromatin. Not upstream of ATR activation, but potentiating ATR activity is the 9-1-1 clamp complex which requires another cofactor, 53BP1, to bind ATR. 


\subsubsection{Response to double-strand DNA breaks: the ATM/Chk2 pathway}

DSBs of DNA result from extensive DNA lesions, for example induced by ionizing radiation or during replication, when DNA polymerases encounter stretches of ssDNA breaks. Another major source of DSBs is the collapse of replication forks, which occurs when repair factors and polymerases cannot overcome a replication block. The highly unstable fork is then cleaved into DSBs by endonucleases, which allows for the second line repair mechanism of DSB repair (see also chapter 1.4.2.1 and fig. 1.7) (Branzei and Foiani 2010). DSBs are sensed by PARP (poly-ADP-ribosylating) enzymes, which immediately synthesize PAR (poly-ADP-ribose) chains on histones around the DNA lesion and on themselves. ATM, which forms the central kinase for the cellular response to DSBs, can then directly bind to PAR chains or is recruited via the MRN protein complex (consisting of MRE11, RAD50 and NBS1) which itself binds to PAR-marked DNA independently of the presence of ATM (see also fig. 1.5). Like ATR, ATM is able to phosphorylate H2AX to amplify DNA damage signaling. Additionally, in the presence of phosphorylated H2AX and the MRN complex, another complex called MDC1 (mediator of DNA damage checkpoint 1) binds to damaged DNA and coordinates a multitude of chromatin modifying processes in response to DNA damage (Stracker et al. 2004; Stucki and Jackson 2006). Immobilized onto DNA, ATM activates its major downstream kinase, the checkpoint kinase Chk2, by phosphorylating it on Thr68 (Matsuoka et al. 2000). Constantly expressed throughout the cell cycle, Chk2 is activated when DNA damage occurs and is rapidly released into the whole nucleus to target its substrates, which are mainly involved in cell cycle regulation, DNA repair and apoptosis (Bartek and Lukas 2003).

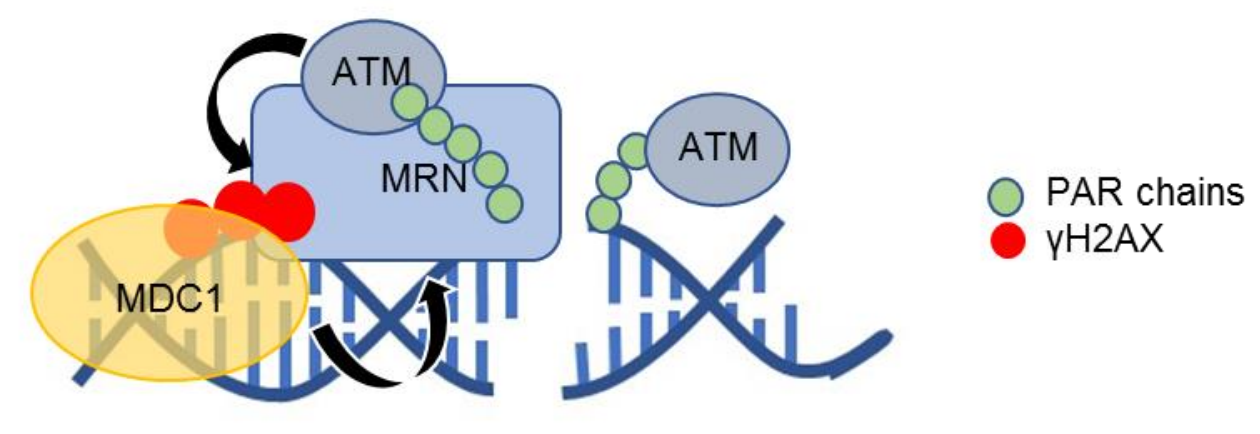

Figure 1.5 Response to double strand breaks.

Either by processing of ssDNA breaks or by the collapse of stalled replication forks, DSBs arise. Those are sensed by PARP enzymes, which start to synthesize PAR chains in proximity to a DSB as primary scaffold for an adequate DDR. ATM can either directly bind to PAR or through the MRN complex, which potentiates its activity. Another amplifier is the MDC1 complex, which facilitates binding of MRN complex components and thereby intensifies the ATM-mediated phosphorylation of $\mathrm{H} 2 \mathrm{AX}$ around DSBs as well as the recruitment of repair factors. 


\subsubsection{Phosphorylation of the histone variant H2AX}

DNA is organized by a multitude of attached factors, the chromatin, that organize virtually every DNA-associated process. One organizational subunit is the nucleosome, which consists of four histone variants $(\mathrm{H} 2 \mathrm{~A}, \mathrm{H} 2 \mathrm{~B}, \mathrm{H} 3, \mathrm{H} 4)$ and the smaller linker histone $\mathrm{H} 1$. $\mathrm{H} 2 \mathrm{AX}$ is a variant of the histone $\mathrm{H} 2 \mathrm{~A}$ and constitutes $2-25 \%$ of the cellular H2A pool depending on cell type and organism (van Attikum and Gasser 2009). While H2A is completely wrapped by DNA, H2AX possesses a 20 amino acid tail on its $\mathrm{C}$-terminus that harbors a Ser139 phosphorylation site and that protrudes from the nucleosome. It is therefore accessible for kinases (Rogakou et al. 1998).

Following DNA damage, ATM, ATR and DNA-PK phosphorylate H2AX on Ser139. The resulting phospho- $\mathrm{H} 2 \mathrm{AX}$ is then referred to as $\mathrm{YH} 2 \mathrm{AX}$. When DSBs are induced, ATM seems to be the major kinase phosphorylating $\mathrm{H} 2 \mathrm{AX}$, leading to $\mathrm{YH} 2 \mathrm{AX}$ foci formation at sites of DSBs, whereas during replicative stress, $\mathrm{YH} 2 \mathrm{AX}$ is induced by ATR (Burma et al. 2001; Fernandez-Capetillo et al. 2004). DSB-induced $\mathrm{yH} 2 \mathrm{AX}$ is detectable to a relevant amount already 1-3 min after the induction of damage, and reaches its maximum after 30 min (Rogakou et al. 1999).

When present on chromatin, the above mentioned MDC1 directly binds to $\mathrm{yH} 2 \mathrm{AX}$, a substantial event for the recruitment of more ATM. This leads to an amplification of the $\mathrm{YH} 2 \mathrm{AX}$ signal up to $2 \mathrm{MB}$ surrounding a DSB and thereby allows the stable recruitment of more DNA repair factors (Paull et al. 2000). Thus, the initial onset of $\mathrm{YH} 2 \mathrm{AX}$ is essential for its own signal amplification but onset and amplification of $\mathrm{yH} 2 \mathrm{AX}$ rely on distinct mechanisms.

To allow DNA repair processes to take place, $\mathrm{yH} 2 \mathrm{AX}$ must be released from DNA in order to give access to repair factors. Spread $\mathrm{YH} 2 \mathrm{AX}$ needs to be removed after sufficient repair to limit damage signaling. The underlying mechanisms are not fully understood (Srivastava et al. 2009). It was shown that $\mathrm{yH} 2 \mathrm{AX}$ underlies the regular exchange of histones, and it is estimated that $50 \%$ of $\mathrm{H} 2 \mathrm{AX}$ is exchanged within 3-4 $\mathrm{h}$, which is done by TIP60/KAT5 (lysine histone acetyl transferase 5), that acetylates and later evicts $\mathrm{yH} 2 \mathrm{AX}$ from DNA (Misteli and Soutoglou 2009). Generally, posttranslational modifications of H2AX are reversible. When ejected from DNA, $\mathrm{YH} 2 \mathrm{AX}$ is rapidly dephosphorylated by protein phosphatases, PP2A (protein phosphatase 2A) at DSBs and PP4 (protein phosphatase 4) at sites of replicative stress as well as WIP1 (wild type p53-induced phosphatase) (Chowdhury et al. 2005; Chowdhury et al. 2008; Keogh et al. 2006). As all phosphatases colocalize with $\mathrm{yH} 2 \mathrm{AX}$, it is presumable that they dephosphorylate DNA-bound $\mathrm{YH} 2 \mathrm{AX}$, too (Svetlova et al. 2010). Of note, H2AX is also and constantly phosphorylated on Tyr142 by the kinase WSTF/BAZ1B (williams syndrome transcription factor). It is dephosphorylated at 
this site upon DNA damage by EYA1/2 (eyes absent homolog 1/2), which is a prerequisite for the binding of MDC1 and the induction of DNA repair. In contrast, the persistent phosphorylation of Tyr142 together with Ser139 phosphorylation upon DNA damage was shown to impair DNA repair and to trigger apoptosis instead, establishing an additional role of $\mathrm{YH} 2 \mathrm{AX}$ in the decision of a cell's fate (Cook et al. 2009). Cells depleted of H2AX fail to induce cell cycle arrest upon DNA damage, possibly because they lack sufficient induction of DNA damage signaling, and H2AX-deficient mice display a high level of chromosomal aberrations (Celeste et al. 2002).

As $\mathrm{YH} 2 \mathrm{AX}$ is reliably induced at damaged DNA and removed after sufficient repair, it has become a hallmark of DNA damage and a standard readout for the overall DDR.

\subsubsection{Cross-talks between main DNA damage response pathways}

Although the ATR/Chk1 as well as the ATM/Chk2 pathway are activated by different kinds of DNA lesions, both pathways interact on more than one point to mediate and coordinate the DDR (see also fig. 1.3).

On the sensor level, ATR is activated when DSBs are processed and stretches of SsDNA arise, for example during the process of HR. On the other hand, the collapse of replication forks gives rise to DSBs which activate ATM signaling (Ciccia and Elledge 2010). Complemented by the above-mentioned DNA-PK, all kinases are responsible for $\mathrm{H} 2 \mathrm{AX}$ phosphorylation, as detailed above. ATM and ATR can additionally induce p38/MK2 signaling, which will be detailed in section 1.6, and the tumor suppressor p53.

Despite their wide range of shared substrate specificity (Matsuoka et al. 2007), both pathways have unique functions in the recruitment of suitable repair factors. Nonetheless, the partial activation of all DDR pathways sets a standby situation to take over the task if the preferential pathway fails (Shiotani and Zou 2009).

Of note, while the replicative stress response cannot be taken over by ATM signaling and germline mutations of ATR and Chk1 are lethal, ATM/Chk2-deficient mice indeed display defects in DNA damage signaling and high risk of developing tumors, but develop a functional organism (Brown and Baltimore 2000; Elson et al. 1996). 


\subsection{Consequences of the DNA damage response}

\subsubsection{Cell cycle regulation}

One of the hallmarks of malignant cells is their constant proliferation, which means that they need to undergo a specific program with the objective of duplicating their genome. The cell cycle is divided into different phases based on the amount of DNA of a cell. Passing through the cell cycle is usually carried out by the tightly regulated transcription of phase-specific genes and is dominated by the E2F/Rb-pathway as well as by the tumor suppressor p53 (Stracker et al. 2009). However, transcriptional reactions are comparably slow, and the cell has established transcription-independent, damage-inducible cell cycle checkpoints ahead of every phase in order to quickly react to DNA damage within seconds. As mentioned before, the activation of either ATR/Chk1 or ATM/Chk2 signaling induces a cell cycle checkpoint, which causes a transient delay in cell cycle progression and provides time to repair DNA (Kastan and Bartek 2004). An overview of the induction of cell cycle checkpoints is given in figure 1.6 .

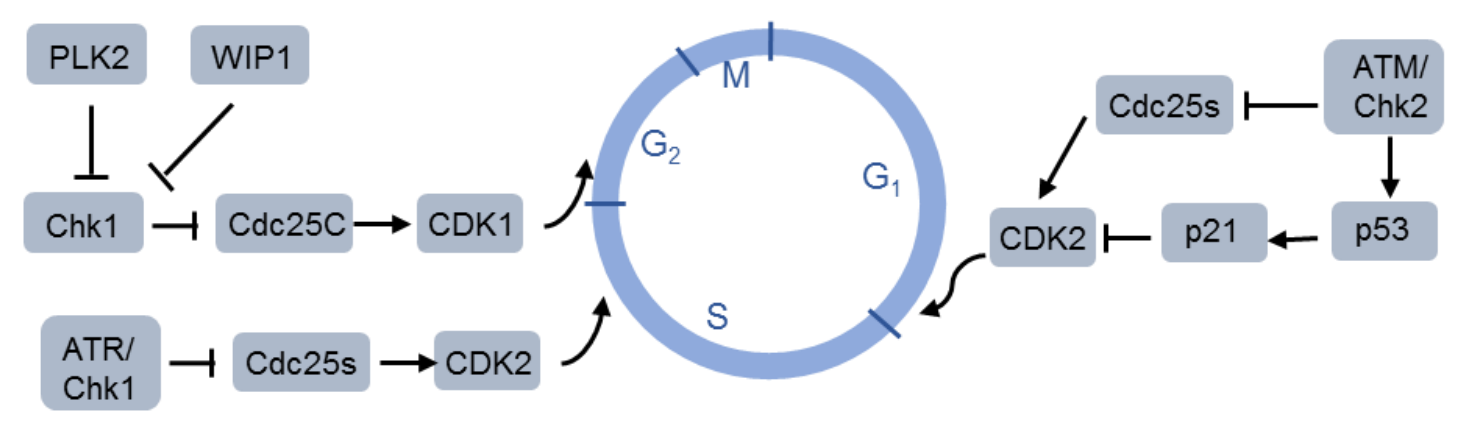

Figure 1.6 Cell cycle checkpoints upon DNA damage.

In G1 phase, ATM/Chk2 stabilize p53, which transcriptionally activates p21, an inhibitor of CDKs. A fastacting $\mathrm{G}_{1}$-arrest is carried out by the direct phosphorylation and thereby degradation of CDC25 phosphatases by ATM/Chk2. Cdc25s usually activate CDKs through the removal of their inhibitory phosphorylation. In Sphase, replication blocks and ssDNA activate ATR/Chk1 and lead to the degradation of Cdc25 and thus to reduced deinhibition of CDK2. In late $\mathrm{G}_{2}$ phase, constant Chk1 signaling prevents the deinhibition of CDK1 by reduction of Cdc25C levels. Chk1 activity is limited through the inhibitory phosphorylation by PLK2 and through the removal of activating phosphorylations by WIP1.

\subsubsection{The $\mathrm{G}_{1} / \mathrm{S}$ checkpoint}

The $G_{1} / S$ checkpoint can be activated by either ATR/Chk1 or ATM/Chk2 signaling depending on the type of DNA damage. Its purpose is to prevent cells from entering $S$ phase when they have accumulated DNA lesions that would affect replication. The 
transcription factor p53 plays the key role for that checkpoint. It stimulates the transcription of its main target p21, which is an inhibitor of CDKs (cyclin-dependent kinases) that, if activated, promote cell cycle progression. P21 activity induces prolonged or even permanent $G_{1}$ arrest, the latter called senescence. P53 is a direct target of ATM, ATR, Chk1 and Chk2. In the absence of functional p53, this checkpoint is thought to be defective. As it was shown that resection of DSBs in $\mathrm{G}_{1}$ does not generate high amounts of SsDNA, this checkpoint might predominantly activate ATM/Chk2 in the absence of functional p53 (Kastan and Bartek 2004).

Another fast but transient induction of the $\mathrm{G}_{1} / \mathrm{S}$-checkpoint is discussed to take place via the direct phosphorylation of the phosphatase Cdc25A (cell division cycle $25 \mathrm{~A}$ ) by all of the above-mentioned kinases, then resulting in its degradation. The continuous inhibitory phosphorylation of CDK1 as direct target of Cdc25A is then stabilized, limiting CDK activity and therefore progression through cell cycle (Kastan and Bartek 2004).

\subsubsection{The intra-S checkpoint}

S-phase is possibly the most vulnerable phase of the cell cycle since preexisting or replication-induced DNA lesions can impair proper DNA replication. All known mechanisms to induce the intra-S checkpoint can be activated independently of p53 and transiently delay ongoing S-phase through the CDK-mediated inhibition of not yet fired origins of replication (Bartek et al. 2004).

Replicative stress-induced S-phase delay can be caused by the inhibition of DNA polymerases, altered DNA structure and depletion of the dNTP pool. It activates the above detailed ATR/Chk1 pathway which, besides DNA damage signaling and repair, reduces fork speed, recruits fork-stabilizing factors and impairs the replication restart from not yet fired origins (Branzei and Foiani 2010).

DSB-induced S-phase delay takes place independently from the presence of replication forks after for example ionizing radiation, when DSBs occur spontaneously, but also after the collapse of replication forks and after topoisomerase-induced DSBs. It primarily and globally activates ATM, whereas ATR assembles on stretches of SSDNA after DSBs have been processed. Both effector kinases, Chk1 and Chk2, target Cdc25 phosphatases. Increased phosphorylation of those mediate their degradation, increasing the inhibitory phosphorylation of their main substrate CDKs, which therefore decrease activity and directly as well as through mediator proteins impair the resumption of replication from dormant origins (Branzei and Foiani 2010). 


\subsubsection{The $\mathrm{G}_{2} / \mathrm{M}$ checkpoint}

The aim of the checkpoint at this transition point is to prevent cells from entering mitosis when errors during $\mathrm{G}_{1}$ - and $\mathrm{S}$-phase have not been repaired properly. It involves both pathways, ATR/Chk1 and ATM/Chk2. In contrast to $\mathrm{G}_{1}$ - and S-phase, the effectors Cdc25C phosphatase and its target CDK1 execute the $\mathrm{G}_{2}$-arrest (Kastan and Bartek 2004). Chk1 activity remains high until $\mathrm{G}_{2}$ and prevents mitotic entry of a cell. Two rate-limiting mechanisms have attracted attention: First, the PLK2 (polo-like kinase 2) is transcribed in late S-Phase and phosphorylates Chk1, which upon this mark is degraded. Second, the phosphatase WIP1 reduces phosphorylation of Chk1 as well as its targets and was shown to reduce phosphorylation of the effector proteins $\mathrm{yH} 2 \mathrm{AX}$, p38 and p53, too (Lu et al. 2005; Shreeram et al. 2006).

The role of ATR/Chk1 in S-phase is underlined by the fact that transcription of Chk1 is highly restricted to $\mathrm{S}$ - and $\mathrm{G}_{2}$-phase, whereas Chk2 is constantly expressed. Furthermore, the constitutive phosphorylation of Cdc25A by Chk1 places a regulatory element during replication also in unperturbed S-phase, whereas upon DNA damage, the induction of ATR/Chk1 and to a certain extent ATM/Chk2 seems to be crucial for checkpoint activation (Bartek and Lukas 2007).

\subsubsection{DNA repair}

Cells are equipped with a variety of DNA repair mechanisms to face diverse DNA lesions. For example, there are repair mechanisms that already excise damaged or mispaired bases from DNA before replication blocks or DSBs result. It is still unclear if and in which manner nucleoside analogues can be excised (Ewald et al. 2008). Still, mutations in DNA repair pathways are a common mediator of resistance to chemotherapy (Jackson and Bartek 2009).

\subsubsection{Repair of stalled replication forks}

As mentioned above, ATR/Chk1 signaling induced upon replicative stress regulates the progression through S-phase and promotes the stabilization of stalled replication forks until they are repaired and DNA replication can be resumed. When a replication fork is terminally blocked, the progression through S-phase is generally attenuated. In order to ensure complete genome replication, another replication fork downstream of the lesion is fired, but still a gap of unreplicated ssDNA persists (Branzei and Foiani 2010). 


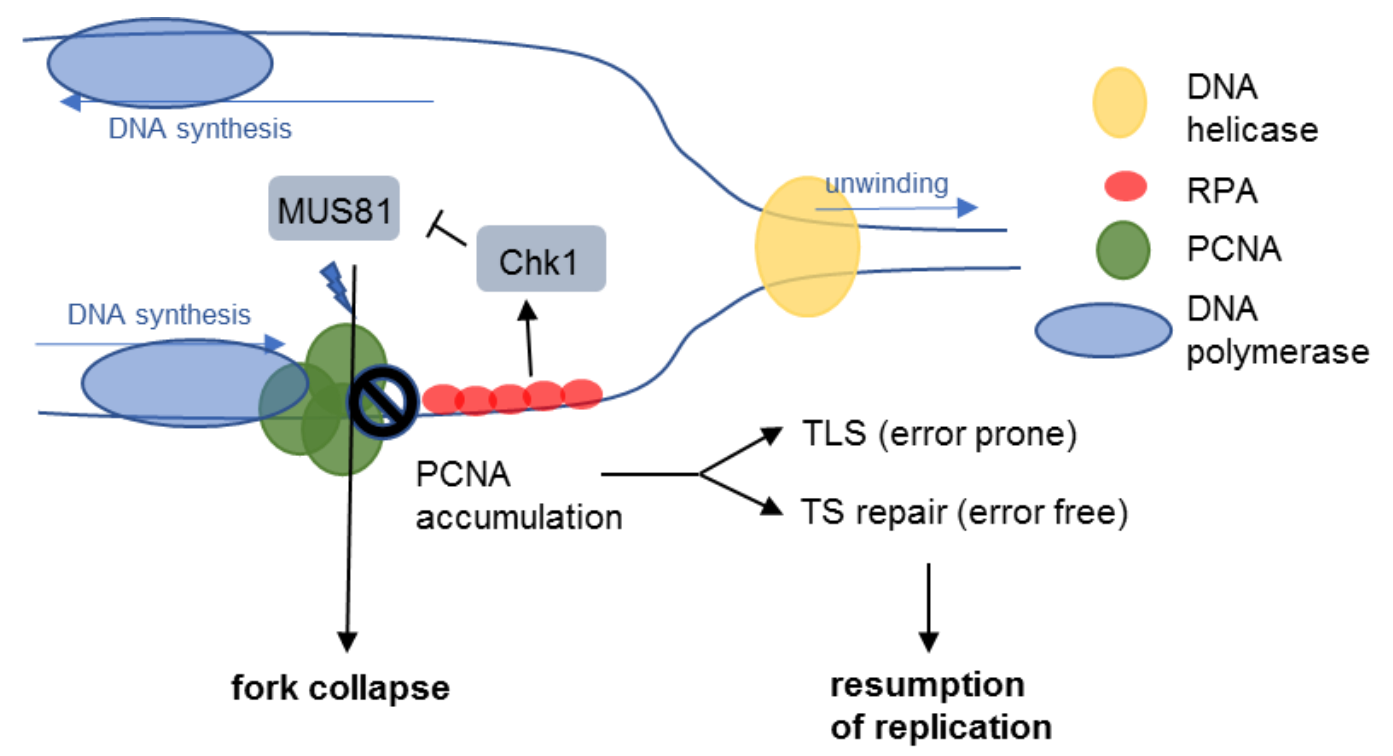

Figure 1.7 Repair of stalled replication forks.

When encountering a replication block, DNA polymerases stall. This leads to the accumulation and ubiquitination of PCNA. Dependent on the ubiquitination motif, either the accurate repair of a stalled fork is induced and resumption of replication using the DNA of a sister chromatid as template can take place,or the induction of TLS as damage tolerance, but not DNA repair mechanism is induced. If both ways to resume replication fail, the endonuclease MUS81 cleaves stalled forks to open up the way for DSB repair as a backup mechanism.

The highly conserved platform protein PCNA (proliferating cell nuclear antigen) is an inherent part of the replisome and cofactor of many DNA polymerases which are tethered to DNA in this way. It rapidly accumulates at sites of DNA damage, where it loads repair factors (Moldovan et al. 2007). Through its ubiquitination motif, PCNA decisively influences the DNA repair or damage tolerance mechanism at a stalled fork. When mono- or polyubiquitinated at Lys164, the error prone translesion synthesis (TLS) is activated in mammalian cells, while ubiquitination at Lys63 promotes error-free template switch repair (TS) in yeast (see figure 1.7) (Haracska et al. 2004; Hoege et al. 2002). While during TLS the replicative DNA polymerase is replaced by a low fidelity TLS-polymerase which accepts base alterations in order to overcome a lesion, template switch repair is an accurate mechanism using the nascent strand of the sister chromatid as template, a process partially HR (Branzei and Foiani 2010).

If DNA repair is not achieved by the above mentioned processes, endonucleases such as MUS81 (MMS and UV sensitive 1), which are usually inhibited by Chk1, can cleave stalled replication forks inducing their collapse and therefore converting them into DSBs (Forment et al. 2011). This processing opens up the opportunity for DSB repair to belatedly, but finally resume replication (Hanada et al. 2007). At already collapsed forks, remaining high activity levels of Chk1 promote the error-free repair pathway of HR (Stracker et al. 2009). 


\subsubsection{Repair of double-strand DNA breaks}

The repair of DSBs follows another class of repair mechanisms which are mainly HR and non-homologous end joining (NHEJ). While HR takes place in $\mathrm{G}_{2}$ and S-Phase when sister chromatids are available, NHEJ can be realized in any phase of the cell cycle.

Following double strand breaks, ATM phosphorylates the tumor suppressor BRCA1 (breast cancer 1), which is essential for its recruitment to damaged sites of DNA (Cortez et al. 1999), and the nuclease CtIP (CT Binding Protein Interacting Protein), which processes DNA ends at DSBs and promotes HR. Both factors bind to damaged DNA in an MRN-dependent manner. On the other hand, the induction and stabilization of 53BP1 (53 binding protein1) by ATM stabilizes DNA at DSBs and favors NHEJ.

The mechanistic basis of how both processes counteract each other remains unclear, but cell cycle dependency and the chromatin context of DSB emergence might constitute critical factors (Lukas et al. 2011).

\subsection{Apoptosis}

If a cell's DNA is extensively damaged and cannot be repaired properly to preserve the accumulation of mutations, apoptosis as programmed cell death is induced. This is governed by p53, which has already been introduced as to its role in activating cell cycle checkpoints. Although there is hardly any protein that gains as much attention as p53, the exact mechanism how a cell decides whether to die or to permanently arrest remains unclear and might depend on the cellular context, the extent of DNA damage and on the predominance of p21-induced cell cycle arrest (Vousden and Prives 2009).

Apoptosis is not only relevant for the elimination of malignant cells but also for developmental processes and tissue renewal. It is marked by characteristic events such as the blebbing of cellular membranes, the fragmentation of chromatin and the loss of intercellular contacts, all of which occur during programmed cell death but do not seem crucial for its induction. Apoptosis can be induced via an intrinsic pathway which responds to stress signals and an extrinsic pathway which is activated by cell surface receptors in response to death signals. Although p53 interconnects both pathways, its role is more pronounced in the intrinsic induction of apoptosis (Vousden and Lane 2007). 


\subsubsection{Activation and regulation of the tumor suppressor p53 in response to DNA damage}

The involvement of p53 in cell death and proliferation as crucial events of organism survival implicates a need for tight regulation. P53 is involved in regulating all types of DNA repair and in the same way targeted by factors of each repair pathway. It triggers chromatin relaxation at repair sites, rescues stalled replication forks - thus preventing them from collapsing into DSBs - and promotes error-free homologous repair (Gatz and Wiesmuller 2006).

P53 is activated by many stimuli, among them DNA damage and oncogenic signaling, as depicted in figure 1.8. The major and priming event for p53 activation is its phosphorylation on Ser15 by virtually all central DNA damage kinases. Except for acetylations which take place on the C-terminus, the major proportion of posttranslational modifications is located in p53's N-terminal domain, where phosphorylation on Ser15 facilitates the phosphorylation and acetylation of other target sequences. First, this disrupts the interaction of the ubiquitin ligase MDM2 (mouse double minute 2 homolog) with p53 as core mechanism to influence p53 stability. MDM2 is the main negative regulator of p53 as it transfers ubiquitin to p53, targeting it for proteasomal degradation. If the interaction is impaired, p53 is stabilized. Second, patterns of posttranslational modifications are relevant for the binding of downstream proteins. And third, phosphorylation enhances the transcriptional activity of p53.

Most known negative feedback loops to regulate p53 activity include MDM2, whose transcription is in turn induced by p53. Therefore, p53 self-limits its activation (Harris and Levine 2005; Lavin and Gueven 2006).

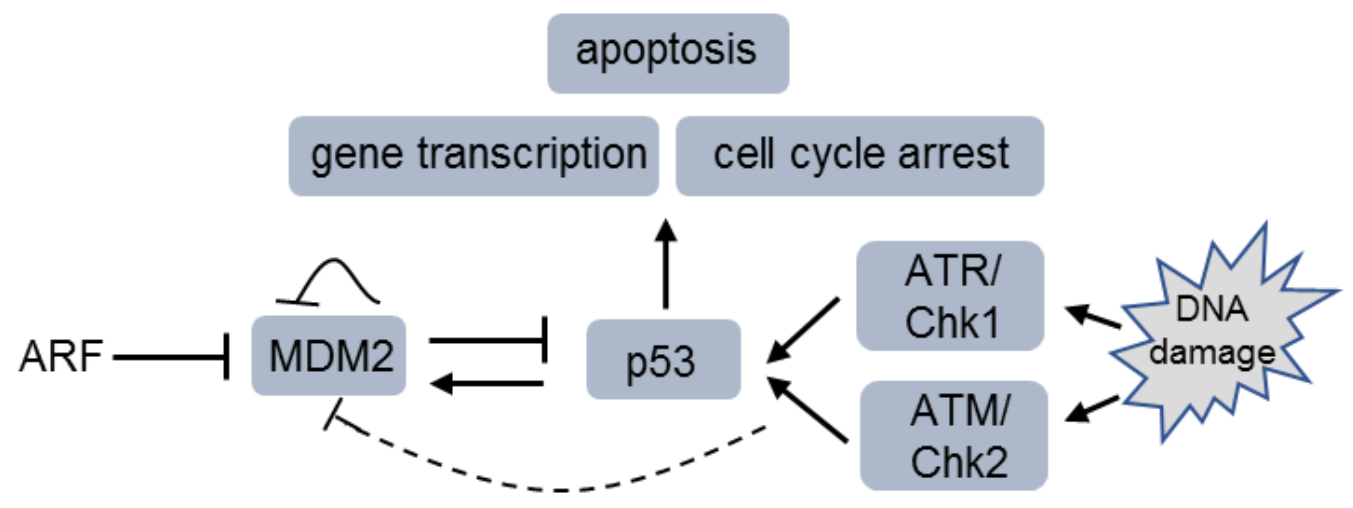

Figure 1.8 Regulation of p53 activity in response to genotoxic stress.

During the DDR, p53 is phosphorylated by several damage kinases, which interrupts the interaction with MDM2. Acting as main negative regulator of p53, MDM2 can no longer ubiquitinate p53 to target it for proteasomal degradation. The transcription of MDM2 is dependent on p53 activity, so p53 self-limits its activity. 
It has been shown that MDM2 itself is phosphorylated after DNA damage, which also reduces the capacity of MDM2 to degrade p53 (Khosravi et al. 1999). Further, MDM2 selfubiquitinates after DNA damage, promoting its own degradation and thereby stabilizing p53 (Lavin and Gueven 2006). MDM2 is further bound and inhibited by the RAS-inducible tumor suppressor p19ARF (Zhang et al. 1998).

\subsubsection{The tumor suppressor and transcription factor p53 in apoptosis}

While the induction of cell cycle arrest in response to oncogenic signaling might be the mechanism through which p53 prevents tumorigenesis, its ability to induce apoptosis is critical for its control of tumor growth and malignancy (Vousden and Prives 2009). P53 exerts transcription-dependent and -independent functions in apoptosis. Once activated, it binds to the promoters of more than 100 known genes to transactivate them, thus executing a dominating role in the transcriptional response to DNA damage (Laptenko and Prives 2006). Among the activated genes are some that induce cell differentiation, DNA repair and apoptosis.

Besides the transcriptional response, p53 induces pore-forming factors that permeabilize the outer mitochondrial membrane to release many pro-apoptotic factors. One of those is cytochrome $\mathrm{C}$, which assembles and activates a subset of caspases (cysteine-dependent aspartate-directed proteases). Those caspases are part of a now irreversible proteolytic cascade leading to the cleavage of cellular adhesion molecules, cytoskeleton proteins and to the activation of nucleases which cleave DNA into fragments (Taylor et al. 2008; Vaseva and Moll 2009). Two late and reliable cleavage events are the cleavage of PARP and the downstream effector caspase-3, which we use as readouts for ongoing apoptosis in this work (Taylor et al. 2008).

Due to its central role in the interconnection of the DDR, checkpoint signaling and apoptosis, tumor cells have a high selective pressure to inactivate p53 in order to increase proliferation and malignancy.

\subsection{The MK2/Chk1 system in the DNA damage response}

Whereas the DNA damage kinases ATM and ATR execute their function bound to DNA, the downstream kinases Chk1 and Chk2 disperse throughout the nucleus and cytoplasm upon 
activation to interfere with non-DNA-bound cellular processes (Bartek et al. 2004). A third kinase, the MAPKAPK2 or MK2 (mitogen-activated protein kinase-activated protein kinase 2) gained attention in recent years and is regarded partially in line with, but also as antagonist of Chk1.

\subsubsection{Activation of MK2}

MK2 is one of three downstream kinases of the p38/MK signaling pathway in mammals. Although all MK-kinases share homology in their catalytic domain, they do not function redundantly and are involved in different cellular processes (Gaestel 2006).

When inactive, MK2 is constitutively bound to its activating kinase p38 forming a mutually stabilizing complex, which is underlined by the fact that knockdown of either one of both proteins leads to a strong decrease of protein levels of the other (Kotlyarov et al. 2002). MK2 is activated via phosphorylation by p38 on Thr334 and is then able to alter cellular signaling by various possibilities: Its phosphorylation motif is related to binding sites for 143-3 proteins typically involved in complex formation, which suggests that phosphorylation by MK2 prepares targets for interaction with other proteins. Further, as a kinase, MK2 can simply activate or inactivate downstream targets by adding one or more phosphate residues (Gaestel 2006; Meng et al. 2002). In its inactive state, MK2 is located in the nucleus but can alter its subcellular localization and can be exported to the cytoplasm or retained in the nucleus dependent on the stimulus (Engel et al. 1998; Kopper et al. 2013).

\subsubsection{Activation of MK2 upon DNA damage}

MK2 was originally identified as a stress-dependent kinase involved in inflammation (Kotlyarov et al. 2002). When it was then found that activation of p38 was substantial to induce the $\mathrm{G}_{2} / \mathrm{M}$ checkpoint after UV irradiation, MK2 was further studied as a damage kinase. MK2 shares substrate specificity with the damage kinases Chk1 and Chk2, and is able to phosphorylate Cdc25B and $-\mathrm{C}$, thereby inhibiting them, acting in line with Chk1 and Chk2 functions (Manke et al. 2005).

Whereas Chk1 is predominantly and directly activated by ATR during replicative stress, the activation of MK2 following DNA damage is less studied. One study argues that MK2 is activated in response to DNA-damaging agents such as chemotherapeutics in an ATM/ATR dependent fashion with the activation of TAO (thousand and one) kinases as intermediates (Raman et al. 2007). Another study finds the activation of MK2 being dependent on 
ATM/ATR following a subset of chemotherapeutics, but identified a damage kinaseindependent activation of MK2 after UV treatment (Reinhardt et al. 2007).

Work in our lab has contradicted the above-mentioned kinase function of MK2 being in line with other checkpoint kinases, but establishes MK2 as an antagonist of Chk1 during replication of damaged as well as undamaged DNA. While the application of gemcitabine leads to stalling of replication forks and subsequent accumulation of $\mathrm{\gamma H} 2 \mathrm{AX}$, this can be antagonized by MK2 inhibition. On the DNA level, MK2 promotes stalling of replication forks and slows down DNA replication. Interestingly, inhibition of MK2 can not only rescue the accumulation of $\mathrm{yH} 2 \mathrm{AX}$ induced by Chk1 inhibition alone or together with gemcitabine treatment, but also rescues the enhanced stalling of replication forks and enhanced origin firing after Chk1 inhibition. Those effects rely on the presence of the ahead mentioned TLS polymerases as the replication promoting effect of MK2 inhibition is completely abolished in the absence of TLS (Kopper et al. 2013).

\subsection{Chromatin remodeling in response to DNA damage}

Each step of chromatin alterations can be affected by genotoxic stress, and the other way around, chromatin perturbations affect all pathways from DNA damage signaling to repair and cell cycle progression (Lukas et al. 2011) already in the absence of DNA damage (Bakkenist and Kastan 2015). For example, chromatin needs to be opened after DNA damage and histones need to be removed from damaged sites in order to allow repair factors to assess damaged DNA, and the more open chromatin is, the more efficient DNA repair seems to be. On the other hand, damage-adjacent chromatin needs to be silenced to impair interference of transcription with repair processes. According to current models, chromatin remodeling factors are classified in three categories: writers that add posttranslational modifications to $\mathrm{N}$-terminal domains of core histones, readers that harbor recognize and binds to histone modifications and either assemble more factors or induce signaling cascades, and erasers that remove posttranslational histone modifications or remove the whole histone or nucleosome from DNA (Cai et al. 2015; Nair and Kumar 2012).

The modification of histones and other chromatin-bound proteins as well as DNA methylation at silenced chromatin are mutually influencing processes involved in the formation of gene-rich and actively transcribed euchromatin and transcriptionally inactive and gene-poor heterochromatin (Briones and Muegge 2012). The chromatin environment of DNA is too complex and heterogenous to be understood in the model of a signaling cascade with upstream factors and downstream targets. It rather embeds the process of 
chromatin remodeling following DNA damage in a context- and cell type-specific manner (Bakkenist and Kastan 2015).

Nonetheless, epigenetic information on histones or on DNA is both passed on to daughter cells and affects genomic stability. It can therefore, and due to transcriptional activation of oncogenes or repression of tumor suppressor genes, not only leave a footprint of occurred DNA damage, but can also drive or inhibit cancer progression (Hargreaves and Crabtree 2011; Jones and Baylin 2007; Roberts and Orkin 2004). Due to its complexity and cell type specificity, chromatin remodeling has been targeted by anti-cancer therapies only in recent years (Cai et al. 2015).

Alterations in chromatin profiles can be arranged by two different mechanisms: The wide variety of histone modifications as well as ATP-dependent chromatin remodeling which disrupts histone-DNA contacts and is able to displace histones and entire nucleosomes (Lans et al. 2012).

\subsubsection{Histone modifications after DNA damage}

Dynamic modifications of histones are carried out by specific enzymes that covalently attach small molecules to exposed histone tails. The most prominent histone modification among DNA damage, the phosphorylation of $\mathrm{H} 2 \mathrm{AX}$, has been detailed before. Just as the addition of PARP residues as the earliest histone modification during the DDR, other histone modifications tether DNA damage signaling and repair factors to damaged DNA (Polo and Jackson 2011). Further, the methylation, ubiquitination and acetylation of histones play a well-established role in the DDR. While acetylation is a marker of chromatin relaxation, methylated histones display a more diverse signaling pattern and can be markers for either relaxed or condensed chromatin (Kouzarides 2007).

\subsubsection{ATP-dependent chromatin remodeling}

ATP-dependent chromatin remodeling enzymes use the energy of ATP to exchange, evict or slide histones or entire nucleosomes. Central communality of all is a SWI2/SNF2-type helicase/ATPase (SWItch/sucrose non-fermentable) domain which is evolutionary highly conserved. Based on the ATPase-flanking regions, chromatin remodelers are commonly grouped into four families, which are SWI/SNF, ISWI (imitation SWI), INO80 and CHD (chromodomain-helicase-DNA-binding protein). All chromatin remodelers are involved in transcriptional regulation via the alteration of higher order chromatin structures or direct binding to promoters and recruitment of transcription factors and polymerases. Thus, 
defects of their function mostly result in occasionally lethal developmental defects of certain organs or whole embryos (Murawska and Brehm 2011). Most of those remodelers are found in multisubunit complexes which specify their activation and function (Hargreaves and Crabtree 2011). Additionally, all families of chromatin remodelers are implicated in the DDR (Lans et al. 2012).

DNA damage can occur in any part of a chromosome, but different chromatin environments initially form a barrier to active damage signaling and repair (Murga et al. 2007). It is thus the role of chromatin remodelers to prime DNA for repair as they actively remove histones from damaged DNA in order to allow access for repair factors, which is done by the sliding or eviction of nucleosomes. Later, they restore chromatin after DNA repair is accomplished, possibly leaving an imprint of former rundown DNA damage (Soria et al. 2012). Indeed, the necessity of histone movement in the DDR and DNA repair is stressed by the fact that, although spreading of $\mathrm{yH} 2 \mathrm{AX}$ occurs bidirectionally around DSBs, there is a loss of $\mathrm{yH} 2 \mathrm{AX}$ and other core histones within $3 \mathrm{~kb}$ from the damaged site, but also a restoration within several hours (Polo 2015).

Detailed mechanistic research has been done on ATP-dependent chromatin remodelers in yeast, and most of those proteins are highly conserved. The fact that the way of action of chromatin remodeling is cell type and context specific brings along difficulties to transfer knowledge from yeast to human cancers. Thus, the following is focused on what is known about chromatin remodelers in mammalian cells.

\subsection{The CHD family of chromatin remodeling enzymes}

\subsubsection{CHD structure and function}

The fourth family of ATP-dependent chromatin remodeling enzymes is evolutionary the least conserved and only exists in mammals, with the exception of a CHD1/2 homolog in yeast (Murawska and Brehm 2011). There are nine members, which share, in addition to the SNF2-like helicase/ATPase members of this family, an N-terminal double chromodomain and in some cases a DNA binding domain, as visualized in figure 1.9 (Sims and Wade 2011). This DNA binding domain is established only for CHD1 while the other family members do not have a canonical but putative DNA binding domain. The tandem chromodomain was shown to interact with acetylated and methylated histones as was especially shown for H3K4me and is a unique feature to CHD proteins among other chromatin remodelers (Flanagan et al. 2005). CHD3 and CHD4 have two PHD zink finger domains which provide an additional DNA binding site, while CHD5-9 harbor additional 
domains which have been interpreted as interaction domains though without a yet clarified mechanism (Hall and Georgel 2007).

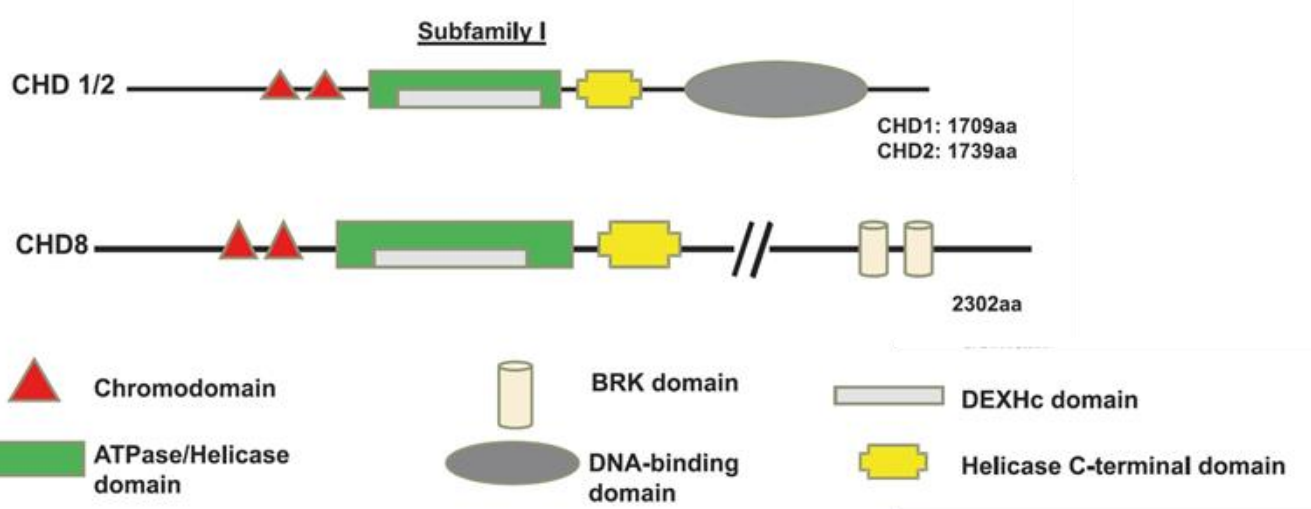

Figure 1.9 Structure and functional domains of CHD8.

The structure of CHD family members is highly heterogenic. Minimal structure similarities are the two Nterminal tandem chromodomains involved in nucleosome binding, the SWF/SNF2-like ATPase/helicase domain as core functional domain which hydrolyses ATP to move histones and nucleosomes, and a helicase C-terminal domain. Only CHD1/2 contain a defined DNA-binding domain, which is not present in any other family member. Those potentially bind chromatin through all other domains. For CHD8, deletion of each domain abrogates its tethering to chromatin. CHD8 possesses two BRK domains of unknown specificity which otherwise exist in CHD7 and CHD9 only, so that these form a subfamily. Figure modified from Hall and Georgel, 2007 with permission from Biochemistry and Cell Biology.

Each of the domains that bind to chromatin is indispensable and CHD remodelers obviously attach to chromatin through various sites as the mutation of single domains consequently lead to a dissociation of the proteins from chromatin (Marfella and Imbalzano 2007).

$\mathrm{CHD}$ remodelers can either act as transcriptional activators or repressors with ascribed functions in multisubunit complexes. They affect each step of transcription, and the decision between transcriptional activation or repression depends on which promoters or transcription factors they bind. The only remodelers with clear repressive functions are $\mathrm{CHD} 3 / 4$, which are part of the NuRD-complex (nucleosome remodeling deacetylase) that also contains histone deacetylases (HDACs) and is involved in gene repression (Hall and Georgel 2007).

\subsubsection{CHD in DNA damage response and disease}

A role in disease and response to damaged DNA is established for some of the CHD chromatin remodelers. Recently, genetic and transcriptomic analysis of all CHD genes strengthened the significance of $\mathrm{CHD}$ in cancer, of which some have mechanistically been 
involved in the DDR (Chu et al. 2017). A CHD1-like protein, referred to as ALC1 (amplified in liver cancer) localizes to sites of DNA damage where it promotes DNA repair (Lans et al. 2012). CHD1 as such is required for the conservation of stemness during embryonic development through the prevention of heterochromatin formation (Gaspar-Maia et al. 2009). A tumor-suppressive role is established for CHD5. It is required for the transcription of the tumor suppressor CDKN2A which controls progression through the cell cycle. In contrast to other chromatin remodeling functions, this role seems to be universal throughout cell types. Mutations in CHD5 frequently occur in human gliomas (Kolla et al. 2014). CHD3 and CHD4 are part of the NuRD complex which is involved in DNA repair through the creation of a permissive chromatin environment (O'Shaughnessy and Hendrich 2013). Upon ionizing radiation, CHD4, a target of ATM, is transiently recruited to DSBs within minutes in a PARP- but not $\mathrm{YH} 2 \mathrm{AX}$-dependent manner and shows enhanced accumulation after ATM depletion. CHD4 controls p300-dependent p53 acetylation, which is enhanced after $\mathrm{CHD} 4$ depletion leading to accumulation of p21 and therefore arrest in $\mathrm{G}_{1}$ of the cell cycle (Polo et al. 2010).

Haploinsufficiency of CHD7 leads to the CHARGE syndrome in humans. This genetic disease with distinct organ anomalities is reproducible in mice experiments showing a misregulated gene expression during development and hyperactivation of p53 (Bosman et al. 2005; Van Nostrand et al. 2014; Vissers et al. 2004). Furthermore, CHD7 was recently suggested as biological marker for the outcome of gemcitabine-treated pancreatic cancer. In vitro, depletion of CHD7 lowers DNA damage signaling as indicated by reduced Chk1 phosphorylation, but leads to a higher percentage of $\mathrm{yH} 2 \mathrm{AX}$-positive cells and reduced survival after treatment with gemcitabine. Patients receiving neoadjuvant treatment with gemcitabine showed a significantly better survival when CHD7 expression was low (Colbert et al. 2014).

\subsubsection{The chromatin remodeling factor CHD8}

CHD8 is one of the less characterized ATP-dependent chromatin remodelers. Mutations in the CHD8 gene are associated with autism spectrum disorders, and CHD8-heterozygous mice display a haploinsufficient phenotype with large abnormalities in brain development due to a lack of differentiation and perturbed gene expression patterns. CHD8 knockout mice die during early embryogenesis with a phenotype of widespread apoptosis and cardiovascular and brain anomalies. CHD8 is highly expressed in embryonic tissues and stem cells in mice with emphasis on neuronal tissue, but expression levels seems to decrease with differentiation (Nishiyama et al. 2009). 


\subsubsection{Structure and function of CHD8}

CHD8 was described to exist in two isoforms which are produced by alternative splicing: the large isoform harboring the domains as depicted above and the small isoform lacking the C-terminal domains (Nishiyama et al. 2009). However, only the large isoform was found to be expressed in human and mouse tissues (Shingleton and Hemann 2015). It is localized to the nucleus and expression of CHD8 seems to be uniform throughout the cell cycle (Mjelle et al. 2015; Nishiyama et al. 2009). To date, the three-dimensional structure of CHD8 has not been resolved and there are no proteomic analyses for the identification of CHD8 binding partners. Some single experimental results have described CHD8 as being part of multisubunit complexes (see below). Mechanistically, CHD8 is able to slide and bind nucleosomes at DNA. This process requires hydrolysis of ATP, which is stimulated by chromatin 10-fold more than by DNA alone. Compared to other CHD chromatin remodelers, CHD8 requires comparably large DNA fragments for this activity and has low affinity to nucleosomal substrates, which restricts CHD8 remodeling function to large linker DNA or spaced nucleosomes of highly transcribed DNA regions. CHD8 can thus condense DNA with highly spaced nucleosomes as well as decondense compacted chromatin establishing a fixed DNA-nucleosome spacing (Manning and Yusufzai 2017).

\subsubsection{CHD8-regulated processes}

Originally, CHD8 was identified as a negative regulator of Wnt signaling, a pathway which is often constitutively activated in human cancers. Characterization of CHD8 functions comprises the involvement of CHD8 in positive or negative regulation of transcription (Logan and Nusse 2004).

While CHD8 directly binds to B-catenin upon induction of Wnt signaling, the binding and recruitment of histone $\mathrm{H} 1$ via an $\mathrm{H} 1$-binding domain on $\mathrm{CHD} 8$ is necessary for the transcriptional repression of Wnt-dependent gene transcription. In the same way, the authors suggested CHD8 to be a negative regulator of p53 and detected increased transcription of p53-dependent genes after depletion of CHD8 (Nishiyama et al. 2012; Nishiyama et al. 2009).

Another mechanism through which CHD8 might regulate transcriptional repression is the maintenance of insulator functions. Chromatin insulators form borders between differentially regulated gene transcription and between eu- and heterochromatin. CHD8 binds to the chromatin insulator CTCF (CCCTC-binding factor), which serves as boundary between differentially regulated chromatin domains. Like CHD8, CTCF can activate and suppress transcription. Two ways for transcriptional repression are the prevention of enhancers from 
binding to promoters and a barrier formation of CTCF which prevents the spreading of heterochromatin to euchromatic regions, where CHD8 is essential for both (Ishihara et al. 2006). The dysregulation of insulator activities is associated with an epigenetic suppression of tumor suppressor genes, and CHD8 together with CTCF was found to be lowered during prostate carcinogenesis (Damaschke et al. 2014).

The activation of transcription by CHD8 might function through the association with RNA polymerase II, which was shown to promote the transcription of CHD8-dependent genes of which some are S-phase specific (Rodriguez-Paredes et al. 2009; Subtil-Rodriguez et al. 2014). Another, yet therapeutic involvement of CHD8 in malignancies is through the binding of the chromatin reader BRD4 (bromodomain-containing protein 4), which drives oncogenic gene transcription in myeloic leukemia and, as has been shown recently, in a subset of gynecological cancers. CHD8 is bound to BRD4 through the histone methyltransferase NSD3 and depletion of either factor leads to growth delay and induces differentiation. Thus, inhibition of BRD4 is subject to clinical trials (Jones and Lin 2017; Shen et al. 2015).

Last, CHD8 is part of histone methyl transferase complexes containing the MLL1-protein (mixed-lineage leukemia-1). It promotes malignancy through the methylation of hox genes promotors and induces a CpG methylator phenotype in colorectal cancer cells (Fang et al. 2014; Yates et al. 2010).

Taken together, CHD8 has established roles during embryogenesis and differentiation, mainly by coordinating the transcriptional network. There are contradictory findings as to whether this chromatin remodeler has proto-oncogenic properties as seem to dominate for hematologic malignancies, or whether it executes a tumor suppressor function as seen in many solid tumors.

So far, CHD8 has no established role in the DDR. 


\subsection{Scope of the thesis}

Chemotherapeutics that target replicating tumor cells have been in clinical use for many decades. In contrast to a new generation of small molecules as cancer therapeutics, the cellular mechanisms to cope with genotoxic stress caused by DNA damaging agents are incompletely understood, especially in the case of replicative stress. This is of fundamental interest given that chemotherapy still forms the main column of anticancer treatment and resistance mechanisms to gemcitabine are bound to develop in the course of treatment. Further, loss of tumor suppressive function of mutant p53 together with arising oncogenic functions is an adverse condition which is found in the majority of cancers. Thus, our work on factors that mediate the cellular response to gemcitabine does not only serve mechanistic research on replicative stress, but meets a major clinical challenge.

We used two approaches to determine mediators of the response to gemcitabine. First, we focused on the kinase MK2 that emerged as damage-responsive in recent years. Previous work in our lab found it to potentially inhibit translesion synthesis as damage tolerance mechanism to gemcitabine in an osteosarcoma cell line, antagonizing Chk1 at that point. We aimed to establish the MK2/Chk1 system as determinant of the DDR and cell proliferation in a pancreatic cancer model, too. Interestingly, our results challenge the general view on Chk1 inhibitors as chemosensitizing agents.

Second, we operated a small interfering RNA (siRNA) screening approach on pancreatic cancer cells in order to identify new regulators of the gemcitabine response that could be exploited mechanistically. Following up on the results obtained, we characterized the chromatin remodeling factor CHD8, in terms of the response to different types of DNA damage and its consequences on transcriptional regulation, cell cycle control and apoptosis - and to the regulation of mutant p53. 


\section{Materials}

\subsection{Technical devices}

Table 2.1 Technical devices

\begin{tabular}{|c|c|}
\hline Device & Company \\
\hline $\begin{array}{l}\text { Biomek® } 2000 \text { Laboratory } \\
\text { Automation Workstation }\end{array}$ & $\begin{array}{l}\text { Beckman Coulter Indianapolis, Indiana, } \\
\text { United States }\end{array}$ \\
\hline Blotting chamber & Biozym, Hessisch Oldendorf, Germany \\
\hline $\begin{array}{l}\text { Cell counting chamber } \\
\text { Neubauer improved }\end{array}$ & Brand, Wertheim, Germany \\
\hline Centrifuge 5415R & Eppendorf, Hamburg, Germany \\
\hline Centrifuge 5810R & Eppendorf, Hamburg, Germany \\
\hline Centrifuge Megafuge 1.0R & $\begin{array}{l}\text { Heraeus, Thermo Scientific, Waltham, MA, } \\
\text { United States }\end{array}$ \\
\hline $\begin{array}{l}\text { Chemoluminescence imager } \\
\text { Chemocam HR } 163200\end{array}$ & $\begin{array}{l}\text { Intas Science Imaging Instruments, } \\
\text { Göttingen, Germany }\end{array}$ \\
\hline Cytometer Celígo & Cyntellect,San Diego, CA United States \\
\hline DNA Gel chamber & Biotech Service Blu, Schauenburg, Germany \\
\hline $\begin{array}{l}\text { Electrophoresis System for } \\
\text { SDS-PAGE }\end{array}$ & $\begin{array}{l}\text { Amersham Bioscience, GE Healthcare, Little } \\
\text { Chalfont, United Kingdom }\end{array}$ \\
\hline $\begin{array}{l}\text { Flow cytometer } \\
\text { Guava EasyCyte plus }\end{array}$ & Millipore, Merck, Darmstadt Germany \\
\hline $\begin{array}{l}\text { Foil swelding machine } \\
\text { Vacupack plus }\end{array}$ & Krups, Groupe SEB, Lyon, France \\
\hline Freezer $-20^{\circ} \mathrm{C}$ & Liebherr, Bulle, Switzerland \\
\hline Freezer $-80^{\circ} \mathrm{C}$ & $\begin{array}{l}\text { Heraeus, Thermo Scientific, Waltham, MA, } \\
\text { United States }\end{array}$ \\
\hline Heating Block & $\begin{array}{l}\text { Grant Instruments, Hillsborough, NJ, } \\
\text { United States }\end{array}$ \\
\hline Heating Block HLC & HLC Biotech, Ditabis, Pforzheim, Germany \\
\hline Ice Machine B100 & Ziegra, Isernhagen, Germany \\
\hline Incubator for bacteria plates & Memmert, Schwabach, Germany \\
\hline Incubator for bacteria vials Minitron & Infors HT, Basel, Switzerland \\
\hline $\begin{array}{l}\text { Incubator for cell culture } \\
\text { Hera Cell } 150\end{array}$ & $\begin{array}{l}\text { Heraeus, Thermo Scientific, Waltham, MA, } \\
\text { United States }\end{array}$ \\
\hline
\end{tabular}




\begin{tabular}{|c|c|}
\hline $\begin{array}{l}\text { Laminar flow cabinet for sterile } \\
\text { handling of cell culture }\end{array}$ & $\begin{array}{l}\text { Heraeus, Thermo Scientific, Waltham, MA, } \\
\text { United States }\end{array}$ \\
\hline Liquid nitrogen tank LS 480 & Taylor-Wharton Theodore, AL, United States \\
\hline Magnetic stirrer MR 3001 & Heidolph, Schwabach, Germany \\
\hline Microscope Axiovert 40C & Zeiss, Oberkochen, Germany \\
\hline Microscope Axioscope 2 Plus & Zeiss, Oberkochen, Germany \\
\hline $\begin{array}{l}\text { Microscope, automated fluorescence } \\
\text { Pathway } 855\end{array}$ & $\begin{array}{l}\text { Becton Dickinson, Franklin Lakes, NJ, } \\
\text { United States }\end{array}$ \\
\hline $\begin{array}{l}\text { Microscope, Confocal Zeiss } \\
\text { Confocal LSM } 510 \text { meta }\end{array}$ & Zeiss, Oberkochen, Germany \\
\hline Microwave & Cinex, Lippstadt, Germany \\
\hline Mini centrifuge MCF-2360 & LMS, Tokyo, Japan \\
\hline $\begin{array}{l}\text { PCR machine for qPCR } \\
\text { CF } X 96, C 1000\end{array}$ & $\begin{array}{l}\text { Biorad Laboratories, Hercules, CA, } \\
\text { United States }\end{array}$ \\
\hline $\begin{array}{l}\text { PCR machine for generation of } \\
\text { cDNA Thermocycler T personal }\end{array}$ & Biometra, Göttingen, Germany \\
\hline pH-meter WTW-720 & WTW, Weilheim, Germany \\
\hline $\begin{array}{l}\text { Pipet multichannel (8-channel) } \\
\text { Research Plus }\end{array}$ & Eppendorf, Hamburg Germany \\
\hline Pipet, electric Portable- $X P$ & Drummond, Broomal, PA, United States \\
\hline $\begin{array}{l}\text { Pipets Eppendorf Research Series } \\
2100(0.1-2.5 \mu \mathrm{l}, 0.5-10 \mu \mathrm{l}, 10-100 \mu \mathrm{l} \text {, } \\
50-200 \mu \mathrm{l}, 100-1000 \mu \mathrm{l})\end{array}$ & Eppendorf, Hamburg, Germany \\
\hline $\begin{array}{l}\text { Power supply unit for electrophoresis } \\
\text { and immunoblotting } \\
\text { Powerpack P25T }\end{array}$ & Biometra, Göttingen, Germany \\
\hline Refrigerator $4^{\circ} \mathrm{C}$ & Liebherr, Bulle, Switzerland \\
\hline $\begin{array}{l}\text { Reservoir } 30 \mathrm{ml} \text { for multichannel } \\
\text { pipet }\end{array}$ & $\begin{array}{l}\text { Beckman Coulter Indianapolis, Indiana } \\
\text { United States }\end{array}$ \\
\hline $\begin{array}{l}\text { Reservoir } 2 \times 15 \mathrm{ml} \text { for multichannel } \\
\text { pipet (divided by length) }\end{array}$ & $\begin{array}{l}\text { Beckman Coulter Indianapolis, } \\
\text { Indiana, United States }\end{array}$ \\
\hline Roller RM5 V-30 & CAT, Staufen, Germany \\
\hline Scales Acculab ALC-6100.1 & Sartorius, Göttingen, Germany \\
\hline Scale LE623S & Sartorius, Göttingen, Germany \\
\hline Scanner CanoScan 8600F & Canon, Tokyo, Japan \\
\hline $\begin{array}{l}\text { Sequencer, automated for DNA } \\
\text { sequencing } \mathrm{ABI} 3100\end{array}$ & Applied Biosystems, Life Technologies \\
\hline Shaker PROMAX 2020 & Heidolph, Schwabach, Germany \\
\hline Sonication Device Bioruptor & Diagenode, Liège, Belgium \\
\hline
\end{tabular}




\begin{tabular}{|l|l|}
\hline $\begin{array}{l}\text { Spectrophotometer NanoDrop ND- } \\
1000\end{array}$ & PeqLab, Erlangen, Germany \\
\hline Thermomixer comfort & Eppendorf, Hamburg, Germany \\
\hline Timer & Oregon Scientific, Portland, OR, United States \\
\hline Ultraviolet crosslinker CL-100 & UVP Analytic Jena AG, Jena, Germany \\
\hline $\begin{array}{l}\text { UV-transilluminator Intas UV system } \\
\text { Gel Jet Imager }\end{array}$ & $\begin{array}{l}\text { Intas Science Imaging Instruments, } \\
\text { Göttingen, Germany }\end{array}$ \\
\hline Vaccum pump & IBS Integra Biosciences, Fernwald, Germany \\
\hline Vortex Genie 2 & $\begin{array}{l}\text { Scientific Industries, Bohemia, NY, } \\
\text { United States }\end{array}$ \\
\hline $\begin{array}{l}\text { Water bath TW20 (to prewarm cell } \\
\text { culture media) }\end{array}$ & Julabo Labortechnik, Seelbach, Germany \\
\hline
\end{tabular}

\subsection{Consumables}

Table 2.2 Consumables

\begin{tabular}{|l|l|}
\hline Product & Company \\
\hline 8-well microscope chamber slides & Nunc, Thermo Scientific \\
\hline 96-well plates for microscopy, clear bottom & $\begin{array}{l}\text { Becton Dickinson, Franklin Lakes, NJ, } \\
\text { United States }\end{array}$ \\
\hline 96-well plates for microscopy, clear bottom & Corning, Corning, NY, United States \\
\hline $\begin{array}{l}\text { 96-well plates for microscopy and automated } \\
\text { imaging Cytometer Celígo, clear bottom }\end{array}$ & Corning, Corning, NY, United States \\
\hline 96-well plates for qPCR & 4titude, Wotton, United Kingdom \\
\hline Bacteria Culture Dishes $(14 \mathrm{~cm}$ diameter) & Sarstedt, Nümbrecht, Germany \\
\hline Bacteria culture vials $(14 \mathrm{~cm})$ & Becton Dickinson, Franklin Lakes, NJ, \\
\hline Cell scraper $(16 \mathrm{~cm}, 25 \mathrm{~cm})$ & Snited States \\
\hline Cover slips & Menzel, Thermo Scientific \\
\hline Cryo tubes for freezing of cells Cryoline & Nunc, Thermo Scientific \\
\hline Filter tips $(10 \mu \mathrm{l})$ & Starlab, Hamburg, Germany \\
\hline Filter tips $(20 \mu l, 200 \mu l, 1000 \mu l)$ & Sarstedt, Nümbrecht, Germany \\
\hline Glass slides Lab Tek \# 154534 & Thermo Fisher Scientific \\
\hline Parafilm & Brand, Wertheim, Germany \\
\hline Pipet tips $(0.5-10 \mu l, 20-200 \mu l, 100-1000 \mu l)$ & Greiner, Essen, Germany \\
\hline
\end{tabular}




\begin{tabular}{|l|l|}
\hline Pipet tips for Biomek automated work station & Greiner, Essen, Germany \\
\hline Protran nitrocellulose transfer membrane & Whatman, Dassel, Germany \\
\hline Reaction tube $(0.2 \mu \mathrm{l})$ & Sarstedt, Nümbrecht, Germany \\
\hline Reaction tube $(0.5 \mu \mathrm{l}, 1.5 \mu \mathrm{l}, 2 \mu \mathrm{l})$ & Eppendorf, Hamburg, Germany \\
\hline Reaction tube $(15 \mathrm{ml}, 50 \mathrm{ml})$ & Greiner \\
\hline Safe-lock reaction tube $(1.5 \mu \mathrm{l})$ & Eppendorf, Hamburg, Germany \\
\hline Sealing foil for 96 -well plates & $\begin{array}{l}\text { Becton Dickinson, Franklin Lakes, NJ, } \\
\text { United States }\end{array}$ \\
\hline Sterile filter & Millipore, Merck, Darmstadt Germany \\
\hline & $\begin{array}{l}\text { Henke-Sass, Wolf, Tuttlingen, } \\
\text { Germany }\end{array}$ \\
\hline Syringes (different gauge) & Braun, Melsungen, Germany \\
\hline Syringe canulas (different sizes) & 4titude, Wotton, United Kingdom \\
\hline Transparent sealing foil for 96 -well plate & Whatman, Dassel, Germany \\
\hline Whatman paper & \\
\hline
\end{tabular}

\subsection{Chemicals and reagents}

Table 2.3 Chemicals and reagents

\begin{tabular}{|l|l|}
\hline Product & Company \\
\hline \hline Agar & $\begin{array}{l}\text { Sigma Aldrich, St. Louis, MO, } \\
\text { United States }\end{array}$ \\
\hline Agarose & Roth, Karlsruhe, Germany \\
\hline $\begin{array}{l}\text { Albumin Fraction V (Bovine Serum } \\
\text { Albumine, BSA) }\end{array}$ & Roth, Karlsruhe, Germany \\
\hline Ammonium persulfate $(\mathrm{APS})$ & Roth, Karlsruhe, Germany \\
\hline Ammonium sulfate $\left(\left(\mathrm{NH}_{4}\right)_{2} \mathrm{SO}_{4}\right)$ & Roth, Karlsruhe, Germany \\
\hline Ampicillin & AppliChem, Darmstadt, Germany \\
\hline Bromphenol blue & $\begin{array}{l}\text { Sigma Aldrich, St. Louis, MO, } \\
\text { United States }\end{array}$ \\
\hline Chloroform & Roth, Karlsruhe, Germany \\
\hline Complete Mini Protease Inhibitor & Roche, Basel, Switzerland \\
\hline Copper sulfate (CuSO $\left.{ }_{4} \times \mathrm{H}_{2} \mathrm{O}\right)$ & Roth, Karlsruhe, Germany \\
\hline Dimethyl sulfoxide $(\mathrm{DMSO})$ & AppliChem, Darmstadt, Germany \\
\hline DNA ladder GeneRuler & Fermentas, Thermo Scientific \\
\hline
\end{tabular}




\begin{tabular}{|c|c|}
\hline Deoxynucleotide triphosphates (dNTPs) & Bio-Budget, Krefeld, Germany \\
\hline $\begin{array}{l}\text { Deoxyribonucleotide triphosphates } \\
\text { (dNTPs) in single tubes as dATPs, dGTPs, } \\
\text { dCTPs, dTTPs) }\end{array}$ & Primitech, Minsk, Belarus \\
\hline Dithiotreitol (DTT) & $\begin{array}{l}\text { Sigma Aldrich, St. Louis, MO, } \\
\text { United States }\end{array}$ \\
\hline Ethanol $99,8 \%$ & Roth, Karlsruhe, Germany \\
\hline Ethanol $99,9 \%$ p.a. $(\mathrm{EtOH})$ for analysis & Merck, Darmstadt Germany \\
\hline Ethidium Bromide (EtBr) & $\begin{array}{l}\text { Sigma Aldrich, St. Louis, MO, } \\
\text { United States }\end{array}$ \\
\hline Ethylene diamine tetraacetate (EDTA) & Roth, Karlsruhe, Germany \\
\hline Fetal calf serum (FCS) HyClone & Thermo Fisher Scientific, Germany \\
\hline Formaldehyde $37 \%$ solution & Roth, Karlsruhe, Germany \\
\hline Glycerol & Roth, Karlsruhe, Germany \\
\hline Glycine & Roth, Karlsruhe, Germany \\
\hline Guava ICF cleaning solution & Millipore, Merck, Darmstadt Germany \\
\hline Hoechst 33342 & Invitrogen, Life Technologies \\
\hline Hydrogen chloride $(\mathrm{HCl})$ & Roth, Karlsruhe, Germany \\
\hline Immersion oil & Zeiss, Oberkochen, Germany \\
\hline Isopropanol & Th. Geyer, Renningen, Germany \\
\hline Lipofectamine 2000 & Invitrogen, Life Technologies \\
\hline $\begin{array}{l}\text { Magnesium chloride water free }\left(\mathrm{Mg}(\mathrm{Cl})_{2}\right) \\
\text { for PCR }\end{array}$ & Fermentas, Thermo Scientific \\
\hline $\begin{array}{l}\text { Magnesium chloride hexahydrate } \\
\left(\mathrm{Mg}(\mathrm{Cl})_{2} \times 6 \mathrm{H}_{2} \mathrm{O}\right.\end{array}$ & Roth, Karlsruhe, Germany \\
\hline Methanol >99 \% (MetOH) & Roth, Karlsruhe, Germany \\
\hline Milk, powdered & Roth, Karlsruhe, Germany \\
\hline Nail Polish & DM Drogerie Markt, Karlsruhe, Germany \\
\hline Nuclease free water & Ambion, Life Technologies \\
\hline Page Ruler Prestained Protein Ladder & Fermentas, Thermo Scientific \\
\hline Pefabloc SC protease inhibitor & Roth, Karlsruhe, Germany \\
\hline Phenol, Roti-Phenol & Roth, Karlsruhe, Germany \\
\hline Ponceau S & Roth, Karlsruhe, Germany \\
\hline Potassium Chloride (KCl) & Roth, Karlsruhe, Germany \\
\hline $\begin{array}{l}\text { Potassium dihydrogene phosphate } \\
\left(\mathrm{KH}_{2} \mathrm{PO}_{4}\right)\end{array}$ & Roth, Karlsruhe, Germany \\
\hline Propidium iodide (PI) & $\begin{array}{l}\text { Sigma Aldrich, St. Louis, MO, } \\
\text { United States }\end{array}$ \\
\hline
\end{tabular}




\begin{tabular}{|c|c|}
\hline $\begin{array}{l}\text { Protein ladder for high molecular weight } \\
\text { proteins (Spectra Multicolour High range } \\
\text { protein marker \#26625) }\end{array}$ & Fermentas, Thermo Scientific \\
\hline RNAse inhibitor & Fermentas, Thermo Scientific \\
\hline Sodium chloride $(\mathrm{NaCl})$ & Roth, Karlsruhe, Germany \\
\hline Sodium deoxycholate & AppliChem, Darmstadt, Germany \\
\hline Sodium dodecyl sulfate (SDS) & Roth, Karlsruhe, Germany \\
\hline Sodium hydroxide $(\mathrm{NaOH})$ pellets & $\begin{array}{l}\text { Sigma Aldrich, St. Louis, MO, } \\
\text { United States }\end{array}$ \\
\hline $\begin{array}{l}\text { Sodium hydrogen phosphate heptahydrate } \\
\left(\mathrm{Na}_{2} \mathrm{HPO}_{4} \times 7 \mathrm{H}_{2} \mathrm{O}\right)\end{array}$ & Roth, Karlsruhe, Germany \\
\hline Sucrose & $\begin{array}{l}\text { Sigma Aldrich, St. Louis, MO, } \\
\text { United States }\end{array}$ \\
\hline SYBRgreen & Invitrogen, Life Technologies \\
\hline Tetracycline & $\begin{array}{l}\text { Sigma Aldrich, St. Louis, MO, } \\
\text { United States }\end{array}$ \\
\hline Tetramethyethylendiamine (TEMED) & Roth, Karlsruhe, Germany \\
\hline Trasylol & Bayer, Leverkusen, Germany \\
\hline Trehalose & $\begin{array}{l}\text { Sigma Aldrich, St. Louis, MO, } \\
\text { United States }\end{array}$ \\
\hline Trisamine (Tris) & Roth, Karlsruhe, Germany \\
\hline Triton $\mathrm{X}-100$ & AppliChem, Darmstadt, Germany \\
\hline Tween 20 & AppliChem, Darmstadt, Germany \\
\hline Tryptone \# 8952.2 & Roth, Karlsruhe, Germany \\
\hline Urea \# 3941.1 & Roth, Karlsruhe, Germany \\
\hline Yeast extract & $\begin{array}{l}\text { Sigma Aldrich, St. Louis, MO, } \\
\text { United States }\end{array}$ \\
\hline$\beta$-Mercaptoethanol & Roth, Karlsruhe, Germany \\
\hline
\end{tabular}

\subsection{Buffers and Solutions}

All buffers and solutions were prepared at room temperature (RT) and automatically stirred until all components were dissolved. All buffers and solutions were stored at $4{ }^{\circ} \mathrm{C}$, except for PBS (phosphate buffered saline), PBS ${ }^{++}$, TBST (Tris buffered Saline) and Ponceau S which were stored at RT and qPCR reaction mix which was shock frozen in liquid nitrogen and stored at $-20^{\circ} \mathrm{C}$. Blocking solution for immunofluorescence was freshly prepared before use, all others where storable. 
RIPA lysis buffer, pH 7,5

\begin{tabular}{lr}
\hline Triton X-100 & $1,0 \%$ \\
Sodium desoxycholate & $1,0 \%$ \\
$\begin{array}{l}\text { Sodium dodecylsulfate } \\
\text { (SDS) }\end{array}$ & $0,1 \%$ \\
$\mathrm{NaCl}$ & $150 \mathrm{mM}$ \\
EDTA & $10 \mathrm{mM}$ \\
Tris, pH 7.5 & $20 \mathrm{mM}$ \\
Trasylol & $50,000 \mathrm{KIU}$ \\
& \\
& \\
dissolved in deionized $\mathrm{H}_{2} \mathrm{O}, \mathrm{pH}$ optimized by \\
titration with dilute $\mathrm{NaOH}$ and $\mathrm{HCl}$, \\
respectively
\end{tabular}

\section{Laemmli buffer, $6 x$}

Tris $\mathrm{pH} 6,8$

$0.35 \mathrm{M}$

Glycerol

$30.00 \%$

SDS

$10,00 \%$

Dithiotreitol (DTT)

$9.30 \%$

Bromphenol blue

$0.02 \%$

dissolved in deionized $\mathrm{H}_{2} \mathrm{O}$, pH optimized by titration with dilute $\mathrm{NaOH}$ and $\mathrm{HCl}$, respectively

\section{Cell lysis buffer}

Urea

$2.5 \mathrm{M}$

To obtain lysates for SDS-PAGE, $6 x$

Laemmli is added 1:5

dissolved in RIPA lysis buffer
Phosphate buffered saline (PBS), pH 7,5, 10x

$\begin{array}{lr}\text { Sodium Chloride }(\mathrm{NaCl}) & 240.0 \mathrm{mM} \\ \text { Potassium chloride }(\mathrm{KCl}) & 2.7 \mathrm{mM} \\ \begin{array}{l}\text { Sodium hydrogen } \\ \text { phosphate heptahydrate } \\ \left(\mathrm{Na}_{2} \mathrm{HPO}_{4} \times 7 \mathrm{H}_{2} \mathrm{O}\right)\end{array} & 8.1 \mathrm{mM} \\ \begin{array}{l}\text { Potassium dihydrogen } \\ \text { phosphate }\left(\mathrm{KH}_{2} \mathrm{PO}_{4}\right)\end{array} & 1.5 \mathrm{mM} \\ \end{array}$

dissolved in deionized $\mathrm{H}_{2} \mathrm{O}$, pH optimized by titration with dilute $\mathrm{NaOH}$ and $\mathrm{HCl}$, respectively. For use, diluted 1:10 in demineralized $\mathrm{H}_{2} \mathrm{O}$

Enriched phosphate buffered saline $\left(\right.$ PBS $\left.^{++}\right)$, pH 7.5

Calcium Chloride $1.00 \mathrm{mM}$

dihydrate $\left(\mathrm{CaCl}_{2} \mathrm{x}\right.$

$2 \mathrm{H}_{2} \mathrm{O}$ )

Magnesium chloride

$0.27 \mathrm{mM}$ hexahydrate $\left(\mathrm{MgCl}_{2} \mathrm{x}\right.$ $\left.6 \mathrm{H}_{2} \mathrm{O}\right)$

dissolved in $1 \mathrm{x}$ phosphate buffered saline (PBS), $\mathrm{pH} 7.5$

\section{Western blot washing solution: Tris} buffered saline + Tween, pH 7.6

Tris $50 \mathrm{mM}$

Sodium Chloride $150 \mathrm{mM}$ $(\mathrm{NaCl})$

Tween 20

$0.1 \%$

dissolved in deionized $\mathrm{H}_{2} \mathrm{O}$, $\mathrm{pH}$ optimized by titration with dilute $\mathrm{NaOH}$ and $\mathrm{HCl}$, respectively 


\section{Western blot blocking solution}

Powdered milk

$5 \%$

dissolved in TBST, pH 7.6

\section{Ponceau S solution}

Ponceau S (powder)

$0.5 \%$

Acetic acid

$1.0 \%$

dissolved in deionized $\mathrm{H}_{2} \mathrm{O}$

SDS-PAGE running buffer

$\begin{array}{lr}\text { Tris } & 25.0 \mathrm{mM} \\ \text { Glycerol } & 86.1 \mathrm{mM} \\ \text { Sodium dodecyl } & 3.5 \mathrm{mM} \\ \text { sulfate (SDS) } & \end{array}$

dissolved in deionized $\mathrm{H}_{2} \mathrm{O}$

Western blot transfer buffer

$\begin{array}{lr}\text { Tris } & 25 \mathrm{mM} \\ \text { Glycin } & 192 \mathrm{mM} \\ \text { MetOH } & 20 \%\end{array}$

dissolved in deionized $\mathrm{H}_{2} \mathrm{O}$

DNA gel loading buffer, $6 x$

$\begin{array}{lr}\text { Sucrose } & 40.00 \% \\ \text { Glycerol } & 10.00 \% \\ \text { Bromphenol blue } & 0.25 \%\end{array}$

IF blocking solution

Fetal Calf Serum (FCS)

$10 \%$

Triton X-100

$0.1 \%$

dissolved in PBS

qPCR reaction buffer, 10x

Tris, $\mathrm{pH} 8,8$

$750 \mathrm{mM}$

Ammonium sulfate

$200 \mathrm{mM}$

$\left(\left(\mathrm{NH}_{4}\right)_{2} \mathrm{SO}_{4}\right)$

Tween 20

$0.1 \%$

dissolved in nuclease free water

qPCR reaction mix, 25x

10x qPCR reaction buffer $10 \%$

SYBRGreen $1: 80,000$

Water-free $\mathrm{MgCl}_{2}$ for $3 \mathrm{mM}$ PCR

Trehalose in $10 \mathrm{mM}$ $300 \mathrm{mM}$ Tris, $\mathrm{pH} 8.5$

dNTPs, mix $0.2 \mathrm{mM}$

Triton X-100 $0.25 \%$

Taq Polymerase

$20 \mathrm{U} / \mathrm{ml}$ 


\subsection{Chemotherapeutics and pharmacological inhibitors}

Table 2.4 Chemotherapeutics

\begin{tabular}{|l|l|l|}
\hline Name & Systematic name & Company \\
\hline \hline Gemcitabine & $\begin{array}{l}\text { 2', 2'-difluorodesoxycytidine } \\
(\mathrm{dFdC})\end{array}$ & $\begin{array}{l}\text { Eli Lilly, Indianapolis, IN, United } \\
\text { States }\end{array}$ \\
\hline Neocarzinostatin & $\begin{array}{l}\text { Neocarzinostatin, } \\
\text { Holocarzinostatin from } \\
\text { Streptomyces } \\
\text { carzinostaticus } \\
\text { Cat. \#N9162 }\end{array}$ & $\begin{array}{l}\text { Sigma-Aldrich, Sigma Aldrich, St. } \\
\text { Louis, MO, United States }\end{array}$ \\
\hline Nocodazole & & $\begin{array}{l}\text { Sigma-Aldrich, Sigma Aldrich, St. } \\
\text { Louis, MO, United States }\end{array}$ \\
\hline
\end{tabular}

Table 2.5 Pharmacological inhibitors

\begin{tabular}{|l|l|l|l|}
\hline Name & Commercial name & Target & Company \\
\hline \hline Chk1 Inh & $\begin{array}{l}\text { SB218078, } \\
\text { Cat. \#559402 }\end{array}$ & Chk1 & $\begin{array}{l}\text { Calbiochem, Merck, Darmstadt, } \\
\text { Germany }\end{array}$ \\
\hline MK2 Inh & $\begin{array}{l}\text { MK2 III, } \\
\text { Cat. \#475864 }\end{array}$ & MK2 & $\begin{array}{l}\text { Calbiochem, Merck, Darmstadt, } \\
\text { Germany }\end{array}$ \\
\hline MG132 & Cat. \#474791 & Proteasome & $\begin{array}{l}\text { Calbiochem, Merck, Darmstadt, } \\
\text { Germany }\end{array}$ \\
\hline z-VAD & $\begin{array}{l}\text { Z-VAD-FMK, } \\
\text { Cat. \#V116-2MG }\end{array}$ & Caspases & $\begin{array}{l}\text { Sigma-Aldrich, Sigma Aldrich, St. } \\
\text { Louis, MO, United States }\end{array}$ \\
\hline
\end{tabular}




\subsection{Enzymes and buffers}

Table 2.6 Enzymes and buffers

\begin{tabular}{|l|l|}
\hline Reagent & Company \\
\hline \hline Buffer for M-MuLV RT, 10x & $\begin{array}{l}\text { New England Biolabs, Ipswich, MA, United } \\
\text { States }\end{array}$ \\
\hline Buffer for Taq with KCl, 10x & Fermentas, Thermo Scientific \\
\hline Buffer R & Fermentas, Thermo Scientific \\
\hline M-MuLV Reverse transcriptase (RT) & $\begin{array}{l}\text { New England Biolabs, Ipswich, MA, United } \\
\text { States }\end{array}$ \\
\hline RNase A & Quiagen, Venlo, Netherlands \\
\hline Taq DNA polymerase (Taq) & Fermentas, Thermo Scientific \\
\hline
\end{tabular}

\subsection{Kits}

Table 2.7 Kits

\begin{tabular}{|c|c|}
\hline Name & Company \\
\hline BigDye Terminator v3.1 Cycle sequencing kit & Invitrogen, Life Technologies \\
\hline $\begin{array}{l}\text { Click-iT }^{\circledR} \text { EdU Alexa Fluor Azide High- } \\
\text { throughput Imaging Assay }\end{array}$ & Invitrogen, Life Technologies \\
\hline Guava Check Kit for FACS & Millipore, Merck, Darmstadt Germany \\
\hline Pure Yield Plasmid Midiprep System & Promega, Madison, WI, United States \\
\hline Invisorb Spin Plasmid Midi Kit Two & $\begin{array}{l}\text { Invitec/Stratec molecular, Berlin, } \\
\text { Germany }\end{array}$ \\
\hline Pierce $®$ BCA Protein Assay Kit & Thermo Scientific \\
\hline \multicolumn{2}{|l|}{ HRP substrate solutions: } \\
\hline $\begin{array}{l}\text { Immobilon Western HRP Substrate Peroxide } \\
\text { Solution }\end{array}$ & Millipore, Merck, Darmstadt Germany \\
\hline $\begin{array}{l}\text { SuperSignal West Femto Maximum } \\
\text { Sensitivity Substrate }\end{array}$ & Thermo Scientific \\
\hline
\end{tabular}




\subsection{Oligonucleotides}

All siRNAs are Silencer Select siRNAs from Ambion, Life Technologies.

For the high-content siRNA-screen we used a customized siRNA library which was obtained from Ambion, catalog number 4392425 and 4390836. It contained siRNAs against gene products which were associated with DNA damage, genomic integrity and cancer and was composed by the European GENICA Consortium (see table 2.20). The gene list was obtained by personal communication.

Only those siRNAs used for further validation of candidates resulting from the secondary screen are shown in table 2.8 below. All other sequences are available from the library.

Table 2.8 Small interfering RNAs

\begin{tabular}{|c|c|c|c|}
\hline \multirow{2}{*}{$\begin{array}{l}\text { Name/ } \\
\text { target }\end{array}$} & \multirow{2}{*}{$\begin{array}{l}\text { Catalog } \\
\text { number/ } \\
\text { siRNA-ID }\end{array}$} & \multicolumn{2}{|l|}{ siRNA-sequence } \\
\hline & & Sense $5^{\prime} \rightarrow 3^{\prime}$ & Antisense $5^{\prime} \rightarrow 3^{\prime}$ \\
\hline $\begin{array}{l}\text { Negative } \\
\text { control \#1 }\end{array}$ & s813 & UAACGACGCGACGACGUAAtt & UUACGUCGUCGCGUCGUUAtt \\
\hline $\begin{array}{l}\text { Negative } \\
\text { control \#2 }\end{array}$ & s814 & UCGUAAGUAAGCGCAACCCtt & GGGUUGCGCUUACUUACGAtt \\
\hline CHD8 A & s33582 & CACCUAGAGUACGAAAACAtt & UGUUUUCGUACUCUAGGUGtg \\
\hline CHD8 B & s33580 & GGCACGAUGUCAUCGAAUUtt & AAUUCGAUGACAUCGUGCCtg \\
\hline $\mathrm{CHD} 8 \mathrm{C}$ & s33581 & GUACUUAUAUGAACGUAUUtt & AAUACGUUCAUAUAAGUACct \\
\hline $\begin{array}{l}\text { CHEK1 } \\
\text { (Chk1) }\end{array}$ & AM51331 & GCAACAGUAUUUCGGUAUAtt & UAUACCGAAAUACUGUUGCca \\
\hline CTCF A & s20966 & not available & not available \\
\hline CTCF B & s20968 & not available & not available \\
\hline HELLS A & s6505 & GGAUAGAGAGUCGACAGAAtt & UUCUGUCGACUCUCUAUCCCa \\
\hline HELLS B & s6507 & GAGUUGUUGUUAGAUCGAAtt & UUCGAUCUAACAACAACUCta \\
\hline HELLS C & s6506 & GGAUCAAGAGAGAAGGUCAtt & UGACCUUCUCUCUUGAUCCtt \\
\hline $\begin{array}{l}\text { MAPKAPK2 } \\
\text { (MK2) }\end{array}$ & & CAGUAUCUGCAUUCAAUCAtt & UGAUUGAAUGCAGAUACUGga \\
\hline MDM2 & 4390828 & GCCAUUGCUUUUGAAGUUAtt & UAACUUCAAAAGCAAUGGCtt \\
\hline MCM10 A & s30853 & GACGAUUUCUCGGAACAAAtt & UUUGUUCCGAGAAAUCGUCtg \\
\hline MCM10 B & s30852 & GCACUCUUGAAGCAACAGAtt & UCUGUUGCUUCAAGAGUGCtg \\
\hline MCM10 C & s30854 & CGGUGAAUCUUAUACAGAAtt & UUCUGUAUAAGAUUCACCGtc \\
\hline TP53 (p53) & s605 & GUAAUCUACUGGGACGGAAtt & UUCCGUCCCAGUAGAUUACca \\
\hline STAG2 A & s21090 & CCACUGAUGUCUUACCGAAtt & UUCGGUAAGACAUCAGUGGaa \\
\hline STAG2 B & s21089 & GGUAGAUGAUUGGAUAGAAtt & UUCUAUCCAAUCAUCUACCaC \\
\hline STAG2 C & s21091 & CCAUCUACAGGAAAACGGAtt & UCCGUUUUCCUGUAGAUGGtt \\
\hline
\end{tabular}


Primers were designed manually with the help of the following databases:

The cDNA sequence for a protein of interest with indicated intron-exon-borders was obtained from ensembl.

Primers were then manually designed according to the PREMIER Biosoft primer design guidelines.

Primers were analyzed for secondary structures, like self- or hetero-dimers, hairpinstructures or melting temperatures using the oligo analyzer tool from Integrated DNA Technologies.

The reverse primer complement was calculated using the Sequence Manipulator Suite:

The reverse primer complement was again analyzed for secondary structures. Both sequences were then blasted against the whole human genome and transcriptome using BLASTN, BLAST, US National Library of Medicine in order to validate target specificity.

For details of the above-mentioned databases and online tools, see table 2.20.

Table 2.9 Primers

\begin{tabular}{|l|l|l|}
\hline Name/target & Sequence & Application \\
\hline \hline CHD8 forward & 5'-TTG TCA AGT ACA AGA ACT ACT CC-3' & qPCR \\
\hline CHD8 reverse & 5'-ACT GTG AGA CTC ATC CAA TAT CC-3' & qPCR \\
\hline HELLS forward & 5'-CTC GCA TGT CTT GGG ATA G-3' & qPCR \\
\hline HELLS reverse & 5'-CCT CAT AAC TGG CTT CTC TTC-3' & qPCR \\
\hline MCM10 forward & 5'-GGC TTC ACC TCC AGA TCC-3' & qPCR \\
\hline MCM10 reverse & 5'-AAC CCC AAA TGT CAC CCA ATC-3' & qPCR \\
\hline STAG2 forward & 5'-AGA TAC CGT GAT GCG ATA GC-3' & qPCR \\
\hline STAG2 reverse & 5'-GCC CTT GTA GAG CAG TAA GAC-3' & qPCR \\
\hline USP11 forward & 5'- CGC AAG AAA GAT GGC ACT TGG -3' & qPCR \\
\hline USP11 reverse & 5'- GCC ACA GAT GCC TGG CTG AC -3' & qPCR \\
\hline Random nonamer & 5'-NNNNNNNNN-3' & RT-PCR \\
\hline GAPDH forward & 5'-TGA AGG TCG GAG TCA ACG GAT TTG GT-3' & qPCR \\
\hline GAPDH reverse & 5'-GCA GAG ATG ATG ACC CTT TTG GCT C-3' & qPCR \\
\hline 36B4 forward & 5'-GAT TGG CTA CCC AAC TGT TG-3' & qPCR \\
\hline 36B4 reverse & 5'-CAG GGG CAG CAG CCA CAA A-3' & qPCR \\
\hline
\end{tabular}




\subsection{Plasmids}

Table 2.10 Plasmids

\begin{tabular}{|l|l|l|}
\hline Name & Source & Description \\
\hline \hline pcDNA3 & $\begin{array}{l}\text { Invitrogen, Life } \\
\text { Technologies }\end{array}$ & $\begin{array}{l}\text { Empty vector, expression vector for the transient } \\
\text { expression of proteins in transfected eukaryotic } \\
\text { cells under the control of a CMV promoter; } \\
\text { ampicillin resistance }\end{array}$ \\
\hline $\begin{array}{l}\text { pcDNA3-HA- } \\
\text { hCHD8L }\end{array}$ & $\begin{array}{l}\text { Personal } \\
\text { communication }\end{array}$ & $\begin{array}{l}\text { Expression vector for the transient expression of } \\
\text { the human large isoform of CHD8 in transfected } \\
\text { eukaryotic cells under the control of a CMV } \\
\text { promoter; ampicillin resistance }\end{array}$ \\
\hline $\begin{array}{l}\text { pcDNA3-HA- } \\
\text { mCHD8S }\end{array}$ & Personal \\
communication & $\begin{array}{l}\text { Expression vector for the transient expression of } \\
\text { the murine small isoform of CHD8 in transfected } \\
\text { eukaryotic cells under the control of a CMV } \\
\text { promoter; ampicillin resistance }\end{array}$ \\
\hline pcDNA3-GFP & Lab inventory & $\begin{array}{l}\text { Expression vector for the transient expression of } \\
\text { GFP in transfected eukaryotic cells under the } \\
\text { control of a CMV promoter; ampicillin resistance }\end{array}$ \\
\hline
\end{tabular}

$\rightarrow$ Expression constructs pcDNA3-HA-hCHD8L and pcDNA3-HA-mCHD8S were obtained from K.I. Nakayama, Department of Molecular and Cellular Biology, Medical Institute of Bioregulation, Kyushu University, Japan (Nishiyama et al. 2009). 


\subsection{Antibodies}

Table 2.11 Primary antibodies for Western Blot

\begin{tabular}{|l|l|l|l|l|l|}
\hline Target & Clone & $\begin{array}{l}\text { Source } \\
\text { organism }\end{array}$ & Dilution & $\begin{array}{l}\text { Cat. } \\
\text { Number }\end{array}$ & Company \\
\hline CHD8 & rabbit & $1: 1,000$ in milk & $\begin{array}{l}\text { A301- } \\
224 A\end{array}$ & $\begin{array}{l}\text { Bethyl } \\
\text { Laboratories }\end{array}$ \\
\hline Chk1 & 2G1D5 & mouse & $1: 1,000$ in milk & 2360 & $\begin{array}{l}\text { Cell Signaling } \\
\text { Technology }\end{array}$ \\
\hline $\begin{array}{l}\text { Chk1 } \\
\text { pSer317 }\end{array}$ & rAb & mouse & $1: 1,000$ in BSA & $\# 2344$ & Cell Signaling \\
\hline Chk2 & A-12 & mouse & $1: 1,000$ in milk & sc-5278 & Santa Cruz \\
\hline Chk2 pThr68 & C13C1 & rabbit & $1: 1,000$ in BSA & 2197 & Cell Signaling \\
\hline $\begin{array}{l}\text { Cleaved } \\
\text { caspase 3 }\end{array}$ & Asp175 & rabbit & $1: 500$ in milk & $\# 9664$ & Cell Signaling \\
\hline HA-tag & C29F4 & rabbit & $1: 1,000$ in milk & 3724 & Cell Signaling \\
\hline H2AX pS319 & JBW301 & mouse & $1: 1,000$ in milk & $05-636$ & Millipore, Merck \\
\hline Hsc70 & B-6 & mouse & $\begin{array}{l}1: 15,000 \text { in } \\
\text { milk }\end{array}$ & sc-7298 & Santa Cruz \\
\hline MDM2 & Ab-1 & mouse & $1: 1,000$ in BSA & OP46 & Calbiochem \\
\hline PARP & & rabbit & $1: 2,000$ in milk & 9542 & Cell Signaling \\
\hline p53 & DO-1 & mouse & $1: 1,000$ in milk & sc-126 & Santa Cruz \\
\hline p53 pS15 & AC-15 & mouse & $\begin{array}{l}1: 20,000 \text { in } \\
\text { milk }\end{array}$ & $\begin{array}{l}\text { ab6276- } \\
100\end{array}$ & Abcam \\
\hline 3-actin & mouse & $1: 1,000$ in BSA & ab213 & Abcam \\
\hline Rad 51 & mouse & $1: 1,000$ & Cell Signaling \\
\hline
\end{tabular}

All primary antibodies for immunoblotting were dissolved in Western Blot blocking solution. Phospho-antibodies were dissolved in BSA.

Table 2.12 Primary antibodies for immunofluorescence

\begin{tabular}{|l|l|l|l|l|l|}
\hline Target & Clone & $\begin{array}{l}\text { Source } \\
\text { organism }\end{array}$ & Dilution & $\begin{array}{l}\text { Cat. } \\
\text { Number }\end{array}$ & Company \\
\hline \hline CPDs & TDM-2 & mouse & $1: 300$ & & Cosmo Bio, Tokyo, Japan \\
\hline $\begin{array}{l}\text { H2AX } \\
\text { pS319 }\end{array}$ & JBW301 & mouse & $1: 1,000$ & $05-636$ & Millipore, Merck \\
\hline HA-tag & C29F4 & rabbit & $1: 1,000$ & 3724 & Cell Signaling \\
\hline
\end{tabular}

All primary antibodies used for IF were diluted in IF blocking solution. 
Table 2.13 Secondary antibodies for Western Blot

\begin{tabular}{|l|l|l|l|}
\hline Antibody & Dilution & $\begin{array}{l}\text { Cat. } \\
\text { Number }\end{array}$ & Company \\
\hline $\begin{array}{l}\text { HRP-coupled AffiniPure F(ab')2 } \\
\text { fragment, anti mouse IgG (H+ } \\
\text { L) }\end{array}$ & $1: 10,000$ & $711-036-152$ & $\begin{array}{l}\text { Jackson } \\
\text { Immunoresearch, Europe, } \\
\text { Newmarket, UK }\end{array}$ \\
\hline $\begin{array}{l}\text { HRP-coupled AffiniPure F(ab')2 } \\
\text { fragment, anti rabbit IgG (H+L) }\end{array}$ & $1: 10,000$ & $715-036-150$ & $\begin{array}{l}\text { Jackson } \\
\text { Immunoresearch, Europe, } \\
\text { Newmarket, UK }\end{array}$ \\
\hline
\end{tabular}

All secondary antibodies were dissolved in Western Blot blocking solution.

Table 2.14 Secondary antibodies for immunofluorescence

\begin{tabular}{|l|l|l|}
\hline Antibody & Cat. Number & Company \\
\hline \hline Alexa-Fluor-488 goat anti mouse & A-11017 & Invitrogen,Life Technologies \\
\hline Alexa-Fluor-488 goat anti rabbit & A-11034 & Invitrogen,Life Technologies \\
\hline Alexa-Fluor-546 goat anti mouse & A-11003 & Invitrogen,Life Technologies \\
\hline Alexa-Fluor-546 goat anti rat & A-21434 & Invitrogen,Life Technologies \\
\hline
\end{tabular}

All secondary antibodies for IF were diluted 1:2000 in IF blocking solution.

\subsection{Human cell culture}

Table 2.15 Human cell lines

\begin{tabular}{|l|l|l|}
\hline Cell line & Origin & Patient \\
\hline \hline BxPC-3 & Pancreatic adenocarcinoma, epithelial phenotype & Female, 61 years \\
\hline MIA PaCa-2 & Pancreatic adenocarcinoma, epithelial phenotype & Male, 65 years \\
\hline PANC-1 & $\begin{array}{l}\text { Ductal pancreatic adenocarcinoma, } \\
\text { epitheloid phenotype }\end{array}$ & Male, 56 years \\
\hline PaTu8902 & $\begin{array}{l}\text { Ductal pancreatic adenocarcinoma, } \\
\text { mesenchymal phenotype }\end{array}$ & Female, 15 years \\
\hline U2OS & Osteosarcoma, epithelial morphology & \\
\hline
\end{tabular}


Table 2.16 Media and additives for eukaryotic cell culture

\begin{tabular}{|l|l|l|}
\hline Medium/additive & $\begin{array}{l}\text { Final } \\
\text { conc. }\end{array}$ & Company \\
\hline Ciprofloxacin & $10 \mu \mathrm{g} / \mathrm{ml}$ & Bayer, Leverkusen, Germany \\
\hline $\begin{array}{l}\text { Dulbecco's Modified Eagle Medium (DMEM), } \\
\text { powder }\end{array}$ & $2 \%$ & Gibco, Life Technologies \\
\hline Fetal Calf Serum (FCS) & $10 \%$ & Gibco, Life Technologies \\
\hline L-glutamine & $200 \mu \mathrm{M}$ & Gibco, Life Technologies \\
\hline PBS tablets & - & Gibco, Life Technologies \\
\hline Penicillin/Streptomycin & $50 \mathrm{U} / \mathrm{ml}$ & Gibco, Life Technologies \\
\hline RPMI Medium & - & Gibco, Life Technologies \\
\hline Tetracyclin & $5 \mathrm{mg} / \mathrm{ml}$ & Gibco, Life Technologies \\
\hline Trypsin/EDTA & $0.1 \%$ & Gibco, Life Technologies \\
\hline
\end{tabular}

\section{DMEM}

without supplements

\begin{tabular}{lr}
\hline \hline DMEM, powder & $10.0 \mathrm{~g}$ \\
$\mathrm{NaHCO}_{3}$ & $3.7 \mathrm{~g}$ \\
HEPES & $5.96 \mathrm{~g}$
\end{tabular}

dissolved in $500 \mathrm{ml}$ deionized

$\mathrm{H}_{2} \mathrm{O}$, sterile filtered
DMEM with supplements

\begin{tabular}{lr}
\hline \hline Fetal Calf Serum (FCS) & $10 \%$ \\
Penicillin/Streptomycin & $50 \mathrm{U} / \mathrm{ml}$ \\
L-glutamine & $200 \mu \mathrm{M}$ \\
Tetracyclin & $5 \mathrm{mg} / \mathrm{ml}$ \\
Ciprofloxacin & $10 \mu \mathrm{g} / \mathrm{ml}$
\end{tabular}

dissolved in $500 \mathrm{ml}$ DMEM without supplements 


\subsection{Bacteria culture and media}

Table 2.17 Bacteria strains

\begin{tabular}{|l|l|}
\hline Strain & Description \\
\hline \hline DH10B & Chemically competent E. coli \\
\hline
\end{tabular}

Table 2.18 Bacteria culture media

\begin{tabular}{|l|l|}
\hline 2YT medium & \\
\hline Tryptone & $1.6 \%$ \\
\hline Yeast extract & $1.0 \%$ \\
\hline Sodium Chloride $(\mathrm{NaCl})$ & $0.5 \%$ \\
\hline
\end{tabular}

dissolved in sterile deionized $\mathrm{H}_{2} \mathrm{O}$

2YT agar

YT agar

$15 \%$

\subsection{Software and databases}

Table 2.19 Software

\begin{tabular}{|l|l|}
\hline Name & Company \\
\hline \hline Adobe Photoshop CS5 & Adobe Systems, San Jose, CA, United States \\
\hline AttoVision BD pathway software & $\begin{array}{l}\text { Becton Dickinson, Franklin Lakes, NJ, } \\
\text { United States }\end{array}$ \\
\hline Celígo Software & Cyntellect,San Diego, CA, United States \\
\hline $\begin{array}{l}\text { CFX Manager Software } \\
\text { for qPCR cycler }\end{array}$ & Biorad Laboratories, Hercules, CA, United States \\
\hline Guava Express Software & Millipore, Merck, Darmstadt, Germany \\
\hline
\end{tabular}




\begin{tabular}{|l|l|}
\hline INTAS lab ID & $\begin{array}{l}\text { Intas Science Imaging Instruments, Göttingen, } \\
\text { Germany }\end{array}$ \\
\hline $\begin{array}{l}\text { Microsoft Excel, Word and } \\
\text { Powerpoint }\end{array}$ & Microsoft, Redmond, WA, United States \\
\hline NanoDrop Software & PeqLab, Erlangen, Germany \\
\hline Fiji for image processing & General Public License \\
\hline R-program & General Public Licence, R-Project \\
\hline $\begin{array}{l}\text { Biomek 2000 Laboratory } \\
\text { Automation Workstation Software }\end{array}$ & $\begin{array}{l}\text { Beckman Coulter Indianapolis, IN, } \\
\text { United States }\end{array}$ \\
\hline Chemostar Imager Software & Intas Science Imaging Instruments, Göttingen \\
\hline
\end{tabular}

Table 2.20 Databases

\begin{tabular}{|c|c|}
\hline Name & Source/description \\
\hline $\begin{array}{l}\text { BLASTN, BLAST, US } \\
\text { National Library of } \\
\text { Medicine }\end{array}$ & $\begin{array}{l}\text { http://blast.ncbi.nlm.nih.gov } \\
\text { blast primer sequences against the whole human genome and } \\
\text { transcriptome to search for specificity of target sequence, } \\
\text { accessed } 01.04 .2016\end{array}$ \\
\hline $\begin{array}{l}\text { DAVID functional } \\
\text { annotation tool }\end{array}$ & $\begin{array}{l}\text { https://david.ncifcrf.gov } \\
\text { Database for Annotation, Visualization and Integrated } \\
\text { Discovery, different integrated tools and databases for } \\
\text { functional annotation of large lists of genes (Huang da et al. } \\
\text { 2009a, 2009b) }\end{array}$ \\
\hline ensembl & $\begin{array}{l}\text { www.ensembl.org } \\
\text { Acquisition of cDNA sequences for a protein of interest (Yates } \\
\text { et al. 2016) accessed on 01.04.2016 }\end{array}$ \\
\hline $\begin{array}{l}\text { Oligo Analyzer } 3.1 \\
\text { Integrated DNA } \\
\text { Technologies }\end{array}$ & $\begin{array}{l}\text { http://eu.idtdna.com/calc/analyzer } \\
\text { Analyzing primers for secondary structures like self- and } \\
\text { heterodimers, hairpins, melting temperatures, accessed on } \\
\text { 01.04.2016. }\end{array}$ \\
\hline PhosphoSitePlus & $\begin{array}{l}\text { www.phosphosite.org } \\
\text { Online database for information on proteins and } \\
\text { posttranslational modifications, including information from } \\
\text { UniProtKB (Hornbeck et al. 2015) }\end{array}$ \\
\hline $\begin{array}{l}\text { Sequence Manipulator } \\
\text { Suite }\end{array}$ & $\begin{array}{l}\text { http://bioinformatics.org/sms/rev comp.html } \\
\text { Calculation of reverse primer sequences, accessed on } \\
\text { 01.04.2016 }\end{array}$ \\
\hline
\end{tabular}




\begin{tabular}{|l|l|}
\hline UniProtKB & $\begin{array}{l}\text { www.uniprot.org } \\
\text { Knowledge base for the collection of functional annotations on } \\
\text { proteins, including their splice variants, mRNA sequence, protein } \\
\text { sequence and structure. }\end{array}$ \\
\hline $\begin{array}{l}\text { GENICA } \\
\text { consortium }\end{array}$ & $\begin{array}{l}\text { http://genica.unige.ch/index.php } \\
\text { European consortium for GEnomic Integrity and Cancer }\end{array}$ \\
\hline $\begin{array}{l}\text { PREMIER } \\
\text { Biosoft primer } \\
\text { design } \\
\text { guidelines }\end{array}$ & $\begin{array}{l}\text { http://www.premierbiosoft.com/tech notes/PCR Primer Design.html } \\
\text { Guidelines for primer design and tool to customize oligonucleotides } \\
\text { accessed on 01.04.2016 }\end{array}$ \\
\hline
\end{tabular}




\section{Methods}

\subsection{Cell biology}

\subsubsection{Culturing of human cells}

All cell culture work was performed under sterile conditions. The lids of dishes and tubes containing living cells, except for UV irradiation, were only opened under a hood provided with continuous positive air pressure and laminar air flow at the opening. Before and after use, the place was cleaned with $70 \%$ ethanol and the hood was sterilized using UV radiation for $30 \mathrm{~min}$ after use. Cells were cultured in an incubator at $37^{\circ} \mathrm{C}$ at humidified ambient air atmosphere enriched with $5 \% \mathrm{CO}_{2}$ to sustain the medium's carbonate buffer. All cell lines grew adherent to coated petri dishes. The cells were cultured in suitable medium with supplements and antibiotics (table 3.1). If the number of cells was not expanded for a specific experiment, they were cultured in $10 \mathrm{~cm}$ dishes. When a visually estimated confluence of $90 \%$ was reached, cells were passaged as follows: The medium was removed, the plate was once washed with pre-warmed phosphate-buffered saline (PBS), then $5 \mathrm{ml}$ of $0.1 \%$ trypsin/EDTA (Ethylene diamine tetraacetate) was added and cells were incubated for $5 \mathrm{~min}$. Then, the trypsinization was stopped by the addition of the same volume of fresh medium and the plate was rocked until all cells had detached. Then, $1 / 12$ to $1 / 3$ of the cell suspension was reseeded for further culturing. Medium was added to a total volume of $10 \mathrm{ml}$ in each dish and the dish was rocked cautiously to equally distribute the cells.

Table 3.1 Culture media for human cell lines

\begin{tabular}{|l|l|}
\hline Cell line & Culture medium \\
\hline \hline BxPC3 & RPMI with supplements and antibiotics \\
\hline MiaPaCa-2 & $\begin{array}{l}\text { DMEM with supplements and antibiotics } \\
\text { except ciprofloxacin }\end{array}$ \\
\hline PANC-1 & $\begin{array}{l}\text { DMEM with supplements and antibiotics } \\
\text { (PANC-1 can also be grown in RPMI) }\end{array}$ \\
\hline PaTu8902 & DMEM with supplements and antibiotics \\
\hline U2OS & DMEM with supplements and antibiotics \\
\hline
\end{tabular}


For the usage of cells in experiments, trypsinized cells were counted under a bright field microscope using a Neubauer counting chamber. Thereafter, the desired cell number was seeded in 6-well, 12-well or 96-well plates and medium was added to a total volume of $2 \mathrm{ml}$, $1 \mathrm{ml}$ or $150 \mu \mathrm{l}$, respectively (table 3.2 ).

Table 3.2 Number of cells which were usually seeded for different cell lines

\begin{tabular}{|l|l|l|l|}
\hline \multirow{2}{*}{ Cell line } & \multicolumn{3}{|c|}{ Cell count per well } \\
\cline { 2 - 4 } & 6-well plate & 12-well plate & 96-well plate \\
\hline \hline BxPC3 & 300,000 & 150,000 & \\
\hline MiaPaCa-2 & 200,000 & 120,000 & 8000 \\
\hline PANC-1 & 200,000 & 120,000 & 5000 \\
\hline PaTu8902 & 150,000 & 90,000 & 5000 \\
\hline U2OS & $180,000 / 200,000$ & $90,000 / 120,000$ & 7000 \\
\hline
\end{tabular}

\subsubsection{Freezing and thawing of cells}

For long term storage, cells were conserved in liquid nitrogen. To this end, near confluently grown cells from a $15 \mathrm{~cm}$ dish with a low passage number were used. After trypsinization and ending of trypsinization as described above, cells were transferred to a $15 \mathrm{ml}$ tube and centrifuged at $900 \mathrm{~g}$ for $7 \mathrm{~min}$. Then, the supernatant medium was removed and the cell pellet was resuspended in $3.6 \mathrm{ml}$ pre-cooled FCS (fetal calf serum) and $0.6 \mathrm{ml}(10 \%)$ DMSO. The suspension was transferred to a cryo tube with $1 \mathrm{ml}$ each and slowly cooled down to $-80^{\circ} \mathrm{C}$ for $24 \mathrm{~h}$. To this end, the vials were either stored in a thermo box isolated with glycerol or wrapped in multiple paper towels. After $24 \mathrm{~h}$, cells were moved to a liquid nitrogen tank.

To thaw cells at low passage number, a cell aliquot was rapidly warmed up in a water bath and the thawed cell suspension was then transferred to a tube containing $10 \mathrm{ml}$ of the respective pre-warmed medium. The tube was vortexed and then centrifuged at $900 \mathrm{~g}$ for $7 \mathrm{~min}$. The supernatant was removed, the cell pellet was resuspended with another $10 \mathrm{ml}$ of pre-warmed medium and the washed suspension was transferred to a petri dish for further culturing. The next day, the medium was replaced in order to remove all cells which had not survived the thawing process. 


\subsubsection{Transfection of human cells}

Cells were transiently transfected with nucleotides to either knockdown a specific protein (siRNA transfection) or to artificially express a protein (transfection of DNA from an expression vector).

\subsubsection{Transient transfection with siRNAs}

For the specific depletion of a protein in an experiment, cells were transfected with siRNA. To this end, the transfection reagent Lipofectamine 2000 (LF 2000 from here) has been optimized to be most efficient in all pancreatic cancer cell lines and has been established for efficient knockdown in U2OS cells in our lab. All pancreatic cancer cell lines were forward-transfected as this increased efficiency in optimization experiments (data not shown), that is, cells were seeded at least $12 \mathrm{~h}$ before transfection. U2OS cells were forward- as well as reverse-transfected with comparable transfection efficiencies. For reverse transfection, the transfection mix was prepared in the wells, and a suspension of freshly trypsinized cells was added.

For the preparation of the transfection mix, siRNA dissolved in nuclease free water was taken from a $500 \mathrm{nM}$ stock and diluted in DMEM without any supplement or antibiotic (solution A, see table 3.3). Then, LF 2000 was separately dissolved in DMEM without supplements (solution B, see table 3.3) and incubated for exactly 5 min at RT. After that, solution $B$ was added to the dissolved siRNA (solution A), cautiously shaken and incubated at $\mathrm{RT}$ for another $20 \mathrm{~min}$. For reverse transfection, cells were now trypsinized, counted, and the desired cell number was added to a volume that equaled that of the transfection mix (see table 3.3). For forward transfection, the medium of the wells for transfection was then removed, and a volume of DMEM that equaled that of the transfection mix and that already contained supplements and antibiotics was added to the cells. After $20 \mathrm{~min}$, the transfection mix was added to the cells and the plate was swayed gently. If not stated differently, the medium that contained transfection mix was replaced by fresh medium with all supplements $24 \mathrm{~h}$ after transfection. The further treatment of the cells was initiated $36 \mathrm{~h}$ to $48 \mathrm{~h}$ after transfection, depending on the period of time for treatment. 
Table 3.3 Volumes of culture medium, siRNA and transfection reagent used for different well sizes for siRNA transfection

\begin{tabular}{|c|c|c|c|c|c|}
\hline Plate & $\begin{array}{l}\text { Volume of } \\
\text { culture } \\
\text { medium } \\
\text { (containing } \\
\text { the desired } \\
\text { cell count) }\end{array}$ & $\begin{array}{l}\text { Solution A } \\
\text { (siRNA) }\end{array}$ & $\begin{array}{l}\text { Solution B } \\
(L F 2000)\end{array}$ & $\begin{array}{l}\text { Total } \\
\text { volume }\end{array}$ & $\begin{array}{l}\text { Fresh } \\
\text { culture } \\
\text { medium }\end{array}$ \\
\hline 6-well & $400 \mu \mathrm{l}$ & $\begin{array}{l}200 \mu \mathrm{l} \text { DMEM (-) } \\
+12 \mu \mathrm{l} \text { siRNA }\end{array}$ & $\begin{array}{l}200 \mu \mathrm{L} \text { DMEM (-) } \\
+4 \mu \mathrm{L} \text { LF } 2000\end{array}$ & $800 \mu \mathrm{l}$ & $2 \mathrm{ml}$ \\
\hline 12-well & $200 \mu \mathrm{l}$ & $\begin{array}{l}100 \mu \mathrm{l} \text { DMEM (-) } \\
+6 \mu \mathrm{l} \text { siRNA }\end{array}$ & $\begin{array}{l}100 \mu \mathrm{Ll} \text { DMEM (-) } \\
+2 \mu \mathrm{LF} 2000\end{array}$ & $400 \mu \mathrm{l}$ & $1 \mathrm{ml}$ \\
\hline 96-well & $50 \mu \mathrm{l}$ & $\begin{array}{l}25 \mu \mathrm{LMEM}(-) \\
+1.25 \mu \mathrm{l} \text { siRNA }\end{array}$ & $\begin{array}{l}25 \mu \mathrm{LMEM}(-) \\
+0.5 \mu \mathrm{L} L F 2000\end{array}$ & $100 \mu \mathrm{l}$ & $100 \mu \mathrm{l}$ \\
\hline
\end{tabular}

For siRNAs used, see table 2.8 .

\subsubsection{Transient transfection with expression vectors}

For the overexpression of a protein, we used expression plasmids, which were transfected into the cells using $L F 2000$. For the overexpression of $\mathrm{CHD8}$, we obtained an expression vector with a pcDNA3 backbone and the cloned sequence of the HA-tagged human large isoform and the murine small isoform of CHD8 from the Keiichi I. Nakayama lab (Nishiyama et al. 2009). The transcription from this DNA sequence is under control of a CMV promoter. For the expression of a protein, we exclusively used forward transfection. U2OS or PANC1 cells were seeded the day before transfection to reach a visually estimated confluence of around $80 \%$. The transfection mix was prepared as follows: Plasmid DNA was dissolved in the respective volume of DMEM without supplements (DMEM-, solution A, table 3.4). Then, LF 2000 was dissolved in DMEM- (solution B, table 3.4) and incubated for exactly 5 min at RT. Afterwards, solution A was added to solution B, carefully shaken, and then incubated for $20 \mathrm{~min}$ at RT. Meanwhile, the medium was removed from the wells, and a volume of culture medium without antibiotics, but with FCS and glutamine as in table 3.4 was added. After the transfection mix had incubated for $20 \mathrm{~min}$, it was added dropwise to the prepipetted medium, and the plate was swayed for a minute to equally distribute the transfection mix. Then, the cells were placed back into the incubator. After $4 \mathrm{~h}$, the transfection mix was removed, fresh culture medium with all supplements was added, and the cells were incubated at $37^{\circ} \mathrm{C}$. Cells were further treated with UV or gemcitabine $24 \mathrm{~h}$ after transfection, and harvested depending on the treatment time. 
Table 3.4 Volumes of culture medium, siRNA and transfection reagent used for different wells sizes for transfection of expression vectors.

\begin{tabular}{|l|l|l|l|l|l|}
\hline Plate & $\begin{array}{l}\text { Culture } \\
\text { medium } \\
\text { (+FCS and } \\
\text { glutamine) }\end{array}$ & $\begin{array}{l}\text { Plasmid DNA } \\
\text { (solution A) }\end{array}$ & $\begin{array}{l}\text { LF 2000 } \\
\text { (solution B) }\end{array}$ & $\begin{array}{l}\text { Total } \\
\text { volume }\end{array}$ & $\begin{array}{l}\text { Volume of } \\
\text { DMEM full to } \\
\text { replace } \\
\text { transfection } \\
\text { mix }\end{array}$ \\
\hline \hline 12 -well & $\begin{array}{l}400 \mu \mathrm{l} \\
\mathrm{DMEM}\end{array}$ & $\begin{array}{l}100 \mu \mathrm{l} \text { DMEM- } \\
+1.2 \mu \mathrm{g} \text { DNA }\end{array}$ & $\begin{array}{l}100 \mu \mathrm{l} \text { DMEM- } \\
+4 \mu \mathrm{l} \mathrm{LF} \mathrm{2000}\end{array}$ & $600 \mu \mathrm{l}$ & $1000 \mu \mathrm{l}$ \\
\hline 96-well & $\begin{array}{l}100 \mu \mathrm{l} \\
\mathrm{DMEM}\end{array}$ & $\begin{array}{l}25 \mu \mathrm{DMEM}- \\
+200 \mathrm{ng} \text { DNA }\end{array}$ & $\begin{array}{l}25 \mu \mathrm{l} \text { DMEM } \\
+0,5 \mu \mathrm{LF} 2000\end{array}$ & $15 \mu \mathrm{l}$ & $100 \mu \mathrm{l}$ \\
\hline
\end{tabular}

For expression vectors used, see table 2.10.

If it was desired to determine the transfection efficiency before the transfected cells were used for further experiments, $10 \%$ of the plasmid DNA was replaced by a GFP (Green Fluorescent Protein) expression vector, for example $0.12 \mu \mathrm{g}$ and $20 \mathrm{ng}$ GFP-DNA per plate for 12-well plates and 96-well plates, respectively. The number of GFP-expressing cells was assessed under a fluorescence microscope (Microscope Axiovert 40C, Zeiss, Oberkochen, Germany) 10 to $20 \mathrm{~h}$ after transfection.

\subsubsection{Chemical treatment, EdU-labeling and UV irradiation}

\subsubsection{Chemical treatment}

Chemotherapeutics and pharmacological inhibitors were pre-dissolved and stored in $\mathrm{H}_{2} \mathrm{O}$ or DMSO. For treatment, the respective chemical was dissolved to its final concentration in a tube containing pre-warmed culture medium (see table 3.4). Controls were treated with the same amount of $\mathrm{H}_{2} \mathrm{O}$ or DMSO which was used for drug dilution. If not stated differently, cells were treated for the time periods listed in table 3.5. 
Table 3.5 Concentrations and time periods for chemical treatment.

\begin{tabular}{|l|l|l|l|l|}
\hline Chemical & $\begin{array}{l}\text { Stock } \\
\text { concentration }\end{array}$ & $\begin{array}{l}\text { Final } \\
\text { concentration }\end{array}$ & Solvent & Treatment time \\
\hline \hline Chk1 Inh & $2.5 \mathrm{mM}$ & $2.5 \mu \mathrm{M}$ & DMSO & $24 \mathrm{~h}$ \\
\hline gemcitabine & $100 \mu \mathrm{M}$ & $50-500 \mathrm{nM}$ & $\mathrm{H}_{2} \mathrm{O}$ & $\begin{array}{l}50-300 \mathrm{nM}: 24 \mathrm{~h} \\
500 \mathrm{nM}: 4 \mathrm{~h}\end{array}$ \\
\hline MG132 & $10 \mathrm{mM}$ & $20 \mu \mathrm{M}$ & DMSO & max. $4 \mathrm{~h}$ \\
\hline MK2 Inh & $10 \mathrm{mM}$ & $10 \mu \mathrm{M}$ & DMSO & $24 \mathrm{~h}$ \\
\hline $\begin{array}{l}\text { Neocarzinostatin } \\
\text { (NCS) }\end{array}$ & $50 \mathrm{mg} / \mathrm{ml}$ & $100 \mathrm{ng} / \mathrm{ml}$ & $\begin{array}{l}20 \mathrm{mM} \text { MES } \\
\text { buffer, } \\
\text { pH 5.5 }\end{array}$ & $1-2 \mathrm{~h}$ \\
\hline Nocodazole & $1 \mathrm{mg} / \mathrm{ml}$ & $100 \mathrm{ng} / \mathrm{ml}$ & DMSO & max. 17 h \\
\hline \multicolumn{2}{|l|}{ For details, see section 3.2.1.9 below, cell synchronization with nocodazole block } \\
\hline Z-VAD & $20 \mathrm{mM}$ & $50 \mu \mathrm{M}$ & DMSO & $24-48 \mathrm{~h}$ \\
\hline
\end{tabular}

\subsubsection{Labeling of cells with EdU}

The nucleoside analogue 5-Ethinyl-2'-desoxyuridine (EdU) is incorporated into the DNA of replicating cells without influence on this process, as the sites for nucleotide crosslinking are not substituted. The substitution of a comparably small ethinyl group does not, like a brome substitution in 5-Bromo-2'-Desoxyuridin (BrdU), sterically alter nucleotide positioning and therefore DNA conformation (Salic and Mitchison 2008).

Additionally, the detection of BrdU is carried out by antibody staining and the DNA needs to be denatured first in order to give the antibody access to this nucleoside analogue. Because this is done by the harsh process of $\mathrm{HCl}$ addition, other proteins associated with the DNA are washed out and especially lowly expressed proteins cannot be stained any more. Time consumption of the extensive washing steps before staining after DNA denaturation is another disadvantage of using BrdU for labeling replicating DNA. Compared to that, EdU is incorporated into DNA like BrdU, but its detection relies on a chemical reaction. Cellular DNA and chromatin-associated proteins can therefore remain in their natural state at the time of detection. This click-reaction is a quantitative coupling of the ethynyl group that is attached to the uridine with an azide group that is bound to an Alexa-dye, whose fluorescence can afterwards be detected and even quantified.

For the labeling of cells with EdU, the cells were grown and transfected in a 96-well plate. $2 \mathrm{~h}$ before gemcitabine treatment, the medium was aspirated and the cells were incubated 
in $75 \mu \mathrm{l}$ of cell culture medium containing $7.5 \mu \mathrm{M}$ EdU diluted from a $10 \mathrm{mM}$ stock. The applied medium had to be incubated in a petri dish before adding the EdU at least for $1 \mathrm{~h}$. This was to adapt the temperature and $\mathrm{pH}$ of the later EdU working solution to the medium in which the cells were already incubated and to avoid $\mathrm{pH}$ and temperature variations which would affect the sensitive process of DNA replication. Cells were incubated with EdU working solution for $2 \mathrm{~h}$. Then, EdU was shortly washed out twice and once incubated for 5 min with pre-incubated culture medium before gemcitabine containing medium was added. For the detection of EdU, see section 3.3.4.

With this procedure, it was possible to identify cells going through S-phase at the beginning of a treatment with S-phase specific drugs like gemcitabine or at the beginning of UV radiation. Generally, EdU can also be added in parallel to gemcitabine treatment or afterwards. As this drug initiates replication fork stalling, DNA replication and consequently nucleotide incorporation is severely slowed down so that higher EdU concentrations or longer incubation times are needed to obtain an EdU-associated fluorescence signal. Still, it is possible to judge the cell's ability to resume DNA replication after gemcitabine treatment this way, either by abrogating DNA damage and cell cycle checkpoints or by repairing the damaged DNA.

\subsubsection{UV irradiation}

For UV irradiation, UVC-light with a wavelength of $254 \mathrm{~nm}$ from a UV crosslinking chamber (UVP, Thermo Fisher Scientific) was used. Prior to irradiation, the medium of each well was aspirated, and the control wells were covered with light proof sealing foil. Then, the cells were irradiated and quickly covered with fresh medium to minimize the stress from drying. For 6-well and 12-well plates, the energy of $20 \mathrm{~J} / \mathrm{m}^{2}$ was used and the cells were harvested $1 \mathrm{~h}, 4 \mathrm{~h}$ or $12 \mathrm{~h}$ after irradiation. For 96-well plates, the energy needed to be increased to $50 \mathrm{~J} / \mathrm{m}^{2}$ because the walls of the wells form a high and small cylinder that absorbs UV light and consequently leads to less DNA crosslinks and less DNA damage signaling. This effect was taken into account when we used a micro pore filter cautiously lain on the surface of the cell layer aiming to limit the cell's exposure to UV irradiation to small foci. To compensate for the reduced amount of irradiation reaching the cell through the pores when comparing it to the $20 \mathrm{~J} / \mathrm{m}^{2}$ that were used for uncovered cells in 12-well plates, an energy of $500 \mathrm{~J} / \mathrm{m}^{2}$ was applied to micro pore filters.

\subsubsection{Generation of cell lysates for SDS-PAGE}

For immunoblot analysis following SDS-PAGE, whole cell lysates were generated. To this end, cells were grown, transfected and treated in 6-well plates or 12-well plates. For cell 
harvest, the plate was put on ice, the supernatant was aspired and the wells were once washed with $4{ }^{\circ} \mathrm{C}$ cold PBS. Then, $1000 \mu \mathrm{l}$ (6-well plate) or $500 \mu \mathrm{l}$ (12-well plate) PBS was added, and the cells were scraped off the well surface. The suspension was then transferred to a $1.5 \mathrm{ml}$ tube and centrifuged at $1400 \mathrm{~g}$ for $4 \mathrm{~min}$. The supernatant was discarded and the cells were re-suspended in $120 \mu \mathrm{l}$ (12-well plate) or $60 \mu \mathrm{l}$ (12-well plate) lysis buffer and sonicated for 5 minutes to shear the DNA and thus avoid high viscosity of the protein lysate caused by DNA smear. For the denaturation of proteins and the reduction of disulfide bonds, the samples were boiled for $5 \mathrm{~min}$ at $95^{\circ} \mathrm{C}$ and $1400 \mathrm{rpm}$. When cooled down on ice, the lysates were either loaded on a polyacrylamide gel or stored at $-20^{\circ} \mathrm{C}$.

For the detection of apoptosis, the supernatant was harvested, as well, in order to include detached and floating apoptotic cells. The supernatant of the well was collected in $1.5 \mathrm{ml}$ tubes, centrifuged and the supernatant of the tube without suspended cells was discarded. The cells that remained in the well were then scraped off in PBS without prior washing, and the suspension in PBS was added to the cell pellet in the tube. The tubes were vortexed, centrifuged again and the sample was once washed with PBS. All following steps were performed as above.

If protein lysates from different cell lines or cell populations with different confluence should be compared, the respective protein concentration was determined using the Pierce $B C A$ Protein Assay Kit according the manufacturer's instructions. The protein concentrations were adjusted by diluting concentrated lysates with RIPA buffer. After that, 6x Laemmli buffer was added to a dilution of 6:1. All following steps were performed as above.

\subsubsection{Isolation of RNA}

For the quantification of gene expression, the specific mRNA levels were quantified in relation to the mRNA levels of a control gene using real-time PCR. Total RNA of a cell was isolated and transcribed into cDNA. To obtain the total cellular RNA, the phenol-chloroform extraction method was used (Chomczynski and Sacchi 1987, 2006). Cells were grown and treated in 6-well plates. For harvest, the medium was discarded and the cells were once washed with PBS. Then, $1 \mathrm{ml}$ Trizol reagent was added and samples were incubated for $5 \mathrm{~min}$ at RT to lyse cells and separate nucleotides from proteins. The lysates were transferred to a $1.5 \mathrm{ml}$ reaction tube and $200 \mu \mathrm{l}$ chloroform was added. After vigorously shaking the tubes and incubating them for 3 min at RT, the samples were centrifuged at $4^{\circ} \mathrm{C}$ and $12,000 \mathrm{~g}$ for $15 \mathrm{~min}$ to reach a clear phase separation. The colorless upper phase contained the RNA and was transferred into a fresh tube. Then, $500 \mu \mathrm{l}$ isopropanol were added, the sample was shaken and incubated for $10 \mathrm{~min}$ at RT again followed by 
centrifugation for $15 \mathrm{~min}$ at $12,000 \mathrm{~g}$. The supernatant was discarded and the pellet once washed with $75 \% \mathrm{EtOH}$ and centrifuged at $4000 \mathrm{~g}$ and $4{ }^{\circ} \mathrm{C}$ for $5 \mathrm{~min}$. After aspirating the supernatant, another purification step was performed to reduce protein contamination: The RNA-containing pellet was resuspended in nuclease free water and again precipitated by addition of $300 \mathrm{nM}$ sodium acetate (NaAc) and $75 \% \mathrm{EtOH}$. After centrifugation at $4000 \mathrm{~g}$ and $4{ }^{\circ} \mathrm{C}$ for $5 \mathrm{~min}$, the supernatant was discarded. The pellet was again washed in $75 \%$ $\mathrm{EtOH}$, centrifuged and, after removal of the supernatant, dried at room atmosphere for 5$30 \mathrm{~min}$. The pellet was then resuspended in $30 \mu \mathrm{l}$ nuclease free water and purity as well as RNA concentration was determined using the NanoDrop Spectrometer. To this end, the absorbance was measured after excitation with different wavelengths and the quotient was taken to assess RNA purity: A quotient of $A_{260} / A_{280}>1.8$ and $A_{260} / A_{230}>2.0$ was considered to be sufficient, with a lower quotient at $A_{260} / A_{230}$ indicating residual phenol contamination and lower quotients at $A_{260} / A_{280}$ indicating protein contamination. The RNA concentration was determined using the absorbance at $260 \mathrm{~nm}$ wavelength.

\subsubsection{Proliferation assay}

To determine the effect of a certain knockdown or treatment on cell proliferation, the confluence of a cell population was measured in the course of several days. To this end, the Celígo cell cytometer was used. It contains a bright field microscope and takes images which cover each well. These were then overlain by a manually optimized mask to determine cell borders by image contrast. The mask varied between the cell lines, but the same mask setting was used throughout an experiment. Based on that, the confluence of a well was calculated.

Cells were seeded in triplicates to sub-confluent densities of at least $10 \%$, then having entered exponential growth. After $24 \mathrm{~h}$, the confluence was determined for the first time and the cells were treated with gemcitabine and inhibitors. $24 \mathrm{~h}$ later, the treatment was washed out and the confluence was again measured. Thereafter, the confluence was determined daily and the medium was exchanged every $48 \mathrm{~h}$.

To test the effect of a knockdown on proliferation, cells were transfected with siRNAs in a 6-well plate as described in section 3.1.3.1. The transfection mix was replaced by fresh medium already $12 \mathrm{~h}$ after transfection. $24 \mathrm{~h}$ after transfection, the cells were trypsinized, counted and plated in a 12-well plate in triplicates. $24 \mathrm{~h}$ later (48 $\mathrm{h}$ after transfection), the confluence was determined for the first time, and gemcitabine was added to the wells and washed out as described in the figures. Cell confluence was determined every day and medium was exchanged every second day. 


\subsubsection{Flow cytometry}

To assess the cell cycle profile of a population, the amount of DNA within the cells is quantified (Krishan 1975). The profile is generated by the assignment of the number of cells to their specific DNA content. This results in typical peaks which represent phases of the cell cycle, and the whole profile represents the period of time or the probability with which a cell is found to be in that respective phase of the cell cycle. A cell in $G_{0}$ or $G_{1}$-phase has a single copy of its DNA. While going through S-phase, the DNA content increases continuously and reaches its maximum in $\mathrm{G}_{2^{-}}$and $\mathrm{M}$-phase, when the amount of DNA has doubled compared to $G_{0} / G_{1}$-phase, right before the cell divides to enter $G_{1}$-phase again. $A$ typical cell cycle profile is depicted in figure 3.1 below:

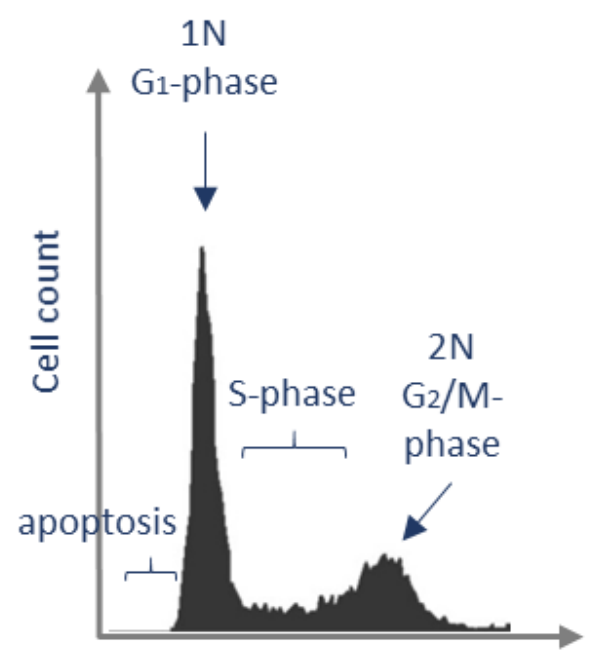

Figure 3.1 Cell cycle profile.

Unsynchronized U2OS cells were harvested and analyzed as described in this chapter. Arrows point to phases of the cell cycle.

DNA content

The fluorophore propidiumiodide $(\mathrm{PI})$ intercalates in nucleotides of DNA and RNA and is therefore suitable to stain and afterwards quantify the DNA via the fluorescence intensity of a cell. PI does not penetrate the membranes of living cells, and that is why the cells need to be fixed before staining. For the specific correlation of fluorescence intensity to DNA content, the cellular RNA needs to be discomposed by the incubation with RNAse. The PImolecule itself emits light when it is excited, but the emission is strongly enhanced by nucleobases (for example in DNA and RNA) forming the direct neighborhood. Because only the size and DNA content of single cells is suitable for analysis, adherently grown cells need to be accurately trypsinized before they are fixed in order to avoid clotting of cells.

Cells were thus seeded and treated in a 12-well plate according to the particular experimental protocol. At every harvesting time point, the supernatant of a sample was 
collected in a $15 \mathrm{ml}$ tube which was placed on ice. The well was washed with $500 \mu \mathrm{l}$ PBS, which was added to the tube. Then, $500 \mu \mathrm{l} 0.1 \%$ trypsin/EDTA were added to the well and incubated for $5 \mathrm{~min}$. Afterwards, $500 \mu \mathrm{l}$ culture medium containing trypsin inhibitor were added and those cells which were still attached or formed clots were loosened by up- and down pipetting. Then, the suspension was added to the tube which already contained the supernatant. The tubes were then centrifuged at $4{ }^{\circ} \mathrm{C}$ and $400 \mathrm{~g}$ for $7 \mathrm{~min}$ and directly afterwards cautiously put back on ice. The supernatant was aspirated and the cell pellet was resuspended in $500 \mu 4^{\circ} \mathrm{C}$ cold PBS ${ }^{++}$on ice. Fixation was done by the dropwise addition of $1.5 \mathrm{ml} 100 \% \mathrm{EtOH}$, which was pre-cooled to $-20^{\circ} \mathrm{C}$, while the tube was slowly vortexed. When the final volume of $2 \mathrm{ml}$ was reached, the tube was vortexed for $1 \mathrm{~min}$ at maximum velocity. Then, the sample was transferred to a $2 \mathrm{ml}$ tube and incubated at least for on $1 \mathrm{~h}$ or stored at $-20^{\circ} \mathrm{C}$.

The preparation of the cells for flow cytometer analysis took place on ice, with the centrifuge and solutions pre-cooled to $4{ }^{\circ} \mathrm{C}$. Cells were centrifuged at $400 \mathrm{~g}$ for $10 \mathrm{~min}$. The supernatant was removed and the cells were resuspended in $1 \mathrm{ml} \mathrm{PBS}^{++}$and rehydrated for $10 \mathrm{~min}$. Then, the cells were again centrifuged and the supernatant was removed. $100 \mu \mathrm{l}$ RNAse $A$ in a concentration of $1 \mathrm{mg} / \mathrm{ml}$ were then added and the tube was vortexed and incubated at $37^{\circ} \mathrm{C}$ for exactly $30 \mathrm{~min}$. After that, $400 \mu \mathrm{PBS}{ }^{++}$were added to a total volume of $500 \mu \mathrm{l}$ per sample. Directly before flow cytometer analysis, $15 \mu \mathrm{l}$ of PI staining solution was added to $500 \mu \mathrm{l}$ of cell suspension to reach a final concentration of $30 \mu \mathrm{g} / \mathrm{ml}$.

For each sample, 10,000 counts/cells were measured to obtain a representative cell cycle profile. If the number of cells was expected to be too low to obtain this event count within the period of $10 \mathrm{~min}$, less volume of $\mathrm{PBS}^{++}$was used for the resuspension and then the volume of PI staining solution needed to be proportionally adapted.

\subsubsection{Cell synchronization with nocodazole block}

The cell cycle profile of randomly distributed, unsynchronized cells is only influenced if a treatment or knockdown has strong impact on a cell cycle checkpoint. Slight effects on cell cycle progression are usually equalized by the asynchronous cell cycle in exponentially growing cells. To assess more decent changes in cell cycle progression, cells can be arrested in different phases of the cell cycle and are thereby synchronized. One possibility to synchronize cells in $\mathrm{G}_{2} / \mathrm{M}$-phase is the mitotic shake-off after nocodazole block. Nocodazole is an inhibitor of microtubule polymerization and prevents the formation of spindles in early metaphase. Therefore, cells treated with nocodazole enter mitosis, but are no longer able to assemble their chromosomes on the metaphase plate and are unable to 
enter cell division (Nusse and Egner 1984; Tan et al. 2006). One morphological and functional feature of cells which enter mitosis is the detachment from other cells or a matrix in order to prepare cell division. Those detached cells can be collected and reseeded after the treatment is washed out.

To this end, U2OS cells were seeded in a $10 \mathrm{~cm}$ or $20 \mathrm{~cm}$ petri dish and transfected with siRNA. After $24 \mathrm{~h}$, the transfection mix was replaced by fresh culture medium, and the cells were incubated for another $24 \mathrm{~h}$. After that, the cells were incubated with $100 \mathrm{ng} / \mathrm{ml}$ nocodazole for $16 \mathrm{~h}$. The plate was then strongly hit against an object and the medium was pipetted strongly onto the cell layer in order to loosen detaching cells in mitosis that had not properly detached before. The supernatant with suspended mitotic cells was collected in a $50 \mathrm{ml}$ tube and centrifuged at $400 \mathrm{~g}$ for $7 \mathrm{~min}$. The supernatant was aspired and the cells were resuspended in $20 \mathrm{ml}$ pre-warmed culture medium, then centrifuged again at $400 \mathrm{~g}$ for $7 \mathrm{~min}$. The supernatant was again discarded and the pellet was resuspended in $400 \mu \mathrm{l}$ culture medium. Cells were counted and 180,000 cells/well were seeded in a 12-well plate and harvested at specific time points (figure 4.22).

\subsection{Molecular biology}

\subsubsection{Polymerase chain reaction}

The polymerase chain reaction (PCR) is the method of choice to amplify whole genome DNA or DNA fragments in vitro on an enzymatic basis (Mullis and Faloona 1987). Thus, no organismal background is needed. It takes advantage of a thermostable polymerase which is activated or inactivated by up- and downregulation of the temperature only. When activated, it needs a starting point to bind to a specific part of the DNA and to start synthesizing a complementary DNA strand. Then, it continues its work as long as the DNA is not denatured, the polymerase activity is not reduced by temperature changes or the DNA template is finished. Such a starting point is formed by specific primers, which are DNA oligonucleotides complementary to the 3'-end of a sense and antisense DNA-sequence, for example of a gene of interest. The polymerase then adds the nucleotides to the free 3 '-end of the primers which are complementary to the template. Three steps are thus repeatedly conducted during a PCR: First, the double stranded DNA is denatured by heat to become single stranded. Second, the temperature is lowered so that the primers can anneal to their specific DNA sequences. The temperature and primers are adapted, so that the primer's 
melting point (the temperature, when it dissociates from the DNA) is above the annealing temperature and that the annealing temperature is not low enough to allow the primers to pair with the DNA unspecifically. Third, the temperature is increased to the optimal reaction temperature for the thermostable polymerase, which then starts to synthesize a complementary DNA strand using dNTPs that are added to the reaction mix. We used 40 repetitions of that cycle leading to a nearly exponential amplification of the DNA. PCR was used for cDNA synthesis from RNA and for the quantification of a gene transcript to either verify a specific knockdown or to assess the influence on gene transcription of a protein. Further, this method forms the basis for the microarray hybridization as described in 4.6.

\subsubsection{Quantification of messenger RNA by PCR}

The quantification of messenger RNA (mRNA) is used to investigate the expression of a gene on a transcriptional level. On the one hand, RNAi acts at this part of gene expression, and qPCR is a suitable method to quantify the knockdown efficiency. On the other hand, many proteins act as transcriptional regulators or even transcription factors, most prominent p53, and this method can be used to give insight in the influence of a specific knockdown or treatment on the transcription of another gene.

RNA cannot be amplified by the thermostable polymerase used for PCR. Aside from that, it is not stable enough for multiple heating cycles. Therefore, it needs to be transcribed into DNA as described below before PCR is applied.

\subsubsection{Reverse transcriptase PCR}

RNA which was isolated as in 4.1.6 was reverse transcribed using the enzyme reverse transcriptase (RevT), which is expressed by various viruses. Here, the viral M-MuLV RevT derived from a murine leukemia virus was used to obtain complementary DNA (cDNA) from RNA. The most essential difference to genomic DNA is that cDNA lacks introns, but is a copy of the transcriptome of the cell, meaning that cDNA results only from the minority of genomic DNA that is actively transcribed.

For the cDNA synthesis, $1 \mu \mathrm{g}$ of total extracted RNA was used and mixed with $2 \mu$ l of $100 \mu \mathrm{M}$ mixed primers consisting of oligo-dT primers and random nonamers. While the oligo-dT primers are complementary to the poly-A-tail of an mRNA and used for the specific mRNA reverse transcription, random nonamers ensure reverse transcription of transcripts that lack a poly-A-tail. The addition of $4 \mu \mathrm{l}$ dNTPs (2.5 mM each) ensured that substrate for DNA synthesis was abundantly available. Then, nuclease free water was added to a total volume 
of $16 \mu \mathrm{l}$ and the mix was heated to $70{ }^{\circ} \mathrm{C}$ for five minutes to resolve precipitated RNA and secondary RNA structures.

The RevT reaction mix was prepared as in table 3.6.

Table 3.6 Reaction mix for reverse transcription of RNA.

\begin{tabular}{|c|c|}
\hline Component & Volume \\
\hline 10x RT buffer & $2.0 \mu \mathrm{l}$ \\
\hline RNAse inhibitor & $0,25 \mu \mathrm{l}$ \\
\hline Reverse transcriptase M-MuLV & $0.125 \mu \mathrm{l}$ \\
\hline Nuclease free $\mathrm{H}_{2} \mathrm{O}$ & $1.625 \mu \mathrm{l}$ \\
\hline Total volume & $4 \mu \mathrm{l}$ \\
\hline
\end{tabular}

After the addition of the reaction mix to the $16 \mu$ l per sample RNA, primers and dNTPs, the samples were incubated at $42^{\circ} \mathrm{C}$ for one hour to facilitate reverse transcription. Afterwards, the enzyme was inactivated at $95^{\circ} \mathrm{C}$ for $5 \mathrm{~min}$ and the sample was slowly cooled down. 30 $\mu \mathrm{l}$ nuclease free water was added to a total volume of $50 \mu \mathrm{l}$ and the samples were stored at $-20^{\circ} \mathrm{C}$. For every sample, a control without the addition of RevT was run as quality control. If qPCR should generate a specific transcript from this sample, it would indicate contamination with genomic DNA.

\subsubsection{Quantitative real-time PCR}

For qPCR, PCR is applied. Multiple cycles of DNA synthesis lead to nearly exponential amplification of a specific DNA fragment. If compared to the amplification of a control gene, it is possible to quantify relative gene expression. For the quantification of gene transcription, cDNA derived from total RNA extracts was used. Then, primer pairs were designed as described in section 2.8. The aim of the primer pair is to bind to specific DNA sequences within the cDNA of a gene of interest. The forward primer binds to the cDNA that in parts resembles the genomic DNA sequence of the gene, leading to the synthesis of a complementary DNA strand. The reverse primer can then bind to this complementary strand which leads to the synthesis of a DNA strand whose sequence is part of the cDNA strand. Thus, during all cycles, a DNA fragment which is spanned by the primer pair is amplified exponentially. In order to exclude the amplification of genomic DNA, the DNA 
fragment spanned by a primer pair should exceed exon borders or be located in two different exons. The composition of the reaction mix for qPCR is detailed in table 3.7.

Table 3.7 Reaction mix for qPCR.

\begin{tabular}{|c|c|}
\hline Component & Volume \\
\hline 25x qPCR reaction mix as detailed in 31.4 & $14 \mu \mathrm{l}$ \\
\hline Forward primer (10 pmol/ $\mu \mathrm{l})$ & $0.75 \mu \mathrm{l}$ (final conc.: $0.3 \mathrm{pmol} / \mu \mathrm{l})$ \\
\hline Reverse primer $(10 \mathrm{pmol} / \mu \mathrm{l})$ & $0.75 \mu \mathrm{l}$ (final conc.: $0.3 \mathrm{pmol} / \mu \mathrm{l})$ \\
\hline cDNA & $1 \mu l$ \\
\hline Nuclease free water & $8.5 \mu l$ \\
\hline Total volume: & $25 \mu \mathrm{l}$ \\
\hline
\end{tabular}

The concentration of DNA is quantified after every replication cycle. This is achieved by the addition of SYBRGreen, a fluorescent dye whose light emission upon excitation is strongly enhanced when bound to DNA. The fluorescence intensity of a sample amplifying a gene of interest can thus be determined after every cycle and can be compared to the fluorescence intensity reached by the amplification of the DNA from a control gene, whose transcription is usually not influenced by treatments (in our experiments, either GAPDH or $36 B 4$ was used). Further, the melting point of the product in each sample is determined after every cycle, which serves as a control of product purity. A specific melting temperature is only achieved when a specific product is formed. All steps and time periods of the cycle program are explained in table 3.8. 
Table 3.8 Cycler program for qPCR.

\begin{tabular}{|l|l|l|}
\hline Temperature & Time & Operation \\
\hline \hline $95^{\circ} \mathrm{C}$ & $2 \mathrm{~min}$ & $\begin{array}{l}\text { Initial denaturation of } \\
\text { CDNA }\end{array}$ \\
\hline $95^{\circ} \mathrm{C}$ & $15 \mathrm{~s}$ & DNA denaturation \\
\hline $\begin{array}{l}\sim 60^{\circ} \mathrm{C} \text {, depending on } \\
\text { melting temp. of primers }\end{array}$ & $30 \mathrm{~s}$ & annealing \\
\hline $72^{\circ} \mathrm{C}$ & $\begin{array}{l}\sim 2 \text { min, depending on } \\
\text { DNA fragment length }\end{array}$ & elongation \\
\hline $\begin{array}{l}55^{\circ} \mathrm{C}-95^{\circ} \mathrm{C} \text { with } 0.5^{\circ} \mathrm{C} \\
\text { increment }\end{array}$ & variable & melting curve \\
\hline $12^{\circ} \mathrm{C}$ & pause & \\
\hline
\end{tabular}

To quantify a PCR product, $\mathrm{C}_{\mathrm{t}}$ values were used. The $\mathrm{C}_{\mathrm{t}}$-value is a measure for the number of amplification cycles at which the fluorescence of a sample reaches a previously defined threshold. Using the $\Delta \Delta \mathrm{C}_{\mathrm{t}}$ method, it is now possible to calculate the original amount of cDNA template, assuming that the amplification was exponential and the PCR product doubled with every cycle. $\Delta \mathrm{C}_{\mathrm{t}}$ values for the gene of interest and the reference gene can thus be calculated for the untreated sample:

$\Delta \mathrm{C}_{\mathrm{t} \text { (control) }}=\mathrm{C}_{\mathrm{t}}$ (ref. gene) $-\mathrm{C}_{\mathrm{t} \text { (target gene) }}$

In the same way, the $\Delta \mathrm{C}_{\mathrm{t}}$ value is calculated for the treated sample, for example after knockdown:

$\Delta \mathrm{C}_{\mathrm{t} \text { (treated) }}=\mathrm{C}_{\mathrm{t} \text { (ref. gene) }}-\mathrm{C}_{\mathrm{t} \text { (target gene) }}$

If now the $\Delta \mathrm{C}_{\mathrm{t}}$ values of treated and untreated samples are subtracted, this results in the $\Delta \Delta \mathrm{C}_{\mathrm{t}}$ value, which is the logarithm to the base 2 of the relative template amount/mRNA expression or the relative gene expression:



For every qPCR analysis, three technical replicates were done, and the average +/- SD gene expression was calculated.

\subsubsection{Heat-shock transformation of chemically-competent bacteria}

In order to amplify plasmid DNA to be used later for the artificial expression of a protein in eukaryotic cells, the chemically-competent bacteria strain DH10B was used. Plasmid DNA 
which contained an ampicillin resistance gene was stored and shipped on filter paper. Prior to use, the DNA was extracted in the supernatant after the paper was soaked with nuclease free water and centrifuged. Afterwards, the nucleic acid concentration was determined. One vial of bacteria was taken from $-80^{\circ} \mathrm{C}$ storage, was thawed on ice and $50 \mu$ l of the bacterial suspension was incubated with $100 \mathrm{ng}$ of plasmid DNA on ice for $30 \mathrm{~min}$. Then, the vials were rapidly put to a $37^{\circ} \mathrm{C}$ heating block and again incubated for $10 \mathrm{~min}$, afterwards cooled down for $10 \mathrm{~min}$ on ice. After the addition of $50 \mu \mathrm{l}$ of $2 Y T$ medium, $50 \mu \mathrm{l}$ of the suspension was directly plated on a $2 Y T$ agar plate containing ampicillin. The plates were then incubated at $37^{\circ} \mathrm{C}$ overnight to allow efficiently transformed bacteria to form colonies. For the further amplification of plasmid DNA, colonies were picked and grown in $2 Y T$ medium containing $200 \mu \mathrm{g} / \mathrm{ml}$ ampicillin (200 $\mathrm{ml}$ for MidiPrep and in 5ml 2YT medium for MiniPrep) overnight.

\subsubsection{Isolation of plasmid DNA}

Plasmid DNA was isolated from bacteria which were grown in 2YT medium overnight. For $200 \mathrm{ml}$ of bacteria culture the PureYield TM Plasmid MidiPrep System (Promega) and for $5 \mathrm{ml}$ bacteria culture the Invisorb Spin Plasmid Midi Kit Two (Invitec) was used according to the manufacturer's protocol. Plasmid DNA as well as genomic DNA is denatured by an alkaline buffer. Whereas the comparably small plasmids are able to renature their DNA upon neutralization of the solution, genomic DNA remains denatured and can be precipitated. The plasmid-containing supernatants are led over silica columns which absorb the plasmid DNA. After washing with ethanol, the plasmids are incubated in an aqueous solution and are eluted from the column.

\subsubsection{Determination of nucleic acid concentrations and purity}

For the determination of nucleic acid concentrations and the purity of nucleic acid solutions, the NanoDrop Spectrometer was used. $2 \mu$ of a sample were measured in duplicates. The concentration of RNA and DNA was determined using the absorbance at $260 \mathrm{~nm}$ wavelength. To determine the purity of a nucleic acid solution, the absorbance quotient was measured after excitation with different wavelengths and the quotient was taken to asses DNA and RNA purity: $A$ quotient of $A_{260} / A_{280}>1.8$ and $A_{260} / A_{230}>2.0$ was considered to be sufficient, with lower quotients at $A_{260} / A_{280}$ indicating protein contamination. 


\subsection{Biochemistry}

\subsubsection{Separation of proteins by SDS-PAGE}

The separation of proteins of a whole cell lysate according to their molecular weight and subsequent detection with specific antibodies allows to investigate total protein levels and protein modifications as consequence of a treatment. Following the separation in an electrical field, the proteins are transferred to a membrane which is then decorated with an antibody against the antigen of interest.

The SDS-PAGE (Sodium Dodecylsulfate Polyacrylamide Gel Electrophoresis) is based on the denaturation and subsequent coating of proteins by the anionic detergent SDS (Shapiro et al. 1967). Denaturation and the reduction of disulfate bonds excludes an influence of the secondary, tertiary and quaternary structures of the protein on its mobility in an electric field through pores in the gel (Laemmli 1970). The association of SDS to the protein occurs on positively charged amino acids, which are thus neutralized and bridged by the SDS molecule. As a consequence, a negative overall charge of the proteins results, which makes the proteins travel constantly towards the anode in the applied electrical field. The velocity is only hampered by pores in a polyacrylamide gel, which leads to the separation of the proteins according to their molecular weight. Additionally, the percentage of acrylamide in a gel determines the pore size with increasing acrylamide concentrations leading to a tighter crosslinking of the polymer and thus smaller pores. The best separation of proteins can therefore be achieved by adjusting the gel composition, with $6 \%$ acrylamide leading to the best separation at high molecular weight proteins over $200 \mathrm{kDa}$ and $12 \%$ acrylamide accurately separating proteins smaller than $50 \mathrm{kDa}$, while in the rest of the gel, a stacking of proteins at a certain protein size predominates.

The gels were manually prepared and consisted of two parts: The upper fourth was a stacking gel buffered by a Tris buffer with a $\mathrm{pH}$ of 6.8 and $5 \%$ acrylamide, containing ten to twelve pockets to load the protein lysates. After loading, a constant voltage of $80 \mathrm{~V}$ was applied. The large pores and a lower $\mathrm{pH}$ led to a stacking and focusing of proteins at the border of the gel parts. After entering the resolving gel in the lower three fourth of the gel chamber, the voltage was increased to $120-140 \mathrm{~V}$, a higher $\mathrm{pH}$ of 8.8 reduced remaining positive charges of the proteins and smaller pores ensured the separation of the proteins by their size.

For orientation and to indicate the protein separation and size, a protein ladder with prestained proteins of a defined size was loaded in one of the pockets of every gel.

The composition of the gels is detailed in table 3.9. 
Table 3.9 Composition of gels for SDS-PAGE.

\begin{tabular}{|l|r|r|}
\cline { 2 - 3 } \multicolumn{1}{c|}{} & \multicolumn{2}{c|}{ Final concentration in gel } \\
\hline Component & stacking gel & resolving gel \\
\hline Acrylamide-bisacrylamide & $5 \%$ & $6 \%, 10 \%, 12 \%$ \\
\hline Tris, pH $6.8(1 \mathrm{M})$ & $126 \mathrm{mM}$ & - \\
Tris, $\mathrm{pH} 8.8(1.5 \mathrm{M})$ & - & $375 \mathrm{mM}$ \\
\hline SDS $(10 \%$ stock $)$ & $0.1 \%$ & $0.1 \%$ \\
\hline APS (10\% stock) & $0.1 \%$ & $0.1 \%$ \\
\hline TEMED & $0.3 \%$ & $0.4 \%$ \\
\hline
\end{tabular}

\subsubsection{Immunoblotting/Western Blot}

Proteins separated by SDS-PAGE need to be transferred to a membrane to make them accessible for immunostaining (Towbin et al. 1979). When the proteins were sufficiently resolved by SDS-PAGE, the procedure was stopped and the proteins were electrochemically transferred to a nitrocellulose membrane using the wet blot technique. To ensure a proper contact with all parts of the membrane to the gel, every component was previously soaked in Western Blot transfer buffer (section 3.4) and the gel together with the membrane was padded in a stack between multiple layers of Whatman paper and sponges (fig. 3.2).

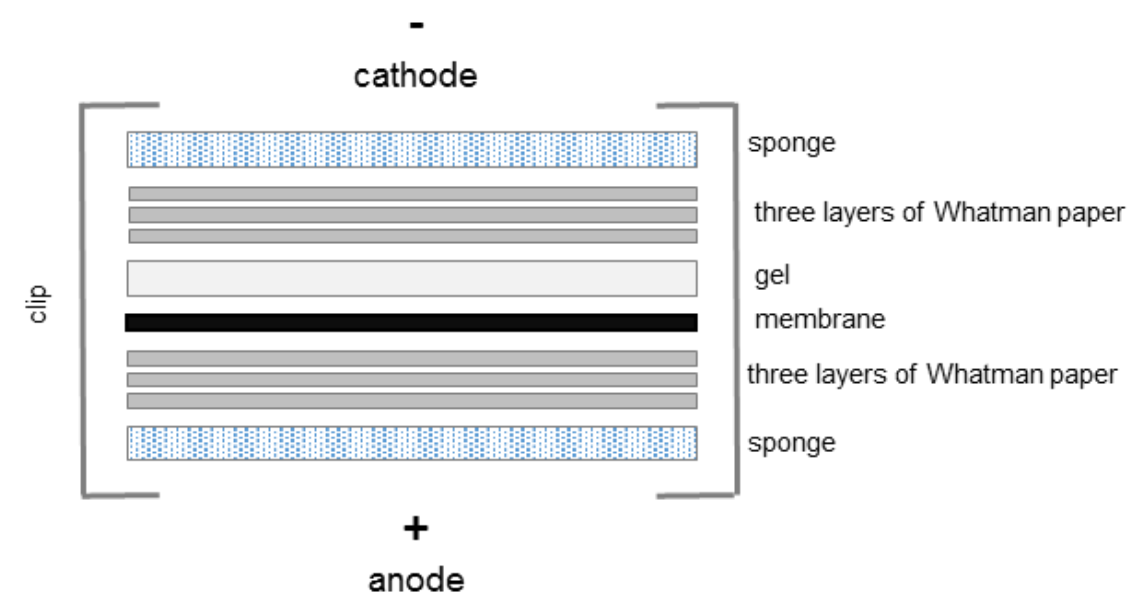

Figure 3.2 Component assembly of a wet blot experiment. 
The stack was fixed with two plane plastic clips and vertically placed into a blotting chamber. The chamber was filled with pre-cooled Western Blot transfer buffer and placed into an ice box. The blotting procedure was performed at $4{ }^{\circ} \mathrm{C}$ atmosphere temperature. A constant voltage of $100 \mathrm{~V}$ was applied for $90 \mathrm{~min}$ in case of $10 \%$ and $12 \%$ gels and $30 \mathrm{~V}$ were applied overnight or at least $8 \mathrm{~h}$ in case of $6 \%$ gels. The proteins traveled to the anode side of the gel and were electrostatically immobilized on the nitrocellulose membrane. After disassembly of the blotting components, the efficient and even protein transfer to the membrane was controlled. To this end, it was incubated in Ponceau S solution (section 2.4) for unspecific staining of proteins.

\subsubsection{Immunostaining}

The amount of a protein or its posttranslational modifications can be detected by specific antibodies. A primary antibody directed against the protein or its modification forms the specific part of immunostaining. The primary antibody is then coupled to a secondary antibody that is specific for the constant region ( $F_{c}$-part) of the organism from which the primary antibody is derived. The second antibody is coupled to horseradish peroxidase (HRP). When luminol is added as substrate, it is oxidized by HRP, which leads to emission of light. The intensity of that chemoluminescence is then detected by a camera and the signal can be quantified and digitally amplified for visualization.

To perform the above described process, the membrane loaded with protein by immunoblotting was incubated with blocking solution (section 2.4) for $1 \mathrm{~h}$ at room temperature. After one washing step with TBST, the membrane was incubated with the primary antibody dissolved in blocking solution or BSA for $3 \mathrm{~h}$ at room temperature or overnight at $4{ }^{\circ} \mathrm{C}$ (for applied antibodies, see table 2.11) and then thoroughly rinsed three times with TBST solution, while for the third washing step, TBST was incubated for 5 min. The appropriate secondary antibody with a dilution of 1:10,000 in blocking solution was then added and the membrane was incubated for $1 \mathrm{~h}$ at RT (for applied secondary antibodies, see table 2.13). To reduce unspecific antibody binding, the membrane was afterwards washed in three steps as before. For the HRP reaction, luminol substrate was added dropwise to the membrane until it was completely covered and chemoluminescence was subsequently detected using a Chemocam HR 3200 imager and processed with the ChemoStar Imager software. 


\subsubsection{Staining for immunofluorescence microscopy}

Proteins or their modifications can be visualized within a cellular context by immunofluorescence microscopy. In contrast to immunoblot analysis, it is thus possible to register the cellular localization of a protein and to demonstrate the interaction with binding partners or subcellular structures. Using quantitative immunofluorescence, alterations in protein levels can be visualized and quantified as with immunoblotting, but a much higher sensitivity can be reached and the fluorescence signal can be easily quantified.

In general, samples are incubated with a primary antibody to a protein of interest. The secondary antibody is then directed against the constant region ( $F_{c}$-part) of the primary antibody, which is specific for the organism from which the primary antibody is derived. The secondary antibody is coupled to a fluorescent dye which upon excitation emits light of a specific wavelength. Thus, several proteins can be assessed at a time, as long as the primary antibodies have different source organisms and the spectrum of the emitted wavelengths of the secondary antibodies do not overlap.

Immunofluorescence was used to assess the cellular localization of overexpressed HAtagged CHD8. To this end, U2OS cells were seeded in an 8-well chamber slide and transfected with HA-tagged CHD8 expression vector as described in section 3.1.3.2. $24 \mathrm{~h}$ after transfection, the cells were UV-irradiated with $50 \mathrm{~J} / \mathrm{m}^{2}$ at $1 \mathrm{~h}, 30 \mathrm{~min}$ or $1 \mathrm{~min}$ before fixation or left untreated. For one well at each irradiation time point, the medium was aspirated and a pre-cut micro pore filter with a pore size of $3 \mu \mathrm{m}$ was cautiously lain on the cell layer in the well. Those filter-covered wells were irradiated with $500 \mathrm{~J} / \mathrm{m}^{2}$ (3.1.4.3). Afterwards, fresh culture medium was added and the filter swimming on the surface could be removed.

The fixation of the cells and the staining for immunofluorescence took place at RT. Cells were fixed with $3.6 \%$ formaldehyde in $\mathrm{PBS}^{++}$for $20 \mathrm{~min}$, then rinsed twice with PBS and permeabilized with $0.5 \%$ Triton X-100 in $\mathrm{PBS}^{++}$for $10 \mathrm{~min}$. After that, cells were rinsed four times with $\mathrm{PBS}^{++}$and a fifth time with PBS before the cells were incubated with IF blocking solution for 10 minutes. Then, the primary antibodies to HA-tag and CPDs were diluted in IF blocking solution (table 2.12) and incubated for $1 \mathrm{~h}$. Afterwards, the primary antibody was removed and the wells were washed three times with IF blocking solution which was incubated for five minutes at the third washing step. Then, the secondary antibody (rabbit anti Myc-tag and mouse anti CPDs, respectively) with a dilution of 1:1,000 in IF blocking solution was added to the wells for $45 \mathrm{~min}$. To this solution, Hoechst was added with a dilution $1: 2,000$ to a final concentration of $0,5 \mu \mathrm{g} / \mathrm{ml}$ to stain nuclei. As Hoechst and Alexa dyes are light sensitive, the plate was covered with a light-proof box during incubation times. After washing three times with PBS, and after the third washing step had incubated for 
$5 \mathrm{~min}$, the cells were covered with a cover slip and analyzed using a Zeiss Confocal LSM 510 meta microscope. The slides were stored in the dark.

For quantitative immunofluorescence, cells were grown, transfected and treated in a 96well plate in triplicates. Afterwards, the cells were fixed and stained as above. A mouse anti $\mathrm{YH} 2 \mathrm{AX}$ antibody was used as primary antibody at a dilution of 1:1,500 and a secondary antibody Alexa546 anti mouse was diluted 1:2000. Again, Hoechst was added to the secondary solution to the above concentration to stain nuclei. After the last washing step, $100 \mu$ I PBS was added to each well and the plate was covered with a light proof sealing foil. It was directly subjected to quantitative immunofluorescence or stored at $4{ }^{\circ} \mathrm{C}$ protected from light.

If EdU labeling took place (section 3.1.4.2), its detection had to be carried out before adding any blocking solution to the wells. As already described, the ethinyl group and even more the later added azide and Alexa-dye are light sensitive, so the complete fixation and staining needs to take place protected from light. After fixation, permeabilization and washing of the cells, the Click-iT EdU Alexa Fluor High-throughput Imaging Assay kit was used according to modified manufacturer's instructions. Thus, a click-iT® reaction cocktail was prepared as in table 3.10:

Table 3.10 Components for click-iT® reaction cocktail.

\begin{tabular}{|l|r|r|r|}
\hline \multirow{2}{*}{ Reaction components } & \multicolumn{3}{|c|}{ Number of wells } \\
\cline { 2 - 4 } & \multicolumn{1}{|c|}{10} & \multicolumn{1}{l|}{50} & \multicolumn{1}{c|}{100} \\
\hline \hline $\begin{array}{l}\text { 1X Click-iT EdU reaction buffer } \\
(1: 15 \text { from stock) }\end{array}$ & $510 \mu \mathrm{l}$ & $2.55 \mathrm{ml}$ & $5.1 \mathrm{ml}$ \\
\hline $\mathrm{CuSO}_{4}$ & $24 \mu \mathrm{l}$ & $120 \mu \mathrm{l}$ & $240 \mu \mathrm{l}$ \\
\hline Alexa Flour Azide & $0.3 \mu \mathrm{l}$ & $1.5 \mu \mathrm{l}$ & $3 \mu \mathrm{l}$ \\
\hline 1 X Click-iT EdU buffer additive & $60 \mu \mathrm{l}$ & $300 \mu \mathrm{l}$ & $600 \mu \mathrm{l}$ \\
\hline \hline Total volume & $594 \mu \mathrm{l}$ & $2.97 \mathrm{ml}$ & $5.94 \mathrm{ml}$ \\
\hline
\end{tabular}

The reaction cocktail was incubated for $30 \mathrm{~min}$ at $\mathrm{RT}$, while the plate was swayed and protected from light. Then, the cells were washed twice with PBS and incubated with ClickiT EdU reaction rinse buffer for $5 \mathrm{~min}$. This buffer contained uncoupled azide to occupy all unspecific binding sites for an azide group and to displace the dye-coupled azide from these. After washing again with PBS, IF blocking solution was added and counter staining with antibodies was conducted as described above. The azide was coupled to an Alexa488 dye so that for the counterstaining with antibodies, dyes with other excitation wavelengths 
and different emission spectra had to be used. For the counterstaining of $\mathrm{yH} 2 \mathrm{AX}$, the Alexa546 anti mouse antibody was used.

Separate special conditions for high-content screening are specified below.

\subsubsection{Quantitative immunofluorescence microscopy}

H2AX phosphorylation and EdU incorporation were quantified using a high-content immunofluorescence microscope (BD Pathway 855). For this, cells were grown, treated, fixed and stained as detailed above in 96-well plates. Using the BD Pathway software, the protocol for microscopy was adapted for every experimental setting, for example occupied wells and used excitation and light detection channels as well as focus definitions were adapted. Firstly, the region of interest (ROI) was identified, which was the Hoechst-stained nucleus in our experiments. Within this ROI, the emitted light of each channel was quantified and either the median or average of all ROls of a well was calculated. For screening, the EdU and $\mathrm{YH} 2 \mathrm{AX}$ intensities were calculated for each single well as there were no replicates within one plate. For all other experiments, the medians or averages of all ROls of a well were calculated. Then, Microsoft Exce/ was used to subtract background fluorescence and to calculate the average and standard deviations of triplicates for each treatment.

\subsection{Statistical analysis}

If not stated differently, average values of triplicate samples were calculated for quantitative immunofluorescence and cell proliferation experiments. Standard errors and standard deviations were calculated as described in the respective figure legend. To assess statistical significance, an unpaired, two-tailed student's t-test was applied. P-values were assigned to asterisks as follows:

$$
\begin{array}{ll}
p<0.05 & * \\
p<0.01 & * * \\
p<0.001 & * * * \\
\text { n.s. } & \text { not significant }
\end{array}
$$

Calculations were done using Microsoft Excel.

For statistical analysis of the high throughput siRNA screen, see below. 


\subsection{High-content screening procedure}

To shed light on novel factors which influence the cellular response to gemcitabine treatment, we performed a high-content screen using RNA interference (RNAi) to deplete pancreatic cancer cells of single proteins (Conrad and Gerlich 2010).

\subsection{1 siRNA library: content, design and preparation}

For the high-content screening procedure, a pre-designed siRNA library from the GENICA consortium was used. It contained 1,743 siRNAs targeting 551 human gene products which have previously been described to be involved in genomic integrity, cancer development and DNA modification. Positive and negative controls were customized. Within the library all siRNAs were SilencerSelect siRNAs obtained from Ambion. Every included gene product was targeted by three different siRNA sequences. The library was provided in 21 96-well PCR plates with 1 nmole of lyophilized siRNA in each well. To each plate, the negative controls SiSel_NC1 and SiSel_NC2 as well as the positive controls ATR, Mdm2, p53 and MK2 were added in a random order. The very right column of the plate was left unfilled for the manual addition of accessory controls.

To the eight empty wells of the very right column, we manually transfected two additional negative controls and the knockdown of Chk1 itself as well as the ubiquitin ligase RNF8 as positive controls. RNF8 is recruited to sites of DNA damage and ubiquitinates the histone variants $\mathrm{H} 2 \mathrm{~A}$ and $\mathrm{H} 2 \mathrm{AX}$, leading to assembly of DNA repair proteins and to an amplification of the DDR. The upper four wells were treated with gemcitabine like the remaining plate, whereas the lower four rows were transfected in the same way but left untreated as quality control for the efficient impact of gemcitabine treatment.

For the preparation of siRNAs, the PCR plates containing the lyophilized siRNA were thawed on ice and shortly centrifuged. The sealing foil was removed and $100 \mu \mathrm{l}$ of nuclease free $\mathrm{H}_{2} \mathrm{O}$ were added to a final concentration of $10 \mu \mathrm{M}$ in the original screening plates using the Biomek 2000 Laboratory Automated Workstation:

$$
c(\operatorname{siRNA})=\frac{n(\operatorname{siRNA})}{V(\operatorname{siRNA})}=\frac{1 \mathrm{nmole}}{100 \mu \mathrm{l}}=\frac{10^{-9} \mathrm{~m}}{10^{-4} \mathrm{l}}=10^{-5} \frac{\mathrm{m}}{\mathrm{l}}=10 \mu \mathrm{M}
$$

Afterwards, dilution plates were installed and the library stock was diluted to a $500 \mathrm{nM}$ stock which was used for screening. To this end, $152 \mu$ l nuclease free water was pipetted to the conic dilution plate and $8 \mu \mathrm{l}$ of the $10 \mu \mathrm{M}$ siRNA stock were added:

$$
c(\operatorname{siRNA}-d i l)=\frac{1}{20} * 10 \mu M=\frac{1}{20} * 10^{-5} \frac{\mathrm{m}}{l}=5 * 10^{-7}=500 \mathrm{nM}
$$


For each transfection of the screening procedure, $6 \mu \mathrm{l}$ of the dilution plate were used as detailed below. The original screening plates as well as the dilution plates were covered with sealing foil and stored at $-20^{\circ} \mathrm{C}$.

\subsubsection{Screening procedure}

5,000 PANC-1 cells were seeded in 96-well plates. After $24 \mathrm{~h}$ the transfection mix was prepared using the Biomek 2000 Laboratory Automated Workstation: $44 \mu$ I DMEM without any supplements were pipetted to each well of a conic 96-well plate. Then, $6 \mu$ l of the diluted, $500 \mathrm{nM}$ siRNA were added and mixed by pipetting.

Concentration of dilution of siRNA in medium: $60 \mathrm{nM}$

$$
c\left(\operatorname{siRNA}_{\text {dil }_{\text {in }} \text { med }}\right)=\frac{6}{50} * 500 \mathrm{nM}=\frac{6}{50} * 5 * 10^{-7} \frac{\mathrm{m}}{\mathrm{l}}=\frac{3}{5} * 10^{-7}=6 * 10^{-8} \frac{\mathrm{m}}{\mathrm{l}}=60 \mathrm{nM}
$$

The controls in the very right row were added manually. Then, $6 \mathrm{ml}$ DMEM without supplements were mixed with $120 \mu \mathrm{l}$ and incubated for exactly five minutes. Then, it was put to a reservoir for multichannel pipetting and $50 \mu \mathrm{l}$ of the lipofectamine solution were added to the siRNA dilution. After 20 min incubation time, $50 \mu$ of the transfection mix were added to the wells which contained the growing cells with $100 \mu \mathrm{l}$ culture medium with all supplements. Thus, the amount of siRNA reached a final concentration of $10 \mathrm{nM}$.

The following steps were performed manually: $24 \mathrm{~h}$ after transfection, the medium containing transfection mix was replaced by fresh medium and incubated another $24 \mathrm{~h}$ to let the cells recover. $48 \mathrm{~h}$ after transfection, the medium was removed and $70 \mu \mathrm{l} 7.5 \mu \mathrm{M}$ EdU were added to the cells as detailed in 3.1.4.2. After $2 \mathrm{~h}$, the EdU-containing culture medium was removed and cells were washed twice with pre-incubated culture medium. Then, $300 \mathrm{nM}$ gemcitabine diluted in pre-incubated culture medium with all supplements was added and incubated for $22 \mathrm{~h}$. Cells were then fixed and stained as described in 3.3.4 using a mouse anti $\mathrm{YH} 2 \mathrm{AX}$ primary antibody diluted 1:1,500 in IF blocking solution and an Alexa546 anti-mouse secondary antibody with a dilution of 1:2,000 together with Hoechstdye for nuclear staining.

\subsubsection{Data acquisition and analysis}

The BD Pathway 855 System was used for automated microscopy and quantitative image analysis. To include most of the cells within a well, nine images of each well were taken. First, nuclei were identified by Hoechst staining and defined as regions of interest (ROI). Within the ROI, the Alexa488 and Alexa546 fluorescence intensity was quantified. For each 
sample, a total ROI count of 800 to 2,500 was achieved. Of those, the median fluorescence intensity was calculated using an R-based analysis tool for EdU and $\mathrm{yH} 2 \mathrm{AX}$ intensity. To establish a gate for replicating cells, the EdU threshold was defined as the doubled background fluorescence intensity for EdU, which included around 15-30\% of the cell population in each well.

For the normalization of all samples within the wells and to achieve comparability of all plates, a robust z-score was calculated (Birmingham et al. 2009; Brideau et al. 2003). This avoids typical problems of control-based approaches, like treatment anormalities, positional effects, variation among controls and outliers among controls. For median-based analysis methods, it is assumed that all samples follow a normal distribution and candidates are identified as outliers. Compared to a z-score, the robust z-score is based on the plate's median instead of its average and is therefore less sensitive to outliers for the calculation of a reference value for every plate. The robust $z$-score is the number of standard deviations of every sample from the median intensity of a plate. First, the median absolute deviation (MAD) was calculated. It equals the standard deviation of the median of each plate.

Then, the robust z-score was calculated:

$$
\begin{aligned}
& r-z-\text { score } \\
& =\frac{(\text { median ROI }- \text { intensity of sample })-(\text { median sample intensity of plate })}{M A D}
\end{aligned}
$$

The median ROI-intensity of sample was calculated for every well, thus for every siRNA using the R-based analysis. The median sample intensity of a plate was calculated from the median of all sample values (median ROI-intensity of sample). Thus, the robust z-score could be calculated for every siRNA and is a measure for the impact of each siRNA corrected for plate to plate variations which occur during transfection and immunofluorescence staining.

\subsection{Microarray hybridization}

To identify genes whose transcription is promoted or suppressed by the presence of CHD8, we performed a whole genome gene expression analysis in U2OS cells using the Agilent/Affimetrix platform in an $8 \times 60 \mathrm{~K}$ Array format. We transfected three different SilencerSelect siRNAs to knock down CHD8 and compared them to three control transfections with SilencerSelect NC1 and NC2 and a Silencer NC1 siRNA. U2OS cells were reversely transfected in a 6-well plate as described in 3.1.3.1. $14 \mathrm{~h}$ after transfection, 
the medium was replaced by fresh culture medium and the cells were grown another $25 \mathrm{~h}$. $39 \mathrm{~h}$ after transfection, the total RNA was isolated (4.1.6). Total RNA extracts were given to Dr. Gabriela Salinas-Riester of the Transcriptome and Genome Analysis Laboratory (TAL) at the Georg-August-University of Göttingen. After quality control, the RNA was hybridized to an Agilent/Affimetrix chip for whole transcriptome analysis. Statistical analysis was done by Dr. Claudia Pommerenke. Candidate genes were defined as those whose transcription was doubled or reduced by half after CHD8 knockdown in all CHD8-depleted samples compared to all control samples. Statistical significance was assumed when the false discovery rate (FDR) was below $5 \%$. 


\section{Results}

\subsection{Preliminary work}

\subsubsection{Sensitivity of pancreatic cancer cells towards gemcitabine treatment correlates with the amount of induced $\mathrm{yH} 2 \mathrm{AX}$}

The phosphorylation of the histone variant $\mathrm{H} 2 \mathrm{AX}$ (then called $\mathrm{YH} 2 \mathrm{AX}$ ) has been proven to be a hallmark of DNA damage. It also serves as a global readout to determine to which extent DNA is damaged independent of the kind of damaging agent or process. However, as the aim of gemcitabine treatment is to drive cancer cells into apoptosis, modulators of gemcitabine sensitivity should not only provoke alterations in cellular $\mathrm{yH} 2 \mathrm{AX}$ levels, but influence cell viability after that kind of chemotherapy.

Pancreatic cancer cells differ largely in their intrinsic sensitivity towards gemcitabine. The higher the endogenous resistance of a cell, the less will be the potential influence of a target protein to increase resistance further. An intermediate sensitive cell line will provide the possibility to identify mediators that render the cells more sensitive on the one hand, but also identify factors that promote gemcitabine resistance on the other hand.

We therefore performed cell proliferation assays with the four cell lines BxPC-3, MIA PaCa-2, PANC-1 and PaTu8902 (all derived from pancreatic adenocarcinoma) to determine their intrinsic gemcitabine sensitivity and identify cell lines with moderate sensitivity. All available cell lines harbor a p53 mutation and only BxPC-3 possess wild type KRAS, whereas this is mutated in MIA PaCa-2, PANC-1 and PaTu8902 (Ahmed et al. 2008). As shown in figure 4.1.a, BxPC-3 are highly sensitive to gemcitabine, and already concentrations as low as $50 \mathrm{nM}$ extensively impair cell growth. We ascribed moderate sensitivity to MIA PaCa-2 and PANC-1, as low gemcitabine concentrations do not affect cell proliferation, but treatment with $100 \mathrm{nM}$ gemcitabine or more results in growth delay. PaTu8902, being the most resistant cell line, did not respond to gemcitabine concentrations lower than $200 \mathrm{nM}$ and even recovered quickly from treatment with higher concentrations.

The extent of gemcitabine resistance correlates not only with endogenous $\mathrm{yH} 2 \mathrm{AX}$ levels (Fig. $4.1 \mathrm{~b}$, untreated cells) - it is the ability of gemcitabine to induce $\mathrm{YH} 2 \mathrm{AX}$ in those 
a
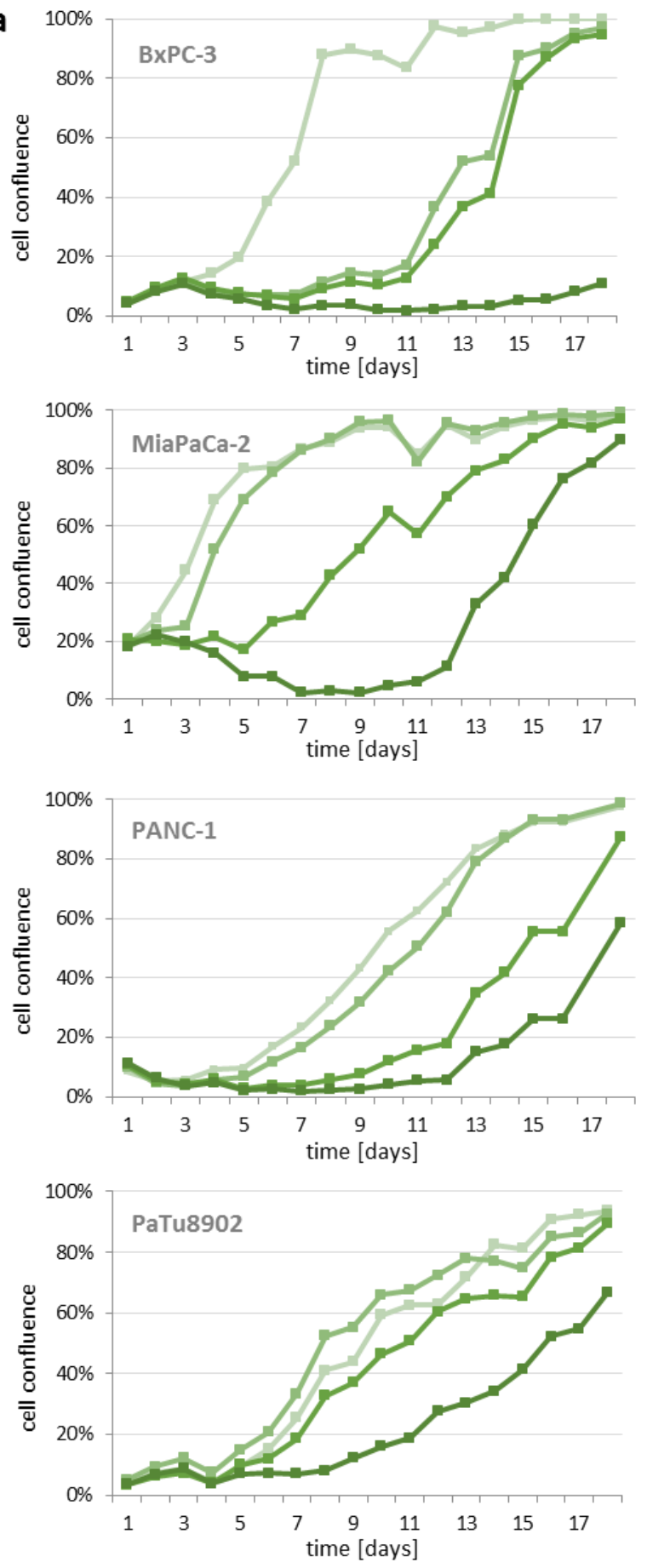

b
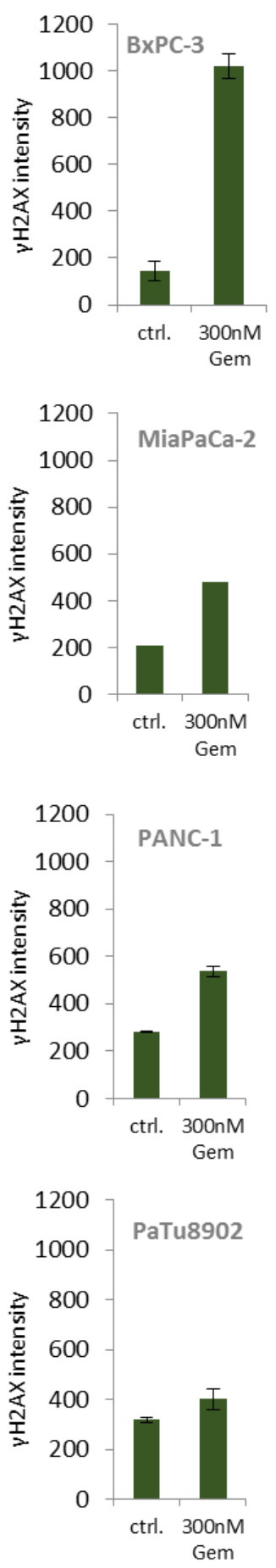

Figure 4.1 Sensitivity of pancreatic cancer cells towards gemcitabine treatment correlates with the amount of gemcitabine-induced $\mathrm{yH} 2 \mathrm{AX}$.

(a) Pancreatic cancer cells display high, intermediate or low sensitivity towards gemcitabine. BxPC-3, MiaPaCa-2, PANC-1 and PaTu8902 cells were seeded and cell confluence was determined the next day before gemcitabine was added in concentrations as indicated. After $24 \mathrm{~h}$, the treatment was washed out and confluence was determined using bright field microscopy and digital image analysis every day for 18 days. (b) Corresponding endogenous and inducible yH2AX levels in pancreatic cancer cells. Cells where treated with $300 \mathrm{nM}$ gemcitabine for $24 \mathrm{~h}$, fixed and stained for immunofluorescence analysis and $\mathrm{yH} 2 \mathrm{AX}$ levels where quantified. 
cell lines that decreases with increasing resistance to this agent (Fig. $4.1 \mathrm{~b}$, treated compared to untreated cells).

We therefore conclude that endogenous and inducible $\mathrm{yH} 2 \mathrm{AX}$ levels reflect gemcitabine sensitivity in pancreatic cancer cells: High endogenous $\mathrm{YH} 2 \mathrm{AX}$ levels indicate resistance, and to a high extent inducible $\mathrm{yH} 2 \mathrm{AX}$ levels indicate sensitivity towards gemcitabine treatment. More important for the high-content screening procedure is that, by using $\mathrm{YH} 2 \mathrm{AX}$ as the main readout, it not only provides a measure for the influence of prospective candidates on DNA damage signaling, but also a chance to identify them as mediators of gemcitabine sensitivity.

\subsubsection{The kinases MK2 and Chk1 modulate gemcitabine sensitivity in pancreatic cancer cells in opposite directions}

As previously introduced, the kinase Chk1 is a potent determinant of DNA damage signaling following replicative stress after chemotherapy. It attenuates DNA replication, leads to cell cycle arrest and activates DNA repair or apoptosis pathways. Inhibition as well as knockdown of Chk1 leads to massively increased DNA damage signaling and apoptosis in U2OS and other cancer cell lines, which has made Chk1 an attractive drug target.

The kinase MK2 is essential for the induction of $\mathrm{H} 2 \mathrm{AX}$ phosphorylation after replicative stress. In contrast to the cellular reaction to Chk1 knockdown, depletion of MK2 reduces $\mathrm{YH} 2 \mathrm{AX}$ levels induced by gemcitabine and UV treatment and helps the cells to overcome replicative stress induced by gemcitabine. MK2 has previously been characterized as mediator of the DDR after replicative stress and gemcitabine in osteosarcoma cells in our lab, antagonizing the effects of Chk1. As gemcitabine is one of the predominant treatment agents for pancreatic cancer, we evaluated the MK2/Chk1-system as a determinant of the gemcitabine response in pancreatic cancer cells, too.

\subsubsection{MK2 is a determinant of the gemcitabine response in pancreatic cancer cells}

To test whether MK2 mediates DDR in pancreatic cancer cells, too, we treated BxPC-3, MIA PaCa-2, PANC-1 and PaTu8902 cells with gemcitabine and MK2 inhibitor and determined the influence on $\mathrm{yH} 2 \mathrm{AX}$ levels using immunoblot analysis. Indeed, $\mathrm{H} 2 \mathrm{AX}$ phosphorylation induced by gemcitabine significantly decreased when MK2 was inhibited (Fig. $4.2 \mathrm{a}-\mathrm{d}$ ). The same was true for PANC-1 cells depleted of MK2 (Fig. 4.2 e). The effect was most pronounced in gemcitabine-sensitive BxPC-3 cells and still distinct in those cell 
a

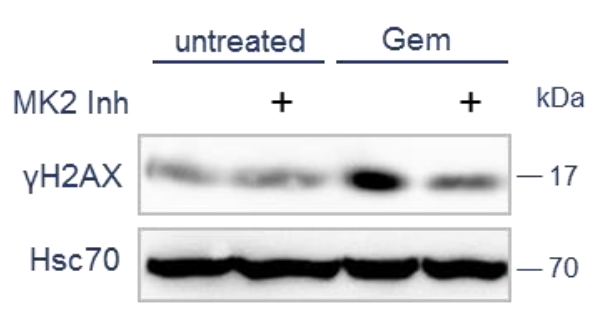

C

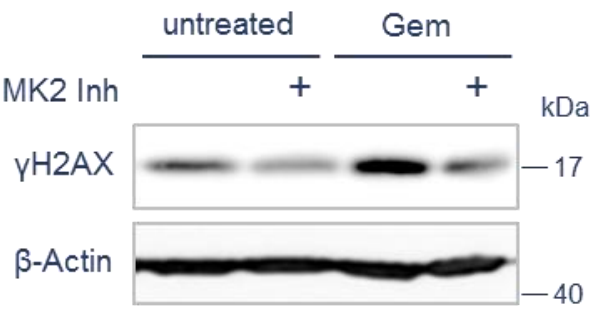

e

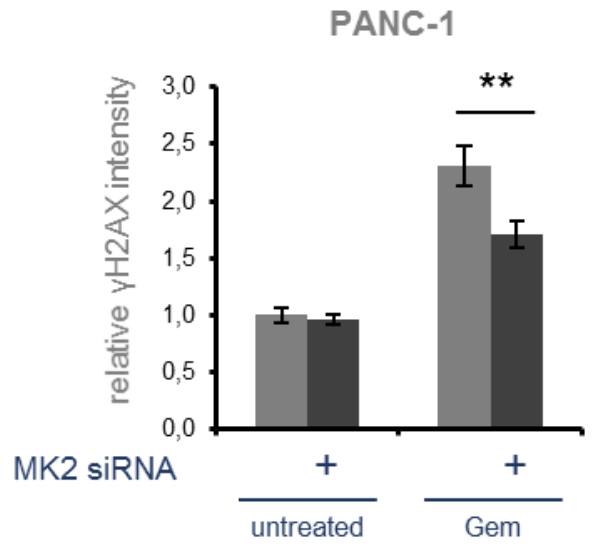

b

MIA PaCa-2

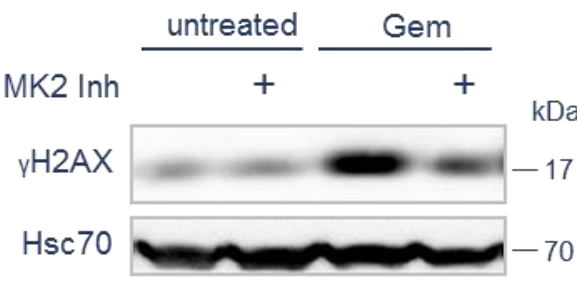

d

PaTu 8902

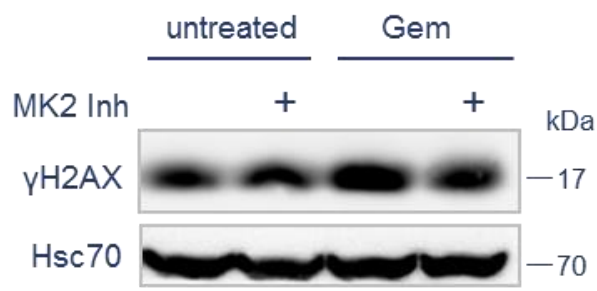

Figure 4.2 Inhibition or depletion of MK2 affects efficient H2AX phosphorylation in pancreatic cancer cells.

(a) BxPC-3, (b) MIA PaCa-2, (c) PANC-1 and (d) PaTu8902 cells where treated with $100 \mathrm{nM}$ gemcitabine for $24 \mathrm{~h}$ or left untreated, together with DMSO and MK2 inhibitor, respectively. H2AX phosphorylation was analyzed using immunoblot. (e) PANC-1 cells where depleted of MK2 by siRNAmediated knockdown and $48 \mathrm{~h}$ after transfection left untreated or treated with $300 \mathrm{nM}$ gemcitabine for $22 \mathrm{~h}$. Cells were then fixed and stained and $\mathrm{yH} 2 \mathrm{AX}$ intensity was quantified using immunofluorescence analysis. Experiments of figures 4.2 a-d were conducted by Dr. Frederik Köpper.

lines with intermediate gemcitabine sensitivity, but hardly detectable in gemcitabineresistant PaTu8902 cells (Fig. 4.2 d). We therefore conclude that MK2 activity is essential for $\mathrm{H} 2 \mathrm{AX}$ phosphorylation after gemcitabine treatment in pancreatic cancer cells, particularly in those sensitive to gemcitabine treatment.

To assess whether this dependence also holds true for cell growth and survival, we performed a cell proliferation assay. While gemcitabine treatment induced growth arrest in all cell lines, this effect could be completely overcome by inhibition of MK2 in BxPC-3, PANC-1 and PaTu8902 cells and also partially in MIA PaCa-2 cells (Fig. 4.3). PaTu8902 cells hardly responded to gemcitabine treatment, but MK2 inhibition provided a growth advantage in untreated as well as in gemcitabine-treated cells, which is probably due to a decrease of the high endogenous replicative stress and DNA damage signaling of this line. 
Thus, MK2 inhibition increases the proliferation rate in all pancreatic cancer cell lines and protects gemcitabine-sensitive pancreatic cancer cells from growth arrest induced by gemcitabine (Fig. 4.3 and (Kopper et al. 2014)).

a

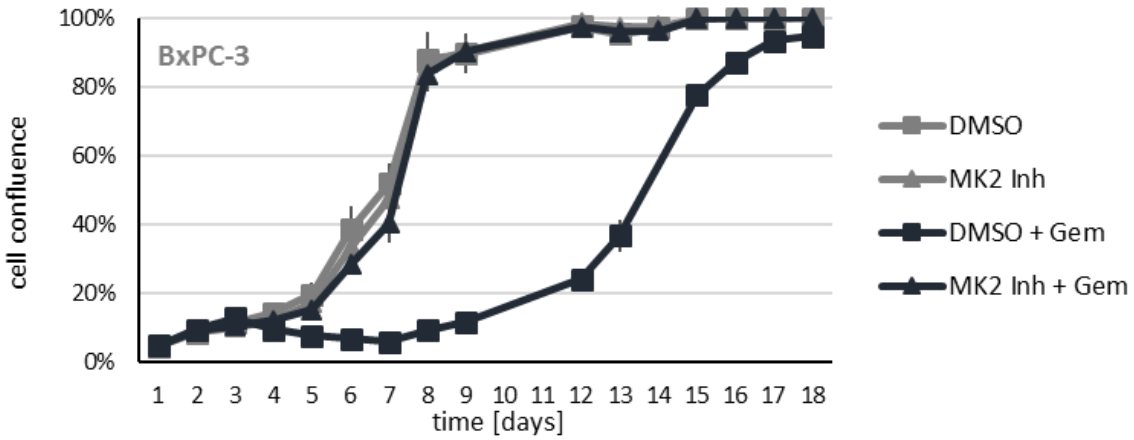

b
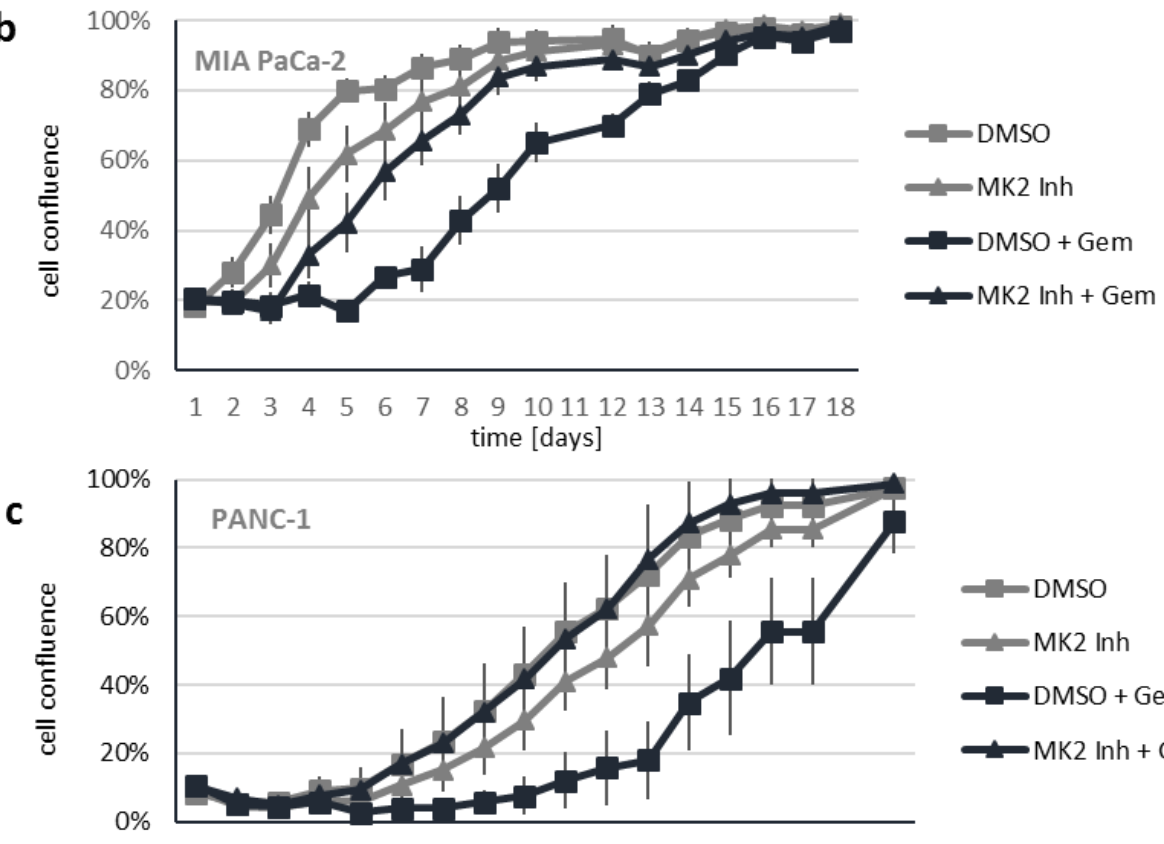

-DMSO

MK2 Inh

-DMSO + Gem

-MK2 Inh + Gem

$\begin{array}{llllllllllllllllll}1 & 2 & 3 & 4 & 5 & 6 & 7 & 8 & 9 & 10 & 11 & 12 & 13 & 14 & 15 & 16 & 17 & 18\end{array}$ time [days]

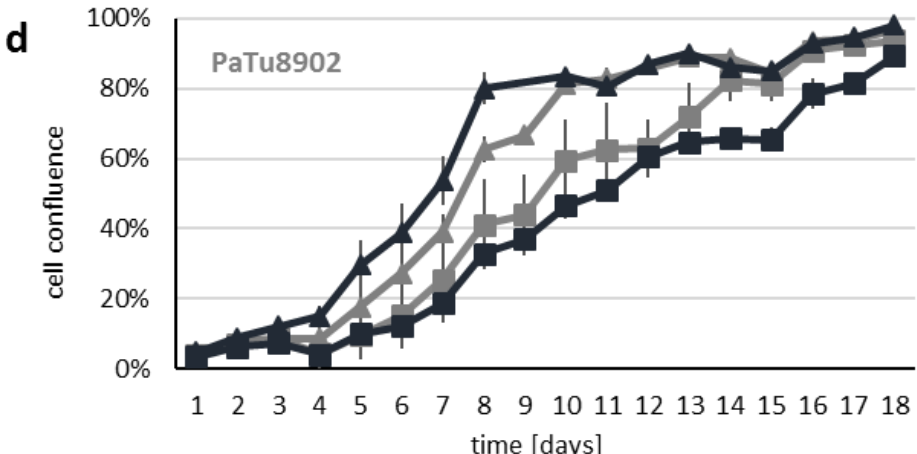

- DMSO

$\longrightarrow \mathrm{MK} 2 \mathrm{Inh}$

$=\mathrm{DMSO}+\mathrm{Gem}$

$\longrightarrow \mathrm{MK} 2 \mathrm{Inh}+\mathrm{Gem}$

time [days]

Figure 4.3 MK2 is a determinant of cell survival after gemcitabine-induced DNA damage.

(a) BxPC-3, (b) MIA PaCa-2, (c) PANC-1 and (d) PaTu8902 cells were seeded and on day one left untreated or treated with $100 \mathrm{nM}$ gemcitabine and DMSO or MK2 inhibitor for $24 \mathrm{~h}$. Then, the treatment was washed out and new medium was added. Cell confluence was measured every day by bright field microscopy followed by digital image analysis. Data points represent average confluence with error bars representing SD of $n=3$. 


\subsubsection{Chk1 is a mediator of DNA damage signaling after gemcitabine treatment in pancreatic cancer cells and an antagonist of MK2}

To test whether MK2 activity is necessary for the effect of Chk1 inhibition as it is reported for U2OS cells (Kopper et al. 2013), we treated BxPC-3, MIA PaCa-2 and PaTu8902 cells with gemcitabine and either MK2 inhibitor, Chk1 inhibitor or both and analyzed $\mathrm{yH} 2 \mathrm{AX}$ levels via immunoblot (Fig 4.4). Consistent with the results previously obtained in human osteosarcoma cells, Chk1 inhibition increased $\mathrm{yH} 2 \mathrm{AX}$ levels after gemcitabine treatment in all pancreatic cancer cells and the extend correlated with their described gemcitabine sensitivity. However, this effect could be rescued by simultaneous MK2 inhibition. Thus, MK2 and Chk1 are crucial antagonistic players in the DDR after gemcitabine treatment in pancreatic cancer cells, too.

a

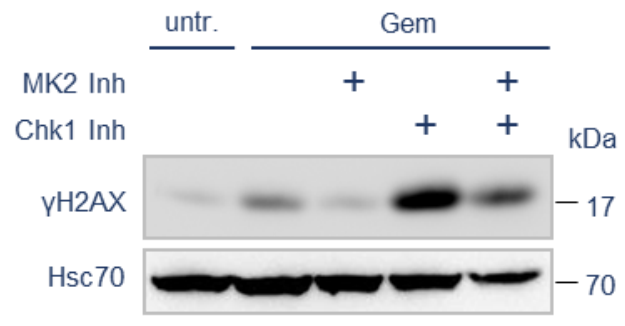

PaTu 8902

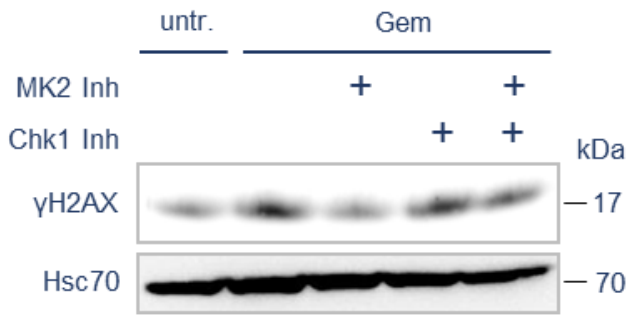

MIA PaCa-2

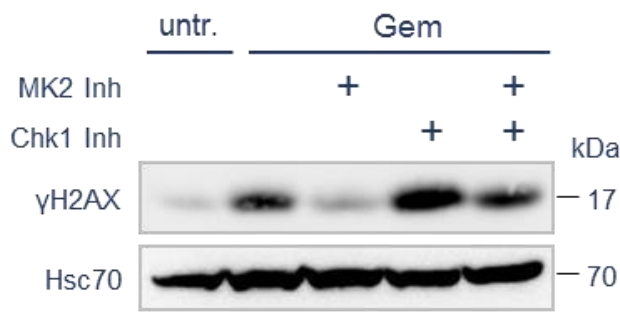

Figure 4.4 MK2 and Chk1 determine H2AX phosphorylation after gemcitabine treatment in pancreatic cancer cells.

(a) BxPC-3, (b) MIA PaCa-2, (c) PaTu8902 cells were treated with $100 \mathrm{nM}$ gemcitabine and DMSO, MK2 inhibitor, Chk1 inhibitor or both for 24 h. H2AX phosphorylation was analyzed by immunoblot. Conducted by Dr. Frederik Köpper

\subsubsection{Chk1 does not influence cancer cell proliferation after gemcitabine treatment in most pancreatic cancer cell lines}

In order to assess the impact of Chk1 inhibition on proliferation after gemcitabine treatment in pancreatic cancer cells, we performed a cell proliferation assay. Unexpectedly, Chk1 inhibition did not sensitize three of four pancreatic cancer cell lines to gemcitabine treatment, but rather mediated resistance towards this chemotherapeutic (Fig 4.5). This is remarkable as Chk1 inhibition as well as its depletion both strongly enhanced $\mathrm{\gamma H} 2 \mathrm{AX}$ levels in all gemcitabine-treated cells (Fig. 4.4, 4.8), and it is obviously in contrast to a widely accepted assumption that the more DNA damage a cell suffers, the more likely it undergoes 
apoptosis as a consequence. Furthermore, our results demonstrate that in the case where Chk1 inhibition sensitizes pancreatic cancer cells towards gemcitabine treatment, which is in MIA PaCa-2 cells, this is highly dependent on MK2 activity, whereas all other cell lines do not show additional effects for inhibition of both, MK2 and Chk1.
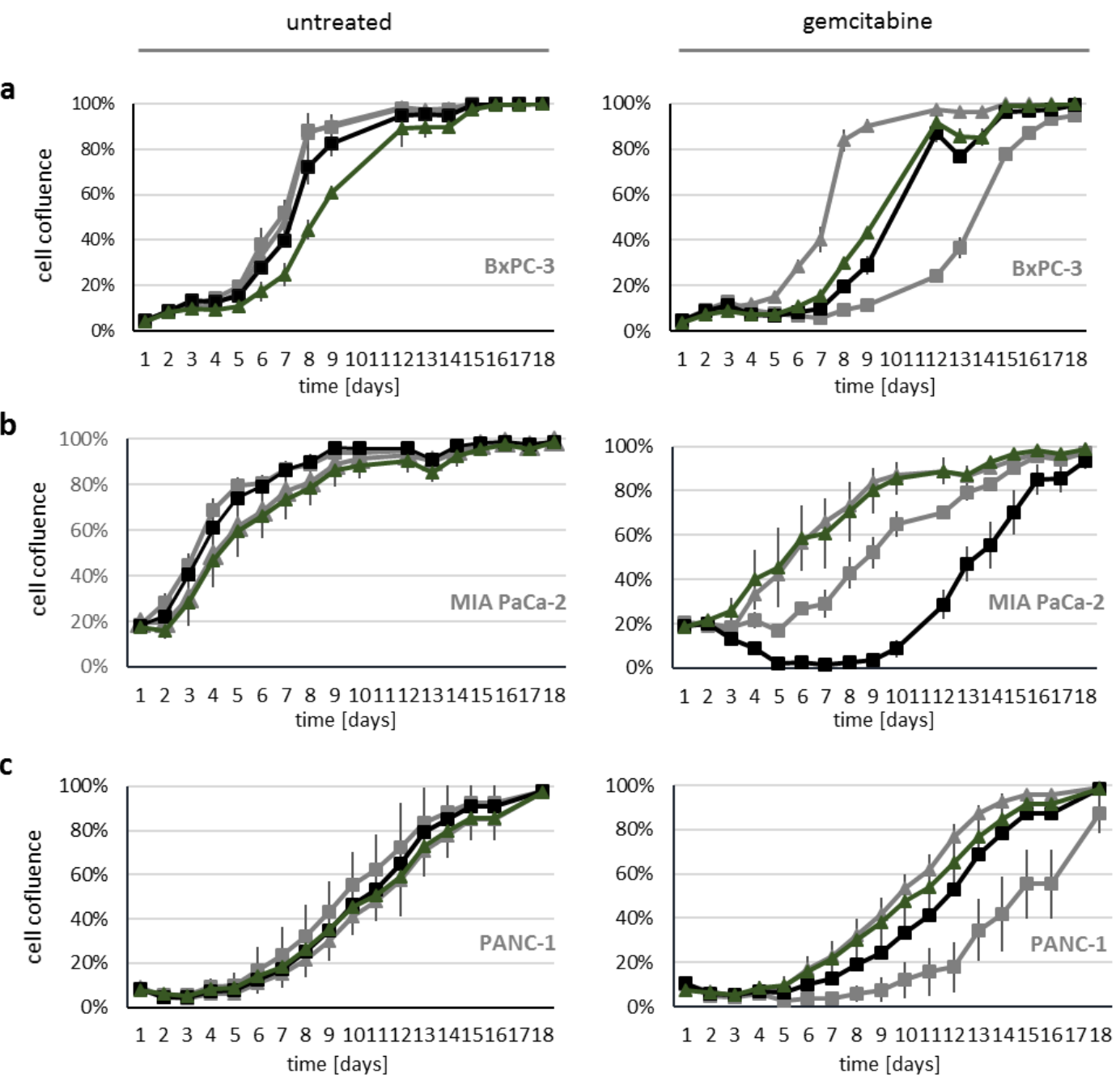

d
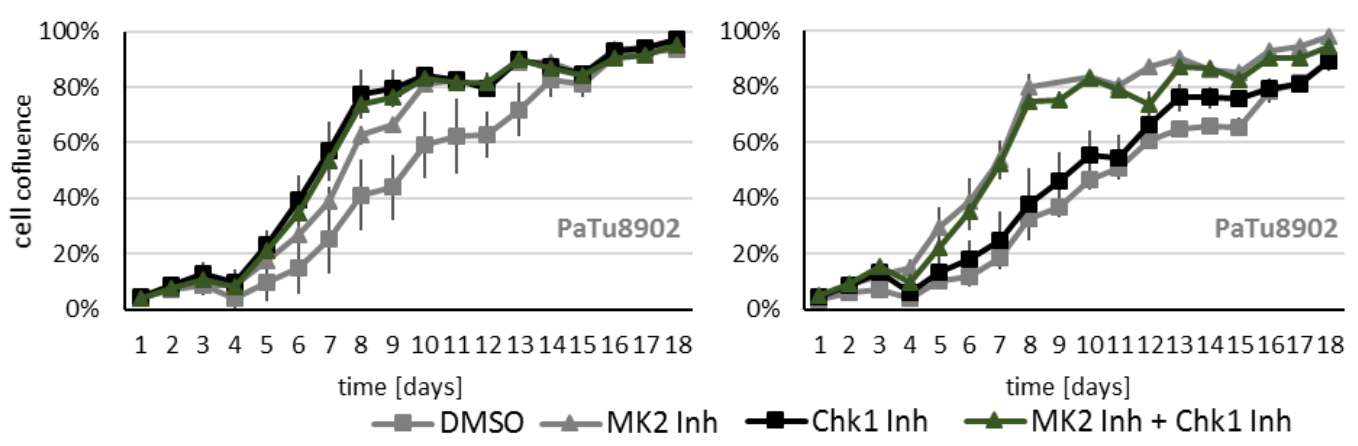

Figure 4.5 Inhibition of MK2 and Chk1 in gemcitabine-treated pancreatic cancer cells.

(a) BxPC-3, (b) MIA PaCa-2, (c) PANC-1 and (d) PaTu8902 cells were seeded and on day one left untreated (left panel) or treated with 100nM gemcitabine (right panel) and DMSO, MK2 inhibitor, Chk1 inhibitor or both for $24 \mathrm{~h}$. Then, the treatment was washed out and fresh culture medium was added. Cell confluence was measured every day by bright field microscopy followed by digital image analysis. Data points represent average confluence with error bars representing $S D$ of $n=3$. 
These results underline that the cell's facilities to cope with induced DNA damage might be even more decisive for the cellular outcome than the extent of damage itself.

In conclusion, these results suggest that the kinase MK2 is a potent mediator of gemcitabine sensitivity in pancreatic cancer cells. Whereas MK2 activity is needed to carry out the chemotherapeutic effects of gemcitabine, Chk1 activity seems to mediate the effect of gemcitabine consistently only in terms of DNA damage signaling and is in that context antagonized by simultaneous MK2 inhibition. In the subset of pancreatic cancer cell lines where Chk1 inhibitors act as chemosensitizers this effect completely relies on MK2.

\subsection{Optimization of systematic high-content cell screening in gemcitabine-treated pancreatic cancer cells}

While gemcitabine is the predominating chemotherapeutic drug in pancreatic adenocarcinoma, the survival after diagnosis of this type of cancer has not improved substantially over the years. Investigating Chk1 and MK2 in the gemcitabine response, we could show that the cellular fate following this treatment highly relies on DNA damage mediators. To shed light on novel factors which influence the cellular response to gemcitabine treatment, we performed a high-content screen using RNA interference (RNAi) to deplete pancreatic cancer cells of single proteins. After that, we treated the cells with gemcitabine and used the immunofluorescence-based quantification of $\mathrm{YH} 2 \mathrm{AX}$ accumulation as global readout for DNA damage signaling. We aimed to identify so far unknown mediators of the gemcitabine response in pancreatic cancer cells. The screening conditions were optimized as follows.

\subsection{1 siRNA-mediated knockdown efficiency and cell growth morphology}

The efficiency of RNAi does not only depend on sequence and quality of the siRNA construct, but strongly varies between cell types and reagents. As RNAi is the method on which the high-content screen for DNA damage mediators was based, knockdown conditions needed to be optimized in a way that at least established siRNA constructs reliably led to the depletion of the respective target protein. Therefore, we first tested the siRNA-mediated knockdown with standardly used siRNAs and transfection reagents. Of all reagents, LF 2000 achieved the best cell survival and knock down efficiency after transfection (data not shown). To quantify knockdown efficiency, all were transfected with siRNA 
a

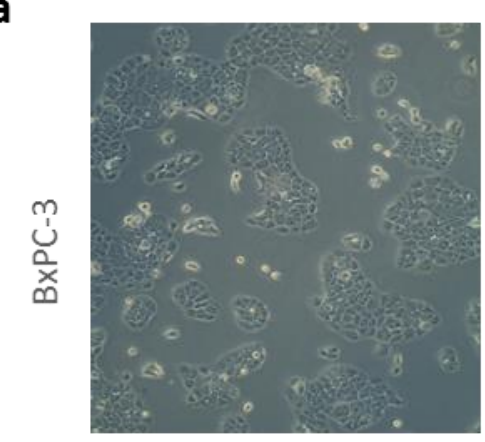

b

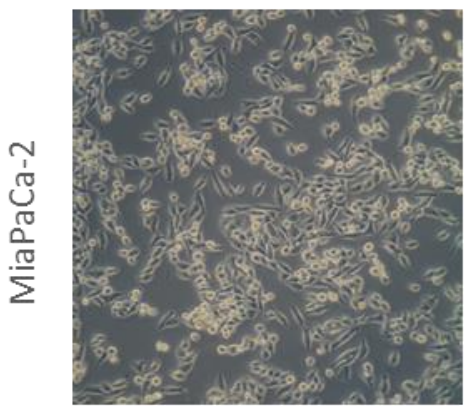

C

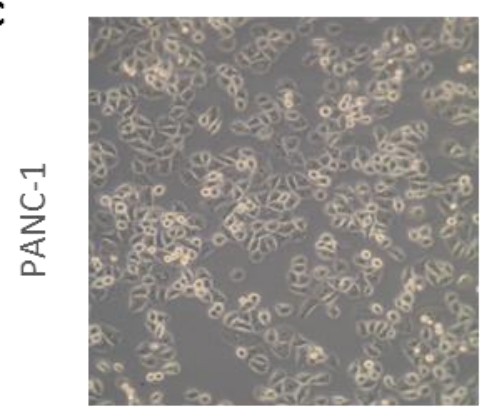

d

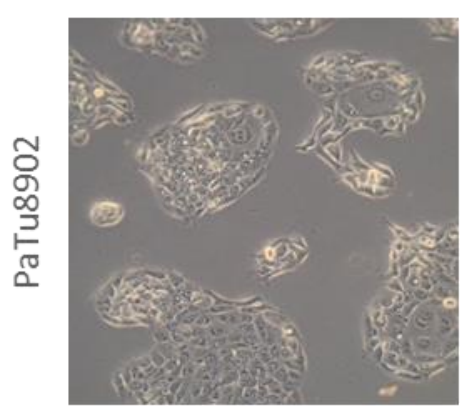

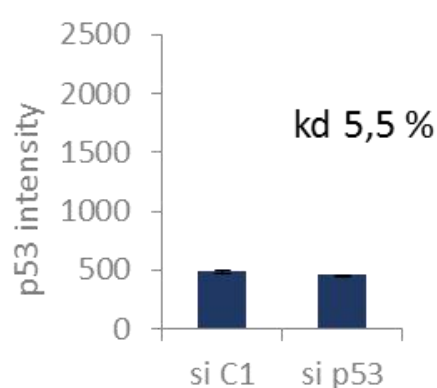
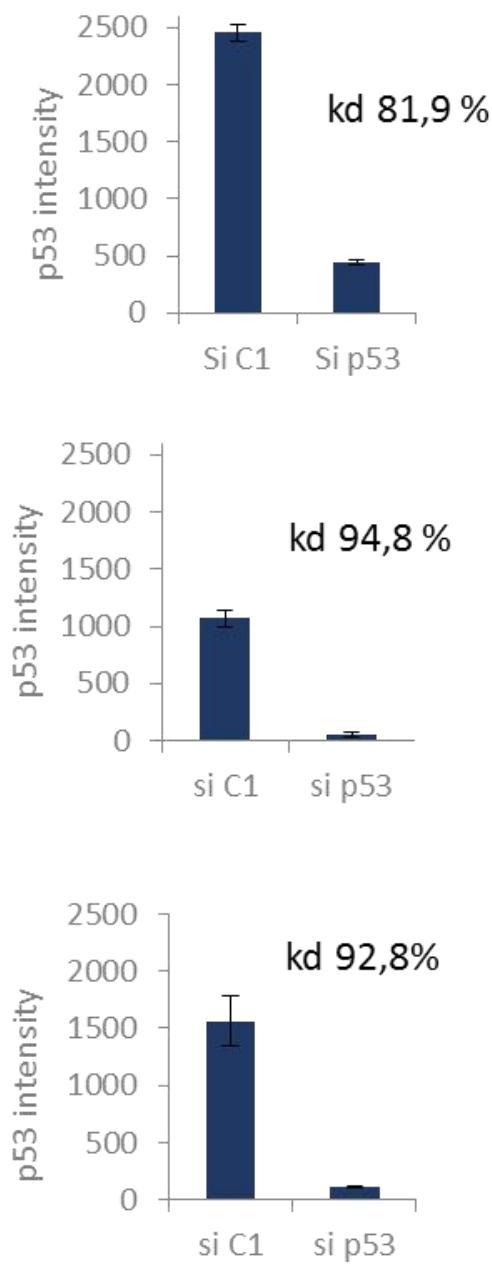

Figure 4.6 siRNAmediated knockdown efficiency and cell growth morphology of pancreatic cancer cells.

(a) BxPC-3, (b) MIA PaCa-2, (c) PANC-1 and (d) PaTu8902 were transfected with siRNA targeting p53 and fixation and staining for immunofluorescence was performed $48 \mathrm{~h}$ after transfection. p53 levels were determined using quantitative immunofluorescence and total p53 levels were used as criteria for the RNAi potential of the cell line. Light microscopic pictures of controltransfected cells were taken to assess cell growth morphology.

to p53 and absolute p53 levels were determined using quantitative immunofluorescence analysis (Fig. 4.6, right column). Although BxPC-3 cells have the lowest absolute p53 levels, knockdown of this protein was not successful. This excluded the cell line for the screening procedure. All other cell lines displayed good knockdown efficiencies.

Another aspect in a cell line's suitability for quantitative immunofluorescence is the accessibility of the region of interest $(\mathrm{ROI})$. As we defined the nucleus as $\mathrm{ROI}$, it is essential that the image processing software can separate neighboring cell nuclei. This is not possible with cells growing in multiple cell layers. We therefore took bright light microscopy images 
of the different cell lines at different levels of confluence (Fig. 4.6, left column), showing that MIA PaCa-2 and PANC-1 cells tend to detach from the dish surface and MIA PaCa-2 and PaTu8902 cells grow in multiple cell layers. Both effects resulted in a substantial cell population not available for quantitative immunofluorescence analysis.

Thus, BxPC-3 could not be used for efficient transfection, while all other cell lines had restrictions which led to a decrease in ROIs suitable for $\mathrm{YH} 2 \mathrm{AX}$ quantification.

\subsubsection{Treatment and readouts}

Gemcitabine-induced H2AX phosphorylation occurs in a dose- and time-dependent manner. Gemcitabine dose and treatment time were optimized to be high enough to distinguish $\mathrm{yH} 2 \mathrm{AX}$ levels in treated and in untreated cells but not to induce maximum $\mathrm{YH} 2 \mathrm{AX}$ which would overlay the effects of a knockdown. In the screen, we wanted to be able to examine the influence of knockdowns on $\mathrm{yH} 2 \mathrm{AX}$ at a time point when other mediators of the DDR are still activated and later onset processes as DNA repair and apoptosis do not predominate yet.

As expected, $\mathrm{yH} 2 \mathrm{AX}$ levels increased with gemcitabine concentrations (data not shown). At intermediate concentrations of gemcitabine (200 nM), increased H2AX phosphorylation was evident $24 \mathrm{~h}$ after the beginning of treatment and further intensified after that.

In contrast, Chk1 phosphorylation, considered earlier in the DDR than H2AX phosphorylation, started to increase already after $12 \mathrm{~h}$ of gemcitabine treatment and peaked after $24 \mathrm{~h}$ with markedly decreasing levels after that (Fig. 4.7). The activation of Chk1 went along with an increase in total Chk1 protein levels, which remained elevated when Chk1 phosphorylation already decreased. This already marks an adaption process of the cell to cope with enhanced replicative stress and could have influence on the readout. To further exclude $\mathrm{YH} 2 \mathrm{AX}$ induction being a secondary effect of apoptosis, PARP cleavage was determined. In PANC-1 cells, PARP cleavage was not yet detectable after $24 \mathrm{~h}$ of treatment, but clearly present after $48 \mathrm{~h}$ (Fig. 4.7).

Thus, our results demonstrate that, for our purpose, treatment of cells with $300 \mathrm{nM}$ gemcitabine for $20 \mathrm{~h}$ to $24 \mathrm{~h}$ is ideal. We therefore chose these conditions for screening.

As already detailed in section 1.2.2, gemcitabine mainly acts during the process of DNA replication. Mediators of the gemcitabine response that specifically act during that process are of interest for two reasons: First, if the influence of a knockdown on $y \mathrm{H} 2 \mathrm{AX}$ is emphasized during S-phase, it is to assume that the knocked down protein is part of a DDR 


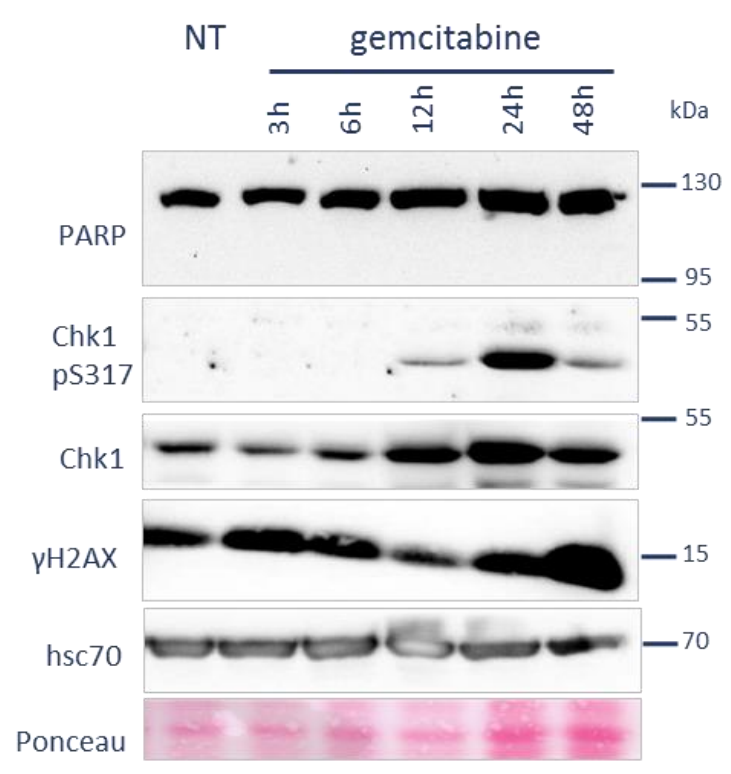

MIA PaCa-2

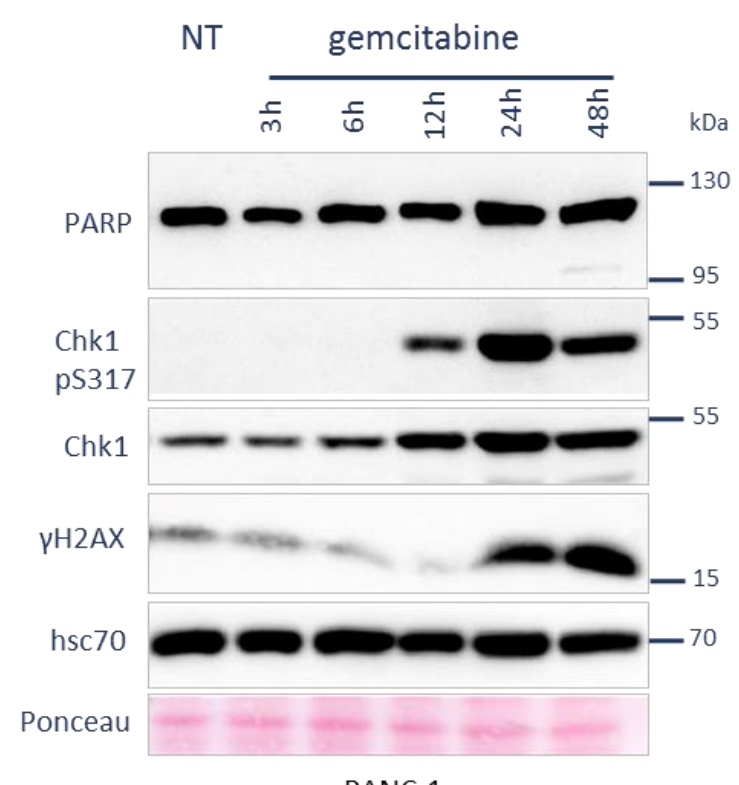

PANC-1

Figure 4.7 Central indicators of the DNA damage response and apoptosis are activated in a timedependent manner.

(a) MIA PaCa-2 and (b) PANC-1 cells were treated with $300 \mathrm{nM}$ gemcitabine for the indicated period of time and cell lysates were analyzed by immunoblotting.

specific for gemcitabine. Second, if the DDR was activated mainly during S-phase, this would target rapidly proliferating cells as found in cancer.

We thus aimed to identify those cells in our screen that have entered S-phase at the time of gemcitabine treatment. Replicating cells incorporate the nucleoside analog ethinyldeoxyuridine (EdU) when incubated with it. EdU can be coupled to a fluorescent dye by a chemical reaction and quantified using immunofluorescence. This creates additional readouts to the phosphorylation of $\mathrm{H} 2 \mathrm{AX}$ in the screen: Overall EdU incorporation is a measure for the influence of a knockdown on DNA replication and was used as minor readout. EdU incorporation can further be used as gate to identify cells which actively replicate their DNA. In addition to the overall accumulation of $\mathrm{yH} 2 \mathrm{AX}$, we gated cells for EdU incorporation and quantified the accumulation of $\mathrm{YH} 2 \mathrm{AX}$ in EdU-positive cells, too.

Our data show that incorporation of EdU into the DNA is almost completely blocked after gemcitabine treatment, probably due to a complete stalling of DNA replication caused by gemcitabine. The labeling of replicating DNA therefore needs to take place before adding gemcitabine to the cells. Optimization experiments revealed that the EdU labeling is useful as a readout if it takes place $2 \mathrm{~h}$ prior to gemcitabine treatment (data not shown). At that point replicating cells have incorporated EdU to a measurable extend and are clearly distinguishable from non-replicating cells. Longer EdU labeling times would lead to more 
EdU-positive cells, but would exceed the objective of the procedure which is to identify replicating cells at the time of gemcitabine administration.

\subsubsection{Variability of the readout $\mathrm{YH} 2 \mathrm{AX}$ after transfection with control siRNA}

As mentioned above, gemcitabine-induced $\mathrm{yH} 2 \mathrm{AX}$ should vary upon depletion of DNA damage transmitters. The influence on $\mathrm{yH} 2 \mathrm{AX}$ accumulation was investigated for the following control knockdowns:

Ring finger protein 8 (RNF8) is a known mediator of the DDR. It mediates the ubiquitination at Lys63 of the histone variants $\mathrm{H} 2 \mathrm{~A}$ and $\mathrm{H} 2 \mathrm{AX}$, which leads to the amplification of DNA damage signaling on the one hand and facilitates the recruitment of DNA repair factors on the other hand (Mailand et al. 2007). We previously ascribed a role for MK2 in the DDR, and that its depletion leads to reduced H2AX phosphorylation. ATR and Chk1 are wellcharacterized mediators of the response to replicative stress.

The knockdown of RNF8 reduced $\mathrm{yH} 2 \mathrm{AX}$ levels in gemcitabine-treated MIA PaCa-2 and PANC-1 cells, and knockdown of Chk1 leads to an extensive induction of $\mathrm{yH} 2 \mathrm{AX}$ in both treated and untreated cells. MK2 knockdown did not reliably alter $\mathrm{yH} 2 \mathrm{AX}$ levels in MIA PaCa-2 cells, but reduced $\mathrm{yH} 2 \mathrm{AX}$ in gemcitabine-treated PANC1 cells. Interestingly, depletion of ATR did not induce H2AX phosphorylation in MIA PaCa-2 and PANC-1 cells,
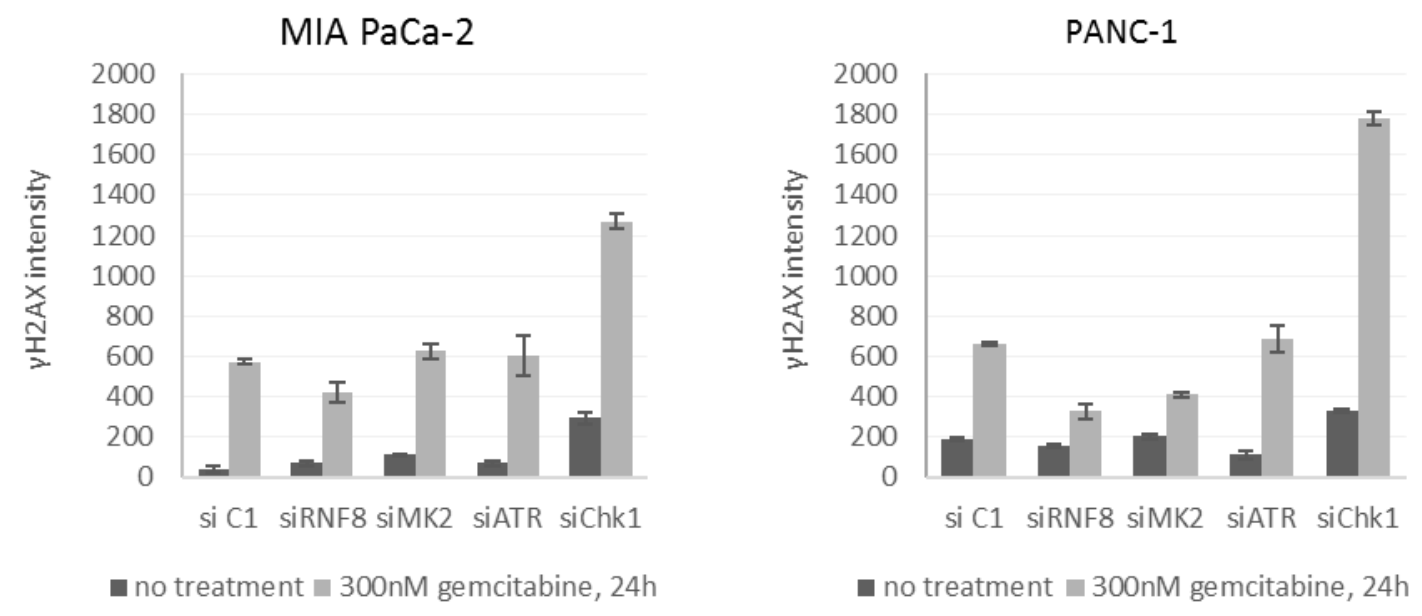

Figure 4.8 yH2AX level in MIA PaCa-2 and PANC-1 cells are modulated by positive and negative controls within the library.

Cells were transfected with siRNA against the indicated targets and treated under screening conditions $48 \mathrm{~h}$ after transfection. Cells were fixed and stained for immunofluorescence and $\mathrm{yH} 2 \mathrm{AX}$ levels were quantified and corrected for background fluorescence. 
although its knockdown is a well-established positive control in DNA damage screens using U2OS cells in our lab (Fig. 4.8).

\subsubsection{Conclusions}

Overviewing all results of the optimization experiments, we chose PANC-1 to be most suitable for high-content screening. BxPC-3 cells are not accessible for siRNA-mediated knockdown, PaTu8902 cells are highly gemcitabine-resistant with hardly any variation in endogenous $\mathrm{YH} 2 \mathrm{AX}$ level and MIA PaCa-2 cells tend to grow in multiple cell layers. Also, MIA PaCa-2 did not react to two of four control transfections in one plate.

The screening protocol was optimized to a time period of $2 \mathrm{~h}$ for the label of actively replicating cells followed by $22 \mathrm{~h}$ of $300 \mathrm{nM}$ gemcitabine treatment in PANC-1 cells.

\subsection{High-content screen for mediators of the DDR after gemcitabine treatment}

With the high-content screening approach, we aimed to identify mediators of the gemcitabine response in pancreatic cancer cells. These could either be further developed as biological markers which predict the patient's response to gemcitabine or they could be a potential target to overcome gemcitabine resistance. We chose a list of pre-selected genes involved in genomic integrity which we obtained via personal communication with the GENICA consortium (table 2.20).

According to the list, we customized a siRNA library of siRNAs directed against 551 target proteins with diverse molecular functions.

\subsubsection{Screening procedure}

The focused GENICA library comprised three different siRNA sequences per target gene in separate wells of a 96-well plate. siRNAs to MDM2, p53, MK2 and ATR served as positive controls within the library, and we manually added siRNAs to Chk1 and RNF8 as positive controls and the non-targeting SilencerSelect control siRNAs \#1 and \#2 as negative controls. Four wells of the plate containing siRNAs to the manually added controls remained untreated to validate efficient gemcitabine treatment. 
The procedure of high-content siRNA screening itself is described in section 3.5.2. In short, PANC-1 cells were transfected with siRNAs and treated with $7.5 \mu \mathrm{M}$ EdU for $2 \mathrm{~h}$ to label cells currently replicating their DNA, followed by $300 \mathrm{nM}$ gemcitabine for $22 \mathrm{~h}$. Cells were then fixed and stained by immunofluorescence. While $\mathrm{yH} 2 \mathrm{AX}$ was detected by a murine primary antibody and stained with an Alexa-dye-coupled secondary antibody, the ethylene group of EdU was bound to an azide-coupled Alexa-dye using click chemistry. Quantitative fluorescence microscopy was used to determine the amount of EdU incorporation and $\mathrm{YH} 2 \mathrm{AX}$ accumulation.

Statistical analysis of changes in fluorescence intensities as described in section 3.2.5.3 was used to identify candidates. The main readout was the overall induction of H2AX phosphorylation and the H2AX phosphorylation in EdU-positive, i.e. actively replicating cells (Fig. 4.9 and 4.10). EdU-incorporation itself was only used as minor readout to assess the influence of a candidate on DNA replication (Fig. 7.1).

We assigned a robust z-score to every siRNA and ranked all genes according to the cumulative robust z-score of all three siRNAs (Fig. 4.9 for overall $\mathrm{yH} 2 \mathrm{AX}$ and Fig. 4.10 for $\mathrm{YH} 2 \mathrm{AX}$ in EdU-positive cells). If a knockdown caused a decrease in $\mathrm{YH} 2 \mathrm{AX}$, the assumed role of the corresponding protein is that it promotes the DDR or increases gemcitabineinduced DNA damage. Increased $\mathrm{yH} 2 \mathrm{AX}$ levels after knockdown suggest that the protein negatively regulates the above processes.

\subsubsection{Strategies to identify candidates}

We used two different approaches for the identification of candidate genes to determine the response to gemcitabine treatment:

First, we considered the cumulative robust z-score. A consistent and strong effect of all three siRNAs for a given gene would result in a high cumulative robust z-score and identify this gene as a candidate. In the case that for one gene the triplet of siRNAs showed small or even opposing effects, i.e. positive and negative influence on $\mathrm{yH} 2 \mathrm{AX}$, this would result in a low cumulative robust z-score, and the gene would not appear in the top of the list. Still, candidates which have diverging but not opposite effects on $\mathrm{yH} 2 \mathrm{AX}$ levels remain. Single siRNAs can be outliers due to plate-to-plate variations, because high variations in $\mathrm{YH} 2 \mathrm{AX}$ levels within one plate lead to a low robust z-score of each sample and the other way around. To compensate for that, we established a secondary screen and either confirmed or rejected the respective candidate. 


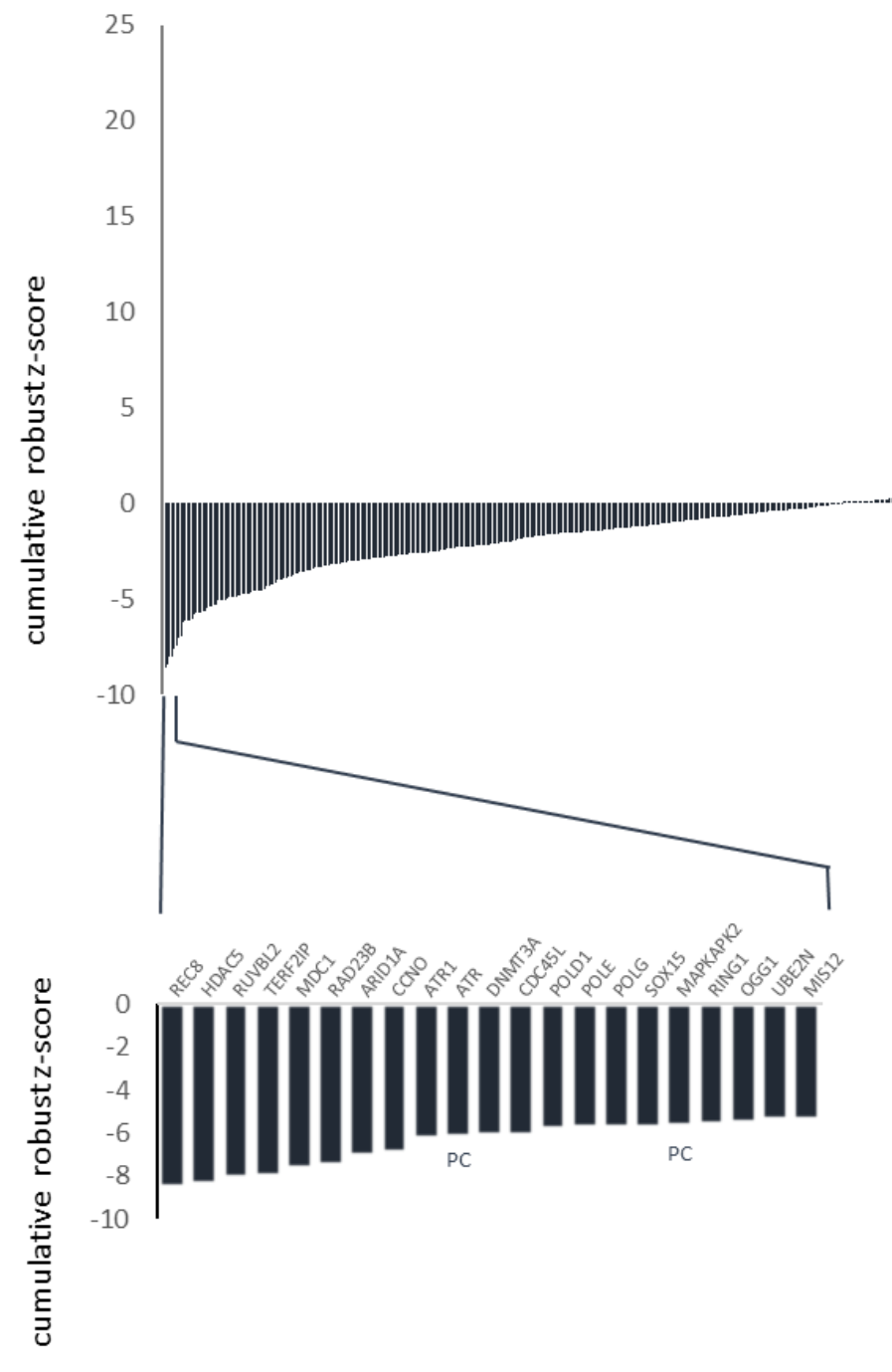

Figure 4.9 RNAi-based screening identifies mediators of H2AX phosphorylation gemcitabine treatment.

PANC-1 cells were transfected with siRNAs and exposed to $300 \mathrm{nM}$ gemcitabine for $22 \mathrm{~h}$. Cells were then fixed and stained for immunofluorescence analysis. All target genes were ranked according to the cumulative robust $z$-score of $\mathrm{yH} 2 \mathrm{AX}$ resulting from three different SiRNA sequences for every target gene. The 20 target genes with the highest and lowest cumulative robust $z$-scores are shown in magnification. $P C=$ positive control 


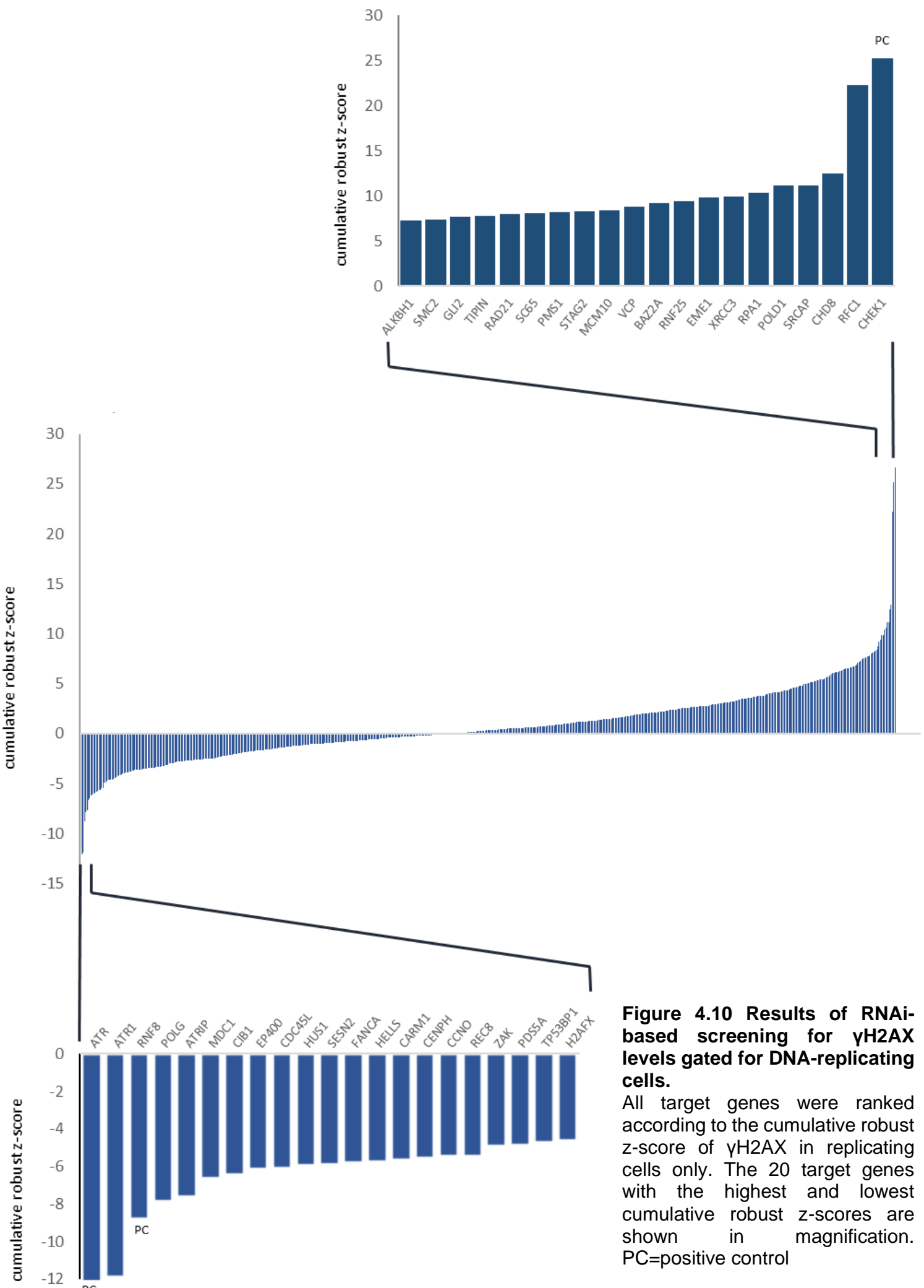


The 20 top genes whose knockdown caused increased or decreased H2AX phosphorylation are shown in figure 4.9 and 4.10. For the gene products with most influence on EdU incorporation, see supplementary figure 7.1.

Second, we assumed that, if at least two of three siRNAs led to a significant change in our readouts, this was due to a true effect. In this approach, we considered those genes candidates which achieved a robust $z$-score of $\geq 2$ or $\leq-2$ with at least two of the siRNAs (listed in table 7.1 for overall $\mathrm{yH} 2 \mathrm{AX}$ and in table 7.2 for $\mathrm{YH} 2 \mathrm{AX}$ in EdU-positive cells).

The second approach identified 27 candidates with significant changes in overall $y \mathrm{H} 2 \mathrm{AX}$ levels and 39 candidates with significant changes of $\mathrm{yH} 2 \mathrm{AX}$ levels in EdU-positive cells. Nine candidates were identified with both readouts, leading to a total number of 56 potential mediators of the gemcitabine response in pancreatic cancer cells using the second approach.

After we had identified 56 candidates as hits with the second approach, we were interested whether, among them, certain relevant processes are overrepresented. We therefore used the DAVID functional annotation tool to find biological processes that are associated with the hits (Huang da et al. 2009b). Not surprisingly, with DNA repair and DDR, two major processes were overrepresented in a pre-selected library. Nucleotide metabolism and cell cycle regulation are also described in the gemcitabine response. A process which has not yet been studied in detail is the modification and remodeling of DNA and chromatin in response to gemcitabine. A plethora of histone modifications as consequence of DNA damage is known, and inhibitors which target histone modification enzymes, for example histone deacetylases, are under investigation for their clinical use (see also 1.7.1). However, not much is known about their role in the response to gemcitabine and even less about the underlying mechanisms. Several chromatin remodeling complexes are regulators of the DDR, but none of them has been connected to the clinics or at least to the cellular fate after gemcitabine treatment. We were therefore especially interested in candidates associated with chromatin remodeling processes.

\subsubsection{Control-based validation of the screen confirms mediators of the DNA damage response to gemcitabine in different cell lines}

While a statistical approach was needed for hit identification in a high throughput procedure, most of the experiments to further investigate candidates would be based on controls. We therefore chose a control-based approach for a secondary screen in PANC-1 cells with 29 of the candidates identified in our primary screen. The candidates to be tested in a secondary screen were chosen because they either had shown a very strong effect on 
H2AX phosphorylation or appeared promising to us after literature research.

Three siRNAs for each candidate were collected on one 96-well plate in a random order together with triplicates of Chk1 siRNA and RNF8 siRNA as positive controls and triplicates of two different non-targeting siRNAs as negative controls. Thereafter, the procedure resembled that for screening, but while one plate was treated with gemcitabine, another plate was left untreated to investigate if the candidates already influenced our readout in untreated cells. Some of the previously identified candidates could be confirmed in the control-based experiment, while others showed no significant change in $\mathrm{yH} 2 \mathrm{AX}$ levels compared to controls (see Fig. 4.11 for overall $\mathrm{yH} 2 \mathrm{AX}$ levels and Fig. 7.2 and 7.3 for $\mathrm{\gamma H} 2 \mathrm{AX}$ levels in EdU-positive cells and for EdU intensities, respectively).

a

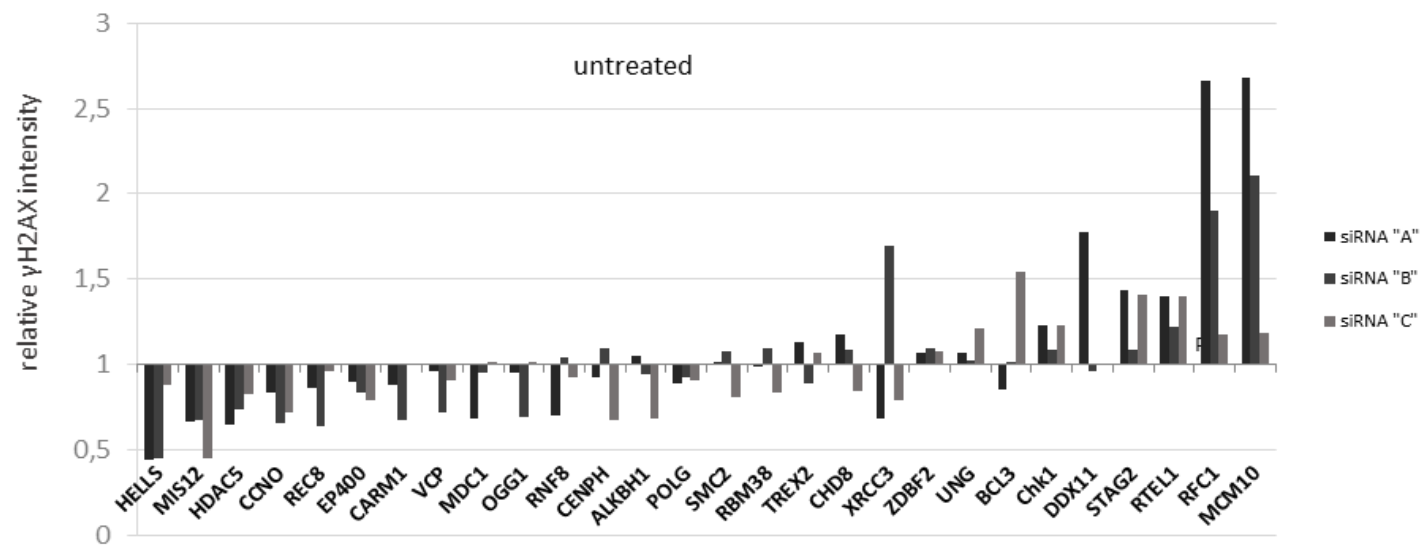

b

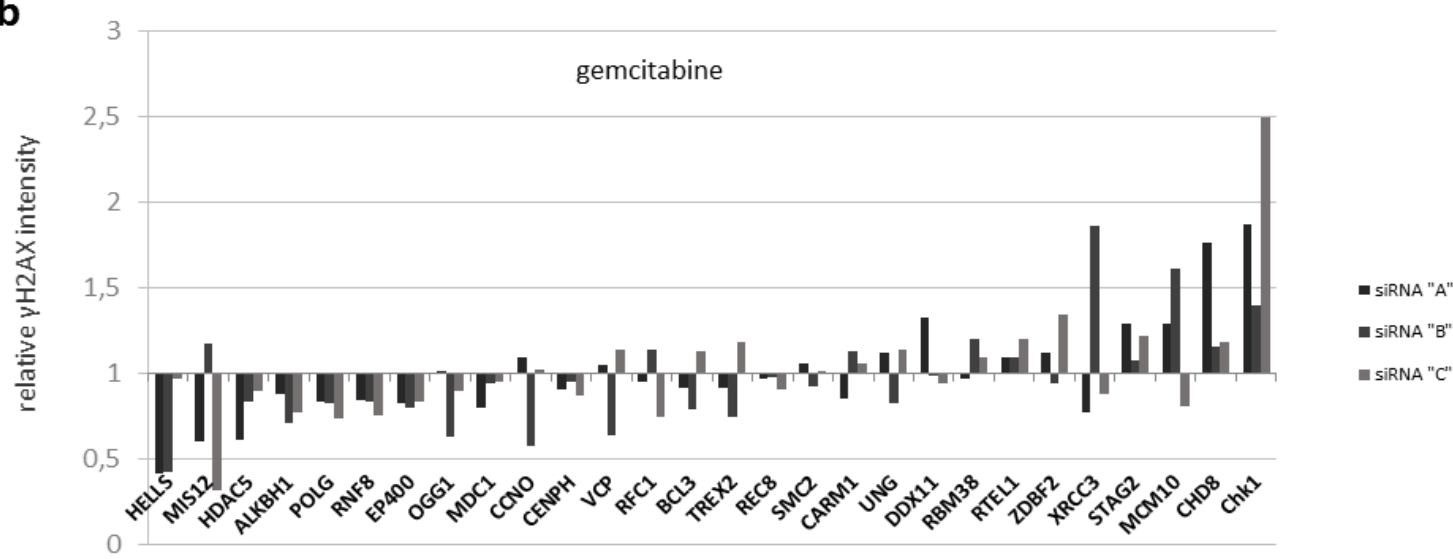

Figure 4.11 Control-based validation of main hits confirms various known and novel mediators of the DNA damage response.

PANC 1 cells were transfected with siRNAs as indicated and (a) left untreated or (b) exposed to $300 \mathrm{nM}$ gemcitabine for $22 \mathrm{~h}$. Cells were then fixed and stained for immunofluorescence analysis. All candidates were ranked according to cumulative relative changes in $\mathrm{yH} 2 \mathrm{AX}$ and were normalized to $\mathrm{yH} 2 \mathrm{AX}$ intensities of a control knockdown. Results from three different siRNA sequences for every target gene are shown. 
Based on the secondary screen, we conducted a second selection of candidates and aimed to investigate their ability to influence the DDR in other cells than PANC-1. Thereby, we would be able to exclude that our candidates executed cell line-specific effects. We used the previously introduced pancreatic cancer cell lines MIA PaCa-2 with intermediate and PaTu8902 with low sensitivity towards gemcitabine, both harboring p53 mutations. The MK2/Chk1-system was primarily investigated in U2OS cells that are highly gemcitabinesensitive and that are extensively used for studies of the DDR. Therefore, we knocked down our hits in this cell line, too. As an additional aspect, U2OS cells are p53 proficient and can therefore give insight in p53-dependent effects (see Fig. 7.4-6 for details).

Based on the secondary screen and the applicability to other cell lines, we selected four candidates, CHD8, HELLS, MCM10 and STAG2 for conformation experiments.

CHD8 (Chromodomain-helicase-DNA binding protein 8) has not yet been investigated in the context of the DDR. It is reported to be a regulator of p53 activity, cell cycle progression and Wnt signaling. Also, it might be needed to sustain clearly defined borders between euand heterochromatin (detailed in Section 1.8.3).

\subsubsection{Knockdown efficiency and confirmation experiments of the main candidates}

We conducted another quality control of the four hits that we selected for further investigation. First, we confirmed the knockdown efficiency of each siRNA using reverse transcription and qPCR to ensure that the influence on DNA damage signaling was not primarily attributable to off-target effects (Fig. 4.12). We then aimed to ascertain the effect on $\mathrm{yH} 2 \mathrm{AX}$ accumulation using immunoblot analysis. Unfortunately, it is not possible to isolate a pure population of replicating cells with this method. While the changes in $\mathrm{YH} 2 \mathrm{AX}$ levels were no longer detectable for HELLS knockdown, we could still identify a slight increase of $\mathrm{yH} 2 \mathrm{AX}$ levels in STAG2-depleted PANC-1 cells and a strong increase in MCM10- and CHD8-depleted cells (Fig. 4.13). Furthermore, we excluded changes in $\mathrm{YH} 2 \mathrm{AX}$ levels being an off-target effect in consequence of reduced levels of the DNA damage factor Rad51. This has been identified to be a frequent source of false positives in high throughput DNA damage screens (Fig. 7.7) (Adamson et al. 2012).

Based on all validation experiments and because it has, in contrast to other ATP-dependent chromatin remodeling factors, never been ascribed to DNA damage signaling before, we decided to further characterize the role of CHD8 in the DDR to gemcitabine. For a short discussion of the other candidates HELLS, MCM10 and STAG2 see section 4.2. 


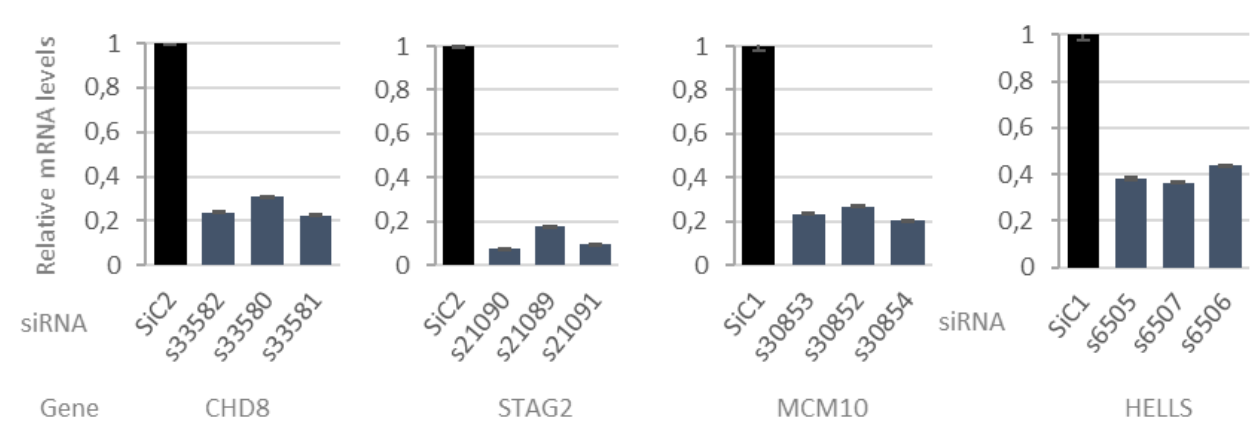

Figure 4.12 Knockdown efficiency of siRNAs against the main hits of the screen.

PANC-1 cells were transfected with the indicated siRNA and RNA was extracted $48 \mathrm{~h}$ after transfection. Relative mRNA levels of the indicated genes were quantified using qPCR and compared to $36 \mathrm{~B} 4$ levels. The same experiment was repeated with GAPDH as control and resulted in comparable knockdown efficiency (data not shown). Error bars represent mean $+/$ - SD of three technical replicates.
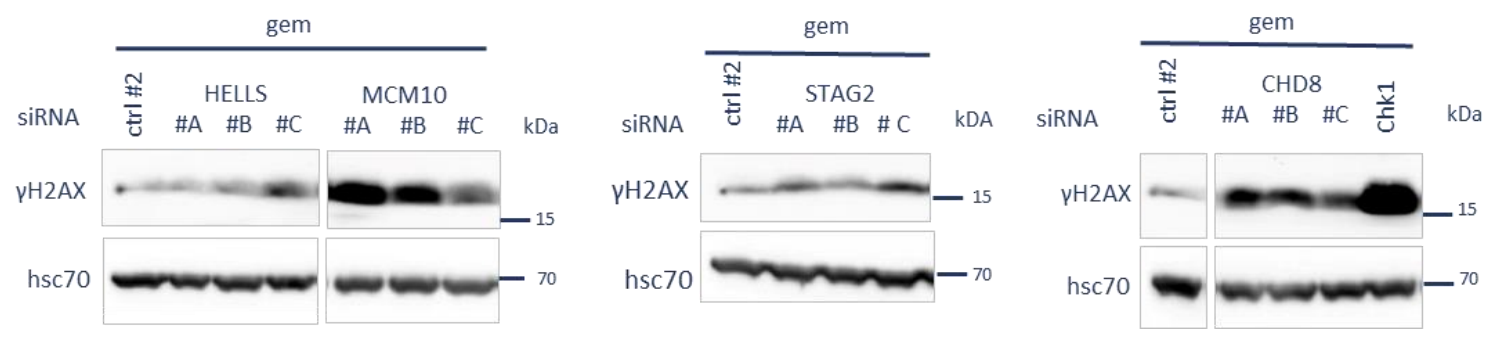

Figure 4.13 DNA damage modulators after depletion of candidate proteins.

According to screening conditions, PANC-1 cells were transfected with the indicated siRNAs and treated with $300 \mathrm{nM}$ gemcitabine for $22 \mathrm{~h}$. Cell lysates were prepared for immunoblot analysis. 


\subsection{CHD8 is a mediator of the DNA damage response}

\subsubsection{CHD8-depleted cells show enhanced DNA damage signaling after gemcitabine treatment}

After analysis and hit validation of the high-content siRNA screen, we found CHD8 to be the most promising candidate. We could repeatedly confirm that CHD8 knockdown increased H2AX phosphorylation in PANC-1 cells and now addressed the question whether CHD8 has influence on other main regulators of the DDR. To this end, we depleted PANC-1 cells of CHD8 and subjected them to gemcitabine treatment. First, we demonstrated that CHD8 levels are not influenced by gemcitabine-induced DNA damage. Further, we could validate

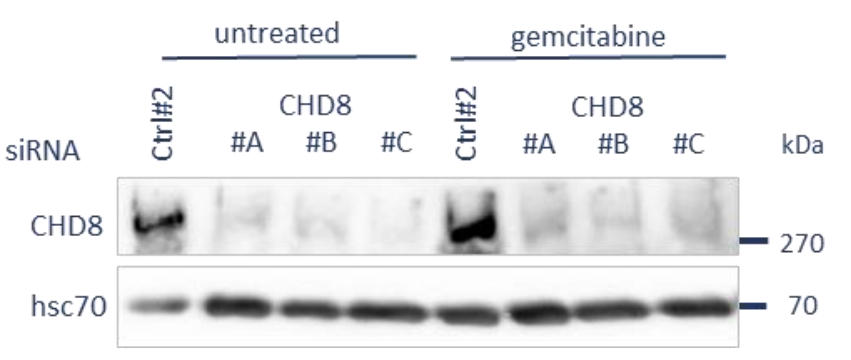

Figure 4.15 CHD8 does not accumulate after DNA damage induction following gemcitabine treatment.

PANC-1 cells were seeded, transfected as indicated and treated with $300 \mathrm{nM}$ gemcitabine for $24 \mathrm{~h}$ or left untreated. Protein lysates were obtained for immunoblot analysis.

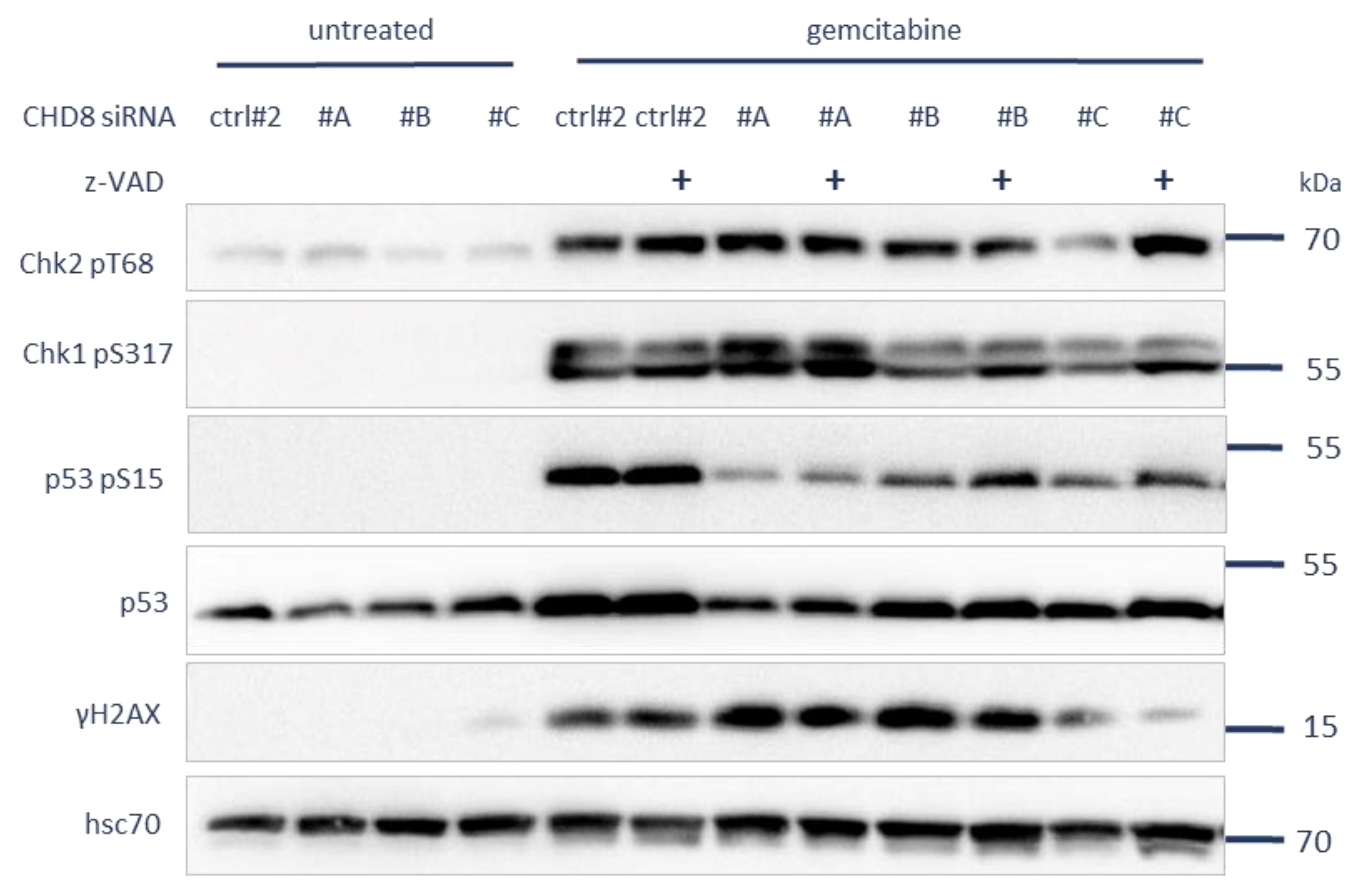

Figure 4.14 Enhanced DNA damage response in CHD8-depleted PANC-1 cells is not a secondary effect due to the induction of apoptosis.

PANC-1 cells were depleted of CHD8 as indicated and treated with $300 \mathrm{nM}$ gemcitabine for $22 \mathrm{~h}$. At the same time, $50 \mu \mathrm{M} z-V A D$ was added to inhibit the caspase cascade leading to apoptosis. Cells were harvested and protein lysates were prepared for immunoblot analysis. 
the knockdown of CHD8 on protein level (Fig. 4.14). Then, we knocked down CHD8 in PANC-1 cells using three different siRNAs and treated them with gemcitabine together with either DMSO or the caspase (cysteinyl-aspartate specific protease) inhibitor z-VAD to inhibit apoptosis (for the efficiency of z-VAD see Fig. 4.20). As shown in Fig. 4.15, gemcitabine treatment led to strong accumulation of pChk1 and pChk2, but depletion of CHD8 did not further influence pChk1 or pChk2 accumulation. Mutant p53 of PANC-1 cells is extensively phosphorylated upon gemcitabine treatment, but the phosphorylation is significantly reduced after CHD8 knockdown. Interestingly, mutant p53 total protein levels are reduced in PANC-1 cells by CHD8 depletion, in seeming contrast to the previously assigned role of CHD8 to suppress wild type p53 levels (Nishiyama et al. 2009). Importantly, we could exclude that the accumulation of $\mathrm{yH} 2 \mathrm{AX}$ induced by $\mathrm{CHD} 8$ is a secondary effect of apoptosis, as caspase inhibition did not rescue the increased DDR after CHD8 knockdown (Fig. 4.15). This led us to assume that CHD8 is not part of the MK2/Chk1 system, but limits DNA damage signaling in a different way. Taken together, these results suggest that CHD8 depletion increased the DDR upstream of the induction of apoptosis.

\subsubsection{CHD8 is a determinant of the DDR following UV irradiation}

UV irradiation causes damage in the DNA mainly through the formation of covalent bonds between nucleobases, which are CPDs and 6-4-PPs (see 1.2.1). Although the mechanism of damage is primarily different from that of gemcitabine as UV irradiation targets the DNA in every state and not only replicating DNA, the signaling pathways activated are similar. Both forms of DNA damage lead to stalled replication forks and the accumulation of SsDNA, which is then processed into DSBs (see 1.2.1 and 1.2.3).

Technically, the advantage of UV irradiation as damaging agent is that high spatiotemporal resolution of induced DNA damage is achievable. For instance, it is possible to irradiate only parts of the cells and the duration of damage induction is precisely restricted to the time of irradiation. Gemcitabine, in contrast, can be washed out, but an uncertain amount of the drug remains in the cell and will continue to damage DNA.

We therefore wanted to see if the results that we obtained in CHD8-depleted and gemcitabine-treated cells can be transferred to UV irradiation. We first determined the timedependent onset of UVC-induced DNA damage in PANC-1 cells and found that Chk1 phosphorylation culminates one hour after irradiation and subsequently starts decreasing, while H2AX phosphorylation is delayed and reaches its peak after four hours (Fig. $4.16 \mathrm{a}$ ). We have previously shown delayed but similar patterns after gemcitabine treatment (Fig. 4.7). 
We then depleted PANC-1 cells of CHD8 using three different siRNAs, subjected the cells to UV irradiation and determined the phosphorylation of the kinases Chk1 and Chk2 as well as the accumulation of $\mathrm{yH} 2 \mathrm{AX}$ using immunoblot. While an accumulation of phospho-Chk2 (pChk2) was not detectable after gemcitabine treatment (Fig. 4.15), this is distinctly the case after UV irradiation (Fig 4.16b). Likewise, pChk1 levels accumulate stronger after UV irradiation than after gemcitabine treatment. Importantly, $\mathrm{yH} 2 \mathrm{AX}$, as the primary readout of our high-content screening approach to identify CHD8, accumulates in CHD8 depleted cells following UV irradiation more strongly than in control cells. This is consistent with the effect seen with gemcitabine.

We therefore conclude that CHD8 is a regulator of the DDR to UV irradiation and CHD8 depletion amplifies the response in this context.

Figure 4.16 CHD8 depletion in PANC-1 cells causes increased DNA damage response following UV irradiation.

(a) Time course after UV irradiation in untransfected cells. PANC-1 cells were harvested at the indicated time points after irradiation with $20 \mathrm{~J} / \mathrm{m}^{2} \mathrm{UV}-\mathrm{C}$.

(b) Central indicators of increased DDR accumulate after CHD8 depletion in a timedependent manner. Cells were transfected as indicated and harvested at the indicated timepoints after irradiation with $20 \mathrm{~J} / \mathrm{m}^{2} \mathrm{UV}-\mathrm{C}$. a

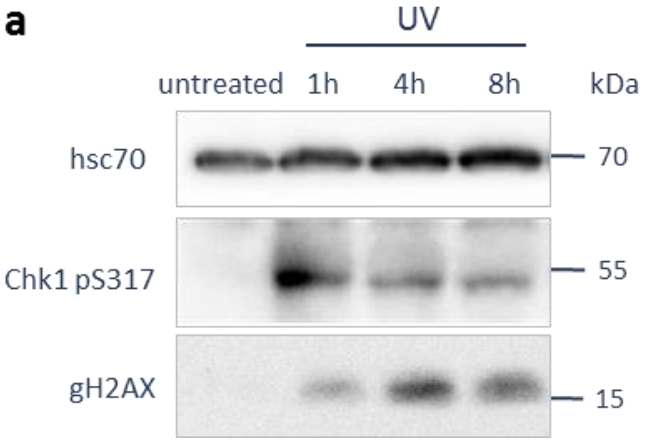

b

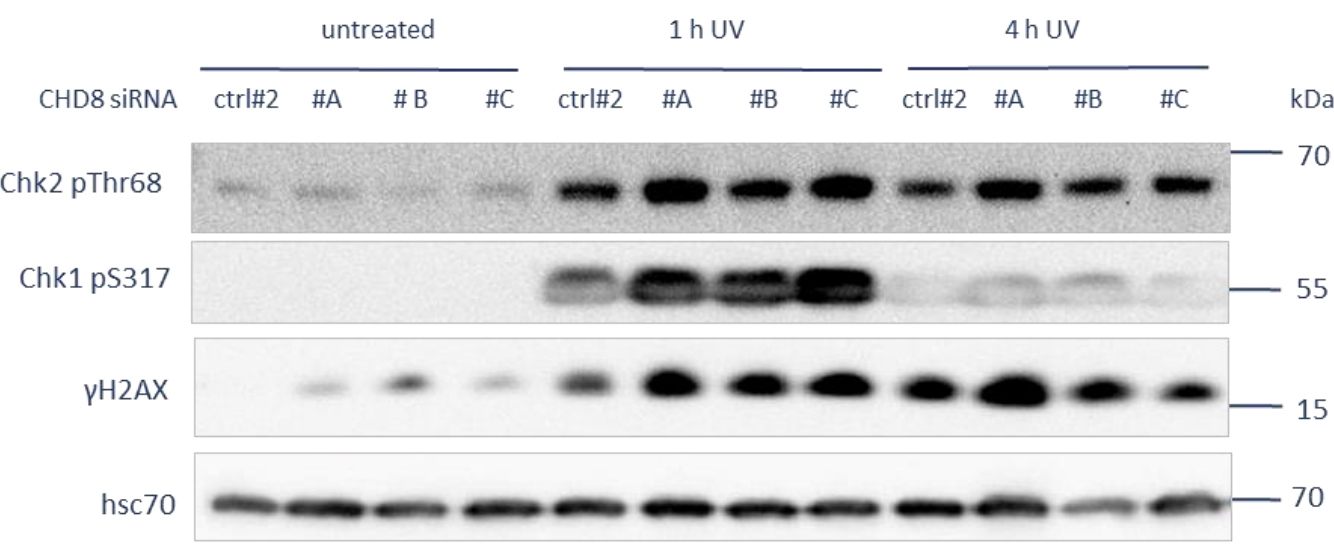

\subsubsection{Overexpression of CHD8 enhances the accumulation of $\mathrm{yH} 2 \mathrm{AX}$}

If the amount of CHD8 is a decisive factor in its role in the response to gemcitabine or UV, it is assumable that CHD8 exhibits a distinct function in a certain signaling pathway. While 
diminishing a cell's amount of CHD8 leads to increased DDR, its increase should lead to the opposite. To investigate this, we used an expression vector to overexpress HA-tagged CHD8 in PANC-1 cells and used a large human isoform of approximately $290 \mathrm{kDa}$ as well as a small murine isoform of $110 \mathrm{kDa}$. The small murine isoform led to higher expression of $\mathrm{CHD} 8$ than the large human isoform (Fig. 4.17.a). While $\mathrm{yH} 2 \mathrm{AX}$ level were not affected by $\mathrm{CHD} 8$ overexpression in the overall cell population (data not shown), $\mathrm{yH} 2 \mathrm{AX}$ levels were increased in those cells expressing CHD8 (Fig. 4.17.b) in the presence or absence of gemcitabine or UV irradiation.

a

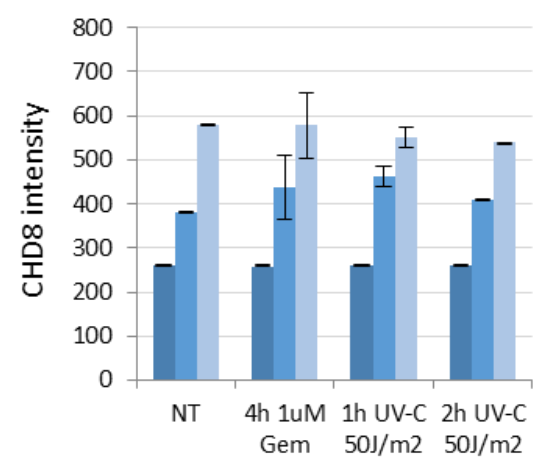

b

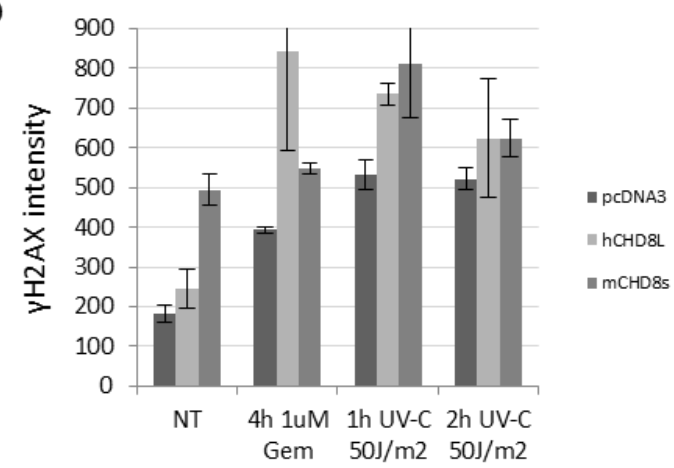

Figure 4.17 Overexpression of CHD8 does not show opposing effects to CHD8 depletion but causes increased DNA damage response.

PANC-1 cells were transfected with CHD8 expression vectors, then treated with either gemcitabine or irradiated with UV-C. Cells were fixed and stained for immunofluorescence analysis and levels of the HAtagged CHD8 protein (a) and $\mathrm{YH} 2 \mathrm{AX}$ levels (b) were quantified.

\subsubsection{DNA damage signaling after DNA double-strand induction is increased in CHD8-depleted cells}

We next addressed the question whether CHD8 specifically acts in the response to DNA damaging agents that cause ssDNA accumulation or whether $\mathrm{CHD} 8$ has a broader function in the DDR. DSBs activate a different, though crosstalking pathway than the one induced by sSDNA. DSBs also occur after the processing of stalled replication forks induced by gemcitabine. We therefore investigated the role of CHD8 in response to DSBs alone, like they are induced by radiotherapy in the clinics. For this purpose, we used the drug neocarzinostatin (NCS) which induces DSBs and was developed to mimic ionizing $\mathrm{y}^{-}$ radiation (1.2.5). CHD8 depletion led to increased H2AX phosphorylation after NCS treatment, as quantified using immunofluorescence (Fig. 4.18). 


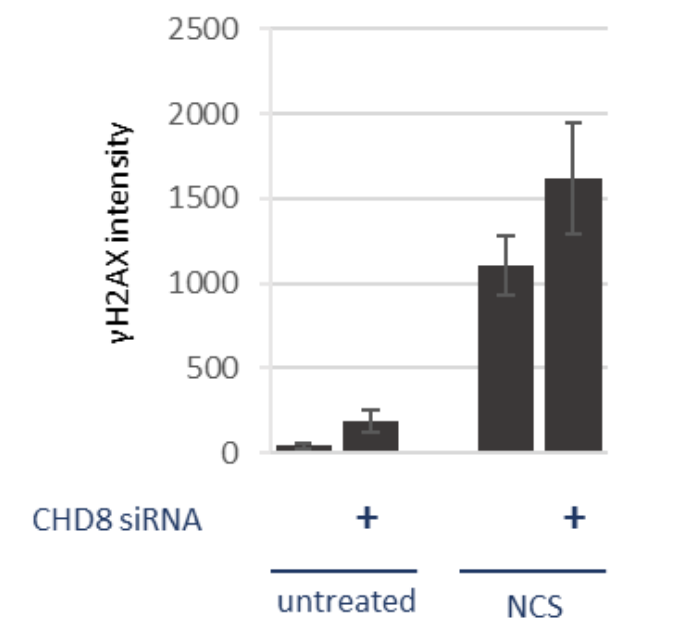

Figure 4.18 CHD8 depletion leads to increased H2AX phosphorylation after induction of double strand breaks.

PANC-1 cells were depleted of CHD8 by siRNAmediated knockdown and exposed to $100 \mathrm{ng} / \mathrm{ml}$ neocarzinostatin for $2 \mathrm{~h}$. Cells were then fixed and stained for immunofluorescence and $\mathrm{yH} 2 \mathrm{AX}$ levels were quantified.

CHD8 is thus not part of a signaling cascade clearly restricted to one kind of DNA damage, but attenuates the DDR to treatments which primarily induce ssDNA as well as to treatments causing DSBs.

\subsubsection{CHD8 depletion increases DNA damage signaling in the p53 wild type osteosarcoma-derived cell line U2OS}

The pancreatic cancer cell line PANC-1 was selected for the high-content siRNA screen because of its intermediate gemcitabine sensitivity, the variability of readouts and its suitability for follow-up experiments. Still, we were interested whether higher gemcitabine sensitivity as well as a wild type p53 status affect our findings. We used the osteosarcomaderived cell line U2OS for transfer experiments. U2OS are widely used for DNA damage experiments and thus our results would be comparable to other studies.

First, we addressed the question whether depletion of U2OS cells from CHD8 results in phosphorylation of Chk1, Chk2 and H2AX in response to gemcitabine treatment and UV irradiation in a similar manner as observed in PANC-1 cells. To obtain a higher temporal resolution and a sudden onset of DNA damage after gemcitabine treatment, we chose higher gemcitabine concentrations for a shorter period of time. Indeed, CHD8-depleted U2OS cells display activation of both, the Chk1 and the Chk2 pathway, following gemcitabine treatment and UV irradiation, in line with increased accumulation of $\mathrm{YH} 2 \mathrm{AX}$ (Fig. 4.19 a) We could also show an activation of MK2 and Chk1 as well as an accumulation of phosphorylated Cdc2/CDK1 downstream of Chk1 signaling (Fig $4.19 \mathrm{c}$ ). We then treated 
a

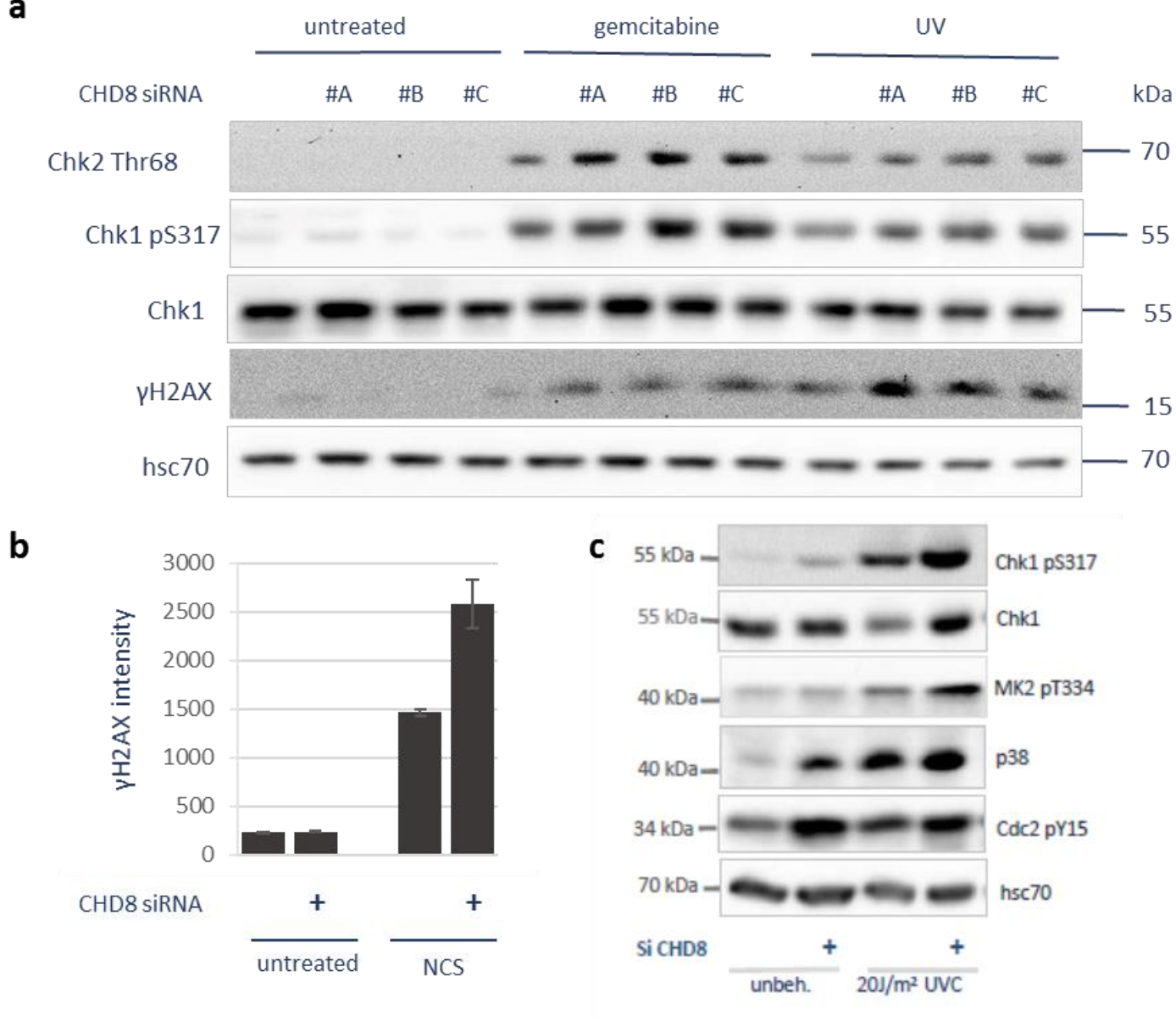

Figure 4.19 Depletion of CHD8 increases the DNA damage response in U2OS cells.

(a) Cells were depleted from CHD8 by siRNA-mediated knockdown and were harvested after $4 \mathrm{~h}$ of $500 \mathrm{nM}$ gemcitabine treatment or $1 \mathrm{~h}$ after irradiation with $20 \mathrm{~J} / \mathrm{m}^{2} \mathrm{UV}$-C. Cell lysates were analyzed by immunoblotting (b) As in figure 4.19, U2OS cells were depleted from CHD8 using RNAi and treated with $100 \mathrm{ng} / \mathrm{ml} \mathrm{NCS}$ for $2 \mathrm{~h}$, then fixed and stained for immunofluorescence analysis and $\mathrm{yH} 2 \mathrm{AX}$ levels were quantified (c) U2OS cells were depleted of CHD8 UV-irradiated as in (a), cell lysates where analyzed by immunoblotting.

CHD8-depleted U2OS cells with NCS and again used quantitative immunofluorescence to assess the induction of $\mathrm{yH} 2 \mathrm{AX}$ (Fig. $4.19 \mathrm{~b}$ ). Here, knockdown of CHD8 increased $\mathrm{yH} 2 \mathrm{AX}$ accumulation after DSB induction even more clearly than in PANC-1 cells.

In contrast to PANC-1, U2OS harbor wild type p53 which is phosphorylated and accumulated after DNA damage to subsequently induce cell cycle arrest and apoptosis. We aimed to exclude that the pronounced effects of CHD8 depletion on DNA damage signaling are due to the induction of apoptosis by wild type p53, too. Therefore, we knocked down CHD8 in U2OS cells and added either DMSO or the caspase inhibitor Z-VAD at the same time when the transfection mix was replaced by fresh medium. Then, we irradiated the cells with UV (Fig. 4.20). Remarkably, CHD8 knockdown induced apoptosis as displayed by the cleavage of PARP, and this was inhibited in z-VAD treated cells. However, z-VAD treatment did not influence Chk1 phopsphorylation, which was still increased in UV-irradiated cells af- 


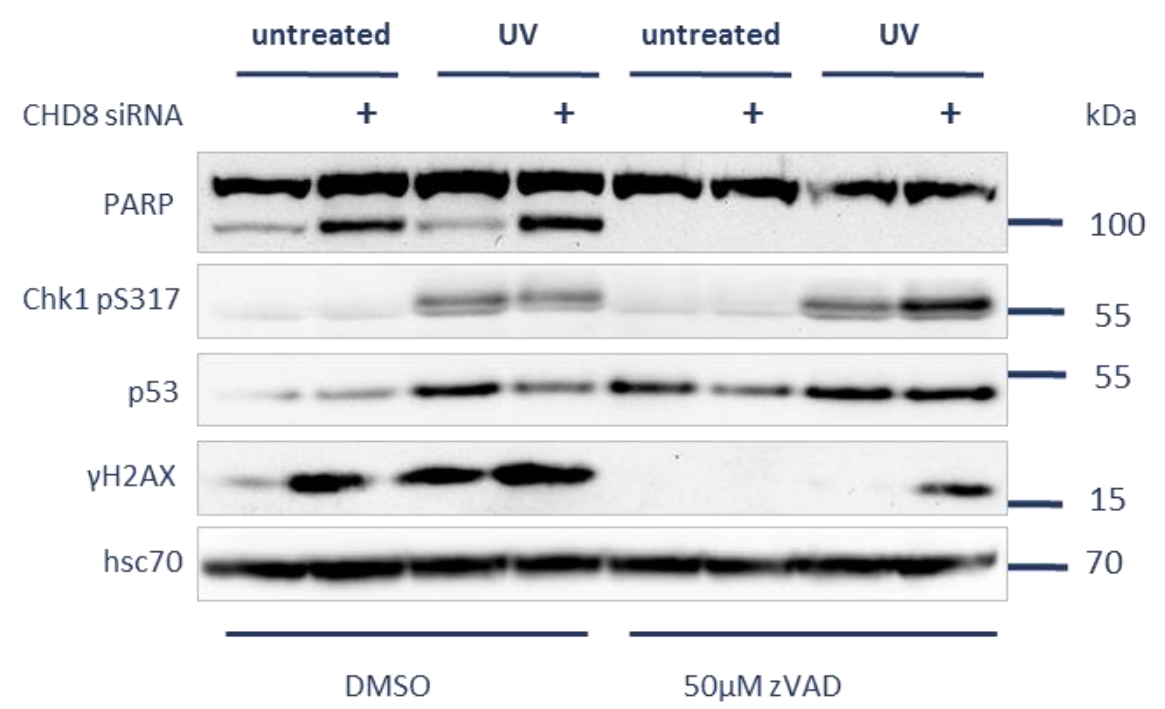

Figure 4.20 CHD8 depletion also causes apoptosis in the presence of p53.

U2OS cells were transfected with CHD8 siRNA as indicated. $24 \mathrm{~h}$ after transfection, the transfection mix was replaced by fresh culture medium containing DMSO or z-VAD. Cells were incubated for another $24 \mathrm{~h}$ and thereafter received irradiation with $20 \mathrm{~J} / \mathrm{m}^{2} \mathrm{UV}-\mathrm{C}$ and were harvested $1 \mathrm{~h}$ after treatment.

ter CHD8 knockdown. Overall levels of $\mathrm{yH} 2 \mathrm{AX}$ are reduced in z-VAD-treated cells, which is likely attributable to the early inhibition of apoptosis that is already induced by cellular stress during transfection. Still, while $\mathrm{yH} 2 \mathrm{AX}$ levels are generally lower in z-VAD-treated cells, CHD8 depletion causes strong H2AX phosphorylation.

Thus, the role of CHD8 in reducing the DDR is not cell type specific and DNA damage signaling induced by CHD8 knockdown occurs upstream of the induction or independently from the onset of apoptosis, and it activates the damage-responsive MK2/Chk1 system.

\subsubsection{Overexpressed CHD8 does not relocalize in response to UV-induced DNA damage}

In response to ssDNA breaks and DSBs, DNA damage transmitters localize to sites of DNA damage and either sense damaged DNA or recruit mediators which amplify the signal or recruit DNA repair factors. We investigated whether CHD8 relocalizes following UV-induced DNA damage. To this end, we overexpressed HA-tagged CHD8 in U2OS cells. At that time, there was no antibody against CHD8 available which was able to detect its endogenous levels and which was suitable for immunofluorescence. We UV-irradiated U2OS cells in a time course and stained UV-induced CPDs and HA-tagged CHD8 for immunofluorescence analysis using confocal microscopy. UV irradiation took place either completely or through a micro pore filter. The latter resulted in small fields of UV-dependent DNA lesions in the nucleus, which were then marked by CPD-staining. 
In untreated cells, overexpressed CHD8 was localized to the nucleus of the cell with a uniform distribution. Some subnuclear structures were excluded from CHD8 occupation that possibly represent nucleoli. Upon UV irradiation, overexpressed CHD8 was neither exported from the nucleus, nor did it display spontaneous foci formation. Also, after UV irradiation of certain nuclear regions through the micro pore filter, there was no relocalization to or exclusion from those regions detectable (Fig. 4.21).

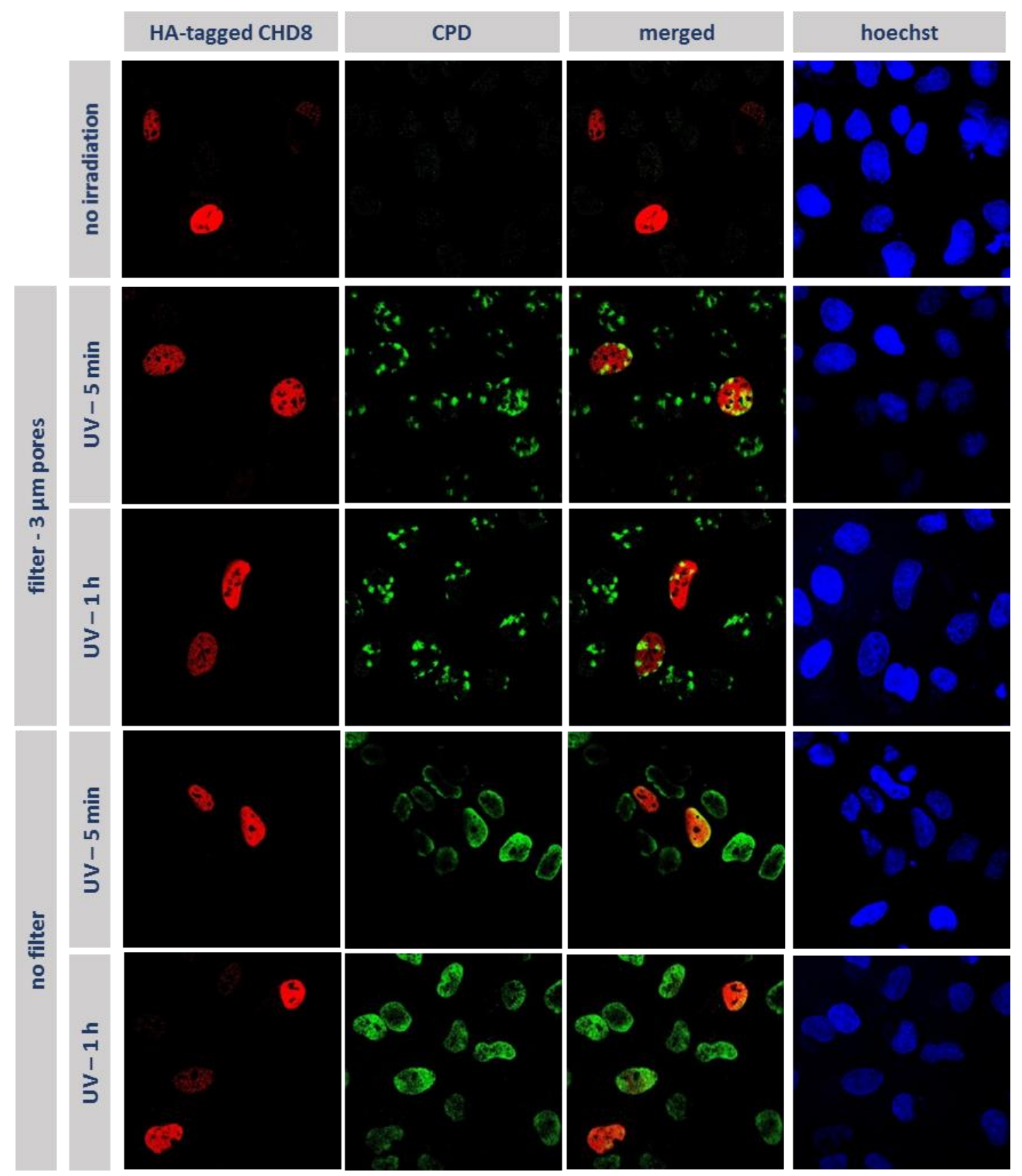

Figure 4.21 Overexpressed CHD8 does not relocalize in response to UV-induced DNA damage.

U2OS cells were transfected with a pcDNA3-CHD8 construct. Cells were then covered with a UV light filter with pores of $3 \mu \mathrm{m}$ and irradiated with $500 \mathrm{~J} / \mathrm{m}^{2}$ or left uncovered and then were irradiated with $50 \mathrm{~J} / \mathrm{m}^{2}$. Cells were fixed and stained for immunofluorescence analysis and pictures were obtained using confocal microscopy. Conducted with Dr. Frederik Köpper. 


\subsection{CHD8 regulates progression through the cell cycle and apoptosis}

Known hallmarks of cancer cells are disturbances of the tight regulation of cell cycle, resistance to apoptotic stimuli and increased proliferation. We were interested whether CHD8 as mediator of the gemcitabine response has impact on these processes typical for malignant tumors.

\subsubsection{Knockdown of CHD8 facilitates cell cycle progression}

Checkpoints of the cell cycle are mainly mediated by protein kinases and the phosphorylation-dependent activation or degradation of cell cycle mediators. The antagonizing kinases MK2 and Chk1 that we characterized as mediators of the gemcitabine response in pancreatic cancer cells significantly influence cell cycle progression. We wanted to know wether alterations in cell cycle progression are a feature of $\mathrm{CHD8}$, too. To address this question, we depleted U2OS cells of CHD8 and analyzed their cell cycle profile (Fig. 4.22). The depletion of MDM2 served as positive control for a pronounced $\mathrm{G}_{1}$-arrest. In unsynchronized cells, no obvious changes were detectable when CHD8 knockdown was compared to a control transfection (Fig. 4.22 a). We then explored whether CHD8 exhibits more delicate functions in the cell cycle than complete checkpoint activation or checkpoint abrogation that would not be detectable in an unsynchronized cell population. We used cells synchronized in $G_{2} / M$-phase in order to analyze whether a more subtle influence by CHD8 knockdown was detectable. U2OS cells were depleted of CHD8 and premitotic cells were enriched and synchronized by treating them with the mitosis inhibitor nocodazole. Premitotic cells detached easily and were shaken off from the dish surface. After release from the nocodazole block, cells were harvested in a time course and the cell cycle profile was analyzed. Interestingly, and in contrast to previous characterization of $\mathrm{CHD} 8$, depleting U2OS cells of CHD8 promoted cell cycle progression: The cells entered S-phase earlier as compared to control knockdown (Fig. 4.22b).

We therefore conclude that CHD8 controls progression through the cell cycle with depletion of $\mathrm{CHD} 8$ helping cells to proceed from $\mathrm{G}_{1}$ to $\mathrm{S}$-phase. 
a



DNA content

b

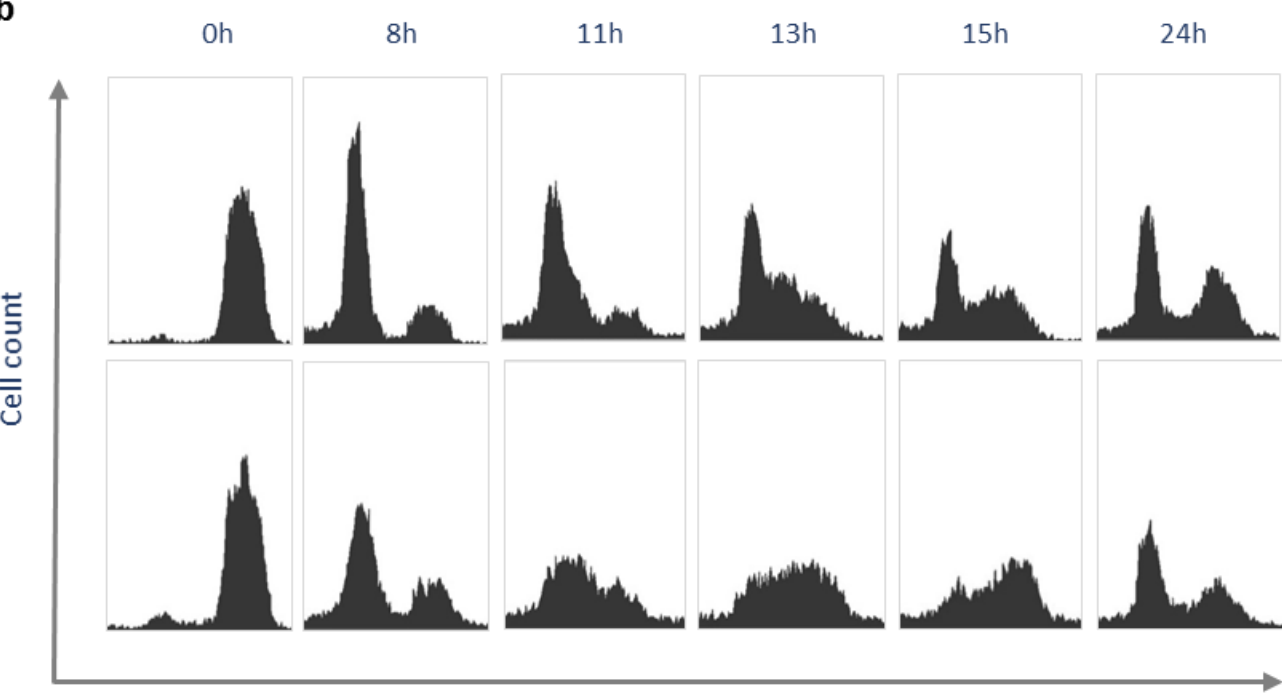

crtl\#2

DNA content

Figure 4.22 CHD8 depletion promotes progression through S-phase.

(a) U2OS cells were depleted of CHD8 and MDM2 as control, respectively. Cell cycle analysis was performed by flow cytometry. (b) U2OS cells were depleted of CHD8 by siRNA-mediated knockdown and trapped in mitosis by a nocodazole block. Mitotic cells were shaken off, released into $\mathrm{G}_{1} / \mathrm{S}$-phase and harvested for cell cycle analysis at the indicated time points after release. Cell cycle analysis was performed by flow cytometry.

\subsubsection{Depleting CHD8 causes apoptosis independent of the presence or functionality of p53}

The induction of growth arrest and apoptosis in malignant cells is the major aim of chemotherapeutic treatment as with gemcitabine. The induction of $\mathrm{yH} 2 \mathrm{AX}$ is a final common event of DNA damage signaling which is enhanced by CHD8 knockdown, and it inversely correlates with cell proliferation in all pancreatic cancer cells used. In mice, CHD8 knockout is lethal between embryonic day 5.5 and 7.5, with a massive enhancement of apoptosis detectable. The amount of apoptosis is reported to be rescued by simultaneous knockout of p53, and survival of the mice improved very little, but significantly, suggesting that CHD8 controls apoptosis by the suppression of p53 activity (detailed in 1.8.3.2). As previously 
stated, our results demonstrate that phosphorylation and total levels of mutant p53 and total levels of wild type p53 decrease after CHD8 knockdown, which contradicts the results obtained in mice experiments. Therefore, we were interested whether the accumulation of $\mathrm{yH} 2 \mathrm{AX}$ after CHD8 knockdown is followed by the induction of apoptosis, and if this is the case, whether this is p53-dependent.

We depleted PANC-1 and U2OS cells of CHD8, p53 or both and either left the cells untreated or induced DNA damage by UV irradiation. After $12 \mathrm{~h}$, a period of time long enough to allow apoptosis to start, we harvested the cells. In p53-proficient U2OS cells, already untreated cells started apoptosis after CHD8 depletion, whereas the depletion of p53 itself did not alter the cleavage of PARP and caspase 3, which were used as apoptosis indicators (Fig. 4.23). Remarkably, co-depletion of p53 in CHD8-depleted cells did not

a

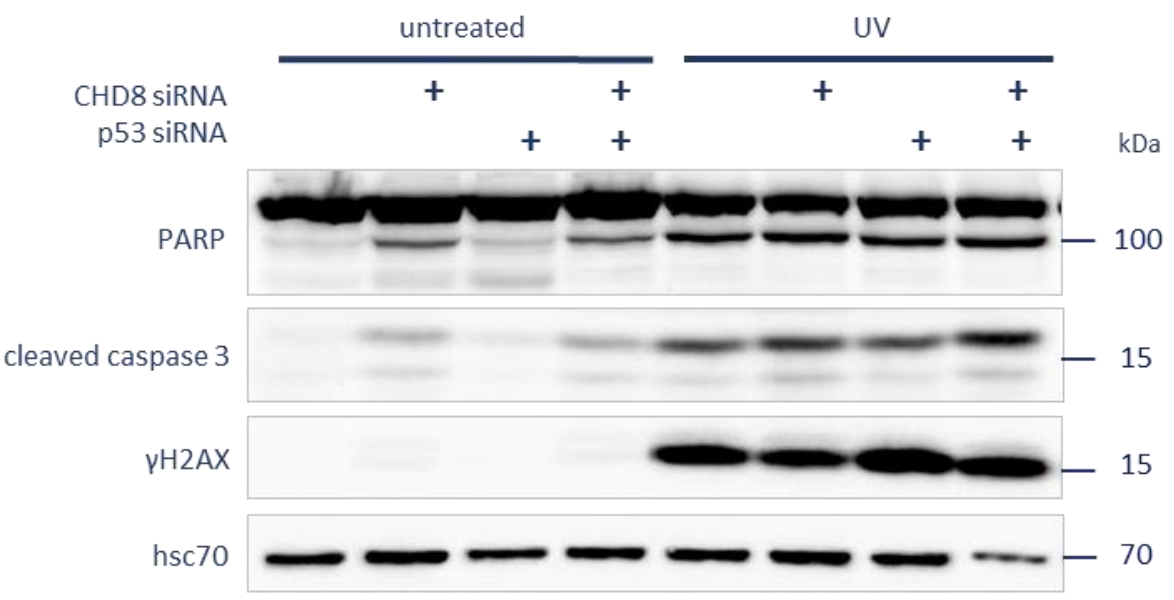

b

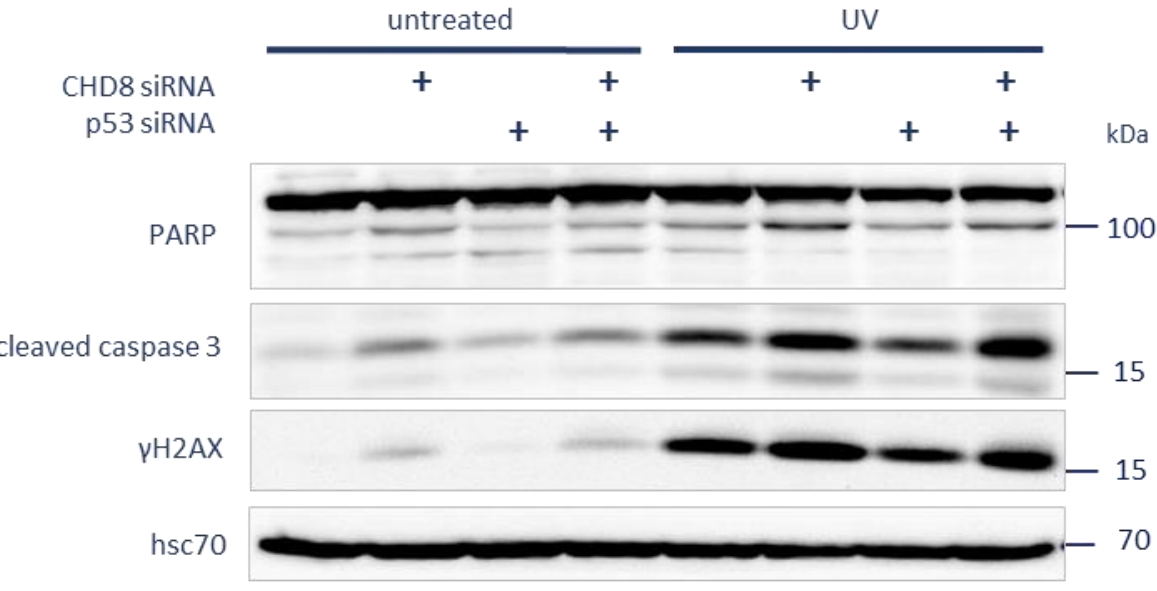

Figure 4.23 CHD8 depletion causes apoptosis independent of the presence or functionality of p53. (a) U2OS (wt p53) and (b) PANC-1 (mutant p53) cells were depleted of CHD8 or p53 by siRNA-mediated knockdown as indicated. $24 \mathrm{~h}$ after transfection, the transfection mix was replaced by fresh culture medium. Cells were incubated for another $24 \mathrm{~h}$ and thereafter received irradiation with $20 \mathrm{~J} / \mathrm{m}^{2} \mathrm{UV}-\mathrm{C}$. Then, culture medium with either DMSO or $50 \mu \mathrm{M} z$-VAD was added and cells were harvested $12 \mathrm{~h}$ after treatment. Protein lysates were prepared and analyzed by immunoblotting. 
rescue the induction of apoptosis. After UV irradiation, apoptosis was enhanced in CHD8depleted cells and again not rescued by p53 depletion. H2AX phosphorylation was not detectable in untreated U2OS cells, possibly due to their low endogenous $\mathrm{yH} 2 \mathrm{AX}$ levels, and was not influenced by CHD8 knockdown $12 \mathrm{~h}$ after UV irradiation. This is attributable to the massive onset of apoptosis, which consequently induces high levels of $\mathrm{yH} 2 \mathrm{AX}$ that overlay direct $\mathrm{H} 2 \mathrm{AX}$ phosphorylation. We did not expect different results in the p53 mutant PANC-1 cells, which have abundant, but unfunctional p53. Indeed, the depletion of CHD8 caused apoptosis already in untreated cells, accompanied by the accumulation of $\mathrm{YH} 2 \mathrm{AX}$, and showed the same relations $12 \mathrm{~h}$ after UV irradiation (Fig. 4.23). Likewise, p53 depletion itself has no influence on the onset of apoptosis alone and in CHD8-depleted cells.

Thus, we conclude that CHD8 depletion induces apoptosis independently of the presence or functionality of p53.

\subsection{CHD8 influences phosphorylation and total protein levels of p53}

\subsubsection{P53 accumulation after DNA damage relies on CHD8}

Following DNA damage, the tumor suppressor p53 is phosphorylated and thereby stabilized. Our results have shown that even mutant p53 in PANC-1 cells was extensively phosphorylated and accumulated after $22 \mathrm{~h}$ of gemcitabine treatment, but failed to do so upon CHD8 depletion (Fig. 4.15). We therefore aimed to investigate the effect of CHD8 on p53 activation. To this end, we again used PANC-1 cells, depleted them of CHD8, and harvested the cells 1 and 4 hours after UV irradiation. We observed that total p53 levels had not yet been altered significantly by CHD8 depletion after a short period of time following DNA damage induction (Fig. 4.24 a). However, the phosphorylation of p53 was reduced in a time-dependent manner with increasing reduction of the protein over time after the onset of DNA damage. We then wanted to know the influence of CHD8 on wild type p53, which underlies physiological regulation. To this end, we depleted U2OS cells of CHD8 and either treated them with gemcitabine or UV (Fig. 4.24 b). Unfortunately, phospho-p53 levels are not detectable in U2OS cells due to low expression of the entire protein and the very low ratio of its phosphorylated form. After CHD8 knockdown, p53 levels were already reduced without DNA damage induction, but the effect was more pronounced in gemcitabine-treated cells and even more evident after UV irradiation. To test whether this was maybe due to an influence of CHD8 on the p53 pathway, we stained for the main nega- 
a

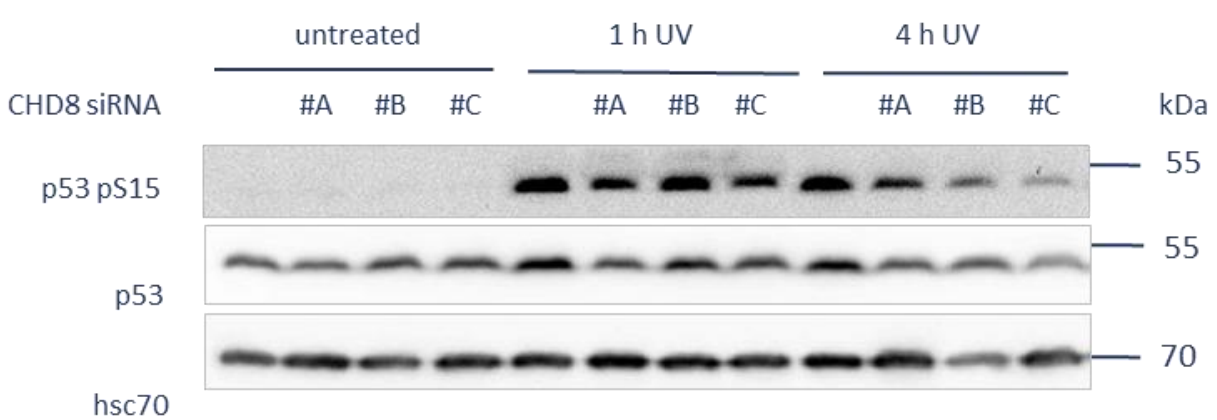

b

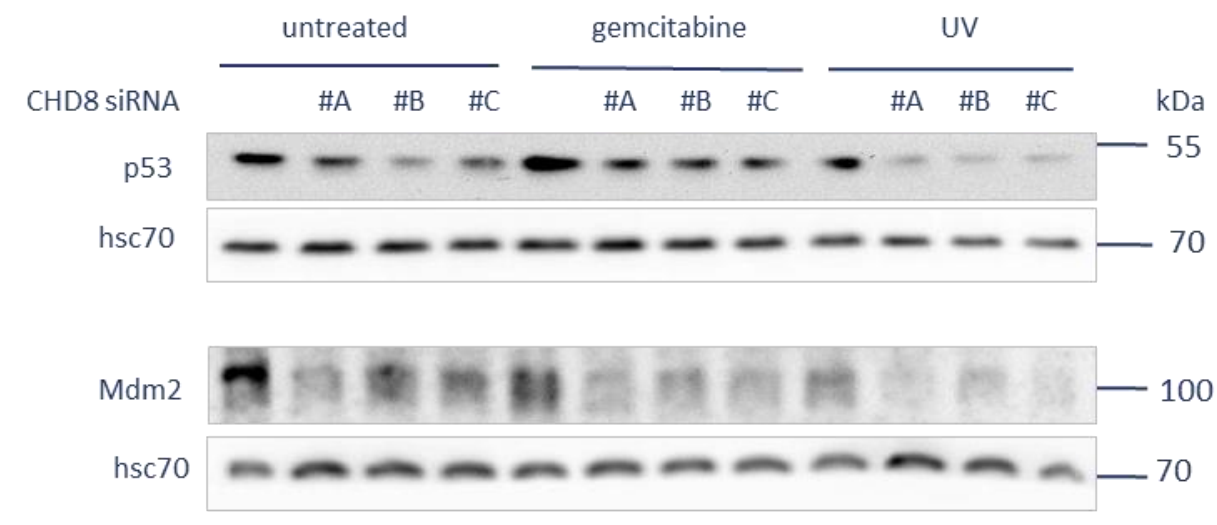

Figure 4.24 CHD8 depletion reduces activated and overall wild type and mutant p53 levels.

(a) High levels of mutated p53 in PANC-1 cells are decreased in CHD8-depleted cells. Cells were depleted of CHD8 and irradiated with $20 \mathrm{~J} / \mathrm{m}^{2} \mathrm{UV}-\mathrm{C} 48 \mathrm{~h}$ after transfection. Cells were harvested $1 \mathrm{~h}$ after irradiation and protein lysates were analyzed by immunoblotting. (b) Wild type p53 levels are reduced in CHD8-depleted U2OS cells with and without DNA damage induced by gemcitabine and UV irradiation. Cells were depleted of CHD8 and harvested either $4 \mathrm{~h}$ after treatment with $500 \mathrm{nM}$ gemcitabine or $1 \mathrm{~h}$ after irradiation with 20 $\mathrm{J} / \mathrm{m}^{2} \mathrm{UV}-\mathrm{C}$. Cell lysates were analyzed by immunoblotting.

tive regulator of p53 in wild type U2OS cells, where MDM2 downregulates p53. Indeed, also MDM2 levels were reduced in CHD8-depleted U2OS cells.

The transcription and therefore the level of MDM2 itself is regulated by p53, with p53 inducing its own downregulation. Therefore, from the above results, we cannot conclude that CHD8 influences p53 levels through an influence on MDM2. Still, CHD8 is necessary for the efficient phosphorylation and accumulation of p53 in a cell, with a special emphasis on p53 induction after DNA damage.

\subsubsection{Decreased p53 levels in CHD8-depleted cells are not or only partially due to modulated protein stability}

MDM2 targets p53 for proteasomal degradation (see 1.5.1). If the proteasome is inhibited, for example by the proteasome inhibitor MG132, the ubiquitination by MDM2 should no longer have an influence on p53 stability. To address physiological p53-regulating 
mechanisms, we used U2OS cells, depleted them of CHD8 and added DMSO or MG132. Whereas p53 levels were decreased in DMSO-treated and CHD8-depleted cells, this was only partially rescued by the inhibition of proteasomal degradation (Fig. 4.25). Due to the low staining intensity, there is no evidence for MDM2 levels in DMSO-treated cells. After MG132 treatment, however, MDM2 was stabilized to a high extend, with no effect of CHD8 knockdown in untreated cells but a reduction of MDM2 levels after UV irradiation.

Thus, whereas the regulation of MDM2 by CHD8 does not rely on protein degradation, CHD8 might sustain the protein stability of wild type p53.



Figure 4.25 Reduced p53 levels are partially based on increased protein degradation.

U2OS cells were depleted of CHD8 by siRNA-mediated knockdown. Thereafter, cells were treated with DMSO or MG132 for $4 \mathrm{~h}$ and irradiated with $20 \mathrm{~J} / \mathrm{m}^{2} \mathrm{UV}-\mathrm{C}$ or left untreated. $1 \mathrm{~h}$ after irradiation, cells were harvested and protein lysates were analyzed by immunoblotting.

\subsection{A genome-wide microarray analysis after CHD8 knockdown identifies DNA damage response genes as potential mediators of CHD8 knockdown effects}

According to literature research, CHD8 is involved in virtually every step of gene transcription. It would thus not be surprising if CHD8 exerts its suppressive effect on damage signaling through the transcriptional regulation of damage-responsive genes or whole signaling cascades. We therefore transfected U2OS cells with three siRNAs to CHD8 as well as with a none-targeting one. After the extraction of total cellular RNA, we analyzed gene expression profiles on the mRNA level by microarray analysis. U2OS cells were chosen because they are an elaborated cancer cell line, and the abundance of databases 
to compare our results with would be far greater than with pancreatic cancer cells. We then took the top 50 candidates whose mRNA levels were influenced by CHD8 knockdown as listed in table 4.1. Non-protein coding genes were part of the plot but exceeded our question, so that we reduced the list to protein-coding genes only.

We then chose genes with a false discovery rate of less than $5 \%$ as generally practiced and a relative change in mRNA expression of less than 0.5 times or more than 1.5 times compared to control, and obtained an even larger plenty of potentially regulated genes. When we sorted the candidate regulated genes for associated processes as shown in table 4.2, it becomes visible that CHD8 appears not to be a distinct regulator of one signaling cascade but involved in transcriptional regulation of many genes. Among all are various candidates involved in DNA damage and DNA repair as well as DNA replication, apoptosis and p53 regulated processes. The latter might be of minor relevance as we would want to transfer our results to mutant p53 pancreatic cancer cells. Interestingly, CHD8-regulated processes comprise kinase signaling and cell adhesion as often dysregulated pathways in cancer, too.

In conclusion, the transcriptional regulation of DNA damage factors might be a potential way of action for CHD8, but needs further validation and characterization.

\section{Table 4.1 Top candidates whose gene expression is most influenced by CHD8 knockdown.}

CHD8-regulated genes sorted by the relative change of gene expression after CHD8 knockdown as determined by microarray analysis. This table results from the 50 top candidate genes of which the non-protein coding candidates were subtracted, resulting in $37 \mathrm{CHD} 8$-regulated genes.

\begin{tabular}{|l|l|l|l|l|l|}
\hline $\begin{array}{l}\text { Gene } \\
\text { Symbol }\end{array}$ & Description & $\begin{array}{l}\text { Entrez } \\
\text { Gene ID }\end{array}$ & $\begin{array}{l}\text { Fold } \\
\text { Change }\end{array}$ & $\begin{array}{l}\text { Av. Expr } \\
\text { CHD8-Ctrl }\end{array}$ & $\begin{array}{l}\text { false } \\
\text { discovery } \\
\text { rate }\end{array}$ \\
\hline \hline CD22 & CD22 molecule & 933 & 0,31 & 5,68 & $3,69 \%$ \\
\hline AP4S1 & $\begin{array}{l}\text { adaptor-related protein complex 4, } \\
\text { sigma 1 subunit }\end{array}$ & 11154 & 0,31 & 5,91 & $0,25 \%$ \\
\hline USP11 & ubiquitin specific peptidase 11 & 8237 & 0,31 & 4,08 & $1,92 \%$ \\
\hline ESM1 & endothelial cell-specific molecule 1 & 11082 & 0,32 & 6,32 & $0,68 \%$ \\
\hline GDAP1 & $\begin{array}{l}\text { ganglioside-induced differentiation- } \\
\text { associated protein 1 }\end{array}$ & 54332 & 0,33 & 5,41 & $0,01 \%$ \\
\hline CHD8 & $\begin{array}{l}\text { chromodomain helicase DNA binding } \\
\text { protein 8 }\end{array}$ & 57680 & 0,35 & 10,85 & $0,00 \%$ \\
\hline PRR3 & $\begin{array}{l}\text { proline rich 3 (PRR3), transcript } \\
\text { variant 1 }\end{array}$ & 80742 & 0,37 & 7,78 & $0,07 \%$ \\
\hline ECM2 & $\begin{array}{l}\text { extracellular matrix protein 2, female } \\
\text { organ and adipocyte specific }\end{array}$ & 1842 & 0,38 & 4,94 & $2,08 \%$ \\
\hline LCE5A & late cornified envelope 5A & 254910 & 0,39 & 4,04 & $2,09 \%$ \\
\hline
\end{tabular}




\begin{tabular}{|c|c|c|c|c|c|}
\hline ADAMTS16 & $\begin{array}{l}\text { ADAM metallopeptidase with } \\
\text { thrombospondin type } 1 \text { motif, } 16\end{array}$ & 170690 & 0,40 & 5,19 & $0,66 \%$ \\
\hline PTX3 & pentraxin 3 , long & 5806 & 0,40 & 10,35 & $0,02 \%$ \\
\hline RIC3 & $\begin{array}{l}\text { resistance to inhibitors of } \\
\text { cholinesterase } 3 \text { homolog (C. } \\
\text { elegans) }\end{array}$ & 79608 & 0,40 & 3,95 & $2,04 \%$ \\
\hline ZNF167 & zinc finger protein 167 & 55888 & 0,40 & 5,24 & $0,90 \%$ \\
\hline ITGA2 & $\begin{array}{l}\text { integrin, alpha } 2 \text { (CD49B, alpha } 2 \\
\text { subunit of VLA-2 receptor) }\end{array}$ & 3673 & 0,41 & 5,91 & $1,09 \%$ \\
\hline KSR2 & $\begin{array}{l}\text { Homo sapiens kinase suppressor of } \\
\text { ras } 2\end{array}$ & 283455 & 0,41 & 4,60 & $2,78 \%$ \\
\hline CARD8 & $\begin{array}{l}\text { caspase recruitment domain family, } \\
\text { member } 8\end{array}$ & 22900 & 0,42 & 7,28 & $0,15 \%$ \\
\hline PRR3 & proline rich 3 & 80742 & 0,43 & 6,11 & $0,09 \%$ \\
\hline KATNAL2 & katanin p60 subunit A-like 2 & 83473 & 0,45 & 4,05 & $3,46 \%$ \\
\hline ZNF678 & zinc finger protein 678 & 339500 & 0,45 & 5,11 & $0,10 \%$ \\
\hline CNTN1 & contactin 1 & 1272 & 0,45 & 4,82 & $3,64 \%$ \\
\hline KPNA5 & karyopherin alpha 5 (importin alpha 6) & 3841 & 0,46 & 5,93 & $0,09 \%$ \\
\hline ARL10 & ADP-ribosylation factor-like 10 & 285598 & 0,46 & 4,90 & $2,26 \%$ \\
\hline B4GALT6 & $\begin{array}{l}\text { UDP-Gal:betaGlcNAc beta } 1,4- \\
\text { galactosyltransferase, polypeptide } 6\end{array}$ & 9331 & 0,46 & 4,63 & $0,66 \%$ \\
\hline FGF7 & fibroblast growth factor 7 & 2252 & 0,48 & 4,13 & $2,03 \%$ \\
\hline USP11 & ubiquitin specific peptidase 11 & 8237 & 0,49 & 11,06 & $0,03 \%$ \\
\hline AREG & amphiregulin & 374 & 0,49 & 10,71 & $0,46 \%$ \\
\hline MBLAC1 & $\begin{array}{l}\text { metallo-beta-lactamase domain } \\
\text { containing } 1\end{array}$ & 255374 & 0,49 & 8,73 & $0,12 \%$ \\
\hline TCEANC & $\begin{array}{l}\text { transcription elongation factor A (SII) } \\
\text { N-terminal and central domain } \\
\text { containing }\end{array}$ & 170082 & 2,06 & 6,36 & $0,70 \%$ \\
\hline B9D2 & B9 protein domain 2 & 80776 & 2,07 & 10,95 & $0,09 \%$ \\
\hline POLR3E & $\begin{array}{l}\text { polymerase (RNA) } 2 \text { (DNA directed) } \\
\text { polypeptide } \mathrm{E}(80 \mathrm{kD})\end{array}$ & 55718 & 2,07 & 10,65 & $2,03 \%$ \\
\hline ETV2 & ets variant 2 & 2116 & 2,09 & 10,30 & $0,01 \%$ \\
\hline PPFIA3 & $\begin{array}{l}\text { protein tyrosine phosphatase, } \\
\text { receptor type, f polypeptide (PTPRF), } \\
\text { interacting protein (liprin), alpha } 3\end{array}$ & 8541 & 2,13 & 7,40 & $1,83 \%$ \\
\hline Q5SRJ3 & $\begin{array}{l}\text { Zinc finger protein } 452 \text { (Fragment), } \\
\text { partial }(3 \%)\end{array}$ & & 2,13 & 6,52 & $0,29 \%$ \\
\hline ETV2 & ets variant 2 & 2116 & 2,25 & 7,38 & $0,00 \%$ \\
\hline IGFL2 & IGF-like family member 2 & 147920 & 2,26 & 5,27 & $0,16 \%$ \\
\hline SH3YL1 & $\begin{array}{l}\text { SH3 domain containing, Ysc84-like } 1 \\
\text { (S. cerevisiae) }\end{array}$ & 26751 & 2,36 & 6,90 & $0,07 \%$ \\
\hline
\end{tabular}


Table 4.2 Candidate CHD8-regulated genes were grouped by cellular processes.

Candidates with a false discovery rate of less than $5 \%$ and a relative increase in gene expression by 1.5 -fold or decrease to 0.5 -fold after CHD8 knockdown compared to control were included and then grouped according to ascribed processes using the DAVID functional annotation tool (Huang da et al. 2009b).

DNA damage response

\begin{tabular}{|l|l|l|l|l|l|}
\hline GeneSymbol & Description & EntrezGeneID & $\begin{array}{l}\text { Av. Expr. } \\
\text { CHD8-Ctrl }\end{array}$ & $\begin{array}{l}\text { FDR } \\
\text { CHD8-Ctrl }\end{array}$ & $\begin{array}{l}\text { fold } \\
\text { change }\end{array}$ \\
\hline \hline TLN1 & Talin 1 & 7094 & 9,19 & $3,80 \%$ & 1,98 \\
\hline RBM38 & RNA binding motif protein 38 & 55544 & 9,70 & $3,74 \%$ & 1,69 \\
\hline MDC1 & $\begin{array}{l}\text { Mediator of DNA-damage } \\
\text { checkpoint 1 }\end{array}$ & 9656 & 11,93 & $0,25 \%$ & 1,64 \\
\hline JMY & $\begin{array}{l}\text { Junction mediating and } \\
\text { regulatory protein, p53 cofactor }\end{array}$ & 133746 & 7,08 & $2,16 \%$ & 1,52 \\
\hline KAT5 & K(lysine) acetyltransferase 5 & 10524 & 9,19 & $3,79 \%$ & 1,50 \\
\hline RASGRF1 & $\begin{array}{l}\text { Ras protein-specific guanine } \\
\text { nucleotide-releasing factor 1 }\end{array}$ & 5923 & 7,91 & $2,40 \%$ & 0,68 \\
\hline ACD & $\begin{array}{l}\text { adrenocortical dysplasia } \\
\text { homolog }\end{array}$ & 65057 & 12,57 & $1,51 \%$ & 1,41 \\
\hline HIPK2 & $\begin{array}{l}\text { homeodomain interacting } \\
\text { protein kinase 2 }\end{array}$ & 6,97 & $2,14 \%$ & 0,59 \\
\hline
\end{tabular}

DNA repair

\begin{tabular}{|l|l|l|l|l|l|}
\hline GeneSymbol & Description & EntrezGeneID & $\begin{array}{l}\text { AveExpr } \\
\text { CHD8-Ctrl }\end{array}$ & $\begin{array}{l}\text { FDR CHD8- } \\
\text { Ctrl }\end{array}$ & $\begin{array}{l}\text { fold } \\
\text { change }\end{array}$ \\
\hline \hline TOP1MT & $\begin{array}{l}\text { Topoisomerase (DNA) I, } \\
\text { mitochondrial }\end{array}$ & 116447 & 12,77 & $4,81 \%$ & 1,93 \\
\hline MDC1 & $\begin{array}{l}\text { Mediator of DNA-damage } \\
\text { checkpoint 1 }\end{array}$ & 9656 & 11,93 & $0,25 \%$ & 1,64 \\
\hline JMY & $\begin{array}{l}\text { Junction mediating and } \\
\text { regulatory protein, p53 cofactor }\end{array}$ & 133746 & 7,08 & $2,16 \%$ & 1,52 \\
\hline KAT5 & K(lysine) acetyltransferase 5 & 10524 & 9,19 & $3,79 \%$ & 1,50 \\
\hline
\end{tabular}

Apoptosis
\begin{tabular}{|l|l|l|l|l|l|}
\hline GeneSymbol & Description & EntrezGenelD & $\begin{array}{l}\text { AveExpr } \\
\text { CHD8-Ctrl }\end{array}$ & $\begin{array}{l}\text { FDR CHD8- } \\
\text { Ctrl }\end{array}$ & $\begin{array}{l}\text { fold } \\
\text { change }\end{array}$ \\
\hline \hline BCL11B & $\begin{array}{l}\text { Homo sapiens B-cell } \\
\text { CLL/lymphoma 11B }\end{array}$ & 64919 & 4,11 & $1,20 \%$ & 1,76 \\
\hline NUDT2 & $\begin{array}{l}\text { Homo sapiens nudix } \\
\text { (nucleoside diphosphate linked } \\
\text { moiety X)-type motif 2 (NUDT2) }\end{array}$ & 318 & 10,04 & $0,41 \%$ & 1,58 \\
\hline BCL2L11/BIM & $\begin{array}{l}\text { Homo sapiens BCL2-like 11 } \\
\text { (apoptosis facilitator) } \\
\text { (BCL2L11) }\end{array}$ & 10018 & 10,18 & $0,70 \%$ & 1,55 \\
\hline
\end{tabular}




\begin{tabular}{|c|c|c|c|c|c|}
\hline JMY & $\begin{array}{l}\text { Homo sapiens junction } \\
\text { mediating and regulatory } \\
\text { protein, p53 cofactor }\end{array}$ & 133746 & 7,08 & $2,16 \%$ & 1,52 \\
\hline RASGRF1 & $\begin{array}{l}\text { Homo sapiens Ras protein- } \\
\text { specific guanine nucleotide- } \\
\text { releasing factor } 1\end{array}$ & 5923 & 7,91 & $2,40 \%$ & 0,68 \\
\hline NGFRAP1 & $\begin{array}{l}\text { Homo sapiens nerve growth } \\
\text { factor receptor (TNFRSF16) } \\
\text { associated protein } 1 \\
\text { (NGFRAP1) }\end{array}$ & 27018 & 13,16 & $4,30 \%$ & 0,67 \\
\hline РPP3СB & $\begin{array}{l}\text { protein phosphatase } 3 \text {, catalytic } \\
\text { subunit, beta isozyme }\end{array}$ & 5532 & 7,37 & $4,41 \%$ & 0,65 \\
\hline ARHGEF9 & $\begin{array}{l}\text { Homo sapiens Cdc42 guanine } \\
\text { nucleotide exchange factor } \\
\text { (GEF) } 9\end{array}$ & 23229 & 6,62 & $0,88 \%$ & 0,63 \\
\hline ADRB2 & $\begin{array}{l}\text { Homo sapiens adrenergic, } \\
\text { beta-2-, receptor, surface }\end{array}$ & 154 & 9,70 & $0,94 \%$ & 0,62 \\
\hline KCNMA1 & $\begin{array}{l}\text { Homo sapiens potassium large } \\
\text { conductance calcium-activated } \\
\text { channel, subfamily M, alpha } \\
\text { member } 1 \text { (KCNMA1), } \\
\text { transcript variant 2, mRNA } \\
\text { [NM_002247] }\end{array}$ & 3778 & 6,66 & $4,72 \%$ & 0,59 \\
\hline IL1RAP & $\begin{array}{l}\text { Homo sapiens interleukin } 1 \\
\text { receptor accessory protein }\end{array}$ & 3556 & 8,04 & $1,46 \%$ & 0,58 \\
\hline SART1 & $\begin{array}{l}\text { Homo sapiens squamous cell } \\
\text { carcinoma antigen recognized } \\
\text { by T cells }\end{array}$ & 9092 & 8,67 & $0,52 \%$ & 0,57 \\
\hline TGM2 & $\begin{array}{l}\text { Homo sapiens } \\
\text { transglutaminase } 2 \text { (C } \\
\text { polypeptide, protein-glutamine- } \\
\text { gamma-glutamyltransferase) }\end{array}$ & 7052 & 10,53 & $4,06 \%$ & 0,54 \\
\hline CARD8 & $\begin{array}{l}\text { Homo sapiens caspase } \\
\text { recruitment domain family, } \\
\text { member } 8\end{array}$ & 22900 & 7,28 & $0,15 \%$ & 0,42 \\
\hline
\end{tabular}

\section{DNA replication}

\begin{tabular}{|l|l|l|l|l|l|}
\hline GeneSymbol & Description & EntrezGenelD & $\begin{array}{l}\text { AveExpr } \\
\text { CHD8-Ctrl }\end{array}$ & $\begin{array}{l}\text { FDR CHD8- } \\
\text { Ctrl }\end{array}$ & $\begin{array}{l}\text { fold } \\
\text { change }\end{array}$ \\
\hline \hline TOP1MT & $\begin{array}{l}\text { Topoisomerase (DNA) I, } \\
\text { mitochondrial }\end{array}$ & 116447 & 12,77 & $4,81 \%$ & 1,93 \\
\hline GINS3 & $\begin{array}{l}\text { GINS complex subunit 3 (Psf3 } \\
\text { homolog) }\end{array}$ & 64785 & 11,95 & $0,25 \%$ & 0,64 \\
\hline AREG & Amphiregulin & 374 & 10,71 & $0,46 \%$ & 0,49 \\
\hline
\end{tabular}


MAPKinase signaling

\begin{tabular}{|l|l|l|l|l|l|}
\hline GeneSymbol & Description & EntrezGeneID & $\begin{array}{l}\text { AveExpr } \\
\text { CHD8-Ctrl }\end{array}$ & $\begin{array}{l}\text { FDR CHD8- } \\
\text { Ctrl }\end{array}$ & $\begin{array}{l}\text { fold } \\
\text { change }\end{array}$ \\
\hline \hline RASGRF1 & $\begin{array}{l}\text { Homo sapiens Ras protein- } \\
\text { specific guanine nucleotide- } \\
\text { releasing factor 1 }\end{array}$ & 5923 & 7,91 & $2,40 \%$ & 0,68 \\
\hline ARAF & $\begin{array}{l}\text { v-raf murine sarcoma 3611 viral } \\
\text { oncogene homolog }\end{array}$ & 369 & 8,32 & $0,42 \%$ & 0,65 \\
\hline PPP3CB & $\begin{array}{l}\text { protein phosphatase 3, catalytic } \\
\text { subunit, beta isozyme }\end{array}$ & 5532 & 7,37 & $4,41 \%$ & 0,65 \\
\hline ADRB2 & $\begin{array}{l}\text { Homo sapiens adrenergic, } \\
\text { beta-2-, receptor, surface }\end{array}$ & 154 & 9,70 & $0,94 \%$ & 0,62 \\
\hline RPS6KA6 & $\begin{array}{l}\text { Homo sapiens ribosomal } \\
\text { protein S6 kinase, 90kDa, } \\
\text { polypeptide 6 }\end{array}$ & 27330 & 6,97 & $0,09 \%$ & 0,61 \\
\hline RGS4 & $\begin{array}{l}\text { Homo sapiens regulator of G- } \\
\text { protein signaling 4 }\end{array}$ & 5999 & 5,21 & $0,75 \%$ & 0,54 \\
\hline FGF7 & $\begin{array}{l}\text { Homo sapiens fibroblast growth } \\
\text { factor 7 }\end{array}$ & 2252 & 4,13 & $2,03 \%$ & 0,48 \\
\hline
\end{tabular}

RAS signaling

\begin{tabular}{|l|l|l|l|l|l|}
\hline GeneSymbol & Description & EntrezGenelD & $\begin{array}{l}\text { AveExpr } \\
\text { CHD8-Ctrl }\end{array}$ & $\begin{array}{l}\text { FDR CHD8- } \\
\text { Ctrl }\end{array}$ & $\begin{array}{l}\text { fold } \\
\text { change }\end{array}$ \\
\hline \hline RAB9B & $\begin{array}{l}\text { RAB9B, member RAS } \\
\text { oncogene family }\end{array}$ & 51209 & 4,82 & $4,14 \%$ & 0,69 \\
\hline RASGRF1 & $\begin{array}{l}\text { Ras protein-specific guanine } \\
\text { nucleotide-releasing factor } 1\end{array}$ & 5923 & 7,91 & $2,40 \%$ & 0,68 \\
\hline SYTL2 & Synaptotagmin-like 2 & 54843 & 10,04 & $4,23 \%$ & 0,50 \\
\hline AGFG1 & ArfGAP with FG repeats 1 & 3267 & 9,94 & $0,91 \%$ & 1,48 \\
\hline ERRF11 & $\begin{array}{l}\text { ERBB receptor feedback } \\
\text { inhibitor 1 }\end{array}$ & 54206 & 11,91 & $0,67 \%$ & 0,71 \\
\hline
\end{tabular}

Cell adhesion

\begin{tabular}{|l|l|l|l|l|l|}
\hline GeneSymbol & Description & EntrezGenelD & $\begin{array}{l}\text { AveExpr } \\
\text { CHD8-Ctrl }\end{array}$ & $\begin{array}{l}\text { FDR CHD8- } \\
\text { Ctrl }\end{array}$ & $\begin{array}{l}\text { fold } \\
\text { change }\end{array}$ \\
\hline \hline TLN1 & Talin 1 (TLN1) & 7094 & 9,19 & $3,80 \%$ & 1,98 \\
\hline MYL5 & Myosin, light chain 5, regulatory & 4636 & 7,69 & $0,25 \%$ & 1,76 \\
\hline MADCAM1 & $\begin{array}{l}\text { Mucosal vascular addressin cell } \\
\text { adhesion molecule 1 } \\
\text { (MADCAM1) }\end{array}$ & 8174 & 4,65 & $1,94 \%$ & 1,75 \\
\hline MDC1 & $\begin{array}{l}\text { Mediator of DNA-damage } \\
\text { checkpoint 1 }\end{array}$ & 9656 & 11,93 & $0,25 \%$ & 1,64 \\
\hline EMB & Embigin & 133418 & 9,14 & $1,82 \%$ & 1,56 \\
\hline
\end{tabular}




\begin{tabular}{|l|l|l|l|l|l|}
\hline BCL2L11 & $\begin{array}{l}\text { BCL2-like 11 (apoptosis } \\
\text { facilitator) }\end{array}$ & 10018 & 10,18 & $0,70 \%$ & 1,55 \\
\hline HAPLN3 & $\begin{array}{l}\text { Hyaluronan and proteoglycan } \\
\text { link protein 3 }\end{array}$ & 145864 & 12,45 & $0,61 \%$ & 1,54 \\
\hline MUC4 & Mucin 4, cell surface associated & 4585 & 5,35 & $3,69 \%$ & 0,70 \\
\hline F11R & F11 receptor & 50848 & 9,28 & $0,47 \%$ & 0,70 \\
\hline PPFIBP1 & $\begin{array}{l}\text { PTPRF interacting protein, } \\
\text { binding protein 1 }\end{array}$ & 8496 & 7,19 & $4,99 \%$ & 0,69 \\
\hline COL6A3 & Collagen, type VI, alpha 3 & 1293 & 7,43 & $0,64 \%$ & 0,55 \\
\hline TGM2 & $\begin{array}{l}\text { Transglutaminase 2 (C } \\
\text { polypeptide, protein-glutamine- } \\
\text { gamma-glutamyltransferase) }\end{array}$ & 7052 & 10,53 & $4,06 \%$ & 0,54 \\
\hline COL13A1 & $\begin{array}{l}\text { Collagen, type X2, alpha 1 } \\
\text { CNTN1 }\end{array}$ & 1305 & 9,48 & $0,41 \%$ & 0,53 \\
\hline ITGA2 & $\begin{array}{l}\text { Contactin 1 } \\
\text { Integrin, alpha 2 (CD49B, alpha }\end{array}$ & 3673 & 4,82 & $3,64 \%$ & 0,45 \\
\hline ECM2 & $\begin{array}{l}\text { Extracellular matrix protein 2, } \\
\text { female organ and adipocyte } \\
\text { specific }\end{array}$ & 1842 & 5,91 & $1,09 \%$ & 0,41 \\
\hline CD22 & CD22 molecule & 933 & 5,68 & $3,69 \%$ & 0,31 \\
\hline
\end{tabular}




\section{Discussion}

Despite extensive research on the treatment of pancreatic adenocarcinomas, this tumor identity still belongs to the most fatal cancers. The nucleoside analog gemcitabine prolongs median survival by a few months, but still therapeutic success ranks far behind the progress achieved in the treatment of other cancers. Resistance mechanisms to gemcitabine are poorly understood, and those we know cannot be targeted to date to improve response rates to this drug. Equally, cancer-driving mutations of pancreatic tumors, which are oncogenic KRAS activating mutations in $95 \%$ and oncogenic missense mutations of the tumor suppressor p53 in $75 \%$ of the cases, are still not druggable. A better understanding of the cellular response to gemcitabine as well as the identification of factors that can be exploited to sensitize pancreatic cancer cells to gemcitabine are a constant challenge for fundamental research.

As a nucleoside analog, gemcitabine acts mainly during the S-phase of the cell cycle, where it is incorporated into a nascent DNA strand and causes the DNA polymerase to stall, while helicases continue unwinding DNA. In this way, ssDNA emerges and is recognized by sensor proteins, which activate a DDR. ATR and Chk1 as sensor and effector kinases then attenuate DNA replication and induce cell cycle arrest and stabilization of the replication fork. If fast repair mechanisms do not take effect, the replication of DNA cannot be resumed, the fork is finally cleaved and gives rise to DSBs, which eventually activate ATM and Chk2 and induce apoptosis.

Besides Chk1, whose depletion or inhibition strongly activates the DDR so that its inhibition has been subject to many clinical trials in combination with chemotherapy, another kinase could be identified in our lab that governs the gemcitabine response in osteosarcoma cells. MK2 is an antagonist of Chk1 at the level of DNA replication where it appears to inhibit the error-prone but pro-survival repair process of translesion synthesis, and promotes replication fork stalling. It was one purpose of this study to transfer the manipulation of the MK2/Chk1-system to pancreatic cancer cells in order to overcome gemcitabine resistance. Furthermore, the central objective was the identification of activated pathways and mediators within the DDR in order to understand the precise way in which a cell deals with genotoxic stress induced by gemcitabine. This could contribute to finding ways to fortify the impact of the drug and specify it to malignant cells. We thus performed a high-content 
screen in gemcitabine-treated pancreatic cancer cells using a pre-selected library of siRNAs to genes already ascribed to DNA damage, DNA repair and genomic integrity.

One of the resulting candidates was the ATP-dependent chromatin remodeling factor CHD8, whose knockdown increased $\mathrm{yH} 2 \mathrm{AX}$ induction after gemcitabine treatment. Not much is known so far about this large protein, which is clinically involved in autism spectrum disorders. Nevertheless, as structurally related family members have well-established roles in DNA repair, we became interested in the characterization of CHD8 in response to DNA damage.

\subsection{MK2 and Chk1: Two kinases govern the response of pancreatic cancer cells to gemcitabine treatment}

\subsubsection{MK2 in the response to replicative stress signaling and chemotherapy}

Fast proliferating tumor cells suffer a high amount of replicative stress, which is enhanced by the treatment with nucleoside analogs like gemcitabine. Here, we show that MK2 is a determinant of both the response to endogenous replicative stress and to gemcitabineinduced stress and DNA damage. We used four different pancreatic cancer cell lines, which we treated with gemcitabine and found that, first, high endogenous $\mathrm{yH} 2 \mathrm{AX}$ levels can be reduced by MK2 inhibition and that, second, this is also the case for exogenous gemcitabine-induced DNA damage signaling. We performed cell proliferation assays to transfer this finding to the ability of MK2 to influence tumor cell growth, which would be the clinical aim of MK2 manipulation. Our results suggest that MK2 activity is fundamental to gemcitabine sensitivity as cells obtain growth advantages when MK2 is inhibited (Fig. 4.3). This finding brings MK2 into clinical relevance as low MK2 levels or activity might confer gemcitabine resistance in pancreatic tumors. Mechanistically, MK2 appears to influence the DDR rather than the known resistance mechanisms mostly involved in drug metabolism, activation of pro-survival pathways and establishment of an anti-apoptotic tumor micro environment (Chand et al. 2016). On the other hand, the activation of MK2, as it is seen in inflammation processes, could be exploited to fortify the cellular response to gemcitabine. Such MK2 promotion could be carried out basically in two ways: first, by inducing MK2's activating kinase p38 and second, by the inhibition of DUSP1/MKP1 (dual specific protein phosphatase1/MAPK phosphatase), the phosphatase of the p38/MK2 heterodimer, thus interrupting a negative feedback loop. Both results in higher levels of activated MK2 (Hu et al. 2007). 
Interestingly, not MK2 itself but its direct downstream target hsp27 (heat shock protein 27) has been discussed in the response to gemcitabine in pancreatic cancers. Hsp27 is phosphorylated by MK2 to such extent that it can be used as readout for MK2 activity (Guay et al. 1997). However, observations of hsp27 being a predictor of gemcitabine sensitivity in pancreatic cancers are contradictory. Some studies report that total levels of hsp27 or its phosphorylated form mark gemcitabine sensitivity (Liu et al. 2012; Nakashima et al. 2011; Schafer et al. 2012) while others found contrary results and ascribe gemcitabine resistance to tumors with such properties (Baylot et al. 2011; Taba et al. 2010). If we take hsp27 phosphorylation as means to quantify MK2 activity, our findings would support the firstmentioned studies.

Hsp27 activity is not yet an established marker for the gemcitabine response in the clinics and no data for patient survival correlated with hsp27 activity in pancreatic cancer samples is available. Nonetheless, hsp27-associated pathways have received increasing attention in recent years. The determination of MK2 activity in tumors is thus a promising factor in the search for more reliable gemcitabine sensitivity markers.

There are more studies that focused on MK2 activity during chemotherapy. For example, it was proposed that MK2 can take over p53 functions as the induction of cell cycle checkpoints seems to rely on MK2 in p53 knockout cells (Reinhardt et al. 2007). Another study ascribes a synthetic lethal effect to MK2 depletion in p53-deficient cells (Morandell et al. 2013). In line with this, it was shown that activated p53 can induce MKP1 and thereby downregulate MK2, a mechanism that might not be functional in p53-deficient cells (Liu et al. 2008). However, the first study was performed in a lung cancer cell line and with cisplatin as DNA damaging agent. Cisplatin acts in a fundamentally different manner than does gemcitabine, and it induces DNA intra and interstrand crosslinks which already affect the unwinding of DNA during replication instead of DNA synthesis. Work in our lab has recently demonstrated that, although MK2 determines the DNA replication after gemcitabine treatment, it has no effect on DNA damage signaling and DNA replication after cisplatin treatment ( $\mathrm{Li}$ et al. 2018). As platinum adducts induce different DDR and repair pathways than does gemcitabine, the results of the above studies do not necessarily contradict our findings of a protective effect of MK2 inhibition that we consistently found in p53-wild type and p53-mutated cell lines.

In summary, cancer cells might respond differentially to MK2 inhibition dependent on their genetic background and the treatment regimen. MK2 specifically mediates the cellular response to replicative stress as induced by gemcitabine, by UV and endogenously. The cellular background and the chemotherapeutic in use would have to be precisely tested before the inhibition of MK2 could be approved for clinical use, but the assessment of MK2 
activity as well as its inhibition is a promising strategy, especially to exploit replicative stress as a cytotoxic treatment strategy.

\subsubsection{MK2 and Chk1: two antagonizing kinases in the DNA damage response and cell survival}

Work in our lab has previously shown that MK2 and Chk1 activity antagonize each other at the level of DNA replication. While Chk1 activity promotes translesion synthesis, MK2 activity appears to reduce this damage tolerance mechanism, which results in opposing effects of both kinases on $\mathrm{yH} 2 \mathrm{AX}$ accumulation (Kopper et al. 2013). We now transferred this finding to pancreatic cancer cells and could show that knockdown or inhibition of Chk1 leads to increased $\mathrm{yH} 2 \mathrm{AX}$ accumulation in gemcitabine sensitive cell lines, while MK2 inhibition as well as depletion completely rescued this effect. Taking DNA damage signaling as a reliable marker for chemosensitivity, we may conclude that high MK2 activity could not only be used to predict chemosensitivity, but that it also promotes the success of Chk1 inhibition, whereas low MK2 activity could diminish this effect. This function of MK2 has to be taken into account when we reflect the mode of action of an older generation Chk1 inhibitor, UCN-01, which also blocks MK2 to a relevant extent and may therefore be less efficient than a new generation of highly selective Chk1 inhibitors. Further, the use of multikinase inhibitors in combination with replicative stress-inducing agents could turn out to be ineffective if MK2 is blocked to a relevant extent, as well.

\subsubsection{Two sides of a coin: Chk1 inhibitors in chemotherapy}

Where chemotherapy alone is not able to induce apoptosis of a cell, the simultaneous inhibition or depletion of another factor can sometimes do so, an effect called synthetic lethality. Chk1 is an example of such a factor and its inhibition has been extensively studied in combination with different chemotherapeutics in a wide range of tumor species. In nearly all cases, Chk1 inhibition has a chemosensitizing effect (Ma et al. 2011). Chk1 inhibition abrogates the intra-S-phase checkpoint that usually, when active, gives the cell a chance to repair damage or at least delay further DNA replication to allow damage tolerance mechanisms to take effect. Abrogation of Chk1 signaling therefore leads to the massive accumulation of DNA damage. This effect seems to be pronounced in p53-deficient cells, which are unable to induce the $G_{1} / S$ checkpoint and therefore heavily rely on other cell cycle checkpoints ( $\mathrm{Ma}$ et al. 2011). A recent study using cell line-based screening found that especially in KRAS-driven cancers that potentially have a high amount of replicative stress, the combined inhibition of Chk1 and MK2 shows a synergistic effect that drives the cells 
into mitotic catastrophe (Dietlein et al. 2015). First, however, our results demonstrate that the cytotoxic effect of Chk1 inhibition is independent of the KRAS status of a cell as two of the cell lines we used, U2OS and BxPC-3, harbor wild type KRAS and can be sensitized by Chk1 inhibition. Second, we find a protective effect of MK2 inhibition after gemcitabine treatment in all cell lines tested, irrespective of their KRAS status.

On the contrary, when investigating the impact of a selective Chk1 inhibitor on proliferation, we were surprised to observe that only one pancreatic cancer cell line, MIA PaCa-2, proved sensitive to Chk1 inhibition at all, and that this is the case despite increased DNA damage accumulation following inhibition or depletion of Chk1, which we reliably observe in all cell lines. In MIA PaCa-2 and in osteosarcoma U2OS, MK2 inhibition led to a complete rescue of DNA damage and growth arrest or apoptosis after Chk1 inhibition. In the other three cell lines, Chk1 inhibition even conferred a protective effect in untreated as well as in gemcitabine-treated conditions independent of or despite the induction of DNA damage signaling.

Our results thus contradict the above-mentioned study in which MK2 and Chk1 act in line to prevent DNA damage, and suggest that MK2 confers chemosensitivity during endogenous and induced replicative stress. Further, and in contrast to most clinical and preclinical trials, only a subset of cells respond to Chk1 inhibitors, but in those, this effect is completely rescueable by MK2 inhibition.

This raises the question whether a model of synthetic lethality after Chk1 inhibition still and generally holds true for gemcitabine treatment. The fact that Chk1 inhibition as well as Chk1 knockdown increase DNA damage signaling in all cell lines tested, and that this effect can be rescued by simultaneous MK2 inhibition or depletion (Fig. 4.4) makes it unlikely to be an effect of poor inhibitor selectivity. Additionally, Chk1 inhibition does decrease proliferation in MIA PaCa-2 cells and an osteosarcoma cell line, and this toxicity mediated by Chk1 inhibition can be clearly rescued by the parallel inhibition of MK2.

\subsubsection{Putative mediators of Chk1 resistance}

\subsubsection{Checkpoint signaling}

There are only few studies that have dealt with Chk1 inhibitor resistance. In this context, the most examined feature of Chk1 is its ability to prevent progression through S-Phase upon replicative stress. When cell cycle checkpoints are abrogated by Chk1 inhibition, this increases the sensitivity to a variety of cytotoxic agents including gemcitabine (Matthews et 
al. 2007; Xiao et al. 2003). This impact of Chk1 inhibition to interfere with checkpoint signaling has been specified in an analysis of Chk1 downstream targets in response to its inhibition in the absence of chemotherapy: First and as a surprising result, only the minority of cell lines was sensitive to the applied Chk1 inhibitor and, second, resistant cell lines were characterized by a failure to accumulate Cdc25A after Chk1 inhibition and therefore fail to activate CDK2 (compare to Fig 5.1 and (Sakurikar et al. 2016)). In line with this, several studies demonstrated a role for Chk1 kinase function during unperturbed S-phase, when the activation of the S-phase checkpoint, an event which is carried out by the phosphorylation of Chk1 target genes, predominates to attenuate DNA replication. The activation of CDKs is the rate limiting step for increased origin firing, ssDNA accumulation and ATR kinase activity after Chk1 inhibition and leads to extensive firing of dormant origins with the accumulation of stalled replication forks as consequence. This effect can be completely rescued when CDKs are simultaneously inhibited and Chk1 inhibitor resistant cells seem to somehow circumvent CDK activation (Sakurikar et al. 2016; Syljuasen et al. 2005). Furthermore, the inhibition of Wee1, a kinase which can directly phosphorylate CDK2 without the interim step of CDC25A phosphorylation and degradation, increases gemcitabine toxicity even in those cell lines that are resistant to Chk1 inhibition, in unperturbed condition as well as after chemotherapy (Saini et al. 2015; Sakurikar et al. 2016).

In summary, the above-mentioned mechanisms suggesting CDK2 activity as mediator of chemoresistance to Chk1 inhibitors would also implicate a lack of DNA damage accumulation after Chk1 inhibition. However, this view is challenged by our findings and

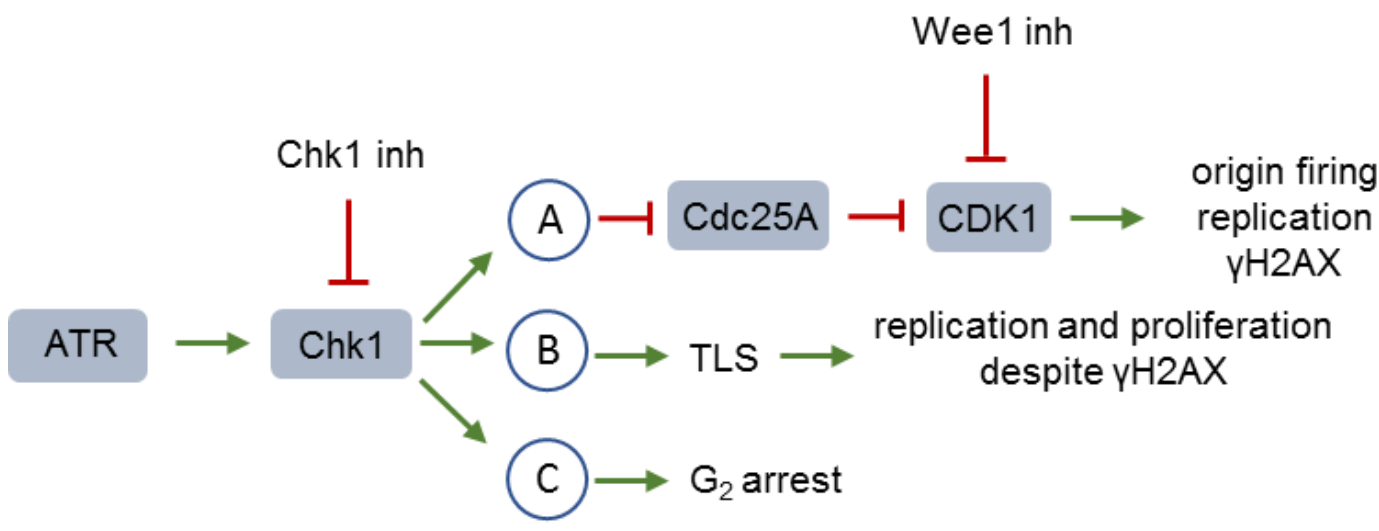

Figure 5.1 A model for the induction of resistance to Chk1 inhibitors.

In response to DNA damage, ATR phosphorylates Chk1 to increase its activity. When Chk1 is inhibited, ATR continues to activate Chk1 due to a lacking negative feedback loop. Chk1 inhibition can now result in pathway $A$, leading to the activation of CDK1 to increase origin firing and DNA damage. It can also result in pathways $B$, which is the induction of TLS as an error prone but fast damage tolerance mechanism to resume replication. If we expand our view to late $S$-phase, pathway $C$ would lead to the abrogation of the $G_{2} / M$ checkpoint. While pathway $A$ and $C$ are kinase-dependent and therefore influenced by Chk 1 inhibition, the kinase-independent pathway $B$ is not. 
those of Parsels et al., according to which neither the induced levels of $\mathrm{yH} 2 \mathrm{AX}$ nor the activation of cell cycle arresting degradation of Cdc25a appears to be predictive for Chk1 inhibitor sensitivity in pancreatic cancer cells after gemcitabine treatment ((Parsels et al. 2009), data not shown).

Furthermore, Chk1 activity promotes DNA repair through the induction of HR. This pathway is potentially defective when Chk1 is inhibited. However, pancreatic cancer cells which have impaired HR through a mutation of the tumor suppressor BRCA1 do show reduced sensitivity to gemcitabine, but no difference in $\mathrm{yH} 2 \mathrm{AX}$ accumulation after Chk1 inhibition in BRCA1 mutant and wild type cells (Hattori et al. 2011). In our model, this effect is of minor relevance as none of the used cell lines have described defects in BRCA1.

\subsubsection{Translesion synthesis}

The promotion of TLS by Chk1 is of minor relevance if replicative stress is comparably low. However, when cells suffer extensive replicative stress after gemcitabine therapy, the activation of checkpoints and induction of DNA repair is overburdened to ensure a proper replication of the genome. Then, cells are forced to undergo apoptosis or activate the Chk1dependent damage tolerance mechanism of TLS. Interestingly, this is, compared to checkpoint activation, carried out independently of Chk1 kinase function (Speroni et al. 2012; Yang et al. 2008). Two scenarios arise in which checkpoint signaling after Chk1 inhibition loses relevance: It is possible that in the subset of pancreatic cancer cells found resistant to Chk1 inhibition, checkpoint signaling is already fully activated without gemcitabine and additional DNA damage largely exceeds the cellular capacities of DNA damage and DNA repair mechanisms. Otherwise, it is reasonable that S-phase checkpoint adaptation is one of the oncogenic features those pancreatic cancer cells already bring along, so that Chk1 activation following DNA damage can hardly induce cell cycle delay. Under those conditions, kinase-dependent functions of Chk1 would step back behind kinase-independent functions of the phosphorylated Chk1 protein. Chk1 could then only act through the mediation of TLS, a process that, when activated, leads to a resumption of DNA replication, promoting gemcitabine resistance and genomic instability (see Fig. 5.1).

A role for kinase-independent functions of Chk1 in response to gemcitabine therapy is fortified by our and others' findings that there is an increase in total Chk1 and Ser317phosphorylated Chk1 levels after inhibition of its kinase domain (data not shown). The Ser317 phosphorylation site is necessary for the release of Chk1 from chromatin and the promotion of TLS following DNA damage (Smits et al. 2006; Speroni et al. 2012). Increasing Chk1 levels would thus further support the induction of TLS. If Chk1 pSer317 was of central importance for the induction of TLS, reducing it should mediate gemcitabine toxicity in cells 
which are resistant to Chk1 inhibition. Indeed, the inhibition of ATR not only reduces Chk1 pSer 317, but also increases gemcitabine toxicity in the same cell lines which we identified as resistant to Chk1 inhibition (Saini et al. 2015).

Our findings of increased cell proliferation after Chk1 inhibition are supported by the results of Syljuasen et al. who demonstrate that Chk1 kinase activity rather controls the maintenance of the $G_{2} / M$ checkpoint. The authors show that ionizing radiation-induced $G_{2}$ arrest requires Chk1 activation on several phosphorylation sites, and that cells can be forced to enter mitosis despite high $\mathrm{yH} 2 \mathrm{AX}$ signaling when the kinase function of Chk1 is inhibited (Syljuasen et al. 2006). This may play a role for Chk1 inhibitor resistance in combination with gemcitabine (Fig 5.1): In the model that we propose, inhibition of Chk1 does not only help cells through S-phase despite high levels of DNA damage. At the same time it also helps cells to abrogate the following $\mathrm{G}_{2} / \mathrm{M}$ checkpoint and divide in the presence of damaged or not fully replicated DNA. Thus, treating Chk1 inhibitor-resistant tumor cells with Chk1 inhibitor would not only have no positive effect, but would even promote genomic instability and cancer progression when the cell can avoid to die of mitotic catastrophe.

Despite promising in vitro results, the transfer of Chk1 inhibitors to bedside has been disappointing. Chk1 inhibitors display inacceptable side effects and, when lowered to doses which make those tolerable, only have low anti-tumor effectivity (Ma et al. 2011; Manic et al. 2015). Our results suggest that the lack of anti-tumor activity of Chk1 inhibition is not only a dosage effect, but is also due to chemotherapy resistance mediated by increased damage tolerance and checkpoint abrogation after Chk1 inhibition.

\subsection{Validation of screening quality of a high-content siRNA screen in pancreatic cancer cells to identify new regulators of the DNA damage response}

High-content siRNA screening is an established approach to identify regulators of a distinct response to a treatment and has been used for the identification of DNA damage transmitters before (Adamson et al. 2012; Higgins et al. 2010). Among our hits were known mediators of the gemcitabine response confirming the design of our approach. As we expected for a cell line with mutant p53, we did not find explicit regulators of the p53 pathway among the candidates, underlining that our candidates have roles in the gemcitabine response independent of p53 modulation. Only ATR, Chk1 (both positive controls), PCNA, RBM38, RPA1 and CHD8 have previously been shown to influence p53 activity. However, 
they all exhibit extensive functions apart from that and some are involved in the DDR. Interestingly, p53 itself ranged among the top 20 candidates whose knockdown led to $\mathrm{yH} 2 \mathrm{AX}$ accumulation, but none of the p53 siRNAs achieved a robust z-score higher than 2. Thus, knockdown of mutant p53 does not have a significant effect on $\mathrm{H} 2 \mathrm{AX}$ phosphorylation in PANC-1 cells, a finding that we confirmed during the following experiments. Additionally, we found the negative controls ranging around the median of each plate and found the positive controls MK2 and ATR among the candidates. Our manually added controls RNF8 and Chk1 strongly down- and upregulated H2AX phosphorylation, respectively. Another surprising result was that every ATR siRNA for control as well as the three ATR-siRNAs that where part of the library significantly reduced $\mathrm{yH} 2 \mathrm{AX}$ levels (see Fig. 4.9), although functional ATR was repeatedly reported to limit the DDR through the activation of checkpoints (also see 1.3.2). One possible explanation is that ATR might be responsible for the majority of $\mathrm{yH} 2 \mathrm{AX}$ phosphorylation in response to replicative stress and that $\mathrm{ATM}$ is not directly able to take over that function. This assumption is supported by the fact that the reduction of $\mathrm{YH} 2 \mathrm{AX}$ following ATR knockdown is more pronounced in replicating, thus EdUpositive cells, as it is the case for $\mathrm{YH} 2 \mathrm{AX}$ accumulation following Chk1 knockdown (Fig. 4.10). Both knockdowns do not influence EdU incorporation itself (Fig 7.1)

Generally, the robust z-scores we achieved during our screen are surprisingly low given that chemotherapy impacts cellular homeostasis on various levels and processes. For the identification of hits in high throughput analysis, a robust z-score of 3 or more is generally accepted for candidate identification (Brideau et al. 2003). We further observe high variance between the three siRNAs of different sequences. This can basically have two major reasons: First and besides the sequence-specific binding of siRNAs, a dose-dependent offtarget effect due to the unspecific interference with gene transcription is one of the major limitations of this method. False conclusions can be minimized by the utilization of different siRNAs of which replicable results can be rated specifically. Second, the robust z-score is highly sensitive to in-plate variations of the readout. Having various readout-influencing factors on one plate would lead to high standard deviations and low robust z-scores in the following. This is especially critical for pre-selected libraries like ours, where an influence on the readout of a comparably large scale of siRNAs is likely. Furthermore, this makes it necessary to perform a control-based approach to evaluate primary candidates. The amount and distribution of control transfections then need to be sufficient to ensure a reliable basis of comparison.

In the end, differences between cell type account for the fact that a gene which proved to have significant influence on the readout might not be suitable for transfer experiments. This should be kept in mind when concentrating on the highly represented proportion of chromatin remodeling enzymes among the candidates resulting from our screen. Especially 
chromatin perturbations that result from the respective knockdown of a chromatin remodeling enzyme can be highly cell type specific (Lans et al. 2012).

We decided to further characterize CHD8 in the gemcitabine response for two reasons: First, because it is a representative of the large family of chromatin remodeling enzymes that have been identified in the screen. Second, because it appeared promising to us according to literature research. Likewise, the following listed candidates have promising roles in cell biology that could account for an effect during replicative stress and DNA damage:

HELLS (Helicase, lymphoid-specific) is required for DNA methylation and maintenance as well as establishment of stemness (Briones and Muegge 2012). A role for HELLS in the DDR has recently been established: HELLS seems to be necessary for efficient H2AX phosphorylation in response to ionizing radiation. Depletion of HELLS leads to reduced $\mathrm{YH} 2 \mathrm{AX}$ levels and to less efficient formation of MDC1 and 53BP1 foci, thus less efficient DNA repair and reduced cell proliferation (Burrage et al. 2012). How exactly H2AXphosphorylation is reduced upon HELLS knockdown or knockout remains unclear. HELLS has not yet been investigated in the response to replicative stress.

MCM10 (Minichromosome maintenance complex component 10) is involved in DNA replication. It is required for unwinding of DNA and its presence on the eukaryotic replicative DNA helicase is necessary to activate replication origins and to recruit DNA polymerases, although it does not belong to and has no structural relation to the core minichromosome maintenance (MCM) 2-7 helicase (Kanke et al. 2012; van Deursen et al. 2012). DNA Polymerase $\alpha(\mathrm{Pol} \alpha)$ and Pol $\delta$ can only be bound to DNA in the presence of MCM10, and through its binding to $\mathrm{Pol} \alpha, \mathrm{MCM} 10$ might have a role in lagging strand synthesis. In addition to its ability to bind polymerases and PCNA, MCM10 can bind to RNA and SsDNA. As it is found to bind transiently to ssDNA at replication forks and is crucial for the association of RPA at these sites, it might have a role in ssDNA stabilization. Depletion of MCM10 results in cell cycle arrest in G2/M-Phase, a reduced entry into S-Phase and the accumulation of $\mathrm{yH} 2 \mathrm{AX}$ (Chattopadhyay and Bielinsky 2007; Thu and Bielinsky 2013). So far, MCM10 was not characterized in response to chemotherapy and has never been investigated for the sensitization of cells towards gemcitabine, but the described mechanisms suggest a role for MCM10 in this context.

STAG2 (Stromal antigen 2) is a subunit of the cohesion complex that is responsible for the separation of sister chromatids during mitosis. Loss or mutation of STAG2 causes aneuploidy in cell lines with a previously stable karyotype. Its cleavage in metaphase is a prerequisite for the adequate separation of sister chromatids (Kleyman et al. 2014; Solomon et al. 2011). STAG2 has been shown to be mutated or deleted as well as overexpressed in 
various solid and mesenchymal tumors, and is an independent prognostic marker for pancreatic adenocarcinoma where its loss correlates with good response to platinum-based regimens (Evers et al. 2014). So far, STAG2 is not known to play a role in the DDR, especially not for S-phase targeting agents as gemcitabine.

\subsection{CHD8 modulates the DNA damage response after various types of damage}

\subsubsection{A role for CHD8 in the DNA damage response and checkpoint signaling}

Our follow-up experiments confirmed the screen results in that CHD8 knockdown increases DNA damage signaling. This is not only true for replicative stress-inducing DNA adducts as achieved by gemcitabine and UV treatment, but also and even stronger after the induction of DSBs (Fig. 4.19, 4.20b). We therefore reasoned that CHD8 is not part of a damagespecific signaling cascade, but executes a broader function in the response to damaged DNA.

In CHD8-depleted PANC-1 and U2OS cells, $\mathrm{yH} 2 \mathrm{AX}$ induction is increased when combining CHD8 knockdown with all types of damaging agents we used. This effect was less pronounced after longer treatment times, which is possibly due to secondary effects that have already taken place over time like the onset of DNA repair or apoptosis. The phosphorylation of checkpoint kinases is an early event after DNA damage. Therefore, we checked for the induction of pChk1 and pChk2. The lack of accumulation of pChk1 after long-time gemcitabine treatment might be attributable to the low temporary precision of gemcitabine treatment and the pronounced time dependency of Chk1 phosphorylation: While those cells which were hit early during the administration time for gemcitabine have already decreased pChk1 levels when the cells are harvested, those cells that enter Sphase later only start to accumulate pChk1 at that time (see also Fig. 4.7). However, the accumulation of $\mathrm{yH} 2 \mathrm{AX}$ after $\mathrm{CHD} 8$ knockdown was still significant enough to identify CHD8 as a mediator of the DDR in our screen after long gemcitabine treatment time. After the administration of gemcitabine for only four hours and after the timely precise UV irradiation, the increased accumulation of $\mathrm{pH} 2 \mathrm{AX}$ as well as of pChk1 and pChk2 was clearly detectable.

Consistent with the accumulation of $\mathrm{yH} 2 \mathrm{AX}$, we thus observed an induction of both main DDR pathways: the phosphorylation of Chk1 as well as the phosphorylation of Chk2. We excluded that those findings were a secondary effect after the induction of apoptosis, which 
usually results in DNA damage signaling induced by fragmented chromatin. Interestingly, although the activation of checkpoint signaling should cause a cell to slow down progression through cell cycle, we observed the opposite to be true: CHD8-depleted, synchronized U2OS cells have a slightly accelerated passage through S-phase. In line with this, we observed that CHD8-depleted cells incorporate more EdU in untreated cells as well as after gemcitabine treatment (Fig. 7.1 and 7.3-6). This contradicts a study of Subtil-Rodriquez et al. who found CHD8 to be necessary for the progression through S-phase during unperturbed replication (Subtil-Rodriguez et al. 2014). The authors identified two CHD8dependent, S-phase specific transcribed genes, TYMS (thymidylate synthetase) and CCNE/Cyclin E1, and found that depletion of CHD8 as transcription factor of both causes a G1 arrest. However, in our microarray analysis, we did not find the above-mentioned proteins to be less transcribed in a CHD8 knockdown condition. We did find some alterations in cell cycle attributable genes, for example a 1.5-fold increase in the tumor suppressor Rb1L, but we cannot state whether this is a direct effect of CHD8 depletion or induced by for example checkpoint signaling. It would thus be of future interest to test if CHD8 depletion has influence on CDKs and CDC25s as indicators for active checkpoint signaling or if it has a pronounced role in transcription-dependent cell cycle regulation.

CHD8 did not cluster at DNA damage sites induced by UV irradiation (Fig 4.22). At such foci, DDR and DNA repair usually take place and some immobilized damage response factors cluster here, while others diffuse throughout the cell to carry out their function. There are chromatin remodeling enzymes such as CHD4 that do cluster to ionizing radiationinduced foci in a time-dependent manner. However, CHD8 is one of the largest CHD family members and constitutively immobilized to chromatin. Even major regulators of the DDR do not cluster in certain conditions, for example ATM does not cluster at sites of heterochromatic DNA damage, but only in open chromatin structures (Soria et al. 2012). As we see no difference in CHD8 levels and chromatin attachment after DNA damage (Fig. 4.15), we presume that CHD8 is a house keeping chromatin remodeler. Further, all our colocalization experiments were done with overexpressed CHD8, which leads to a flooding of the cell with the protein possibly covering moderate spatiotemporal changes.

Overexpressed CHD8 also failed to rescue the induction of $\mathrm{yH} 2 \mathrm{AX}$ after DNA damage. Already the transfection of the vector led to a strong apoptotic response, which could partially contribute to the accumulation of $\mathrm{yH} 2 \mathrm{AX}$. Given that $\mathrm{CHD} 8$ is a house keeping chromatin remodeler, and that already haploinsufficiency of CHD8 leads to strong developmental defects, any change in CHD8 levels might cause a chromatin response and DNA damage signaling. 


\subsubsection{Consequences of CHD8 in the regulation of wild type and mutant p53}

\subsubsection{Induction of apoptosis}

The activation of p53 is a major consequence of DNA damage signaling. We were especially interested in the characterization of p53-independent modulators of the gemcitabine response to meet the most frequent condition of pancreatic cancers in humans. CHD8 was first described to suppress the transcription of p53-dependent genes in mice embryonic fibroblasts and human cultured cells (Nishiyama et al. 2009). While CHD8 knockout mice die early during embryogenesis due to the widespread onset of apoptosis, the simultaneous knockout of p53 only slightly but significantly rescues the apoptotic phenotype.

In our experiments, we observed the induction of apoptosis after CHD8 knockdown in a p53 wild type as well as in a p53 mutant context in U2OS and PANC-1 cells, respectively (figures. 4.16, 4.21). This is of note because the major loss of function feature of mutant p53 is its inability to induce apoptosis, letting us assume that induction of DNA damage signaling and apoptosis in CHD8-depleted cells is not mediated by activated p53. Indeed, we could show that the accumulation of $\mathrm{yH} 2 \mathrm{AX}$ as well as of apoptosis markers is not decreased after the combined knockdown of CHD8 and p53 (figure 4.24). At this point, our results contradict the findings of Nishiyama and colleagues, but also underline a much broader function for CHD8 beyond the modulation of the p53 response (Nishiyama et al. 2009). Cells which lack functional p53 can still undergo apoptosis, and some of the mechanisms for that are known although their significance for chemotherapy-induced apoptosis remains unclear to date. One possibility is that CHD8 suppresses the p53 homologues p63 and p73 (Walerych et al. 2015).

\subsubsection{CHD8 impacts the cellular homeostasis of p53}

We also found that a cell's ability to sustain p53 active and at high levels relies on the presence of CHD8. After CHD8 knockdown, not only wild type p53 is lowered, but also the high levels of mutant p53 in PANC-1 cells are reduced, as is its phosphorylation. Although not discussed by them, Nishiyama et al. could detect the same effects in their wild type p53 experiments (figure $1 \mathrm{f}$ in Nishiyama et al., 2009). This is of particular interest as p53 is one of the best characterized proteins, and a plethora of p53-inducing and stabilizing factors are known. However, hardly any pathway is described to down-regulate p53 if not via the activity of p53 itself. Usually, in p53 mutant cancer cells, high levels of p53 as well as of MDM2 as the main ubiquitin ligase for p53 and thus its main antagonist are detectable. While p53 induces the transcription of MDM2 in a wild type setting, either this transcription or the 
interaction between MDM2 and p53 are lost when p53 is mutated. To test whether CHD8 limits p53 degradation, we stained for the cellular levels of MDM2. We found that in wild type as well as in mutant conditions, MDM2 levels decrease after CHD8 knockdown in line with p53 levels, suggesting that MDM2 is not the missing link between CHD8 depletion and loss of p53 levels. Furthermore, we find p53 levels to be decreased after CHD8 knockdown when the proteasome is blocked. This makes it unlikely that CHD8 exerts its effect on p53 levels by influencing other stabilizing factors that would normally target p53 for proteasomal degradation.

How does CHD8 then influence the cellular homeostasis of p53? If we assume that CHD8 indeed represses the transcription of p53-dependent, pro-apoptotic genes, then it should also be able to limit the transcription of p53 itself. However, during our microarray analysis we found p53 mRNA to be reduced to $66 \%$ in p53 wild type U2OS cells after CHD8 knockdown, with a false discovery rate of $11 \%$. Although we have not confirmed reduced p53 transcription in mutant p53 PANC-1 cells, we expect p53 mRNA to be reduced to match the changes we see of high mutant p53 protein levels (Fig 4.25).

\subsubsection{Regulation of mutant p53 in tumor biology}

Why is the decrease of mutant p53 levels of particular biological and clinical interest? Oncogenic signaling and elevated levels of DDR are key features of a developing malignant cell and are kept under control by the constant activation of p53. This leads to a high selective pressure for loss of function mutations of the tumor suppressor, which accounts for the fact that p53 is mutated in around $50 \%$ of tumors (Hollstein et al. 1991; Kandoth et al. 2013). Nonsense mutations account for only $10 \%$ of occurring p53 interruptions, and while deletions of p53 mainly occur in hematological malignancies, around $75 \%$ are missense mutations as found for pancreatic cancers (Leroy et al. 2014). Those missense mutations occur mainly in the DNA binding domain, while the transactivation domain remains unaffected. Mutations thus interfere with p53-dependent transcription but conserve the ability to activate gene transcription when bound to DNA in an alternative manner (Oren and Rotter 2010). Missense-mutated p53 leads to the flooding of a cell with dysfunctional p53 protein, mainly because it is withdrawn from feedback loops and unable to induce the transcription of its main negative regulator MDM2. Mutant p53 is not more stable than its wild type counterpart, but is rather stabilized in the same manner, which is the constantly elevated DDR in tumor cells (Oren and Rotter 2010). Interestingly, many oncogenic gain of function features of missense p53 mutations have been reported that, dependent on the mutated sequence and expression level, render mutant p53 a heterogenic group of cancer 
driving proteins (Bykov et al. 2018). Stabilizing mutant p53 by the above-mentioned mechanisms enhances its oncogenic potential.

These gain of function mutations enable p53 to suppress other family members, for example p63 and p73, which usually take over some of p53 functions in knockout experiments (Gaiddon et al. 2001). Mutant p53 collaborates with activated Ras signaling, the most common oncogenic pathway in pancreatic cancer, to promote tumor cell transformation (Suh et al. 2011). .

At a DDR level, mutant p53 can inactivate proper DNA damage signaling by preventing ATM activation. The mutated p53 protein binds to MRE11, which is part of the ahead mentioned MRN complex (Section 1.3.3). Mutant p53 impairs complex assembly which further is critical for the tethering of ATM to damaged DNA and its activation (Song et al. 2007). Thus, mutant p53 drives cancer cell malignancy through transcriptional interference, as well as altered protein binding and recruitment compared to wild type p53, and by impairing tumor suppressive functions of other factors (Oren and Rotter 2010).

It is thus of interest for anti-cancer therapy and matter of debate and research for years how wild type functions of mutant p53 can be restored or how the abundance of mutant p53 can be downregulated (Bykov et al. 2018).

To our knowledge, there are only few known factors whose manipulation can lower the cancer cells' load of mutant p53. One of those is the HSP 90 (heat shock protein 90) which stabilizes gain of function mutant p53 in colorectal cancers and whose inhibition suppresses p53 levels and tumor growth (Schulz-Heddergott et al. 2018). It is thus of interest to obtain a more detailed view of the interference of CHD8 with the transcription of mutant p53.One question is whether a decrease of the entire CHD8 protein is necessary for this effect or whether the inhibition of a certain domain of CHD8 by small molecules is already sufficient. The latter would make CHD8 a potentially druggable target for mutant p53 malignancies such as pancreatic cancer, even more so if we take into account that a slight disturbance of p53 activity can be sufficient for extensive effects to be seen (Vousden and Lane 2007).

\subsection{CHD8-dependent transcription of DNA damage response factors}

In the literature, $\mathrm{CHD} 8$ is characterized mainly as to its regulation of transcription by various mechanisms (see also 1.8). We therefore grouped the results from microarray analysis 
according to cellular functions (Table 4.2). Of those, some candidates appeared promising to us because they are already mechanistically involved in the DDR.

The downregulation of USP11 (Ubiquitin-specific protease 11) following CHD8 knockdown has already been found before (Rodriguez-Paredes et al. 2009) and could be detected and confirmed via qPCR and on a protein basis in our lab (data not shown). USP11 is an established DDR factor acting in the BRCA2-dependent HR pathway. While patients with germline BRCA2 mutations have a high risk to develop pancreatic and other tumors, sporadic BRCA2 mutations in pancreatic cancer samples are comparatively rare. Pancreatic cancer cells with an intact HR pathway are susceptible to mitoxantrone treatment that is, among its conventional DNA damaging properties, able to potently inhibit USP11 (Burkhart et al. 2013). However, while this study found mitoxantrone being much more effective to reduce pancreatic cancer cell proliferation than is gemcitabine, it did not find a significant cytoreductive effect with RNAi-mediated USP11 depletion to $60 \%$ in untreated cells. Possibly, mitoxantrone exhibits its cytoreductive effect through other mechanisms than via USP11 inhibition. Nonetheless, the RNAi-mediated reduction of cellular USP11 levels did have a sensitizing effect for gemcitabine treatment, making it plausible that the enhanced DDR after CHD8 depletion is a secondary effect mediated by the suppression of USP11. Still, the knockdown of CHD8 in our experiments reduces USP11 levels more than does the knockdown of USP11 itself in the above-mentioned publication, which is to $31 \%$ instead of $60 \%$. Another study showed that USP11 binds to BRCA2 to ubiquitinate it, and it sensitized cells to mitomycin $C$ treatment only in a BRCA2 wild type condition. However, cellular levels of BRCA 2 were not lowered after USP11 depletion, so that it the question remains whether USP11 specifically promotes HR or whether BRCA2 defective cells exhibit high chemoresistance in general (Schoenfeld et al. 2004). Of note, USP11 stabilizes p53 by reducing its ubiquitination, leading to a proapoptotic response of a cell (Ke et al. 2014). In the same way it stabilizes p21 to promote cell cycle arrest and senescence (Deng et al. 2018). Besides the influence on protein turnover, USP11 promotes the transcription of IKKa in response to NF-KB signaling and its depletion leads to reduced p53 expression in p53 wild type conditions (Yamaguchi et al. 2007).

Although we cannot detect a p53-stabilizing effect following CHD8 knockdown, the known features of USP11 depletion would well explain at least some of our observations like cell cycle progression and reduced p53 levels in CHD8-depleted cells. Still, it is not known whether USP11 has any effect on the transcription of mutant p53.

With its DNA repair and p53/p21-promoting properties, USP11 would rather act as a tumor suppressor and its knockdown should lead to an increase in DDR through impaired HR, but 
also to apoptosis resistance through reduced p53 levels and cell survival after DNA damage.

The downregulation of the scaffolding protein KSR2 (kinase-suppressor of Ras 2) connects CHD8 to cellular stress and proliferation signaling cascades. KSR2 positively regulates Ras signaling, which is a signaling cascade connecting receptor tyrosine kinase signaling to DNA damage and transcriptional responses of a cell. The most common tumor driving mutation of pancreatic cancer, an activating KRAS mutation, leads to a constant induction of this kinase cascade. While oncogenic KRAS activations cannot be targeted yet, the inhibition of downstream kinases such as ERKs induces DNA damage signaling and apoptosis (Kirkpatrick et al. 2013) as well as p53 phosphorylation and stabilization (Melnikova et al. 2003). KSR2 positively regulates receptor tyrosine kinase-mediated ERK signaling and might thus have tumor-promoting functions, but the KSR2-dependent growth induction of several tumor cell lines is independent of upstream kinase signaling (Fernandez et al. 2012). Based on the above-mentioned, the decrease in KSR2 levels could also be a mediator of the effects of CHD8 knockdown on DNA damage signaling and apoptosis.

When we focused on genes whose transcription is induced upon CHD8 knockdown, two DNA repair factors are noticeable: First, the 1.5-fold induction of the histone acetylase KAT5/TIP60 links CHD8 to the repair of DSBs, too. Following the induction of DSBs, the acetylation of $\mathrm{H} 4$ by the histone acetyl transferase TIP60 is required for efficient recruitment of repair proteins like ATM, which itself is acetylated by KAT5 to increase its activity (Murr et al. 2006; Sun et al. 2005). TIP60 further acetylates $\mathrm{YH} 2 \mathrm{AX}$ as a prerequisite for H2AX ubiquitination and removal from DNA after damage is repaired (Ikura et al. 2007). If CHD8 acted via KAT5, CHD8-deficient tumor cells would hyper-activate ATM, DNA repair and, if not defective for it, apoptosis.

Second, with MDC1, another DNA repair protein is induced after CHD8 knockdown. MDC1 is a large scaffolding protein which has a central role in the activation of ATM and therefore the spreading of $\mathrm{yH} 2 \mathrm{AX}$ away from the actual DNA lesion to promote not only DDR, but also apoptosis (see section 1.3.3). Indeed, high expression levels of MDC1, although a repair protein, are associated with chemoresistance in malignant cells. The cause seems to be a general activation of the DNA repair machinery in response to an amplification of DNA damage signaling after drug-induced damage, leading to high levels of $\mathrm{yH} 2 \mathrm{AX}$ on the one hand, but fast DNA repair and the resumption of cell cycle progression and tumor proliferation on the other hand. MDC1 recruits the ubiquitin ligases RNF8 and RNF168 to chromatin, where they ubiquitinate histone $\mathrm{H} 2 \mathrm{~A}$ as a prerequisite for $\mathrm{BRCA} 1$-dependent repair of DSBs (Luijsterburg and van Attikum 2011). MDC1 is increased to 1.6-fold after CHD8 depletion, so to a much lower extent as usually seen for transcriptional responses in 
signaling cascades. Still, as MDC1 acts far upstream of the DDR and its abundance delicately influences the intensity of DNA damage signaling, already small changes would have a dramatic effect. Interestingly, MDC1 was among the main candidates whose knockdown robustly lowered $\mathrm{yH} 2 \mathrm{AX}$ levels in our siRNA screen showing that it promotes $\mathrm{H} 2 \mathrm{AX}$ phosphorylation in response to gemcitabine treatment (Fig. 4.12, table 7.1 and 7.2).

\subsection{A model of chromatin reorganization induced by CHD8 depletion for efficient promotion of DNA repair after UV and gemcitabine treatment}

Higher order chromatin structure profoundly influences genome maintenance and DNA repair. Chromatin structures are non-randomly distributed within the nucleus, one of the best examples being the organization of DNA into euchromatin and heterochromatin. Euchromatin contains actively transcribed genes, and facultative heterochromatin occurs by gene silencing for example during cellular differentiation (Nair and Kumar 2012). Constitutive heterochromatin represents around $25 \%$ of the genome and is characterized by low gene density but highly repetitive sequences that increase the risk for recombination and might necessitate an even tighter control of genome maintenance (Goodarzi and Jeggo 2012; Soria et al. 2012). Although chromatin is undoubtedly needed for the regulation of virtually all DNA-associated processes to take place, it primarily forms a barrier to efficient DNA repair. High compaction in heterochromatin hinders the access for repair factors even more, but due to its high abundance, it forms the major environment in which the whole DDR takes place (Bakkenist and Kastan 2015). A cell deals with such a challenge and threat to genomic integrity by tightly regulated mechanisms:

When damaged DNA is encountered, chromatin needs to be opened first to elicit a fully activated DDR and needs to be restored when damage is repaired. One well characterized process is the CHD3-dependent relaxation of heterochromatin: ATM, when activated, phosphorylates the heterochromatin-associated protein KAP-1, which loosens contact to DNA and to CHD3, which in turn diffuses from chromatin to open it. After repair, the restoration of KAP-1 to DNA tethers CHD3 to the NuRD complex, again leading to the reformation of heterochromatin (Klement et al. 2014).

Indeed, spreading of $\mathrm{YH} 2 \mathrm{AX}$ is impaired when meeting heterochromatin border and $\mathrm{YH} 2 \mathrm{AX}$ foci form slower in heterochromatin (Brunton et al. 2011; Soria et al. 2012). Also, repair of DSBs seems to occur 2-fold slower in heterochromatin than in euchromatin and is predominantly dependent on ATM, whereas in euchromatin some studies found that it is not (Goodarzi et al. 2008). 


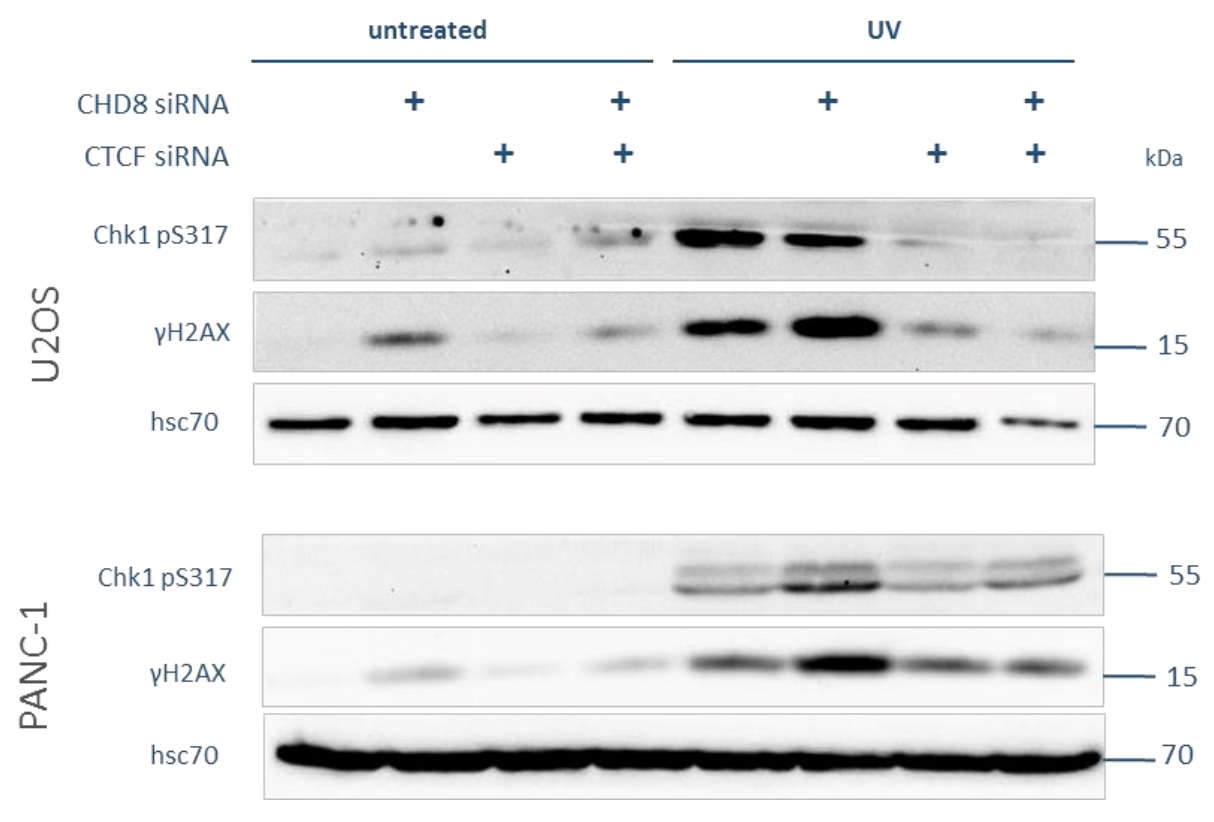

Figure 5.2 Depletion of CTCF does not increase the cellular DNA damage response but rescues the effect of CHD8 depletion in UV-treated cells.

U2OS and PANC- 1 cells were depleted of CHD8 and CTCF as indicated and treated with $20 \mathrm{~J} / \mathrm{m}^{2} \mathrm{UV}-\mathrm{C}$ or left untreated. One hour after treatment, cells were harvested and analyzed by immunoblotting.

Heterochromatin is refractory to the spreading of $\mathrm{yH} 2 \mathrm{AX}$ and $\mathrm{yH} 2 \mathrm{AX}$ foci occur mutually exclusively with heterochromatin marks but cluster in the periphery of those (Goodarzi and Jeggo 2012). In yeast, $\mathrm{YH} 2 \mathrm{AX}$ spreading is immediately stopped when encountering a heterochromatic region (Kim et al. 2007).

The generation of global chromatin environments requires boundary elements, to which chromatin modifying enzymes are recruited. One of those boundary elements is CTCF. Indeed, we observed that the induction of DNA damage signaling upon CHD8 $\mathrm{kd}$ is dependent on the presence of CTCF in a preliminary result, but here both factors appear to have antagonistic effects on the DDR (Fig. 5.2).

The relevance of the above-mentioned becomes clear when we take into account that, indeed, an open chromatin structure as found in stem cell like populations confers higher chemoresistance through a higher capacitie to repair DNA. CHD8 can be integrated in a model of chromatin organization to modulate the DDR and chemoresistance as follows: The linker histone $\mathrm{H} 1$ has been found to delicately influence chemoresistance as its deletion leads to an open chromatin structure and hyperresistance to a variety of DNA damaging agents (Hargreaves and Crabtree 2011; Murga et al. 2007). CHD8 could do the same by providing an open chromatin environment. It evidently binds histone $\mathrm{H} 1$ to chromatin (Nishiyama et al. 2009) and it would be of interest whether depletion of CHD8 leads to a 

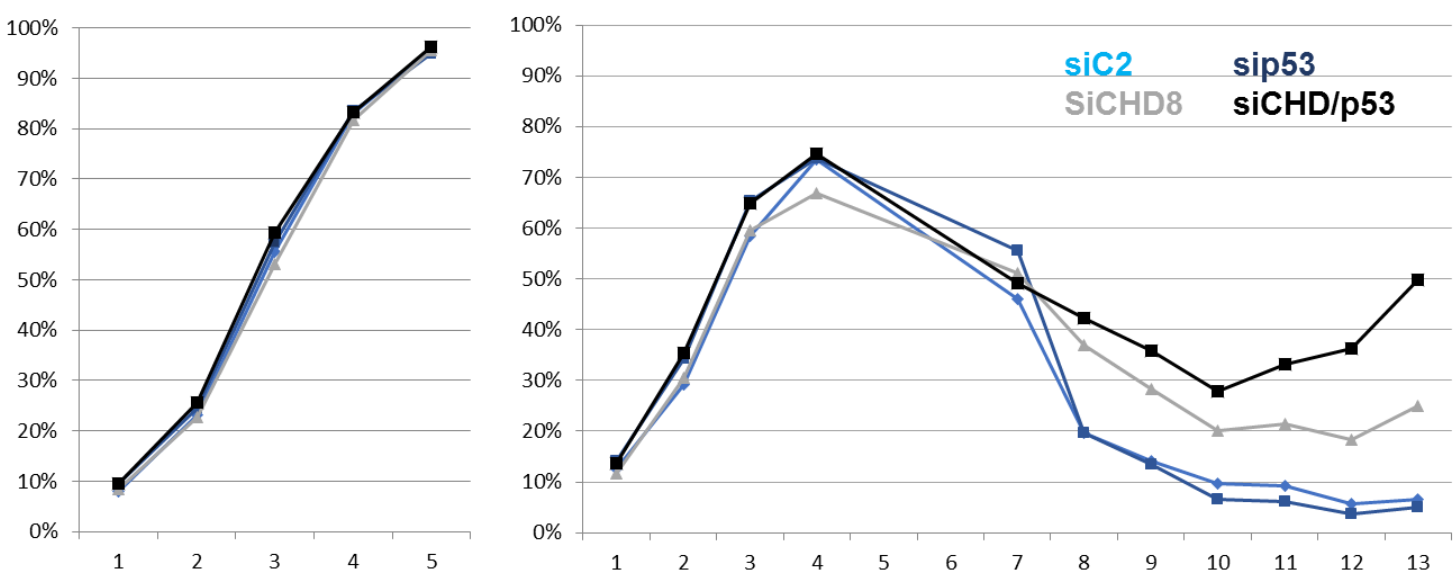

Figure 5.3 Influence of CHD8 knockdown on cell proliferation after gemcitabine treatment.

U2OS cells were transfected with the siRNAs as indicated. After the replacement of transfection mix and recovery, they were trypsinized, counted and seeded and either treated with gemcitabine or left untreated as indicated. The confluence of a plate was determined every day using bright field microscopy and digital image analysis.

phenotype comparable to $\mathrm{H} 1$ depletion. However, open chromatin structures do not unilaterally promote DNA repair and cell survival. Decompacted DNA becomes hydrolyzed easily activating the DDR (Walerych et al. 2015). Further, facilitating DDR leads to an apoptotic response (Bakkenist and Kastan 2015). As a consequence, decompaction of chromatin may initially lead to increased $\mathrm{YH} 2 \mathrm{AX}$ accumulation and cell death, but in the long term increases the fraction of chemoresistant cells. If we apply this model to the phenotype we see after CHD8 knockdown, we should not only observe increased DNA damage response but also chemoresistance. Indeed, as a preliminary result, we do see a slight -though not significant -- reduction of cell growth in CHD8-depleted, gemcitabine-treated cells initially. This is independent of the presence of p53. As soon as cells start to recover

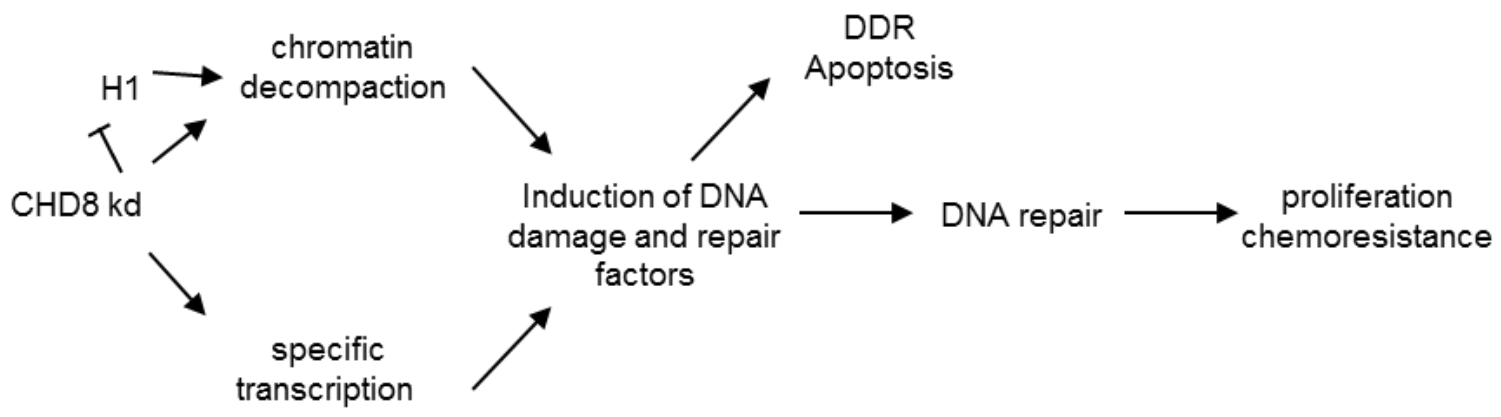

Figure 5.4 A model for CHD8 in the DNA damage response.

This speculative model integrates transcription and chromatin remodeling functions of CHD8. Either the decompaction of chromatin after CHD8 knockdown or the enhanced transcription lead to accumulation of DNA damage and repair factors, resulting in increased DNA damage signaling and apoptosis on the one hand but a higher fraction of cells which can repair their DNA and therefore resume proliferation and acquire chemoresistance on the other hand. 
from gemcitabine treatment, CHD8-depleted cells show a slight growth advantage (Fig. 5.3). Furthermore, we observe increased EdU incorporation and slightly faster progression through cell cycle after CHD8 depletion.

Thus, a speculative model emerges bringing together the decompaction of chromatin as potential mechanistic basis for CHD8's role in the DNA damage response together with the expression of KAT5 and MDC1 following CHD8 knockdown (see Fig. 5.4): CHD8 knockdown could either specifically activate the transcription of KAT5 and MDC1 or both factors could be induced as a secondary effect of chromatin decompaction after CHD8 knockdown. The acetylation of histones by KAT5 supports an open chromatin structure, which facilitates the clustering of highly transcribed MDC1 even more. Both initially leads to increased DNA damage signaling but also the activation of ATM and DNA repair pathways, leading to a low response to DNA damaging agents.

\subsection{Conclusions and future perspectives}

In the work presented here we transferred a newly discovered function of MK2 as antagonist of Chk 1 to the treatment of pancreatic cancer cells with gemcitabine. We could confirm a protective effect of MK2 inhibition to chemotherapy in all cell lines tested. This suggests MK2 as a novel predictor of gemcitabine sensitivity and its activation to be a promising drug target in pancreatic cancers. Interestingly, when we approached the transferability of the antagonism of MK2 and Chk1 to pancreatic cancers, we found the system to work in only one of four tested cell lines. All other cell lines acquired chemoresistance to gemcitabine when Chk1's kinase function was impaired. This puts the break to the enthusiasm of applying checkpoint kinase inhibitors as chemosensitizers.

In our high throughput approach to find novel modulators of the gemcitabine response we identified the chromatin remodeling factor CHD8, which has been described with contradicting properties in terms of its role in tumor biology and DNA-associated processes. In our experiments, knockdown of CHD8 led to increased DNA damage signaling, i.e. the induction of $\mathrm{yH} 2 \mathrm{AX}$, but also to increased phosphorylation of the checkpoint kinases Chk1 and Chk2. This was true for UV, gemcitabine as well as for the radiomimetic NCS, suggesting a broad function for CHD8 in the DDR and possibly the involvement of numerous pathways. The effect of CHD8 knockdown was most pronounced when the induction of DNA damage was restricted to a short period of time, and even stronger after the induction of DSBs. As a consequence, we could detect the onset of apoptosis in CHD8-depleted cells, 
irrespective of p53. We further detected faster resumption of cell cycle progression, increased incorporation of nucleotides into DNA and a debatable advantage in terms of the recovery after gemcitabine treatment. It is of note that CHD8-deficient cells display diminished levels of wild type as well as oncogenic mutant p53, whose non-targetable abundance remains a challenging task in research on tumor biology. We expand the still small library of mutant-p53 regulating factors by one.

However, other scientists have reported features for CHD8 that apparently contradict our findings. It will thus be of future interest to shed more light on CHD8-regulated processes in the DDR, which we could only roughly outline in this work. To specify CHD8's role in cell cycle regulation, it would be of interest to determine CDK and Cdc25 activity in a cell cyclespecific manner. If cell cycle progression were resumed faster after the induction of DNA damage by gemcitabine or other agents, it would suggest faster repair of damaged DNA. Finally, it would be of interest to find the underlying mechanism for the decrease of p53 levels in CHD8-depleted cells, and whether this is attributable to CHD8's transcriptional function or a secondary effect of general interference of CHD8 with transcription or chromatin reorganization. We further gained ideas for $\mathrm{CHD} 8$-regulated processes through our microarray analysis: The downregulation of USP11 as well as the upregulation of Tip60 would promote HR, a DNA repair pathway which we have not analyzed in detail so far. In particular, CHD8 knockdown upregulates MDC1, whose levels and binding to chromatin increase DNA damage signaling. Therefore, the levels and activity of ATM should be determined more directly than via the phosphorylation of Chk2, which we clearly observe in CHD8-depleted cells as first evidence for increased ATM-dependent signaling in our experiments. If this were the case, DNA damage signaling would lead to faster recovery after DNA damage. The preliminary result that CHD8-depleted cells resume proliferation faster after chemotherapy require replication. Further, established markers of eu- and heterochromatin may serve as a readout for the influence of CHD8 on chromatin organization.

Summarized, the data presented in this work does not only establish MK2 as a determinant in the gemcitabine response in pancreatic cancer cells, but challenges the strategy of applying checkpoint inhibitors as cancer therapeutics. Furthermore, our findings demonstrate for the first time a role for CHD8 in the DDR. Mechanistic details need to be analyzed to clarify the contradicting findings for CHD8 in cancer cell biology before one could exploit it as prognostic factor or drug target. Our results rather open a new door for the understanding of a chromatin response to DNA damage, which is well examined in hematological malignancies but is only beginning to be appreciated in terms of cancer promotion in solid tumors. The relaxation and restoration of chromatin is a tightly regulated and ATP-consuming process and therefore susceptible to dysregulation in cancers. It would 
be no surprise if a balanced activation and silencing of CHD8 turned out to be a cellular mechanism for resistance as well as for the response to chemotherapy. More generally, instead of inhibiting a single molecule, it seems to be reasonable to target whole pathways and physiological cellular responses in order to account for genetic heterogeneity and the fast acquirement of drug resistance seen in pancreatic cancer. For this purpose, chromatin modifying enzymes are potential candidates as their loss of function broadly affects cellular homeostasis in terms of various signaling pathways. 


\section{Abstract}

DNA damage occurs and accumulates in every cell and is cause and consequence of cancerogenesis. Massive induction of exogenous DNA damage has its use in chemotherapy as it causes growth arrest and apoptosis in malignant cells. The cellular response to replicative stress and DNA damage consists of a signaling network called DNA damage response.

The chemotherapeutic drug gemcitabine is a nucleoside analog selectively acting during Sphase of the cell cycle and therefore affects mainly highly proliferative cells like those found in tumors. Its main application is the treatment of pancreatic cancer, which is characterized by poor therapeutic response and fast development of chemoresistance. Manipulating DNA damage and repair pathways in order to sensitize tumors to this drug has been part of many clinical trials. In this context, the knockdown or inhibition of the DNA damage effector kinase Chk1 highly activates the DNA damage response and apoptosis. Another DNA damage kinase, MK2, was previously identified in our lab as antagonist of Chk1 in the response to DNA replicative stress caused by gemcitabine.

In the first part of this work, the antagonism of the two kinases MK2 and Chk1 was established as determinant of the sensitivity to gemcitabine in a variety of pancreatic cancer cell lines. Interestingly, the inhibition of Chk1 induces apoptosis only in one cell line while it mediates chemoresistance to gemcitabine in the others. This remarkable observation adds a new aspect to the criticism of Chk1 inhibitors as cancer therapeutics.

The second part of this work focuses on identifying new determinants of the gemcitabine response. To this end, a high throughput screen in gemcitabine-treated pancreatic cancer cells was performed using RNA-interference to deplete cells of 551 gene products which have a previously assigned function in the DNA damage response and genomic integrity. The screen identifies the chromatin remodeling factor CHD8 to protect cells from the early consequences of gemcitabine treatment. Its knockdown causes the accumulation of DNA damage and apoptosis markers after replicative stress induced by gemcitabine and ultraviolet radiation as well as after DNA double strand breaks induced by the radiomimetic neocarzinostatin. In contrast to these seemingly chemosensitizing effects, cells depleted of $\mathrm{CHD} 8$ obtain a growth advantage through faster recovery after gemcitabine treatment. The transcriptional expression of a number of factors involved in the DNA damage response is 
found to be influenced by CHD8, as demonstrated by microarray analysis. These effects are independent of the presence or functionality of the tumor suppressor $p 53$, whose mRNA expression as well as protein levels are diminished in CHD8-depleted cells. Remarkably, CHD8 depletion can also reduce the abundance of oncogenic mutant p53. This is of potential clinical relevance as there are only few ways known to achieve this reduction. In summary, we identify CHD8 as a modulator of chemosensitivity with influence on the expression of central DNA damage response genes. 


\section{Appendix}

Table 7.1 Screen candidates based on overall yH2AX levels.

Screen candidates were defined as genes whose knockdown led to a robust $z$-score $<-2$ or $>2$ of overall $\mathrm{yH} 2 \mathrm{AX}$ levels with at least two of three siRNAs. All candidates were sorted by their achieved cumulative robust z-scores in $\mathrm{yH} 2 \mathrm{AX}$ levels. Column A to $\mathrm{C}$ indicate the respective siRNA of the library. Robust $\mathrm{z}$-scores of the candidates in EdU-positive cells and their influence on EdU incorporation are coated blue and green, respectively. Candidates which were further validated are marked red. Candidates achieving a robust-Z-score $<-2$ or $>2$ in EdU-positive cells are marked blue.

YH2AX in all cells

pH2AX in EdU-positive cells

\begin{tabular}{|c|c|c|c|c|c|c|c|c|c|c|c|c|c|}
\hline \multirow{2}{*}{$\begin{array}{l}\text { Gene } \\
\text { Symbol }\end{array}$} & \multirow[t]{2}{*}{ Gene Name } & \multicolumn{4}{|c|}{ robust z-score } & \multicolumn{4}{|c|}{ robust z-score } & \multicolumn{4}{|c|}{ robust z-score } \\
\hline & & A & B & C & Cum. & A & B & C & Cum. & A & B & C & Cum. \\
\hline REC8 & REC8 homolog (yeast) & $-5,03$ & $-2,71$ & $-0,83$ & $-8,57$ & $-6,20$ & 1,09 & $-0,36$ & $-5,47$ & $-0,16$ & $-2,00$ & 1,78 & $-0,38$ \\
\hline HDAC5 & Histone deacetylase 5 & $-3,73$ & 0,10 & $-4,78$ & $-8,41$ & $-1,21$ & $-1,07$ & $-0,05$ & $-2,33$ & $-0,93$ & 0,00 & $-0,77$ & $-1,70$ \\
\hline RUVBL2 & RuvB-like 2 (E. coli) & $-2,46$ & $-0,26$ & $-5,34$ & $-8,06$ & $-2,98$ & 1,86 & 7,63 & 6,51 & $-1,02$ & 0,75 & $-1,70$ & $-1,97$ \\
\hline TERF2IP & $\begin{array}{l}\text { Telomeric repeat } \\
\text { binding factor 2, } \\
\text { interacting protein }\end{array}$ & $-4,51$ & $-2,28$ & $-1,21$ & $-7,99$ & $-0,05$ & 13,00 & $-0,06$ & 12,90 & $-1,58$ & $-1,74$ & $-0,95$ & $-4,27$ \\
\hline MDC1 & $\begin{array}{l}\text { Mediator of DNA- } \\
\text { damage checkpoint } 1\end{array}$ & $-3,04$ & $-1,96$ & $-2,66$ & $-7,65$ & $-1,44$ & $-2,87$ & $-2,35$ & $-6,66$ & $-1,00$ & $-0,96$ & 1,27 & $-0,70$ \\
\hline RAD23B & $\begin{array}{l}\text { RAD23 homolog B (S. } \\
\text { cerevisiae) }\end{array}$ & $-2,79$ & $-1,68$ & $-3,02$ & $-7,49$ & $-1,59$ & 0,44 & $-0,76$ & $-1,91$ & $-1,33$ & $-0,63$ & $-0,78$ & $-2,74$ \\
\hline ARID1A & $\begin{array}{l}\text { AT rich interactive } \\
\text { domain } 1 \mathrm{~A} \text { (SWI-like) }\end{array}$ & $-3,40$ & $-2,52$ & $-1,14$ & $-7,06$ & $-0,05$ & $-1,24$ & $-1,06$ & $-2,36$ & $-0,96$ & $-1,04$ & 0,15 & $-1,85$ \\
\hline CCNO & Cyclin O & $-1,53$ & $-2,55$ & $-2,85$ & $-6,93$ & 1,65 & $-1,73$ & $-5,40$ & $-5,48$ & $-0,69$ & $-0,85$ & 1,37 & $-0,17$ \\
\hline ATR1 & $\begin{array}{l}\text { Ataxia telangiectasia } \\
\text { and Rad3 related }\end{array}$ & $-2,24$ & $-1,75$ & $-2,27$ & $-6,26$ & $-3,90$ & $-3,00$ & $-5,02$ & 11,92 & 1,28 & 1,47 & 2,40 & 5,16 \\
\hline SOX15 & $\begin{array}{l}\text { SRY (sex determining } \\
\text { region } Y \text { )-box } 15\end{array}$ & $-2,01$ & $-3,32$ & $-0,40$ & $-5,72$ & $-1,23$ & 0,00 & 0,95 & $-0,28$ & $-0,96$ & $-4,01$ & $-0,88$ & $-5,86$ \\
\hline UBE2N & $\begin{array}{l}\text { Ubiquitin-conjugating } \\
\text { enzyme E2N (UBC13 } \\
\text { homolog, yeast) }\end{array}$ & $-2,60$ & $-0,27$ & $-2,52$ & $-5,39$ & 0,20 & $-0,38$ & $-0,60$ & $-0,78$ & $-1,16$ & $-0,12$ & $-0,95$ & $-2,23$ \\
\hline C9orf102 & $\begin{array}{l}\text { Chromosome } 9 \text { open } \\
\text { reading frame } 102\end{array}$ & $-0,86$ & $-2,09$ & $-2,11$ & $-5,06$ & 1,73 & $-1,82$ & 1,62 & 1,53 & $-1,31$ & $-0,98$ & $-0,99$ & $-3,28$ \\
\hline HELLS & $\begin{array}{l}\text { Helicase, lymphoid- } \\
\text { specific }\end{array}$ & $-2,93$ & $-2,36$ & 0,25 & $-5,03$ & $-3,18$ & $-2,08$ & $-0,49$ & $-5,75$ & $-0,35$ & $-0,63$ & 1,99 & 1,02 \\
\hline EP400 & $\begin{array}{l}\text { E1A binding protein } \\
\text { p400 }\end{array}$ & $-0,37$ & $-2,29$ & $-2,26$ & $-4,92$ & $-1,72$ & $-1,59$ & $-2,84$ & $-6,15$ & 0,35 & $-0,97$ & $-0,82$ & $-1,45$ \\
\hline FANCA & $\begin{array}{l}\text { Fanconi anemia, } \\
\text { complementation } \\
\text { group A }\end{array}$ & $-0,02$ & $-2,34$ & $-2,49$ & $-4,85$ & $-0,46$ & $-2,38$ & $-3,00$ & $-5,85$ & 3,36 & $-1,18$ & $-0,83$ & 1,36 \\
\hline MYC & $\begin{array}{l}\text { V-myc } \\
\text { myelocytomatosis viral }\end{array}$ & $-2,05$ & $-3,35$ & 0,63 & $-4,77$ & 0,78 & 0,46 & 1,15 & 2,40 & $-1,10$ & $-1,04$ & 7,57 & 5,44 \\
\hline
\end{tabular}




\begin{tabular}{|c|c|c|c|c|c|c|c|c|c|c|c|c|c|}
\hline & $\begin{array}{l}\begin{array}{l}\text { oncogene homolog } \\
\text { (avian) }\end{array} \\
\text { (avian }\end{array}$ & & & & & & & & & & & & \\
\hline SUV39H2 & $\begin{array}{lr}\text { Suppressor } & \text { of } \\
\text { variegation } & 3-9 \\
\text { homolog } 2 \text { (Drosophila) }\end{array}$ & $-0,02$ & $-2,10$ & $-2,62$ & $-4,73$ & $-0,37$ & $-0,71$ & 1,71 & 0,63 & 1,31 & $-2,62$ & $-1,56$ & $-2,87$ \\
\hline SMUG1 & $\begin{array}{l}\text { Single-strand-selective } \\
\text { monofunctional uracil- } \\
\text { DNA glycosylase } 1\end{array}$ & $-2,24$ & 0,16 & $-2,49$ & $-4,57$ & $-0,51$ & $-0,28$ & 2,51 & 1,72 & $-1,51$ & 3,66 & $-1,70$ & 0,46 \\
\hline H1FX & $\begin{array}{l}\text { H1 histone family, } \\
\text { member } X\end{array}$ & 2,21 & 0,03 & 2,27 & 4,51 & 0,79 & 0,17 & 1,83 & 2,80 & 3,29 & $-0,44$ & 3,79 & 6,65 \\
\hline GTF2H4 & $\begin{array}{l}\text { General transcription } \\
\text { factor IIH, polypeptide } \\
4,52 \mathrm{kDa}\end{array}$ & $-0,17$ & 1,05 & 3,79 & 4,66 & $-2,13$ & 0,46 & 9,49 & 7,82 & $-0,55$ & $-0,69$ & $-0,65$ & $-1,89$ \\
\hline PARP2 & $\begin{array}{l}\text { Poly (ADP-ribose) } \\
\text { polymerase } 2\end{array}$ & 0,86 & 1,61 & 2,19 & 4,67 & 0,09 & 1,00 & 2,05 & 3,14 & $-0,36$ & 4,62 & 0,63 & 4,89 \\
\hline SMC2 & $\begin{array}{l}\text { Structural } \\
\text { maintenance } \\
\text { chromosomes } 2\end{array}$ & 2,77 & 0,44 & 2,16 & 5,36 & 1,41 & $-0,08$ & 6,09 & 7,42 & 3,80 & $-0,90$ & $-1,10$ & 1,80 \\
\hline RBM38 & $\begin{array}{l}\text { RNA binding motif } \\
\text { protein } 38\end{array}$ & 2,29 & 3,14 & 0,24 & 5,66 & 2,26 & 2,80 & 0,33 & 5,40 & 5,17 & 6,09 & 1,33 & 12,59 \\
\hline STAG2 & Stromal antigen 2 & 2,48 & 1,75 & 3,34 & 7,57 & 2,61 & 1,44 & 4,27 & 8,33 & 3,60 & $-0,60$ & 0,36 & 3,36 \\
\hline MCM10 & $\begin{array}{l}\text { Minichromosome } \\
\text { maintenance complex } \\
\text { component } 10\end{array}$ & 6,62 & 5,68 & $-1,05$ & 11,25 & 2,48 & 5,13 & 0,78 & 8,40 & 2,17 & 21,00 & $-0,63$ & 22,54 \\
\hline CHD8 & $\begin{array}{l}\text { Chromodomain } \\
\text { helicase DNA binding } \\
\text { protein } 8\end{array}$ & 7,49 & 1,70 & 3,46 & 12,65 & 6,99 & 1,66 & 3,79 & 12,44 & 15,65 & 2,74 & 0,72 & 19,11 \\
\hline CHEK1 & $\begin{array}{l}\text { CHK1 checkpoint } \\
\text { homolog (S. pombe) }\end{array}$ & 11,91 & 6,97 & 0,83 & 19,71 & 13,76 & 10,58 & 0,87 & 25,21 & 1,35 & $-0,61$ & $-0,99$ & $-0,24$ \\
\hline
\end{tabular}

\section{Table 7.2 Screen candidates based on yH2AX levels in EdU-positive cells.}

Screen candidates were defined as genes whose knockdown led to a robust z-score $<-2$ or $>2$ of $\gamma \mathrm{H} 2 \mathrm{AX}$ levels in EdU-positive cells with at least two of three siRNAs. All candidates (coated blue) were sorted by their achieved cumulative robust z-score in EdU-gated $\mathrm{yH} 2 \mathrm{AX}$ levels. Column A to C indicate the respective siRNA of the library. Robust z-scores of the candidates in all cells and their influence on EdU incorporation are coated grey and green, respectively. Candidates which have been further validated are marked red. Candidates achieving a robust $z$-score $<-2$ or $>2$ in overall $\mathrm{yH} 2 \mathrm{AX}$ levels are marked blue.

\begin{tabular}{|c|c|c|c|c|c|c|c|c|c|c|c|c|c|}
\hline \multicolumn{6}{|c|}{ pH2AX in EdU-positive cells } & \multicolumn{4}{|c|}{ YH2AX in all cells } & \multicolumn{4}{|c|}{ EdU incorporation } \\
\hline \multirow{2}{*}{$\begin{array}{l}\text { Gene } \\
\text { Symbol }\end{array}$} & \multirow[t]{2}{*}{ Gene Name } & \multicolumn{4}{|c|}{ robust z-score } & \multicolumn{4}{|c|}{ robust z-score } & \multicolumn{4}{|c|}{ robust z-score } \\
\hline & & A & B & C & Cum. & A & B & C & Cum. & A & B & C & Cum. \\
\hline ATR1 & $\begin{array}{l}\text { Ataxia telangiectasia } \\
\text { and Rad3 related }\end{array}$ & $-3,90$ & $-3,00$ & $-5,02$ & $-11,92$ & $-2,24$ & $-1,75$ & $-2,27$ & $-6,26$ & 1,28 & 1,47 & 2,40 & 5,16 \\
\hline RNF8 & Ring finger protein 8 & $-3,28$ & $-1,33$ & $-4,19$ & $-8,81$ & $-1,40$ & $-1,21$ & $-1,29$ & $-3,90$ & 0,20 & 2,02 & 1,08 & 3,29 \\
\hline ATRIP & ATR interacting protein & $-3,71$ & $-3,05$ & $-0,90$ & $-7,66$ & $-1,45$ & $-0,48$ & 0,45 & $-1,47$ & $-0,59$ & 2,20 & 1,60 & 3,21 \\
\hline MDC1 & $\begin{array}{l}\text { Mediator of DNA- } \\
\text { damage checkpoint } 1\end{array}$ & $-1,44$ & $-2,87$ & $-2,35$ & $-6,66$ & $-3,04$ & $-1,96$ & $-2,66$ & $-7,65$ & $-1,00$ & $-0,96$ & 1,27 & $-0,70$ \\
\hline
\end{tabular}




\begin{tabular}{|c|c|c|c|c|c|c|c|c|c|c|c|c|c|}
\hline CIB1 & $\begin{array}{l}\text { Calcium and integrin } \\
\text { binding } 1 \text { (calmyrin) }\end{array}$ & $-1,59$ & $-2,60$ & $-2,26$ & $-6,45$ & $-0,61$ & $-2,28$ & $-1,00$ & $-3,89$ & $-0,65$ & $-2,00$ & $-0,82$ & $-3,47$ \\
\hline CDC45L & $\begin{array}{llr}\text { CDC45 } & \text { cell } & \text { division } \\
\text { cycle } & 45-\text { like } & \text { (S. } \\
\text { cerevisiae) } & \\
\end{array}$ & $-3,14$ & $-2,63$ & $-0,37$ & $-6,14$ & $-1,90$ & $-2,93$ & $-1,30$ & $-6,13$ & $-0,79$ & $-1,29$ & $-0,90$ & $-2,98$ \\
\hline HUS1 & $\begin{array}{l}\text { HUS1 checkpoint } \\
\text { homolog (S. pombe) }\end{array}$ & $-3,72$ & $-2,01$ & $-0,25$ & $-5,98$ & $-0,62$ & $-1,11$ & $-1,91$ & $-3,63$ & 1,81 & $-0,40$ & $-0,75$ & 0,65 \\
\hline FANCA & $\begin{array}{l}\text { Fanconi anemia, } \\
\text { complementation } \\
\text { group A }\end{array}$ & $-0,46$ & $-2,38$ & $-3,00$ & $-5,85$ & $-0,02$ & $-2,34$ & $-2,49$ & $-4,85$ & 3,36 & $-1,18$ & $-0,83$ & 1,36 \\
\hline HELLS & $\begin{array}{l}\text { Helicase, lymphoid- } \\
\text { specific }\end{array}$ & $-3,18$ & $-2,08$ & $-0,49$ & $-5,75$ & $-2,93$ & $-2,36$ & 0,25 & $-5,03$ & $-0,35$ & $-0,63$ & 1,99 & 1,02 \\
\hline CENPH & Centromere protein $\mathrm{H}$ & $-2,23$ & $-1,04$ & $-2,31$ & $-5,59$ & 0,92 & 0,75 & $-1,45$ & 0,21 & 1,12 & 2,04 & $-0,63$ & 2,53 \\
\hline PCNA & $\begin{array}{l}\text { Proliferating cell } \\
\text { nuclear antigen }\end{array}$ & 2,16 & $-0,63$ & 2,30 & 3,84 & 1,01 & $-0,83$ & 0,55 & 0,72 & $-1,05$ & $-1,12$ & 3,01 & 0,84 \\
\hline ZNFX1 & $\begin{array}{l}\text { Zinc finger, NFX1-type } \\
\text { containing } 1\end{array}$ & $-1,01$ & 2,68 & 2,67 & 4,34 & $-0,10$ & 2,20 & 1,37 & 3,46 & 4,86 & 3,05 & $-0,58$ & 7,32 \\
\hline APEX1 & $\begin{array}{lr}\text { APEX } & \text { nuclease } \\
\text { (multifunctional } & \text { DNA } \\
\text { repair enzyme) } 1\end{array}$ & 3,19 & $-0,57$ & 2,01 & 4,63 & $-0,95$ & $-2,02$ & $-0,13$ & $-3,10$ & $-1,41$ & $-1,69$ & 0,36 & $-2,73$ \\
\hline RPAIN & RPA interacting protein & 3,44 & 2,83 & $-1,01$ & 5,26 & $-0,01$ & 1,06 & 0,45 & 1,50 & $-1,03$ & $-0,84$ & 0,24 & $-1,62$ \\
\hline TLK2 & Tousled-like kinase 2 & 2,04 & 0,36 & 2,93 & 5,32 & $-1,77$ & 0,01 & 2,59 & 0,83 & $-0,54$ & $-0,52$ & 6,16 & 5,09 \\
\hline TOP2A & $\begin{array}{l}\text { Topoisomerase (DNA) II } \\
\text { alpha } 170 \mathrm{kDa}\end{array}$ & 2,21 & 0,27 & 2,91 & 5,39 & $-0,91$ & $-0,45$ & $-3,96$ & $-5,32$ & $-0,84$ & $-0,74$ & $-2,45$ & $-4,04$ \\
\hline RBM38 & $\begin{array}{l}\text { RNA binding motif } \\
\text { protein } 38\end{array}$ & 2,26 & 2,80 & 0,33 & 5,40 & 2,29 & 3,14 & 0,24 & 5,66 & 5,17 & 6,09 & 1,33 & 12,59 \\
\hline RFC3 & $\begin{array}{l}\text { Replication factor C } \\
\text { (activator 1) 3,38kDa }\end{array}$ & 1,03 & 2,46 & 1,99 & 5,48 & $-0,46$ & 1,25 & 1,79 & 2,58 & $-1,91$ & $-1,24$ & $-0,67$ & $-3,82$ \\
\hline POLD4 & \begin{tabular}{|l} 
Polymerase (DNA- \\
directed), delta 4
\end{tabular} & 2,27 & 3,00 & 0,39 & 5,66 & $-0,19$ & 0,99 & 1,62 & 2,43 & $-1,35$ & $-0,82$ & 7,30 & 5,12 \\
\hline SHPRH & $\begin{array}{l}\text { SNF2 histone linker } \\
\text { PHD RING helicase }\end{array}$ & $-0,16$ & 3,41 & 2,76 & 6,02 & 1,18 & 2,20 & 1,00 & 4,37 & 1,75 & $-0,39$ & $-1,09$ & 0,27 \\
\hline HAP1 & $\begin{array}{l}\text { Huntingtin-associated } \\
\text { protein } 1\end{array}$ & 2,69 & 2,74 & 0,71 & 6,14 & $-1,03$ & 1,30 & 0,04 & 0,32 & $-1,16$ & $-0,26$ & $-0,42$ & $-1,85$ \\
\hline POLA1 & $\begin{array}{l}\text { Polymerase (DNA } \\
\begin{array}{l}\text { directed), alpha } 1, \\
\text { catalytic subunit }\end{array}\end{array}$ & 2,50 & 3,27 & 0,43 & 6,19 & 0,99 & 2,65 & $-0,82$ & 2,82 & $-0,65$ & 5,01 & $-0,74$ & 3,63 \\
\hline HIST1H1C & Histone cluster 1, H1c & $-0,43$ & 3,52 & 3,35 & 6,44 & 0,88 & 3,37 & $-1,45$ & 2,80 & 0,33 & 0,26 & $-1,18$ & $-0,59$ \\
\hline PHB & Prohibitin & 3,13 & 4,68 & $-1,29$ & 6,52 & 2,53 & $-1,49$ & $-0,57$ & 0,47 & 3,42 & $-1,65$ & 0,50 & 2,27 \\
\hline CHMP1A & $\begin{array}{l}\text { Chromatin modifying } \\
\text { protein } 1 \mathrm{~A}\end{array}$ & 1,72 & 2,58 & 2,23 & 6,54 & $-0,27$ & $-2,89$ & 0,47 & $-2,69$ & $-1,41$ & $-1,43$ & $-0,67$ & $-3,51$ \\
\hline RPA4 & Replication protein A4 & 2,84 & 2,70 & 1,64 & 7,17 & 0,71 & 2,32 & 1,31 & 4,34 & 0,90 & 8,49 & $-0,39$ & 9,00 \\
\hline ALKBH1 & $\begin{array}{l}\text { AlkB, alkylation repair } \\
\text { homolog } 1 \text { (E. coli) }\end{array}$ & 1,86 & 3,35 & 2,08 & 7,30 & 0,82 & $-1,43$ & $-0,60$ & $-1,22$ & $-0,69$ & $-1,35$ & $-0,85$ & $-2,90$ \\
\hline SOD1 & $\begin{array}{l}\text { Superoxide dismutase } \\
1 \text {, soluble }\end{array}$ & $-1,70$ & 6,90 & 2,43 & 7,63 & $-0,81$ & $-0,13$ & $-1,04$ & $-1,98$ & $-1,20$ & $-1,35$ & $-1,27$ & $-3,83$ \\
\hline STAG2 & Stromal antigen 2 & 2,61 & 1,44 & 4,27 & 8,33 & 2,48 & 1,75 & 3,34 & 7,57 & 3,60 & $-0,60$ & 0,36 & 3,36 \\
\hline MCM10 & $\begin{array}{l}\text { Minichromosome } \\
\text { maintenance complex } \\
\text { component } 10\end{array}$ & 2,48 & 5,13 & 0,78 & 8,40 & 6,62 & 5,68 & $-1,05$ & 11,25 & 2,17 & 21,00 & $-0,63$ & 22,54 \\
\hline VCP & $\begin{array}{l}\text { Valosin-containing } \\
\text { protein }\end{array}$ & $-0,08$ & 3,68 & 5,17 & 8,77 & 0,82 & $-0,34$ & 0,38 & 0,86 & 0,25 & $-0,58$ & $-0,48$ & $-0,81$ \\
\hline
\end{tabular}




\begin{tabular}{|c|c|c|c|c|c|c|c|c|c|c|c|c|c|}
\hline BAZ2A & $\begin{array}{l}\text { Bromodomain adjacent } \\
\text { to zinc finger domain, } \\
2 \mathrm{~A}\end{array}$ & 0,40 & 6,40 & 2,38 & 9,17 & 0,63 & 0,87 & 0,85 & 2,34 & $-0,96$ & $-1,42$ & 8,57 & 6,19 \\
\hline RNF25 & Ring finger protein 25 & 0,56 & 2,32 & 6,49 & 9,37 & $-1,19$ & $-4,47$ & 2,71 & $-2,95$ & $-0,84$ & $-1,27$ & $-0,30$ & $-2,41$ \\
\hline RPA1 & Replication protein A1 & 2,64 & 5,18 & 2,55 & 10,37 & 2,50 & 1,87 & 1,80 & 6,17 & 2,70 & $-0,41$ & 3,94 & 6,22 \\
\hline POLD1 & \begin{tabular}{|lr} 
Polymerase & (DNA \\
directed), & delta 1, \\
catalytic & subunit \\
$125 \mathrm{kDa}$ & \\
\end{tabular} & 5,34 & 3,79 & 2,00 & 11,13 & $-4,06$ & $-1,27$ & $-0,48$ & $-5,81$ & $-1,93$ & $-1,65$ & $-0,88$ & $-4,45$ \\
\hline SRCAP & $\begin{array}{l}\text { Snf2-related CREBBP } \\
\text { activator protein }\end{array}$ & 7,26 & 1,56 & 2,33 & 11,15 & 0,06 & 1,08 & $-0,86$ & 0,28 & $-1,25$ & 1,20 & $-1,81$ & $-1,87$ \\
\hline CHD8 & $\begin{array}{l}\text { Chromodomain } \\
\text { helicase DNA binding } \\
\text { protein } 8\end{array}$ & 6,99 & 1,66 & 3,79 & 12,44 & 7,49 & 1,70 & 3,46 & 12,65 & 15,65 & 2,74 & 0,72 & 19,11 \\
\hline RFC1 & $\begin{array}{l}\text { Replication factor C } \\
\text { (activator 1) } 1,145 \mathrm{kDa}\end{array}$ & 17,72 & 2,76 & 1,78 & 22,26 & 1,07 & 3,60 & 1,57 & 6,24 & $-1,97$ & 5,71 & 2,36 & 6,09 \\
\hline CHEK1 & $\begin{array}{l}\text { CHK1 checkpoint } \\
\text { homolog (S. pombe) }\end{array}$ & 13,76 & 10,58 & 0,87 & 25,21 & 11,91 & 6,97 & 0,83 & 19,71 & 1,35 & $-0,61$ & $-0,99$ & $-0,24$ \\
\hline
\end{tabular}


Table 7.3 Relevant biological processes associated with screen candidates.

All gene products whose knockdown caused a significant change in $\mathrm{yH} 2 \mathrm{AX}$ levels, i.e. a robust z-score $>2$ of at least 2 of 3 siRNAs (see table 7.1 and 7.2) were annotated to functional categories using the DAVID functional annotation tool for gene ontology of biological processes. A selection of biological processes which are relevant for the cell's reaction to chemotherapy is displayed in the table, corresponding to figure 5.11 .

\begin{tabular}{|c|c|c|}
\hline Biological process & $\begin{array}{l}\text { Candidates whose knockdown causes } \\
\text { decreased } \mathrm{yH} 2 \mathrm{AX} \text { levels }\end{array}$ & $\begin{array}{l}\text { Candidates whose knockdown } \\
\text { causes increased } \mathrm{yH} 2 \mathrm{AX} \text { levels }\end{array}$ \\
\hline $\begin{array}{l}\text { DNA damage } \\
\text { response }\end{array}$ & $\begin{array}{l}\text { ATR, ATRIP, CCNO, CIB1, C9ORF102, } \\
\text { FANCA, HUS1, MDC1, MYC, RAD23B, } \\
\text { RNF8, RUVBL2, SMUG1, TERF2IP, } \\
\text { UBE2N }\end{array}$ & $\begin{array}{l}\text { ALKBH1, APEX1, CHEK1, GTF2H4, } \\
\text { PARP2, PCNA, POLD1, POLD4, } \\
\text { RBM38, RFC1, RFC3, RPA1, RPAIN, } \\
\text { SHPRH, SOD1, TLK2, TOP2A, VCP }\end{array}$ \\
\hline DNA repair & $\begin{array}{l}\text { RAD23B, HUS1, SMUG1, MDC1, CCNO, } \\
\text { FANCA, ATRIP, CIB1, C9ORF102, } \\
\text { UBE2N, RNF8, RUVBL2, }\end{array}$ & $\begin{array}{l}\text { ALKBH1, APEX1, CHEK1, GTF2H4, } \\
\text { PARP2, PCNA, POLD1, POLD4, } \\
\text { RFC1, RFC3, RPA1, RPAIN, SHPRH, } \\
\text { SOD1, TOP2A, VCP }\end{array}$ \\
\hline ds-break repair & UBE2N, RNF8, HUS1, CIB1 & RPA1, VCP, SOD1 \\
\hline BE repair & SMUG1, CCNO & POLD1, PCNA, APEX1, PARP2 \\
\hline NE repair & & $\begin{array}{l}\text { RPA1, POLD4, RFC3, RFC1, POLD1, } \\
\text { PCNA }\end{array}$ \\
\hline $\begin{array}{l}\text { DNA-synthesis during } \\
\text { DNA repair }\end{array}$ & & RFC3, POLD1 \\
\hline $\begin{array}{l}\text { DNA metabolic } \\
\text { process }\end{array}$ & $\begin{array}{l}\text { ATRIP, ATR, RAD23B, HUS1, TERF2IP, } \\
\text { SMUG1, MDC1, MYC, CCNO, FANCA, } \\
\text { HELLS, CIB1, C9ORF102, UBE2N, RNF8, } \\
\text { RUVBL2, }\end{array}$ & $\begin{array}{l}\text { ALKBH1, APEX1, BAZ2A, CHEK1, } \\
\text { GTF2H4, MCM10, PARP2, PCNA, } \\
\text { PHB, POLD1, POLD4, REC8, RFC1, } \\
\text { RFC3, RPA1, RPA4, RPAIN, SHPRH, } \\
\text { SOD1, TOP2A, VCP }\end{array}$ \\
\hline $\begin{array}{l}\text { nucleotide metabolic } \\
\text { process }\end{array}$ & $\begin{array}{l}\text { ARID1A, ATR, CCNO, HDAC5, HELLS, } \\
\text { HUS1, MYC, SMUG1, SOX15, TERF2IP, } \\
\text { UBE2N }\end{array}$ & BAZ2A, CHD8, CHMP1A, PHB, \\
\hline DNA replication & HUS1, TERF2IP & $\begin{array}{l}\text { ATR, PCNA, POLD1, POLD4, RFC1, } \\
\text { RFC3, RPA1, RPA4, RPAIN }\end{array}$ \\
\hline apoptosis & HELLS, MYC & CHD8, PHB, SOD1, TOP2A, VCP \\
\hline cell cycle & $\begin{array}{l}\text { ATRIP, CENPH, FANCA, HELLS, HUS1, } \\
\text { MDC1, MYC, REC8, RNF8, SUV39H2 }\end{array}$ & $\begin{array}{l}\text { ATR, CHD8, CHEK1, CHMP1A, } \\
\text { POLD1, RBM38, RPA1, SMC2, TLK2 }\end{array}$ \\
\hline $\begin{array}{l}\text { DNA and chromatin } \\
\text { modification and } \\
\text { remodeling }\end{array}$ & $\begin{array}{l}\text { ARID1A, CENPH, EP400, HELLS, HDAC5, } \\
\text { REC8, RNF8, RUVBL2, TERF2IP, SOX15, } \\
\text { SUV39H2, UBE2N }\end{array}$ & $\begin{array}{l}\text { BAZ2A, CHD8, CHMP1A, HIST1H1C, } \\
\text { H1FX, PHB, RFC1, RPA1, SHPRH, } \\
\text { SMC2, SRCAP, TLK2, TOP2A }\end{array}$ \\
\hline chromatin remodeling & ARID1A, HDAC5, HELLS, SUV39H2 & BAZ2A, CHD8 \\
\hline chromatin assembly & HELLS, SUV39H2 & CHD8, HIST1H1C, H1FX, SHPRH \\
\hline DNA methylation & HELLS & $\mathrm{BAZ2A}$ \\
\hline $\begin{array}{l}\text { chromatin } \\
\text { modification }\end{array}$ & $\begin{array}{l}\text { ARID1A, EP400, HDAC5, HELLS, RNF8, } \\
\text { RUVBL2 SUV39H2, UBE2N }\end{array}$ & BAZ2A, CHD8, PHB, SRCAP, TLK2 \\
\hline histone acetylation & EP400, RUVBL2 & \\
\hline
\end{tabular}




\begin{tabular}{|l|l|l|}
\hline histone deacetylation & HDAC5 & BAZ2A, PHB \\
\hline histone ubiquitination & RNF8, UBE2N & \\
\hline $\begin{array}{l}\text { regulation of } \\
\text { transcription }\end{array}$ & $\begin{array}{l}\text { ARID1A, HDAC5, HELLS, MYC, RUVBL2, } \\
\text { SOX15, SUV39H2, TERF2IP, UBE2N }\end{array}$ & $\begin{array}{l}\text { BAZ2A, CHD8, CHMP1A, GTF2H4, } \\
\text { PHB, RFC1, SRCAP, ZNFX1 }\end{array}$ \\
\hline
\end{tabular}



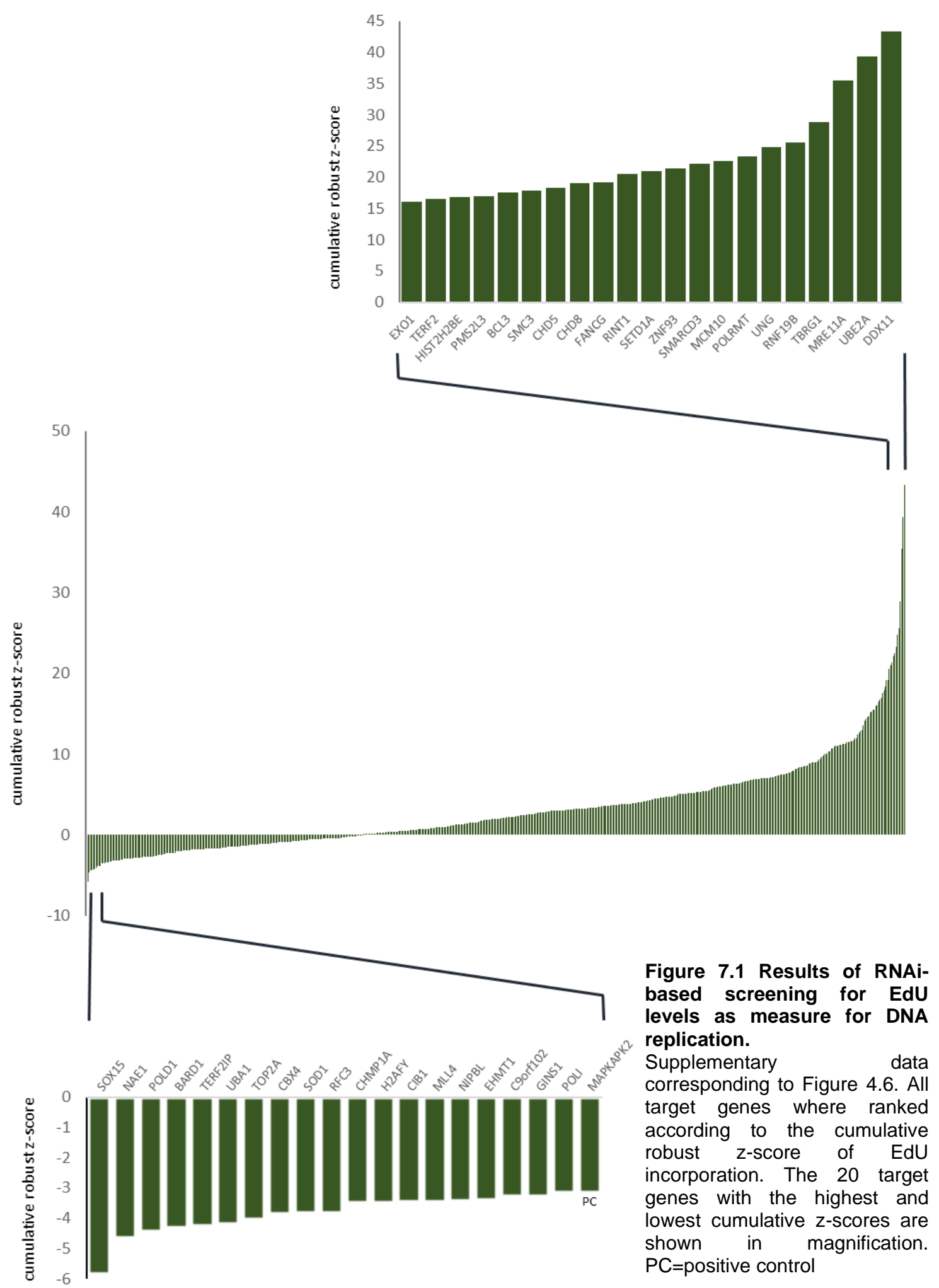

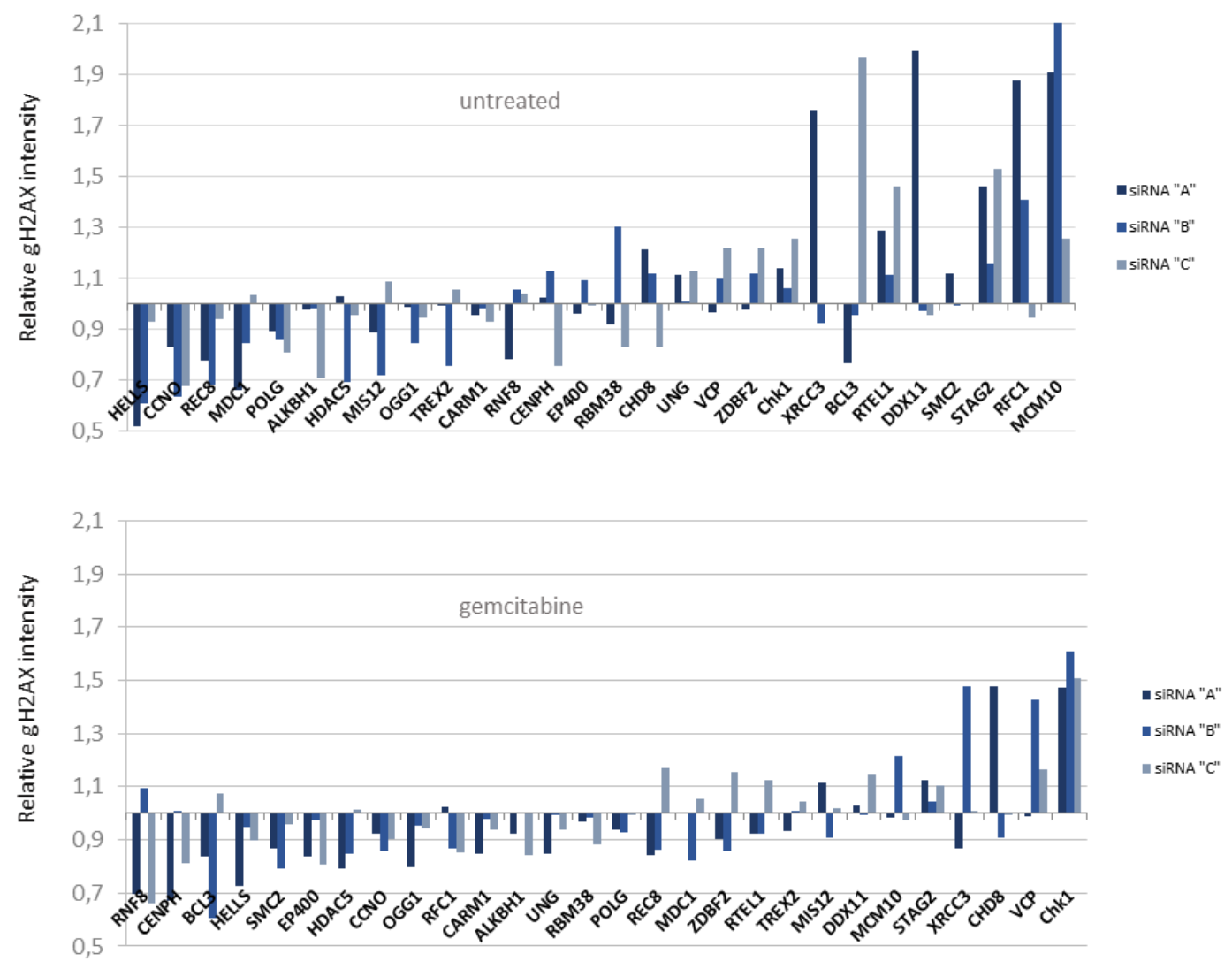

Figure 7.2 Control-based validation of main hits in EdU-positive cells.

PANC-1 cells were transfected with siRNAs as indicated and (a) left untreated or (b) exposed to $300 \mathrm{nM}$ gemcitabine for $22 \mathrm{~h}$. Cells were then fixed and stained for immunofluorescence analysis. H2AX phosphorylation was quantified in EdU-positive cells. All candidates were ranked according to cumulative relative changes in $\mathrm{yH} 2 \mathrm{AX}$ compared to control knockdown resulting from three different siRNA sequences for every target gene. The relative $\mathrm{yH} 2 \mathrm{AX}$ induction by each siRNA is shown for every target gene. 



Figure 7.3 Relative changes in EdU levels caused by main hits of the screen.

PANC-1 cells were transfected with siRNAs as indicated and (a) left untreated or (b) exposed to $300 \mathrm{nM}$ gemcitabine for $22 \mathrm{~h}$. Cells were then fixed and stained for immunofluorescence analysis. EdU incorporation was quantified and compared to control transfection. All candidates were ranked according to cumulative relative changes in EdU levels compared to control knockdown resulting from three different siRNA sequences for every target gene. The relative $\mathrm{YH} 2 \mathrm{AX}$ induction by each siRNA is shown for every target gene. 


\section{MIA PaCa-2}



Figure 7.4 Control-based validation of selected hits in MIA PaCa-2 cells.

Genes whose depletion proved to have influence on H2AX phosphorylation in PANC-1 cells and which were of interest as novel DNA damage mediators were selected and tested in MIA PaCa-2 cells. Cells were transfected with siRNAs as indicated and either left untreated (left column) or exposed to $300 \mathrm{nM}$ gemcitabine for $22 \mathrm{~h}$ (right column). Cells were fixed and stained for immunofluorescence analysis and EdU as well as yH2AX levels were quantified. Relative changes in (a) overall yH2AX levels, (b) $\mathrm{yH} 2 \mathrm{AX}$ levels in EdU-positive cells and (c) incorporation of EdU are ranked according to the cumulative changes of all three siRNAs against the respective target gene. The relative change of every readout is displayed for each siRNA individually. 


\section{PaTu8902}

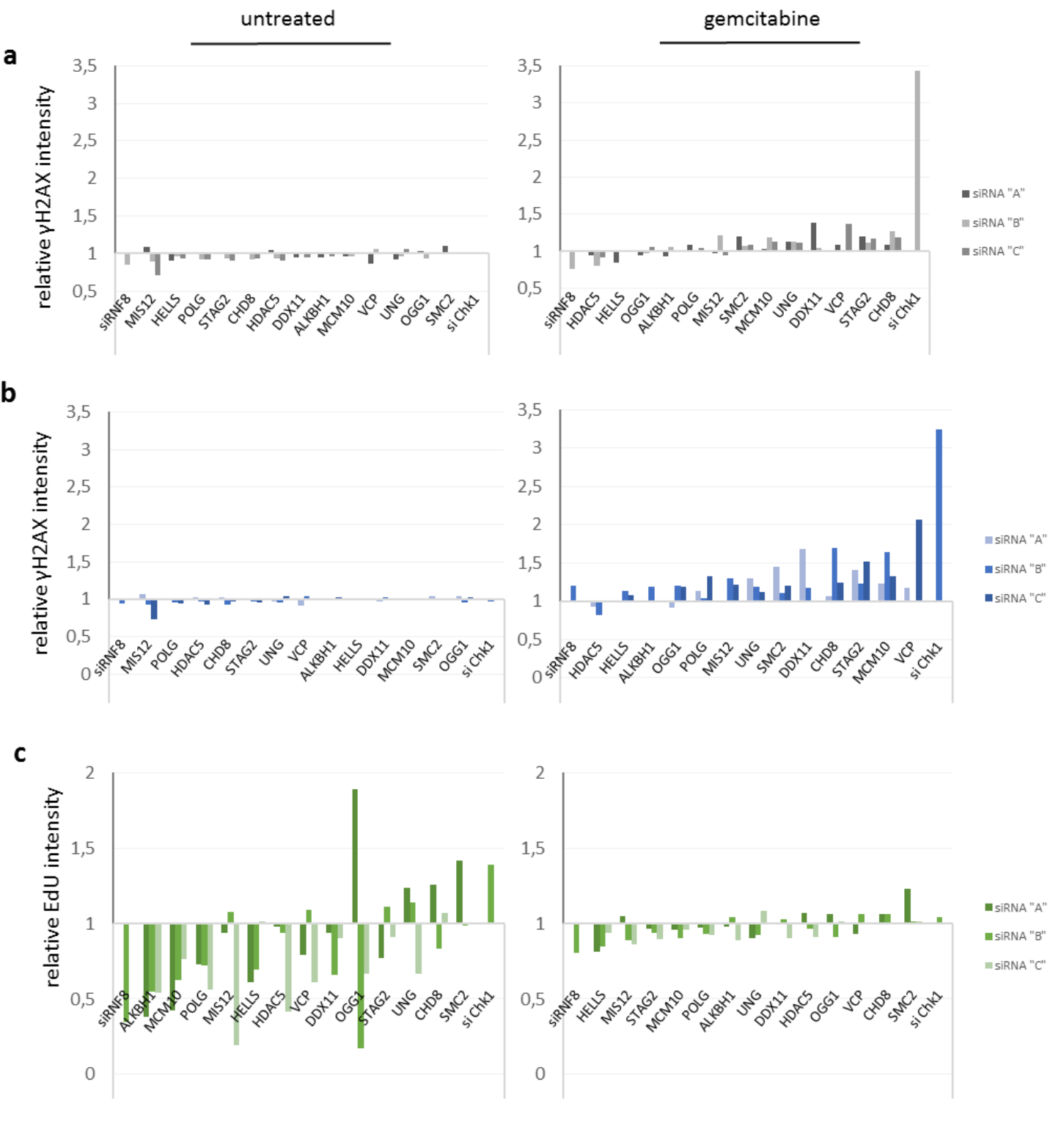

Figure 7.5 Control-based validation of selected hits in PaTu8902 cells.

Genes whose depletion proved to have influence on H2AX phosphorylation in PANC-1 cells and which were of interest as novel DNA damage mediators were selected and tested in PaTu8902 cells. Cells were transfected with siRNAs as indicated and either left untreated (left column) or exposed to $300 \mathrm{nM}$ gemcitabine for $22 \mathrm{~h}$ (right column). Cells were then fixed and stained for immunofluorescence analysis and EdU as well as $\mathrm{yH} 2 \mathrm{AX}$ levels were quantified. Relative changes in (a) overall $\mathrm{yH} 2 \mathrm{AX}$ levels, (b) $\mathrm{yH} 2 \mathrm{AX}$ levels in EdUpositive cells and (c) incorporation of EdU are ranked according to the cumulative changes of all three siRNAs against the respective target gene. The relative change of every readout is displayed for each siRNA individually. 


\section{U2OS}

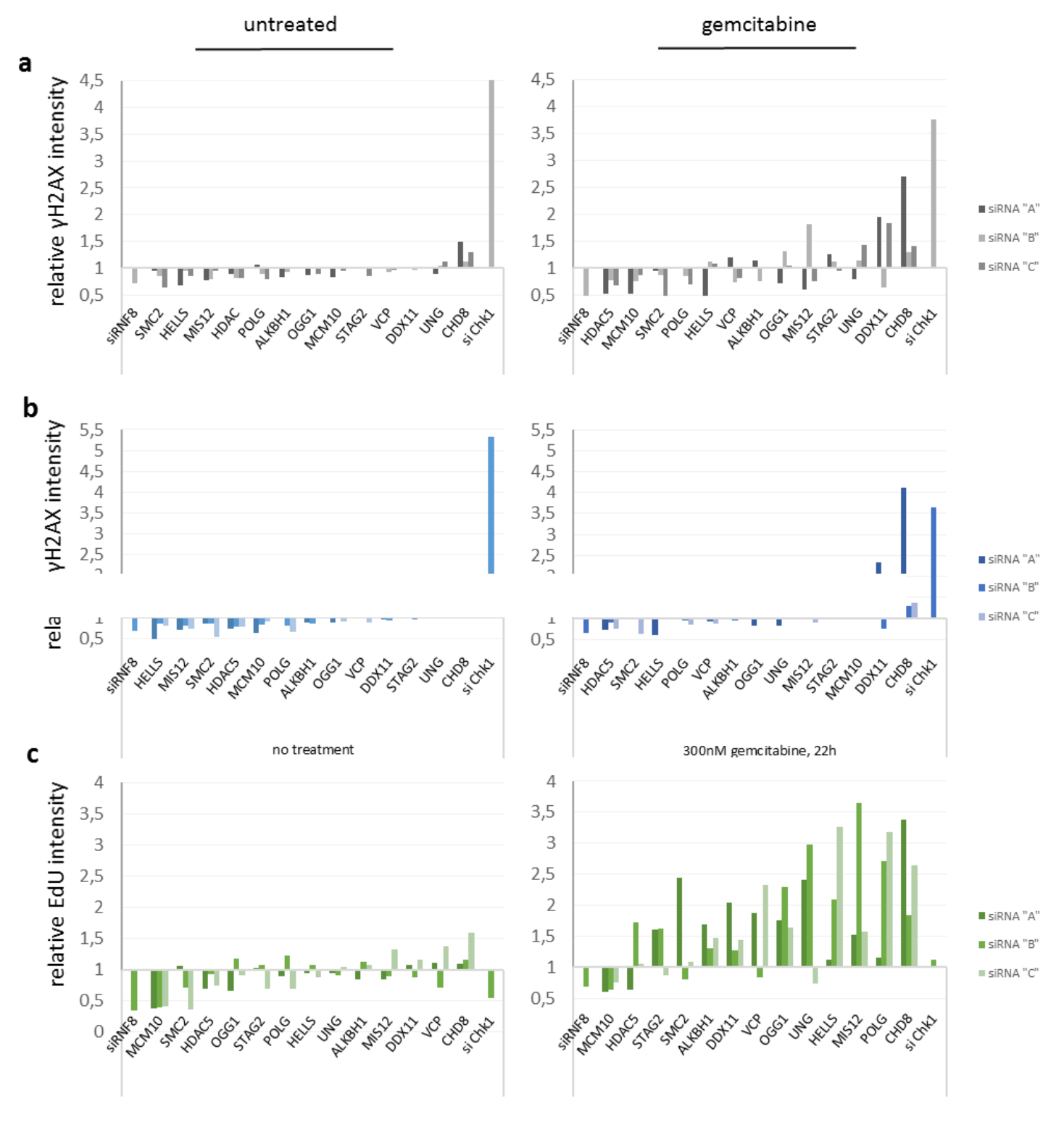

Figure 7.6 Control-based validation of selected hits in U2OS cells.

Genes whose depletion proved to have influence on H2AX phosphorylation in PANC-1 cells and which were of interest as novel DNA damage mediators were selected and tested in U2OS cells. Cells were transfected with siRNAs as indicated and either left untreated (left column) or exposed to $300 \mathrm{nM}$ gemcitabine for $22 \mathrm{~h}$ (right column). Cells were fixed and stained for immunofluorescence analysis and EdU as well as $\mathrm{yH} 2 \mathrm{AX}$ levels were quantified. Relative changes in (a) overall $\mathrm{yH} 2 \mathrm{AX}$ levels, (b) $\mathrm{yH} 2 \mathrm{AX}$ levels in EdU-positive cells and (c) incorporation of EdU are ranked according to the cumulative changes of all three siRNAs against the respective target gene. The relative change of every readout is displayed for each siRNA individually. 



Figure 7.7 Effect of candidate gene knockdown on $\mathrm{yH} 2 \mathrm{AX}$ is not attributable to a decrease in Rad51 or p53 levels.

PANC-1 cells were transfected with the indicated siRNAs and all wells were treated with $300 \mathrm{nM}$ gemcitabine for $22 \mathrm{~h}$ according to screening conditions. Cell lysates were analyzed by immunoblotting. 


\section{References}

Adamson B, Smogorzewska A, Sigoillot FD, King RW, Elledge SJ (2012): A genome-wide homologous recombination screen identifies the RNA-binding protein RBMX as a component of the DNA-damage response. Nat Cell Biol 14, 318-328

Ahmed MM, Sheldon D, Fruitwala MA, Venkatasubbarao K, Lee EY, Gupta S, Wood C, Mohiuddin M, Strodel WE (2008): Downregulation of PAR-4, a pro-apoptotic gene, in pancreatic tumors harboring K-ras mutation. Int J Cancer $\underline{122}, 63-70$

Akada M, Crnogorac-Jurcevic T, Lattimore S, Mahon P, Lopes R, Sunamura M, Matsuno S, Lemoine NR (2005): Intrinsic chemoresistance to gemcitabine is associated with decreased expression of BNIP3 in pancreatic cancer. Clin Cancer Res 11, 3094-3101

Bakkenist CJ, Kastan MB (2015): Chromatin perturbations during the DNA damage response in higher eukaryotes. DNA Repair (Amst) $\underline{36}$, 8-12

Bartek J, Lukas J (2003): Chk1 and Chk2 kinases in checkpoint control and cancer. Cancer Cell $\underline{3}$, 421-429

Bartek J, Lukas J (2007): DNA damage checkpoints: from initiation to recovery or adaptation. Curr Opin Cell Biol $\underline{19}, 238-245$

Bartek J, Lukas C, Lukas J (2004): Checking on DNA damage in S phase. Nat Rev Mol Cell Biol $\underline{5}, 792-804$

Bartek J, Bartkova J, Lukas J (2007): DNA damage signalling guards against activated oncogenes and tumour progression. Oncogene $\underline{26}, 7773-7779$

Baylot V, Andrieu C, Katsogiannou M, Taieb D, Garcia S, Giusiano S, Acunzo J, lovanna J, Gleave M, Garrido $C$ et al. (2011): OGX-427 inhibits tumor progression and enhances gemcitabine chemotherapy in pancreatic cancer. Cell Death Dis $\underline{2}$, e221

Birmingham A, Selfors LM, Forster T, Wrobel D, Kennedy CJ, Shanks E, Santoyo-Lopez J, Dunican DJ, Long A, Kelleher D et al. (2009): Statistical methods for analysis of high-throughput RNA interference screens. Nat Methods $\underline{6}, 569-575$

Blackford AN, Jackson SP (2017): ATM, ATR, and DNA-PK: The Trinity at the Heart of the DNA Damage Response. Mol Cell $\underline{66}$, 801-817

Bosman EA, Penn AC, Ambrose JC, Kettleborough R, Stemple DL, Steel KP (2005): Multiple mutations in mouse Chd7 provide models for CHARGE syndrome. Hum Mol Genet 14, 3463-3476

Branzei D, Foiani M (2010): Maintaining genome stability at the replication fork. Nat Rev Mol Cell Biol 11, 208219

Brideau C, Gunter B, Pikounis B, Liaw A (2003): Improved statistical methods for hit selection in high-throughput screening. J Biomol Screen $\underline{8}$, 634-647 
Briones V, Muegge K (2012): The ghosts in the machine: DNA methylation and the mystery of differentiation. Biochim Biophys Acta 1819, 757-762

Brown EJ, Baltimore D (2000): ATR disruption leads to chromosomal fragmentation and early embryonic lethality. Genes Dev 14, 397-402

Brunton H, Goodarzi AA, Noon AT, Shrikhande A, Hansen RS, Jeggo PA, Shibata A (2011): Analysis of human syndromes with disordered chromatin reveals the impact of heterochromatin on the efficacy of ATM-dependent G2/M checkpoint arrest. Mol Cell Biol 31, 4022-4035

Burkhart RA, Peng Y, Norris ZA, Tholey RM, Talbott VA, Liang Q, Ai Y, Miller K, Lal S, Cozzitorto JA et al. (2013): Mitoxantrone targets human ubiquitin-specific peptidase 11 (USP11) and is a potent inhibitor of pancreatic cancer cell survival. Mol Cancer Res $\underline{11}, 901-911$

Burma S, Chen BP, Murphy M, Kurimasa A, Chen DJ (2001): ATM phosphorylates histone H2AX in response to DNA double-strand breaks. J Biol Chem 276, 42462-42467

Burrage J, Termanis A, Geissner A, Myant K, Gordon K, Stancheva I (2012): The SNF2 family ATPase LSH promotes phosphorylation of $\mathrm{H} 2 \mathrm{AX}$ and efficient repair of DNA double-strand breaks in mammalian cells. J Cell Sci $\underline{125}, 5524-5534$

Burris HA, 3rd, Moore MJ, Andersen J, Green MR, Rothenberg ML, Modiano MR, Cripps MC, Portenoy RK, Storniolo AM, Tarassoff $P$ et al. (1997): Improvements in survival and clinical benefit with gemcitabine as firstline therapy for patients with advanced pancreas cancer: a randomized trial. J Clin Oncol 15, 2403-2413

Bykov VJN, Eriksson SE, Bianchi J, Wiman KG (2018): Targeting mutant p53 for efficient cancer therapy. Nat Rev Cancer 18, 89-102

Cadet J, Sage E, Douki T (2005): Ultraviolet radiation-mediated damage to cellular DNA. Mutat Res $\underline{571}, 3-17$

Cai SF, Chen CW, Armstrong SA (2015): Drugging Chromatin in Cancer: Recent Advances and Novel Approaches. Mol Cell $\underline{60}, 561-570$

Celeste A, Petersen S, Romanienko PJ, Fernandez-Capetillo O, Chen HT, Sedelnikova OA, Reina-San-Martin B, Coppola V, Meffre E, Difilippantonio MJ et al. (2002): Genomic instability in mice lacking histone H2AX. Science 296, 922-927

Chand S, O'Hayer K, Blanco FF, Winter JM, Brody JR (2016): The Landscape of Pancreatic Cancer Therapeutic Resistance Mechanisms. Int J Biol Sci 12, 273-282

Chattopadhyay S, Bielinsky AK (2007): Human Mcm10 regulates the catalytic subunit of DNA polymerase-alpha and prevents DNA damage during replication. Mol Biol Cell 18, 4085-4095

Chomczynski P, Sacchi N (1987): Single-step method of RNA isolation by acid guanidinium thiocyanate-phenolchloroform extraction. Anal Biochem 162, 156-159

Chomczynski P, Sacchi N (2006): The single-step method of RNA isolation by acid guanidinium thiocyanatephenol-chloroform extraction: twenty-something years on. Nat Protoc $\underline{1}, 581-585$

Chowdhury D, Keogh MC, Ishii H, Peterson CL, Buratowski S, Lieberman J (2005): gamma-H2AX dephosphorylation by protein phosphatase 2A facilitates DNA double-strand break repair. Mol Cell 20, 801-809 
Chowdhury D, Xu X, Zhong X, Ahmed F, Zhong J, Liao J, Dykxhoorn DM, Weinstock DM, Pfeifer GP, Lieberman $\mathrm{J}$ (2008): A PP4-phosphatase complex dephosphorylates gamma-H2AX generated during DNA replication. Mol Cell $\underline{31}, 33-46$

Chu X, Guo X, Jiang Y, Yu H, Liu L, Shan W, Yang ZQ (2017): Genotranscriptomic meta-analysis of the CHD family chromatin remodelers in human cancers - initial evidence of an oncogenic role for CHD7. Mol Oncol 11, $1348-1360$

Ciccia A, Elledge SJ (2010): The DNA damage response: making it safe to play with knives. Mol Cell $\underline{40}, 179-$ 204

Cimprich KA, Cortez D (2008): ATR: an essential regulator of genome integrity. Nat Rev Mol Cell Biol $\underline{9}, 616-$ 627

Colbert LE, Petrova AV, Fisher SB, Pantazides BG, Madden MZ, Hardy CW, Warren MD, Pan Y, Nagaraju GP, Liu EA et al. (2014): CHD7 expression predicts survival outcomes in patients with resected pancreatic cancer. Cancer Res $\underline{74}, 2677-2687$

Conrad C, Gerlich DW (2010): Automated microscopy for high-content RNAi screening. J Cell Biol $\underline{188}$, 453461

Conroy T, Bachet JB, Ayav A, Huguet F, Lambert A, Caramella C, Marechal R, Van Laethem JL, Ducreux M (2016): Current standards and new innovative approaches for treatment of pancreatic cancer. Eur J Cancer $\underline{57}$, $10-22$

Cook PJ, Ju BG, Telese F, Wang X, Glass CK, Rosenfeld MG (2009): Tyrosine dephosphorylation of H2AX modulates apoptosis and survival decisions. Nature $\underline{458}, 591-596$

Cortez D, Wang Y, Qin J, Elledge SJ (1999): Requirement of ATM-dependent phosphorylation of brca1 in the DNA damage response to double-strand breaks. Science 286, 1162-1166

Creech RH, Tritchler D, Ettinger DS, Ferraro JA, Ruckdeschel JC, Vogl SE, Woll J (1984): Phase II study of PALA, amsacrine, teniposide, and zinostatin in small cell lung carcinoma (EST 2579). Cancer Treat Rep $\underline{68}$, 1183-1184

Crul M, van Waardenburg RC, Bocxe S, van Eijndhoven MA, Pluim D, Beijnen JH, Schellens JH (2003): DNA repair mechanisms involved in gemcitabine cytotoxicity and in the interaction between gemcitabine and cisplatin. Biochem Pharmacol $\underline{65}, 275-282$

Dai Y, Grant S (2010): New insights into checkpoint kinase 1 in the DNA damage response signaling network. Clin Cancer Res $\underline{16}$, 376-383

Damaschke NA, Yang B, Blute ML, Jr., Lin CP, Huang W, Jarrard DF (2014): Frequent disruption of chromodomain helicase DNA-binding protein 8 (CHD8) and functionally associated chromatin regulators in prostate cancer. Neoplasia $\underline{16}, 1018-1027$

De Bont R, van Larebeke N (2004): Endogenous DNA damage in humans: a review of quantitative data. Mutagenesis $\underline{19}, 169-185$ 
Deng T, Yan G, Song X, Xie L, Zhou Y, Li J, Hu X, Li Z, Hu J, Zhang Y et al. (2018): Deubiquitylation and stabilization of 21 by USP11 is critical for cell-cycle progression and DNA damage responses. Proc Natl Acad Sci U S A $115,4678-4683$

Dietlein F, Kalb B, Jokic M, Noll EM, Strong A, Tharun L, Ozretic L, Kunstlinger H, Kambartel K, Randerath WJ et al. (2015): A Synergistic Interaction between Chk1- and MK2 Inhibitors in KRAS-Mutant Cancer. Cell 162, 146-159

Elson A, Wang Y, Daugherty CJ, Morton CC, Zhou F, Campos-Torres J, Leder P (1996): Pleiotropic defects in ataxia-telangiectasia protein-deficient mice. Proc Natl Acad Sci U S A $\underline{93}, 13084-13089$

Engel K, Kotlyarov A, Gaestel M (1998): Leptomycin B-sensitive nuclear export of MAPKAP kinase 2 is regulated by phosphorylation. EMBO J $\underline{17}, 3363-3371$

Evers L, Perez-Mancera PA, Lenkiewicz E, Tang N, Aust D, Knosel T, Rummele P, Holley T, Kassner M, Aziz $\mathrm{M}$ et al. (2014): STAG2 is a clinically relevant tumor suppressor in pancreatic ductal adenocarcinoma. Genome Med $\underline{6}, 9$

Ewald B, Sampath D, Plunkett W (2008): Nucleoside analogs: molecular mechanisms signaling cell death. Oncogene 27, 6522-6537

Falasca M, Kim M, Casari I (2016): Pancreatic cancer: Current research and future directions. Biochim Biophys Acta $1865,123-132$

Fang M, Ou J, Hutchinson L, Green MR (2014): The BRAF oncoprotein functions through the transcriptional repressor MAFG to mediate the CpG Island Methylator phenotype. Mol Cell $\underline{55}, 904-915$

Fernandez-Capetillo O, Lee A, Nussenzweig M, Nussenzweig A (2004): H2AX: the histone guardian of the genome. DNA Repair (Amst) $\underline{3}, 959-967$

Fernandez MR, Henry MD, Lewis RE (2012): Kinase suppressor of Ras 2 (KSR2) regulates tumor cell transformation via AMPK. Mol Cell Biol $\underline{32}, 3718-3731$

Flanagan JF, Mi LZ, Chruszcz M, Cymborowski M, Clines KL, Kim Y, Minor W, Rastinejad F, Khorasanizadeh $S$ (2005): Double chromodomains cooperate to recognize the methylated histone H3 tail. Nature $\underline{438}, 1181$ 1185

Forment JV, Blasius M, Guerini I, Jackson SP (2011): Structure-specific DNA endonuclease Mus81/Eme1 generates DNA damage caused by Chk1 inactivation. PLoS One $\underline{6}$, e23517

Gaestel M (2006): MAPKAP kinases - MKs - two's company, three's a crowd. Nat Rev Mol Cell Biol $\underline{7}, 120-130$

Gaiddon C, Lokshin M, Ahn J, Zhang T, Prives C (2001): A subset of tumor-derived mutant forms of p53 downregulate p63 and p73 through a direct interaction with the p53 core domain. Mol Cell Biol 21, 1874-1887

Galmarini CM, Mackey JR, Dumontet C (2002): Nucleoside analogues and nucleobases in cancer treatment. Lancet Oncol $\underline{3}, 415-424$

Gandhi V, Legha J, Chen F, Hertel LW, Plunkett W (1996): Excision of 2',2'-difluorodeoxycytidine (gemcitabine) monophosphate residues from DNA. Cancer Res $\underline{56}, 4453-4459$ 
Gaspar-Maia A, Alajem A, Polesso F, Sridharan R, Mason MJ, Heidersbach A, Ramalho-Santos J, McManus MT, Plath K, Meshorer E et al. (2009): Chd1 regulates open chromatin and pluripotency of embryonic stem cells. Nature $\underline{460}, 863-868$

Gatz SA, Wiesmuller L (2006): p53 in recombination and repair. Cell Death Differ $\underline{13}, 1003-1016$

Goodarzi AA, Jeggo PA (2012): The heterochromatic barrier to DNA double strand break repair: how to get the entry visa. Int J Mol Sci $\underline{13}, 11844-11860$

Goodarzi AA, Noon AT, Deckbar D, Ziv Y, Shiloh Y, Lobrich M, Jeggo PA (2008): ATM signaling facilitates repair of DNA double-strand breaks associated with heterochromatin. Mol Cell 31, 167-177

Guay J, Lambert H, Gingras-Breton G, Lavoie JN, Huot J, Landry J (1997): Regulation of actin filament dynamics by p38 map kinase-mediated phosphorylation of heat shock protein 27. J Cell Sci 110 ( Pt 3), 357-368

Halazonetis TD, Gorgoulis VG, Bartek J (2008): An oncogene-induced DNA damage model for cancer development. Science $\underline{319}, 1352-1355$

Hall JA, Georgel PT (2007): CHD proteins: a diverse family with strong ties. Biochem Cell Biol $\underline{85}$, 463-476

Hanada K, Budzowska M, Davies SL, van Drunen E, Onizawa H, Beverloo HB, Maas A, Essers J, Hickson ID, Kanaar R (2007): The structure-specific endonuclease Mus81 contributes to replication restart by generating double-strand DNA breaks. Nat Struct Mol Biol $\underline{14}, 1096-1104$

Hanahan D, Weinberg RA (2000): The hallmarks of cancer. Cell $\underline{100}, 57-70$

Haracska L, Torres-Ramos CA, Johnson RE, Prakash S, Prakash L (2004): Opposing effects of ubiquitin conjugation and SUMO modification of PCNA on replicational bypass of DNA lesions in Saccharomyces cerevisiae. Mol Cell Biol 24, 4267-4274

Hargreaves DC, Crabtree GR (2011): ATP-dependent chromatin remodeling: genetics, genomics and mechanisms. Cell Res 21, 396-420

Harris SL, Levine AJ (2005): The p53 pathway: positive and negative feedback loops. Oncogene 24, 2899-2908

Harsha HC, Kandasamy K, Ranganathan P, Rani S, Ramabadran S, Gollapudi S, Balakrishnan L, Dwivedi SB, Telikicherla D, Selvan LD et al. (2009): A compendium of potential biomarkers of pancreatic cancer. PLoS Med $\underline{6}, \mathrm{e} 1000046$

Hattori H, Skoulidis F, Russell P, Venkitaraman AR (2011): Context dependence of checkpoint kinase 1 as a therapeutic target for pancreatic cancers deficient in the BRCA2 tumor suppressor. Mol Cancer Ther $\underline{10}, 670$ 678

Herrlich P, Karin M, Weiss C (2008): Supreme EnLIGHTenment: damage recognition and signaling in the mammalian UV response. Mol Cell 29, 279-290

Higgins GS, Prevo R, Lee YF, Helleday T, Muschel RJ, Taylor S, Yoshimura M, Hickson ID, Bernhard EJ, McKenna WG (2010): A small interfering RNA screen of genes involved in DNA repair identifies tumor-specific radiosensitization by POLQ knockdown. Cancer Res $\underline{70}$, 2984-2993 
Hoege C, Pfander B, Moldovan GL, Pyrowolakis G, Jentsch S (2002): RAD6-dependent DNA repair is linked to modification of PCNA by ubiquitin and SUMO. Nature $\underline{419}, 135-141$

Hoeijmakers JH (2009): DNA damage, aging, and cancer. N Engl J Med $\underline{361}, 1475-1485$

Hollstein M, Sidransky D, Vogelstein B, Harris CC (1991): p53 mutations in human cancers. Science $\underline{253}$, 4953

Hornbeck PV, Zhang B, Murray B, Kornhauser JM, Latham V, Skrzypek E (2015): PhosphoSitePlus, 2014: mutations, PTMs and recalibrations. Nucleic Acids Res $\underline{43}$, D512-520

Hu JH, Chen T, Zhuang ZH, Kong L, Yu MC, Liu Y, Zang JW, Ge BX (2007): Feedback control of MKP-1 expression by p38. Cell Signal $\underline{19}, 393-400$

Huang da W, Sherman BT, Lempicki RA (2009a): Bioinformatics enrichment tools: paths toward the comprehensive functional analysis of large gene lists. Nucleic Acids Res $\underline{37}, 1-13$

Huang da W, Sherman BT, Lempicki RA (2009b): Systematic and integrative analysis of large gene lists using DAVID bioinformatics resources. Nat Protoc 4 , 44-57

Huang P, Chubb S, Hertel LW, Grindey GB, Plunkett W (1991): Action of 2',2'-difluorodeoxycytidine on DNA synthesis. Cancer Res $\underline{51}, 6110-6117$

Ikura T, Tashiro S, Kakino A, Shima H, Jacob N, Amunugama R, Yoder K, Izumi S, Kuraoka I, Tanaka K et al. (2007): DNA damage-dependent acetylation and ubiquitination of H2AX enhances chromatin dynamics. Mol Cell Biol 27, 7028-7040

Ishihara K, Oshimura M, Nakao M (2006): CTCF-dependent chromatin insulator is linked to epigenetic remodeling. Mol Cell $\underline{23}, 733-742$

Ishii H, Furuse J, Nagase M, Maru Y, Yoshino M, Hayashi T (2003): A phase I study of hepatic arterial infusion chemotherapy with zinostatin stimalamer alone for hepatocellular carcinoma. Jpn J Clin Oncol 33, 570-573

Jackson AL, Loeb LA (2001): The contribution of endogenous sources of DNA damage to the multiple mutations in cancer. Mutat Res $\underline{477}, 7-21$

Jackson SP, Bartek J (2009): The DNA-damage response in human biology and disease. Nature $\underline{461}, 1071$ 1078

Jette N, Lees-Miller SP (2015): The DNA-dependent protein kinase: A multifunctional protein kinase with roles in DNA double strand break repair and mitosis. Prog Biophys Mol Biol 117, 194-205

Jones DH, Lin DI (2017): Amplification of the NSD3-BRD4-CHD8 pathway in pelvic high-grade serous carcinomas of tubo-ovarian and endometrial origin. Mol Clin Oncol $\underline{7}, 301-307$

Jones PA, Baylin SB (2007): The epigenomics of cancer. Cell $\underline{128}, 683-692$

Kamisawa T, Wood LD, Itoi T, Takaori K (2016): Pancreatic cancer. Lancet $\underline{388}$, 73-85 
Kandoth C, McLellan MD, Vandin F, Ye K, Niu B, Lu C, Xie M, Zhang Q, McMichael JF, Wyczalkowski MA et al. (2013): Mutational landscape and significance across 12 major cancer types. Nature $\underline{502}$, 333-339

Kanke M, Kodama Y, Takahashi TS, Nakagawa T, Masukata $H$ (2012): Mcm10 plays an essential role in origin DNA unwinding after loading of the CMG components. EMBO J $\underline{31}, 2182-2194$

Kastan MB, Bartek J (2004): Cell-cycle checkpoints and cancer. Nature 432, 316-323

Ke JY, Dai CJ, Wu WL, Gao JH, Xia AJ, Liu GP, Lv KS, Wu CL (2014): USP11 regulates p53 stability by deubiquitinating p53. J Zhejiang Univ Sci B 15, 1032-1038

Keogh MC, Kim JA, Downey M, Fillingham J, Chowdhury D, Harrison JC, Onishi M, Datta N, Galicia S, Emili A et al. (2006): A phosphatase complex that dephosphorylates gammaH2AX regulates DNA damage checkpoint recovery. Nature $\underline{439}, 497-501$

Khosravi R, Maya R, Gottlieb T, Oren M, Shiloh Y, Shkedy D (1999): Rapid ATM-dependent phosphorylation of MDM2 precedes p53 accumulation in response to DNA damage. Proc Natl Acad Sci U S A $\underline{96}, 14973-14977$

Kim JA, Kruhlak M, Dotiwala F, Nussenzweig A, Haber JE (2007): Heterochromatin is refractory to gamma$\mathrm{H} 2 \mathrm{AX}$ modification in yeast and mammals. J Cell Biol $\underline{178}, 209-218$

Kim ST, Lim DS, Canman CE, Kastan MB (1999): Substrate specificities and identification of putative substrates of ATM kinase family members. J Biol Chem $\underline{274}$, 37538-37543

Kirkpatrick DS, Bustos DJ, Dogan T, Chan J, Phu L, Young A, Friedman LS, Belvin M, Song Q, Bakalarski CE et al. (2013): Phosphoproteomic characterization of DNA damage response in melanoma cells following MEK/PI3K dual inhibition. Proc Natl Acad Sci U S A $\underline{110}$, 19426-19431

Klement K, Luijsterburg MS, Pinder JB, Cena CS, Del Nero V, Wintersinger CM, Dellaire G, van Attikum H, Goodarzi AA (2014): Opposing ISWI- and CHD-class chromatin remodeling activities orchestrate heterochromatic DNA repair. J Cell Biol 207, 717-733

Kleyman M, Kabeche L, Compton DA (2014): STAG2 promotes error correction in mitosis by regulating kinetochore-microtubule attachments. J Cell Sci 127, 4225-4233

Kolla V, Zhuang T, Higashi M, Naraparaju K, Brodeur GM (2014): Role of CHD5 in human cancers: 10 years later. Cancer Res 74, 652-658

Konerding D, James TL, Trump E, Soto AM, Marky LA, Gmeiner WH (2002): NMR structure of a gemcitabinesubstituted model Okazaki fragment. Biochemistry $\underline{41}, 839-846$

Kopper F, Binkowski AM, Bierwirth C, Dobbelstein M (2014): The MAPK-activated protein kinase 2 mediates gemcitabine sensitivity in pancreatic cancer cells. Cell Cycle $\underline{13}, 884-889$

Kopper F, Bierwirth C, Schon M, Kunze M, Elvers I, Kranz D, Saini P, Menon MB, Walter D, Sorensen CS et al. (2013): Damage-induced DNA replication stalling relies on MAPK-activated protein kinase 2 activity. Proc Natl Acad Sci U S A $110,16856-16861$ 
Kotlyarov A, Yannoni Y, Fritz S, Laass K, Telliez JB, Pitman D, Lin LL, Gaestel M (2002): Distinct cellular functions of MK2. Mol Cell Biol 22, 4827-4835

Kouzarides T (2007): Chromatin modifications and their function. Cell $\underline{128}, 693-705$

Krishan A (1975): Rapid flow cytofluorometric analysis of mammalian cell cycle by propidium iodide staining. J Cell Biol $\underline{66}, 188-193$

Laemmli UK (1970): Cleavage of structural proteins during the assembly of the head of bacteriophage T4. Nature 227, 680-685

Lans H, Marteijn JA, Vermeulen W (2012): ATP-dependent chromatin remodeling in the DNA-damage response. Epigenetics Chromatin $\underline{5}, 4$

Laptenko O, Prives C (2006): Transcriptional regulation by p53: one protein, many possibilities. Cell Death Differ $\underline{13}, 951-961$

Lavin MF, Gueven N (2006): The complexity of p53 stabilization and activation. Cell Death Differ $\underline{13}, 941-950$

Lecona E, Fernandez-Capetillo O (2014): Replication stress and cancer: it takes two to tango. Exp Cell Res $\underline{329}, 26-34$

Leroy B, Anderson M, Soussi T (2014): TP53 mutations in human cancer: database reassessment and prospects for the next decade. Hum Mutat $\underline{35}, 672-688$

Li J, Uchida T, Todo T, Kitagawa T (2006): Similarities and differences between cyclobutane pyrimidine dimer photolyase and (6-4) photolyase as revealed by resonance Raman spectroscopy: Electron transfer from the FAD cofactor to ultraviolet-damaged DNA. J Biol Chem 281, 25551-25559

Li Y, Kopper F, Dobbelstein M (2018): Inhibition of MAPKAPK2/MK2 facilitates DNA replication upon cancer cell treatment with gemcitabine but not cisplatin. Cancer Lett $428,45-54$

Liu QH, Zhao CY, Zhang J, Chen Y, Gao L, Ni CY, Zhu MH (2012): Role of heat shock protein 27 in gemcitabineresistant human pancreatic cancer: comparative proteomic analyses. Mol Med Rep $\underline{6}$, 767-773

Liu YX, Wang J, Guo J, Wu J, Lieberman HB, Yin Y (2008): DUSP1 is controlled by p53 during the cellular response to oxidative stress. Mol Cancer Res $\underline{6}, 624-633$

Logan CY, Nusse R (2004): The Wnt signaling pathway in development and disease. Annu Rev Cell Dev Biol $\underline{20}, 781-810$

Lu X, Nannenga B, Donehower LA (2005): PPM1D dephosphorylates Chk1 and p53 and abrogates cell cycle checkpoints. Genes Dev $\underline{19}, 1162-1174$

Luijsterburg MS, van Attikum $\mathrm{H}$ (2011): Chromatin and the DNA damage response: the cancer connection. Mol Oncol $\underline{5}, 349-367$

Lukas J, Lukas C, Bartek J (2011): More than just a focus: The chromatin response to DNA damage and its role in genome integrity maintenance. Nat Cell Biol $\underline{13}, 1161-1169$ 
Ma CX, Janetka JW, Piwnica-Worms H (2011): Death by releasing the breaks: CHK1 inhibitors as cancer therapeutics. Trends Mol Med $\underline{17}, 88-96$

Mailand N, Bekker-Jensen S, Faustrup H, Melander F, Bartek J, Lukas C, Lukas J (2007): RNF8 ubiquitylates histones at DNA double-strand breaks and promotes assembly of repair proteins. Cell $\underline{131}, 887-900$

Manic G, Obrist F, Sistigu A, Vitale I (2015): Trial Watch: Targeting ATM-CHK2 and ATR-CHK1 pathways for anticancer therapy. Mol Cell Oncol 2, e1012976

Manke IA, Nguyen A, Lim D, Stewart MQ, Elia AE, Yaffe MB (2005): MAPKAP kinase-2 is a cell cycle checkpoint kinase that regulates the G2/M transition and $S$ phase progression in response to UV irradiation. Mol Cell $\underline{17}$, $37-48$

Manning BJ, Yusufzai T (2017): The ATP-dependent chromatin remodeling enzymes CHD6, CHD7, and CHD8 exhibit distinct nucleosome binding and remodeling activities. J Biol Chem 292, 11927-11936

Marfella CG, Imbalzano AN (2007): The Chd family of chromatin remodelers. Mutat Res $\underline{618}, 30-40$

Marnett LJ, Plastaras JP (2001): Endogenous DNA damage and mutation. Trends Genet 17, 214-221

Matsuoka S, Rotman G, Ogawa A, Shiloh Y, Tamai K, Elledge SJ (2000): Ataxia telangiectasia-mutated phosphorylates Chk2 in vivo and in vitro. Proc Natl Acad Sci U S A 97, 10389-10394

Matsuoka S, Ballif BA, Smogorzewska A, McDonald ER, 3rd, Hurov KE, Luo J, Bakalarski CE, Zhao Z, Solimini N, Lerenthal $Y$ et al. (2007): ATM and ATR substrate analysis reveals extensive protein networks responsive to DNA damage. Science $\underline{316}, 1160-1166$

Matthews DJ, Yakes FM, Chen J, Tadano M, Bornheim L, Clary DO, Tai A, Wagner JM, Miller N, Kim YD et al. (2007): Pharmacological abrogation of S-phase checkpoint enhances the anti-tumor activity of gemcitabine in vivo. Cell Cycle $\underline{6}, 104-110$

McKelvey EM, Murphy W, Zander A, Bodey GP (1981): Neocarzinostatin: report of a phase II clinical trial. Cancer Treat Rep $\underline{65}$, 699-701

Meek K, Dang V, Lees-Miller SP (2008): DNA-PK: the means to justify the ends? Adv Immunol 99, 33-58

Melnikova VO, Santamaria AB, Bolshakov SV, Ananthaswamy HN (2003): Mutant p53 is constitutively phosphorylated at Serine 15 in UV-induced mouse skin tumors: involvement of ERK1/2 MAP kinase. Oncogene $\underline{22}, 5958-5966$

Meng W, Swenson LL, Fitzgibbon MJ, Hayakawa K, Ter Haar E, Behrens AE, Fulghum JR, Lippke JA (2002): Structure of mitogen-activated protein kinase-activated protein (MAPKAP) kinase 2 suggests a bifunctional switch that couples kinase activation with nuclear export. J Biol Chem 277, 37401-37405

Mini E, Nobili S, Caciagli B, Landini I, Mazzei T (2006): Cellular pharmacology of gemcitabine. Ann Oncol $\underline{17}$ Suppl 5, v7-12

Misteli T, Soutoglou E (2009): The emerging role of nuclear architecture in DNA repair and genome maintenance. Nat Rev Mol Cell Biol $\underline{10}$, 243-254 
Mjelle R, Hegre SA, Aas PA, Slupphaug G, Drablos F, Saetrom P, Krokan HE (2015): Cell cycle regulation of human DNA repair and chromatin remodeling genes. DNA Repair (Amst) $\underline{30}, 53-67$

Moldovan GL, Pfander B, Jentsch S (2007): PCNA, the maestro of the replication fork. Cell $\underline{129}, 665-679$

Morandell S, Reinhardt HC, Cannell IG, Kim JS, Ruf DM, Mitra T, Couvillon AD, Jacks T, Yaffe MB (2013): A reversible gene-targeting strategy identifies synthetic lethal interactions between MK2 and p53 in the DNA damage response in vivo. Cell Rep $\underline{5}, 868-877$

Mullis KB, Faloona FA (1987): Specific synthesis of DNA in vitro via a polymerase-catalyzed chain reaction. Methods Enzymol 155, 335-350

Murawska M, Brehm A (2011): CHD chromatin remodelers and the transcription cycle. Transcription 2 $244-253$

Murga M, Jaco I, Fan Y, Soria R, Martinez-Pastor B, Cuadrado M, Yang SM, Blasco MA, Skoultchi Al, Fernandez-Capetillo O (2007): Global chromatin compaction limits the strength of the DNA damage response. J Cell Biol $\underline{178}, 1101-1108$

Murr R, Loizou JI, Yang YG, Cuenin C, Li H, Wang ZQ, Herceg Z (2006): Histone acetylation by Trrap-Tip60 modulates loading of repair proteins and repair of DNA double-strand breaks. Nat Cell Biol $\underline{8}, 91-99$

Nair SS, Kumar R (2012): Chromatin remodeling in cancer: a gateway to regulate gene transcription. Mol Oncol $\underline{6}, 611-619$

Nakashima M, Adachi S, Yasuda I, Yamauchi T, Kawaguchi J, Itani M, Yoshioka T, Matsushima-Nishiwaki R, Hirose Y, Kozawa O et al. (2011): Phosphorylation status of heat shock protein 27 plays a key role in gemcitabine-induced apoptosis of pancreatic cancer cells. Cancer Lett $\underline{313}, 218-225$

Nicolaou KC, Smith AL, Yue EW (1993): Chemistry and biology of natural and designed enediynes. Proc Natl Acad Sci U S A 90, 5881-5888

Nishiyama M, Skoultchi AI, Nakayama KI (2012): Histone H1 recruitment by CHD8 is essential for suppression of the Wnt-beta-catenin signaling pathway. Mol Cell Biol $\underline{32}, 501-512$

Nishiyama M, Oshikawa K, Tsukada Y, Nakagawa T, lemura S, Natsume T, Fan Y, Kikuchi A, Skoultchi Al, Nakayama KI (2009): CHD8 suppresses p53-mediated apoptosis through histone H1 recruitment during early embryogenesis. Nat Cell Biol $\underline{11}, 172-182$

Nusse M, Egner HJ (1984): Can nocodazole, an inhibitor of microtubule formation, be used to synchronize mammalian cells? Accumulation of cells in mitosis studied by two parametric flow cytometry using acridine orange and by DNA distribution analysis. Cell Tissue Kinet 17, 13-23

O'Shaughnessy A, Hendrich B (2013): CHD4 in the DNA-damage response and cell cycle progression: not so NuRDy now. Biochem Soc Trans $\underline{41}, 777-782$

Oren M, Rotter V (2010): Mutant p53 gain-of-function in cancer. Cold Spring Harb Perspect Biol 2, a001107 
Parsels LA, Morgan MA, Tanska DM, Parsels JD, Palmer BD, Booth RJ, Denny WA, Canman CE, Kraker AJ, Lawrence TS et al. (2009): Gemcitabine sensitization by checkpoint kinase 1 inhibition correlates with inhibition of a Rad51 DNA damage response in pancreatic cancer cells. Mol Cancer Ther $\underline{8}, 45-54$

Paull TT, Rogakou EP, Yamazaki V, Kirchgessner CU, Gellert M, Bonner WM (2000): A critical role for histone $\mathrm{H} 2 \mathrm{AX}$ in recruitment of repair factors to nuclear foci after DNA damage. Curr Biol $\underline{10}, 886-895$

Polo SE (2015): Reshaping chromatin after DNA damage: the choreography of histone proteins. J Mol Biol $\underline{427}$, 626-636

Polo SE, Jackson SP (2011): Dynamics of DNA damage response proteins at DNA breaks: a focus on protein modifications. Genes Dev 25, 409-433

Polo SE, Kaidi A, Baskcomb L, Galanty Y, Jackson SP (2010): Regulation of DNA-damage responses and cellcycle progression by the chromatin remodelling factor CHD4. EMBO J $29,3130-3139$

Povirk LF (1996): DNA damage and mutagenesis by radiomimetic DNA-cleaving agents: bleomycin, neocarzinostatin and other enediynes. Mutat Res $\underline{355}, 71-89$

Raman M, Earnest S, Zhang K, Zhao Y, Cobb MH (2007): TAO kinases mediate activation of p38 in response to DNA damage. EMBO J $\underline{26}, 2005-2014$

Rastogi RP, Richa, Kumar A, Tyagi MB, Sinha RP (2010): Molecular mechanisms of ultraviolet radiation-induced DNA damage and repair. J Nucleic Acids 2010, 592980

Reinhardt HC, Aslanian AS, Lees JA, Yaffe MB (2007): p53-deficient cells rely on ATM- and ATR-mediated checkpoint signaling through the p38MAPK/MK2 pathway for survival after DNA damage. Cancer Cell 11, 175189

Roberts CW, Orkin SH (2004): The SWI/SNF complex--chromatin and cancer. Nat Rev Cancer $\underline{4}, 133-142$

Rodriguez-Paredes M, Ceballos-Chavez M, Esteller M, Garcia-Dominguez M, Reyes JC (2009): The chromatin remodeling factor CHD8 interacts with elongating RNA polymerase II and controls expression of the cyclin E2 gene. Nucleic Acids Res $\underline{37}, 2449-2460$

Rogakou EP, Boon C, Redon C, Bonner WM (1999): Megabase chromatin domains involved in DNA doublestrand breaks in vivo. J Cell Biol $\underline{146}, 905-916$

Rogakou EP, Pilch DR, Orr AH, Ivanova VS, Bonner WM (1998): DNA double-stranded breaks induce histone H2AX phosphorylation on serine 139. J Biol Chem $\underline{273}, 5858-5868$

Saini P, Li Y, Dobbelstein M (2015): Wee1 is required to sustain ATR/Chk1 signaling upon replicative stress. Oncotarget $\underline{6}, 13072-13087$

Sakurikar N, Thompson R, Montano R, Eastman A (2016): A subset of cancer cell lines is acutely sensitive to the Chk1 inhibitor MK-8776 as monotherapy due to CDK2 activation in S phase. Oncotarget $\underline{7}, 1380-1394$

Salic A, Mitchison TJ (2008): A chemical method for fast and sensitive detection of DNA synthesis in vivo. Proc Natl Acad Sci U S A 105, 2415-2420 
Schafer C, Seeliger H, Bader DC, Assmann G, Buchner D, Guo Y, Ziesch A, Palagyi A, Ochs S, Laubender RP et al. (2012): Heat shock protein 27 as a prognostic and predictive biomarker in pancreatic ductal adenocarcinoma. J Cell Mol Med $\underline{16}, 1776-1791$

Schoenfeld AR, Apgar S, Dolios G, Wang R, Aaronson SA (2004): BRCA2 is ubiquitinated in vivo and interacts with USP11, a deubiquitinating enzyme that exhibits prosurvival function in the cellular response to DNA damage. Mol Cell Biol 24, 7444-7455

Schulz-Heddergott R, Stark N, Edmunds SJ, Li J, Conradi LC, Bohnenberger H, Ceteci F, Greten FR, Dobbelstein M, Moll UM (2018): Therapeutic Ablation of Gain-of-Function Mutant p53 in Colorectal Cancer Inhibits Stat3-Mediated Tumor Growth and Invasion. Cancer Cell 34, 298-314 e297

Shapiro AL, Vinuela E, Maizel JV, Jr. (1967): Molecular weight estimation of polypeptide chains by electrophoresis in SDS-polyacrylamide gels. Biochem Biophys Res Commun 르, 815-820

Shen C, Ipsaro JJ, Shi J, Milazzo JP, Wang E, Roe JS, Suzuki Y, Pappin DJ, Joshua-Tor L, Vakoc CR (2015): NSD3-Short Is an Adaptor Protein that Couples BRD4 to the CHD8 Chromatin Remodeler. Mol Cell $\underline{60}$, 847859

Shingleton JR, Hemann MT (2015): The Chromatin Regulator CHD8 Is a Context-Dependent Mediator of Cell Survival in Murine Hematopoietic Malignancies. PLoS One $\underline{10}$, e0143275

Shiotani B, Zou L (2009): Single-stranded DNA orchestrates an ATM-to-ATR switch at DNA breaks. Mol Cell $\underline{33}, 547-558$

Shreeram S, Demidov ON, Hee WK, Yamaguchi H, Onishi N, Kek C, Timofeev ON, Dudgeon C, Fornace AJ, Anderson CW et al. (2006): Wip1 phosphatase modulates ATM-dependent signaling pathways. Mol Cell $\underline{23}$, 757-764

Sims JK, Wade PA (2011): SnapShot: Chromatin remodeling: CHD. Cell 144, 626-626 e621

Smith AL, Nicolaou KC (1996): The enediyne antibiotics. J Med Chem 39, 2103-2117

Smits VA, Reaper PM, Jackson SP (2006): Rapid PIKK-dependent release of Chk1 from chromatin promotes the DNA-damage checkpoint response. Curr Biol $\underline{16}, 150-159$

Solomon DA, Kim T, Diaz-Martinez LA, Fair J, Elkahloun AG, Harris BT, Toretsky JA, Rosenberg SA, Shukla $\mathrm{N}$, Ladanyi M et al. (2011): Mutational inactivation of STAG2 causes aneuploidy in human cancer. Science $\underline{333}$, 1039-1043

Song $\mathrm{H}$, Hollstein M, Xu Y (2007): p53 gain-of-function cancer mutants induce genetic instability by inactivating ATM. Nat Cell Biol $\underline{9}, 573-580$

Soria G, Polo SE, Almouzni G (2012): Prime, repair, restore: the active role of chromatin in the DNA damage response. Mol Cell $\underline{46}, 722-734$

Speroni J, Federico MB, Mansilla SF, Soria G, Gottifredi V (2012): Kinase-independent function of checkpoint kinase 1 (Chk1) in the replication of damaged DNA. Proc Natl Acad Sci U S A $\underline{109}, 7344-7349$

Srivastava N, Gochhait S, de Boer P, Bamezai RN (2009): Role of H2AX in DNA damage response and human cancers. Mutat Res $\underline{681}, 180-188$ 
Stracker TH, Usui T, Petrini JH (2009): Taking the time to make important decisions: the checkpoint effector kinases Chk1 and Chk2 and the DNA damage response. DNA Repair (Amst) $\underline{8}, 1047-1054$

Stracker TH, Theunissen JW, Morales M, Petrini JH (2004): The Mre11 complex and the metabolism of chromosome breaks: the importance of communicating and holding things together. DNA Repair (Amst) $\underline{3}$, 845854

Stratton MR, Campbell PJ, Futreal PA (2009): The cancer genome. Nature 4ㄷ8, 719-724

Stucki M, Jackson SP (2006): gammaH2AX and MDC1: anchoring the DNA-damage-response machinery to broken chromosomes. DNA Repair (Amst) $\underline{5}, 534-543$

Subtil-Rodriguez A, Vazquez-Chavez E, Ceballos-Chavez M, Rodriguez-Paredes M, Martin-Subero JI, Esteller M, Reyes JC (2014): The chromatin remodeller CHD8 is required for E2F-dependent transcription activation of S-phase genes. Nucleic Acids Res $\underline{42}, 2185-2196$

Suh YA, Post SM, Elizondo-Fraire AC, Maccio DR, Jackson JG, El-Naggar AK, Van Pelt C, Terzian T, Lozano $G$ (2011): Multiple stress signals activate mutant p53 in vivo. Cancer Res $\underline{71}, 7168-7175$

Sun Y, Jiang X, Chen S, Fernandes N, Price BD (2005): A role for the Tip60 histone acetyltransferase in the acetylation and activation of ATM. Proc Natl Acad Sci U S A 102, 13182-13187

Svetlova MP, Solovjeva LV, Tomilin NV (2010): Mechanism of elimination of phosphorylated histone H2AX from chromatin after repair of DNA double-strand breaks. Mutat Res $\underline{685}, 54-60$

Swenberg JA, Lu K, Moeller BC, Gao L, Upton PB, Nakamura J, Starr TB (2011): Endogenous versus exogenous DNA adducts: their role in carcinogenesis, epidemiology, and risk assessment. Toxicol Sci $\underline{120}$ Suppl 1, S130-145

Syljuasen RG, Jensen S, Bartek J, Lukas J (2006): Adaptation to the ionizing radiation-induced G2 checkpoint occurs in human cells and depends on checkpoint kinase 1 and Polo-like kinase 1 kinases. Cancer Res $\underline{66}$, 10253-10257

Syljuasen RG, Sorensen CS, Hansen LT, Fugger K, Lundin C, Johansson F, Helleday T, Sehested M, Lukas J, Bartek J (2005): Inhibition of human Chk1 causes increased initiation of DNA replication, phosphorylation of ATR targets, and DNA breakage. Mol Cell Biol $\underline{25}$, 3553-3562

Taba K, Kuramitsu Y, Ryozawa S, Yoshida K, Tanaka T, Maehara S, Maehara Y, Sakaida I, Nakamura K (2010): Heat-shock protein 27 is phosphorylated in gemcitabine-resistant pancreatic cancer cells. Anticancer Res $\underline{30}$, 2539-2543

Takahashi T, Yamaguchi T, Kitamura K, Noguchi A, Honda M, Otsuji E (1990): [Missile therapy of colorectal and pancreatic cancers--clinical trial of monoclonal antibody, A7-NCS, in 73 patients with colorectal and pancreatic cancers]. Gan To Kagaku Ryoho 17, 1111-1119

Tan BC, Chien CT, Hirose S, Lee SC (2006): Functional cooperation between FACT and MCM helicase facilitates initiation of chromatin DNA replication. EMBO J 25, 3975-3985

Taylor RC, Cullen SP, Martin SJ (2008): Apoptosis: controlled demolition at the cellular level. Nat Rev Mol Cell Biol $\underline{9}, 231-241$ 
Thu YM, Bielinsky AK (2013): Enigmatic roles of Mcm10 in DNA replication. Trends Biochem Sci $\underline{38}, 184-194$

Towbin H, Staehelin T, Gordon J (1979): Electrophoretic transfer of proteins from polyacrylamide gels to nitrocellulose sheets: procedure and some applications. Proc Natl Acad Sci U S A $\underline{76}, 4350-4354$

van Attikum H, Gasser SM (2009): Crosstalk between histone modifications during the DNA damage response. Trends Cell Biol 19, 207-217

van Deursen F, Sengupta S, De Piccoli G, Sanchez-Diaz A, Labib K (2012): Mcm10 associates with the loaded DNA helicase at replication origins and defines a novel step in its activation. EMBO J $\underline{31}, 2195-2206$

Van Nostrand JL, Brady CA, Jung H, Fuentes DR, Kozak MM, Johnson TM, Lin CY, Lin CJ, Swiderski DL, Vogel $\mathrm{H}$ et al. (2014): Inappropriate p53 activation during development induces features of CHARGE syndrome. Nature $514,228-232$

Vaseva AV, Moll UM (2009): The mitochondrial p53 pathway. Biochim Biophys Acta 1787, 414-420

Veltkamp SA, Beijnen JH, Schellens JH (2008): Prolonged versus standard gemcitabine infusion: translation of molecular pharmacology to new treatment strategy. Oncologist $\underline{13}, 261-276$

Vissers LE, van Ravenswaaij CM, Admiraal R, Hurst JA, de Vries BB, Janssen IM, van der Vliet WA, Huys EH, de Jong PJ, Hamel BC et al. (2004): Mutations in a new member of the chromodomain gene family cause CHARGE syndrome. Nat Genet $\underline{36}, 955-957$

Vousden KH, Lane DP (2007): p53 in health and disease. Nat Rev Mol Cell Biol $\underline{8}, 275-283$

Vousden KH, Prives C (2009): Blinded by the Light: The Growing Complexity of p53. Cell $\underline{137}$, 413-431

Walerych D, Lisek K, Del Sal G (2015): Mutant p53: One, No One, and One Hundred Thousand. Front Oncol $\underline{5}$, 289

Xiao Z, Chen Z, Gunasekera AH, Sowin TJ, Rosenberg SH, Fesik S, Zhang H (2003): Chk1 mediates S and G2 arrests through Cdc25A degradation in response to DNA-damaging agents. J Biol Chem 278, 21767-21773

Yamaguchi T, Kimura J, Miki Y, Yoshida K (2007): The deubiquitinating enzyme USP11 controls an IkappaB kinase alpha (IKKalpha)-p53 signaling pathway in response to tumor necrosis factor alpha (TNFalpha). J Biol Chem 282, 33943-33948

Yang XH, Shiotani B, Classon M, Zou L (2008): Chk1 and Claspin potentiate PCNA ubiquitination. Genes Dev 22, $1147-1152$

Yates A, Akanni W, Amode MR, Barrell D, Billis K, Carvalho-Silva D, Cummins C, Clapham P, Fitzgerald S, Gil $L$ et al. (2016): Ensembl 2016. Nucleic Acids Res $\underline{44}$, D710-716

Yates JA, Menon T, Thompson BA, Bochar DA (2010): Regulation of HOXA2 gene expression by the ATPdependent chromatin remodeling enzyme CHD8. FEBS Lett $\underline{584}$, 689-693 
Ying H, Dey P, Yao W, Kimmelman AC, Draetta GF, Maitra A, DePinho RA (2016): Genetics and biology of pancreatic ductal adenocarcinoma. Genes Dev $\underline{30}, 355-385$

Zhang Y, Xiong Y, Yarbrough WG (1998): ARF promotes MDM2 degradation and stabilizes p53: ARF-INK4a locus deletion impairs both the $\mathrm{Rb}$ and p53 tumor suppression pathways. Cell $\underline{92}, 725-734$

Zhao H, Piwnica-Worms H (2001): ATR-mediated checkpoint pathways regulate phosphorylation and activation of human Chk1. Mol Cell Biol 21, 4129-4139

Zhou BB, Elledge SJ (2000): The DNA damage response: putting checkpoints in perspective. Nature $\underline{408}$, 433439

Zou L, Elledge SJ (2003): Sensing DNA damage through ATRIP recognition of RPA-ssDNA complexes. Science $\underline{300}, 1542-1548$ 
